NASA/TM-20205007358

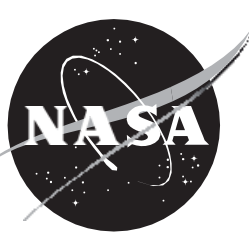

\title{
EXPORTS Measurements and Protocols for the NE Pacific Campaign
}

Editors:

Ivona Cetinić and Inia Soto Ramos

GESTAR/Universities Space Research Association, Columbia, Maryland 


\section{NASA STI Program ... in Profile}

Since its founding, NASA has been dedicated to the advancement of aeronautics and space science. The NASA scientific and technical information (STI) program plays a key part in helping NASA maintain this important role.

The NASA STI program operates under the auspices of the Agency Chief Information Officer. It collects, organizes, provides for archiving, and disseminates NASA's STI. The NASA STI program provides access to the NTRS Registered and its public interface, the NASA Technical Reports Server, thus providing one of the largest collections of aeronautical and space science STI in the world. Results are published in both nonNASA channels and by NASA in the NASA STI Report Series, which includes the following report types:

- TECHNICAL PUBLICATION. Reports of completed research or a major significant phase of research that present the results of NASA Programs and include extensive data or theoretical analysis. Includes compilations of significant scientific and technical data and information deemed to be of continuing reference value. NASA counterpart of peer-reviewed formal professional papers but has less stringent limitations on manuscript length and extent of graphic presentations.

- TECHNICAL MEMORANDUM.

Scientific and technical findings that are preliminary or of specialized interest, e.g., quick release reports, working papers, and bibliographies that contain minimal annotation. Does not contain extensive analysis.

- CONTRACTOR REPORT. Scientific and technical findings by NASA-sponsored contractors and grantees.
- CONFERENCE PUBLICATION.

Collected papers from scientific and technical conferences, symposia, seminars, or other meetings sponsored or co-sponsored by NASA.

- SPECIAL PUBLICATION. Scientific, technical, or historical information from NASA programs, projects, and missions, often concerned with subjects having substantial public interest.

- teChNICAL TRANSLATION.

English-language translations of foreign scientific and technical material pertinent to NASA's mission.

Specialized services also include organizing and publishing research results, distributing specialized research announcements and feeds, providing information desk and personal search support, and enabling data exchange services.

For more information about the NASA STI program, see the following:

- Access the NASA STI program home page at http://www.sti.nasa.gov

- E-mail your question to help@sti.nasa.gov

- Phone the NASA STI Information Desk at 757-864-9658

- Write to:

NASA STI Information Desk

Mail Stop 148

NASA Langley Research Center

Hampton, VA 23681-2199 


\section{NASA/TM-20205007358}

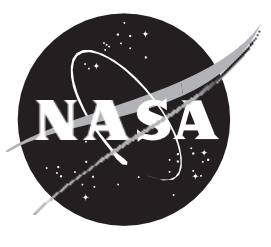

\section{EXPORTS Measurements and Protocols for the NE Pacific Campaign}

\section{Editors:}

Ivona Cetinić and Inia Soto Ramos

GESTAR/Universities Space Research Association, Columbia, Maryland 


\section{Notice for Copyrighted Information}

This manuscript has been authored by members of the EXPORTS Science Team and the National Aeronautics and Space Administration. The United States Government has a nonexclusive, irrevocable, worldwide license to prepare derivative works, publish or reproduce this manuscript for publication acknowledges that the United States Government retains such a license in any published form of this manuscript. All other rights are retained by the copyright owner.

Trade names and trademarks are used in this report for identification only. Their usage does not constitute an official endorsement, either expressed or implied, by the National Aeronautics and Space Administration.

Level of Review: This material has been technically reviewed by technical management.

Available from

NASA STI Program

Mail Stop 148

NASA's Langley Research

Center Hampton, VA

23681-2199
National Technical Information

Service 5285 Port Royal Road

Springfield, VA 22161

703-605-6000 


\section{EXPORTS Measurements and Protocols for the NE Pacific Campaign}

Editors:

Ivona Cetinić

GESTAR/Universities Space Research Association, Columbia, Maryland

Inia Soto Ramos

GESTAR/Universities Space Research Association, Columbia, Maryland

Authors:

Michael Behrenfeld, Oregon State University, Corvallis,Oregon /mjb@science.oregonstate.edu

Claudia Benitez-Nelson, University of South Carolina, Columbia, South Carolina / cbnelson@geol.sc.edu

Emmanuel Boss, University of Maine, Orono, Maine / emmanuel.boss@maine.edu

Mark Brzezinski, University of California - Santa Barbara, Santa Barbara, California I

mark.brzezinski@lifesci.ucsb.edu

Kristen Buck, University of South Florida, St. Petersburg, Florida / kristenbuck@usf.edu

Ken Buesseler, Woods Hole Oceanographic Institution, Woods Hole, Massachusetts / kbuesseler@whoi.edu

Adrian Burd, University of Georgia, Athens, Georgia / adrianb@uga.edu

Craig Carlson, University of California Santa Barbara, California/ craig.carlson@lifesci.ucsb.edu

Nicolas Cassar, Duke University, Durham, North Carolina /nicolas.cassar@duke.edu

Ivona Cetinić, GESTAR/Universities Space Research Association, Columbia, Maryland I

ivona.cetinic@nasa.gov

Hilary Close, University of Miami, Coral Gables, Florida / hclose@ rsmas.miami.edu

Susanne Craig, GESTAR/Universities Space Research Association, Columbia, Maryland /

susanne.e.craig@nasa.gov

Eric D’Asaro, University of Washington, Washington / dasaro@apl.washington.edu

Colleen Durkin, Moss Landing Marine Laboratories, Moss Landing, California / cdurkin@mlml.calstate.edu

Meg Estapa, Skidmore College, Saratoga Springs, New York / mestapa@ skidmore.edu

Andrea Fassbender, Monterey Bay Aquarium Research Institute, Moss Landing, CA / fassbender@mbari.org

James Fox, Oregon State University, Corvallis,Oregon/james.fox@oregonstate.edu

Scott Freeman, Science Systems and Applications Inc, Lanham, Maryland / scott.a.freeman@nasa.gov

Scott Gifford, The University of North Carolina at Chapel Hill, Chapel Hill, North Carolina I

sgifford@email.unc.edu

Weida Gong, The University of North Carolina at Chapel Hill, Chapel Hill, North Carolina I

wdgong@live.unc.edu

Jason Graff, Oregon State University, Corvallis, Oregon /jrgraff@science.oregonstate.edu

Deric Gray, Naval Research Laboratory, Washington, DC / deric.gray@nrl.navy.mil

Lionel Guidi, Laboratoire d'Océanographie de Villefranche-sur-Mer, Villefranche-sur-Mer, France I

lguidi@obs-vlfr.fr

Kim Halsey, Oregon State University, Corvallis, Oregon / halseyk@science.oregonstate.edu

Dennis Hansell, University of South Florida, St. Petersburg, Florida / d.hansell@ miami.edu 
Nils Haëntjens, University of Maine, Orono, Maine /nils.haentjens@maine.edu

Tristan Horner, Woods Hole Oceanographic Institution, Woods Hole, Massachusetts / tristan.horner@whoi.edu

Bethany Jenkins, University of Rhode Island, Narragansett, Rhode Island / bjenkins@uri.edu Janice Jones, University of California - Santa Barbara, Santa Barbara, California I

janice.jones@lifesci.ucsb.edu

Lee Karp-Boss, University of Maine, Orono, Maine / lee.karp-boss@maine.edu

Sasha Kramer, University of California - Santa Barbara, Santa Barbara, California I

sasha.kramer@lifesci.ucsb.edu

Phoebe Lam, University of California - Santa Cruz, SantaCruz, California / pjlam@ucsc.edu

Craig Lee, University of Washington, Seattle,Washington/craiglee@uw.edu

Jong-mi Lee, University of California - Santa Cruz, Santa Cruz, California /jlee377@ucsc.edu

Shuting Liu, University of California - Santa Barbara, Santa Barbara, California / shuting.liu@ucsb.edu

Antonio Mannino, NASA Goddard Space Flight Center, Greenbelt, Maryland / Antonio.mannino-1@nasa.gov

Amy Maas, Bermuda Institute of Ocean Sciences, St.George's, Bermuda / amy.Maas@bios.edu

Olivier Marchal, Woods Hole Oceanographic Institution,Woods Hole, Massachusetts / omarchal@whoi.edu

Adrian Marchetti, The University of North Carolina at Chapel Hill, Chapel Hill, North Carolina I

amarchetti@unc.edu (primarylead)

Andrew McDonnell, The University of Alaska Fairbanks, Fairbanks, Alaska / amcdonnell@alaska.edu Heather McNair, University of Rhode Island, Narragansett, Rhode Island / hmcnair@uri.edu (co-lead) Susanne Menden-Deuer, University of Rhode Island, Narragansett, Rhode Island / smenden@uri.edu Francoise Morison, University of Rhode Island, Narragansett, Rhode Island/fmorison@uri.edu Norman Nelson, University of California - Santa Barbara,California /normannelson@ucsb.edu David Nicholson, Woods Hole Oceanographic Institution, Woods Hole, Massachusetts / dnicholson@whoi.edu

Alex Niebergall, Duke University,Durham, North Carolina / alexandria.niebergall@duke.edu Melissa M. Omand, University of Rhode Island, Narragansett, Rhode Island / momand@uri.edu Uta Passow, Memorial University, St. John's, Canada / uta.passow@mun.ca Mary Jane Perry, University of Maine, Orono, Maine / perrymj@maine.edu Brian Popp, University of Hawaii, Honolulu, Hawaii / popp@ hawaii.edu

Chris Proctor, Science Systems and Applications Inc, Lanham, Maryland / christopher.w.proctor@nasa.gov Patrick Rafter, University of California - Irvine, Irvine, California / prafter@uci.edu

Montserrat Roca-Martí, Woods Hole Oceanographic Institution, Woods Hole, Massachusetts / mrocamarti@whoi.edu

Collin Roesler, Bowdoin College, Brunswick, Maine / croesler@bowdoin.edu

Edwina Rubin, University of Rhode Island, Narragansett, Rhode Island / ewelina_rubin@uri.edu

Tatiana Rynearson, University of Rhode Island, Narragansett, Rhode Island / rynearson@uri.edu Alyson Santoro, University of California - Santa Barbara, California / asantoro@ucsb.edu

David Siegel, University of California - Santa Barbara, Santa Barbara, California / david.siegel@ucsb.edu Heidi Sosik, Woods Hole Oceanographic Institution, Woods Hole, Massachusetts / hsosik@whoi.edu Inia Soto Ramos, GESTAR/Universities Space Research Association, Columbia, Maryland / inia.m.sotoramos@nasa.gov

Karen Stamieszkin, Virginia Institute of Marine Science, Gloucester Point, Virginia / karens@vims.edu 
Deborah K. Steinberg, Virginia Institute of Marine Science, Virginia/ debbies@vims.edu Brandon Stephens, University of California - Santa Barbara, Santa Barbara, California I bstephens@ucsb.edu

Andrew Thompson, California Institute of Technology, Pasadena, California / andrewt@caltech.edu

Benjamin Van Mooy, Woods Hole Oceanographic Institution, Woods Hole, Massachusetts / bvanmooy@whoi.edu

Xiaodong Zhang, University of Southern Mississippi, Mississippi / Xiaodong.Zhang@usm.edu 


\section{Table of Contents}

Chapter 1 Introduction to the EXPORTS Parameter Working Groups 1

$\begin{array}{ll}\text { Background } & 1\end{array}$

Chapter 2 Stocks, Proxies and Context (SPC) Working Group Report $\quad 7$

$\begin{array}{ll}\text { Overview } & 7\end{array}$

Definitions and parameter tables $\quad 7$

Stock, Proxy and Context Measurement Tables 9

Relationship to EXPORTS science questions 11

Chapter 3 Exports Optics Working Group Report 12

$\begin{array}{ll}\text { Overview } & 12\end{array}$

Measured parameters and associated methods 12

Inter-instrument calibration $\quad 15$

Chapter 4 EXPORTS Particle Characterization working group 16

$\begin{array}{ll}\text { Overview } & 16\end{array}$

Summary of measurements to characterize particles: 17

I. Concentrations (abundances) of particles 17

II. Particle Size Distribution (PSD) 17

III. Composition: morphology and genomics 20

Chapter 5 EXPORTS Rates Working Group Report

Overview 23

Subgroup Primary Production $\quad 25$

Subgroup Respiration $\quad 26$

Subgroup Organic Carbon transformations 26

$\begin{array}{ll}\text { Subgroup Aggregation/Sinking rates } & 27\end{array}$

Subgroup Nutrient (Si, Fe, N) Uptake rates $\quad 28$

Chapter 6 Export Pathways Working Group Report 32

Overview 32

Summary of measurements by export pathway 35

$\begin{array}{ll}\text { Closure of C flux budgets } & 37\end{array}$

References: $\quad 41$

$\begin{array}{ll}\text { Chapter } 7 \text { Protocols } & 43\end{array}$ 
Boss, E., Derive hyperspectral reflectance measuring downwelling irradiance, and upwelling radiance, in buoy mode.

Boss, E., Derive hyperspectral reflectance measuring downwelling irradiance, downwelling radiance and upwelling radiance, removing sky contribution from upwelling radiance

Boss, E., Near forward particulate VSF at $670 \mathrm{~nm}$ is derived from measurements of nearforward scattering of a laser. Measurements are inverted to obtain a PSD.

Boss, E., Particulate backscattering coefficient at one wavelength derived from VSF measurement in one wavelength in the back direction

Boss, E. and Simpson B., CDOM absorption spectra from the Slow descent rate optical package (SLOW-DROP)

Brzezinski, M., Size fractionated (0.6-5.0 \& >5.0 um) assessment of Si and Fe limitation of silica and primary production

Brzezinski, M., Size fractionated primary production (0.6-5.0 \& $>5.0$ um)

Brzezinski, M., Size fractionated silicic acid uptake

Buessler, K., ${ }^{234}$ Th survey combined with particulate Element:234Th ratios from large volume pumps

Buessler, K. and Roca-Marti, M., ${ }^{210} \mathrm{~Pb}$ and ${ }^{210} \mathrm{Po}$ survey combined with particulate Element:210Po ratios from large volume pumps

Buessler, K., Roca-Marti, M., and Horner, T. Abundance and isotopic composition of barium

Burd A., Coagulation Modeling

Carlson, C. Bulk DOC and DON stocks

Carlson, C., DOC Remineralization Experiments

Carlson, C., Dissolved organic matter composition 
Carlson, C., 3H- Leucine incorporation rate as a proxy for net heterotrophic bacterial

Carlson, C., Bacterioplankton Cell Enumeration

Carlson, C., DOC Export

Cassar, N. and Nicholson, D., Winkler titrations for total dissolved $\mathrm{O} 2$ concentration and saturation

Cassar, N., O2/Ar Net Community Production Estimates

Close, H. G. Compound-specific isotope analysis of amino acids (AA-CSIA) isolated from

sinking particles, size-fractionated particles, and zooplankton fecal pellets

Durkin, C., Genetic characterization of bulk sinking particles in sediment traps

Durkin, C., Genetic characterization of sinking aggregates in gel traps

Durkin, C., Genetic characterization of zooplankton products in gel traps

Durkin, C., Visual cell ID in gel traps

Durkin, C., Visual characterization of zooplankton products in gel traps

Estapa, M., Bulk particle flux to sediment traps

Estapa, M. Particle flux to optical sediment traps

Fassbender, A., Net community production, net primary production, and particulate inorganic 
Fassbender, A., Underway Nitrate and pH

Fox, J., Fast Repetition Rate (FRR) fluorescence data

Freeman, S., Volume Scattering Function at 9 angles (VSF-9)

Gifford, S., Microbial metagenomics and metatranscriptomics

Gifford, S., O2 drawdown community and bacterial respiration rates

Graff, J. and Behrenfeld, M., Phytoplankton concentrations and elemental stocks

Gray, D., Volume Scattering Function measurements and particle size distributions. rates based on size-fractionated lithogenic particle concentrations

Lam, P. J., Lee, J-M., and Marchal, O., Estimation of particle (dis)aggregation and sinking rates based on size-fractionated lithogenic particle concentrations 
Maas, A., Zooplankton respiration, excretion, and egestion experiments

Maas, A., Zooplankton respiration, excretion, and egestion as a function of size and temperature

Maas, A., Analysis of zooplankton particles from MOCNESS net sampling with ZooScan and associated EcoTaxa Pipeline

Mannino, A., Particulate inorganic carbon (PIC) by coulometry

Marchetti, A., 18S rDNA amplicon analysis of eukaryotic plankton

Marchetti, A., mRNA sequencing of poly-A selected (eukaryotic) genes

Marchetti, A. and Gong W., Experimental chlorophyll - 90\% ethanol extraction

Marchetti, A. and Gong W., New production/Gross primary productivity/Net primary productivity mesopelagic

Menden-Deuer, S., McNair, H., Plankton population dynamics via deckboard incubations (dilution method)

Morison, F., Characterization of species composition and size distribution of microphytoplankton with a FlowCAM Benchtop B3 Series 
Nelson, N. B., In water radiometric profiles

Nelson, N. B., CTD processing, 20191002 edition

Nelson, N. B., Roesler, C., Cetinic, I., and Kramer, S. HPLC Pigment analysis

Nelson, N. B., Inorganic Nutrients

Nicholson, D., Net Community production from mass balance

Nicholson, D., Mesopelagic Oxygen Utilization Rate from Autonomous Platform Sensors

Niebergall, A., 16S/18S amplicon sequencing of surface ocean microbial community

Perry, M.J. and Omand, M., Flux of large sinking particles from profiles of optical spikes

(Pathways 2 and 3 )

Passow, U., Quantification of Transparent Exopolymer Particles (TEP) in the water (collected via Niskin bottles)

Passow, U., Quantification of POC, PON, total C, BSi, LSi and TEP in sinking particle fractions collected from the Marine Snow Catcher

Passow, U., Characterization of Particles collected from the Marine Snow Catcher

Popp, B., Determine whether microbially-degraded biomass is important for midwater zooplankton metabolism

Rafter, P., and Santoro, A., The $\mathrm{N}$ and $\mathrm{O}$ isotopic composition of nitrate (nitrate $\mathrm{d} 15 \mathrm{~N}$ and $\mathrm{d} 180$ ) in seawater using the denitrifier method

Roesler, C., Chlorophyll analysis - 90\% acetone method

Roesler, C., In-line Hyperspectral Size -Fractioned Particulate Absorption

Roesler, C., In-line Multi-excitation Chlorophyll Fluorescence, WET Labs ECO 3X1M 
Roesler, C., In-line Single Channel Backscattering and Chlorophyll and CDOM Fluorescence, 205 WET Labs ECO BBFL2

Roesler, C., Surface Hyperspectral Radiometry

Roesler, C., Spectrophotometric Particulate Absorption Analysis - EXPORTS

Rubin, E. and Rynearson, T., Metabarcoding of water column eukaryotic plankton

Rynearson, T., Enumeration of phytoplankton and microzooplankton using microscopy

Rynearson, T., and Rubin, E. Ecogenomic grazing markers

Santoro, A., 16S rRNA gene amplicon analysis of water column bacterioplankton

Santoro, A., Ammonium concentration in seawater using the orthophthaldialdehyde (OPA)

from sediment traps

Santoro, A., and Durkin, C., Genetic characterization of prokaryotes in sinking aggregates collected in gel traps

Santoro, A., Water column nitrification rates

Santoro, A., Particle-associated respiration using an in situ particle capture incubation device (RESPIRE)

Sosik, H., Imaging of phytoplankton and other particles with Imaging FlowCytobot

(IFCB;McLane Research Laboratories, Inc, Falmouth, MA)

Steinberg, D., Reconstruction of Zooplankton Export from Gel and particle ID Traps 
Thompson, A. and Omand, M., Observation-based vertical advection and mixing of organic carbon to depth by physical oceanographic processes (Pathway 5)

Van Mooy, B., Lipidomics of suspended and sinking particles

Zhang, X., Measurements of $P 11$ (the volume scattering function, VSF), $P 12$ and $P 22$ elements of the scattering Mueller matrix at $517 \mathrm{~nm}$ from $0.1-155^{\circ}$ (nominal) in water.

Zhang, X., Characterization of size distribution of nanoparticles with a Manta ViewSizer 


\section{Chapter 1 Introduction to the EXPORTS Parameter Working Groups}

Inia Soto Ramos, GESTAR/Universities Space Research Association, Columbia, Maryland / inia.m.sotoramos@nasa.gov

Ivona Cetinić, GESTAR/Universities Space Research Association, Columbia, Maryland /

ivona.cetinic@nasa.gov

David Siegel, University of California - Santa Barbara, Santa Barbara, California / david.siegel@ucsb.edu Chris Proctor, Science Systems and Applications Inc, Lanham, Maryland / christopher.w.proctor@nasa.gov Susanne Craig, GESTAR/Universities Space Research Association, Columbia, Maryland / susanne.e.craig@nasa.gov

\section{Background}

EXport Processes in the Ocean from Remote Sensing (EXPORTS) is a large-scale NASA-led and NSF co-funded field campaign that will provide critical information for quantifying the export and fate of upper ocean net primary production (NPP) using satellite information and state of the art technology.

The goal of EXPORTS is to develop a predictive understanding of the export and fate of global ocean net primary production (NPP) and its implications for the Earth's carbon cycle in present and future climates (oceanexports.org). To develop this quantitative understanding, EXPORTS is measuring and modeling the export pathways that remove fixed organic carbon from the upper ocean and drive the attenuation of these vertical fluxes within the ocean interior. EXPORTS datasets will be used to develop and test numerical predictive and satellite-data diagnostic models of NPP fates and their carbon cycle impacts. EXPORTS builds on decades of NASA-funded research on developing and validating satellite data-driven models of regional to global NPP and hence, EXPORTS will contribute to NASA's upcoming Plankton, Aerosol, Cloud and ocean Ecosystem (PACE) mission (Werdell et al., 2019). NSF segment in the program stems from the long-term investment in the science of biological pump, culminating with the NSF Biology of the Biological Pump Workshop (BoBP) in 2016 (Burd et al., 2016).

The initial stages of EXPORTS date back to COOPEX, a NASA ROSES (2012, A.3) funded project which final objective was to draft a Science Plan for a field campaign entitled "Controls on Open Ocean Productivity and Export Experiment". The original COOPEX plan, which required constraining both the production and the fate of fixed organic carbon, was too ambitious and had budgetary limitations. Therefore, it was decided that the field campaign should focus on the fates of fixed carbon and not its production. It was during the COOPEX expert meeting at the University of California Santa Barbara (UCSB) in June 2013, that the EXport Processes in the Ocean from RemoTe Sensing (EXPORTS) field campaign was born. Science plan for the field campaign was published as a report (EXPORTS Writing Team, 2015) and an overview paper(Siegel et al., 2016). Following the extensive peer and panel reviews of the proposed science plan, in October 2015, NASA OBB selected another team of scientists to 
form a Science Definition Team, who was tasked with development of the implementation plan for EXPORTS. After a year of work, and several meetings, team published the final report (EXPORTS Science Definition Team, 2016).

Following the recommendations from the NASA EXPORTS science plan (EXPORTS Writing Team, 2015), EXPORTS science implementation plan (EXPORTS Science Definition Team, 2016), and NSF's Biology of the Biological Pump workshop report (Burd et al., 2016), EXPORTS is being conducted as a three phase project. EXPORTS commenced with the release of the Request For Proposals (RFP) by NASA Ocean Biology and Biogeochemistry in August 2016 to fund data mining and Observing System Simulation Experiment (OSSE) numerical modeling in support of EXPORTS planning and science activities. Following, NSF's released a Dear Colleague Letter (DCL) stating they would consider proposals that leveraged the NASA investment with objectives that supported the BoBP workshop report. In 2017, NASA released a general call for funding of the field portion of the EXPORTS, known as the First phase/stage of EXPORTS, that will span over the two field campaigns, starting in the North Pacific, in 2018, and North Atlantic in 2020. The second of EXPORTS, targets the implementation and translation of the knowledge learned during the field campaigns into predictive and forecasting models and satellite-derived NPP algorithms.

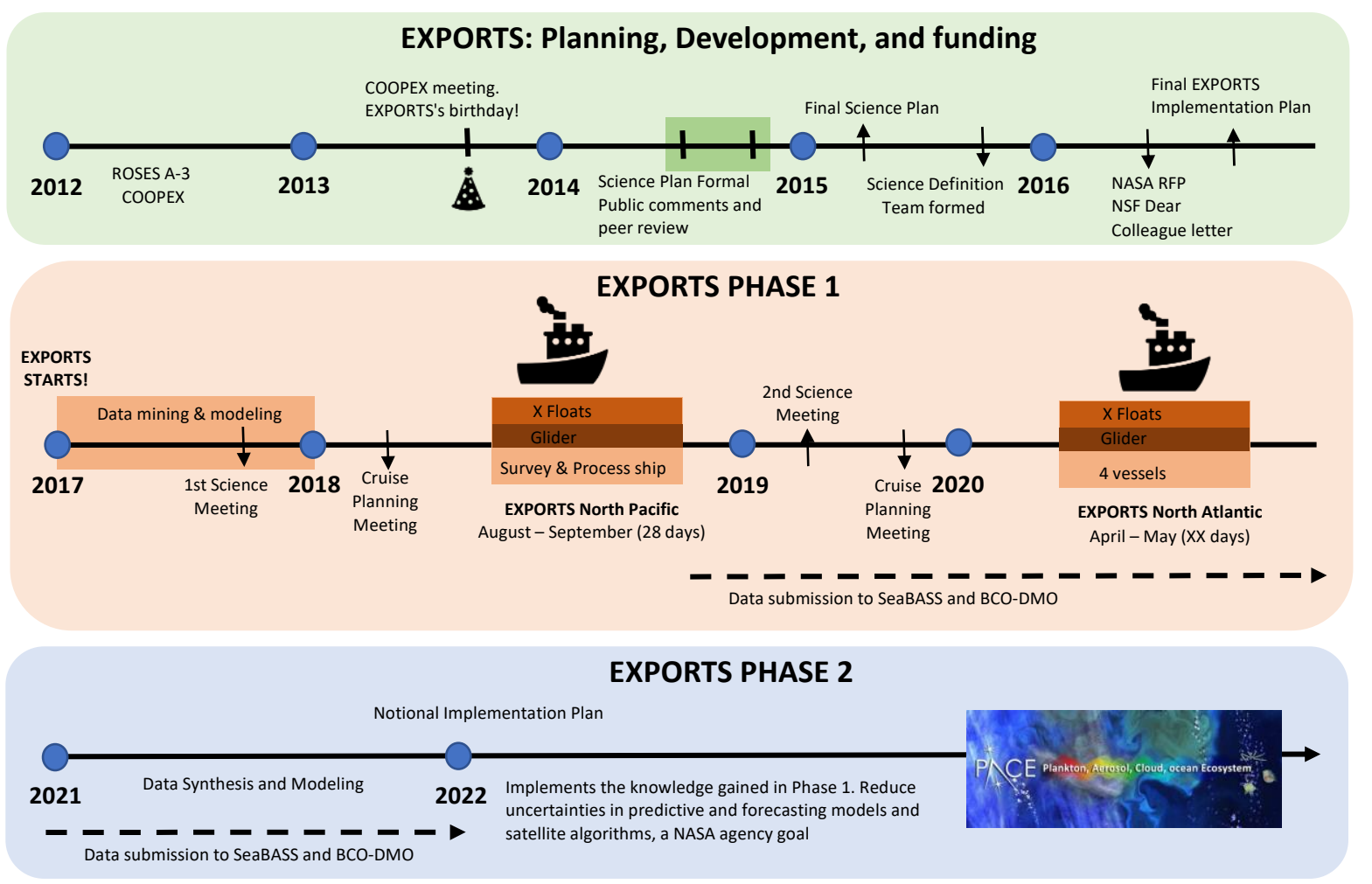

Figure 1-1. Timeline of the EXPORTS field campaign.

EXPORTS field campaigns combine research vessels, autonomous platforms and remote sensing observations to achieve the overarching goals. The North Pacific field campaign, that took place in 2018, consisted of two UNOLS vessels: (1) a process ship (R/V Roger Revelle) 
responsible for the deployment of short-term drifting arrays, sediment traps, most net tows, CTD casts to collect material for shipboard experimentation, and incubation-based biological rate determinations; and (2) a survey ship (R/V Sally Ride) responsible for the physical and geochemical measurements requiring distributed CTD sampling, large-volume in situ pumping, and towed profiler surveys. The autonomous array consisted of 2 biogeochemical (BCG) Argo floats, 6 Neutrally Buoyant Sediment Traps (NBST), single Lagrangian float, a Wire Walker, and a surface-tethered trap. The North Atlantic field Campaign was planned to have an additional vessel (through collaboration with WHOl's Ocean Twilight Zone project) and additional AUV platforms, however the protocols and sampling regime will remain very similar to the North Pacific field work. As this is being written, global pandemic of Covid -19 has postponed the planned North Atlantic campaign to foreseeable future. In addition to the vessel and autonomous assets, the field campaigns were planned near long-term monitoring stations such as the Ocean Observatories Initiative Station Papa in the North Pacific and the Porcupine Abyssal Plain (PAP) site in the North Atlantic which will provide additional historical and reference data.

In early phase of the EXPORTS field stage, the Project Office and PIs implemented a parameter group organizational structure to facilitate the inter-project communication, planning, and data management. The main goal of the parameter groups was to compile all the methods and protocols used during the EXPORTS field campaigns. The parameter groups were clustered around five main topics (Table 1.1): (1) Stocks, Proxies \& Context, (2) Optics, (3) Particle Characterization, (4) Rates, and (5) Exports. Stocks, Proxies and Context parameter group is responsible for all biogeochemical measurements (e.g., dissolved oxygen, DOC, POC), physical observations including those collected using sensors onboard the ship and autonomous platforms, and synthesized observations created by mapping one variable onto another (e.g., POC derived from optical backscatter). The optics parameter group is responsible for all the inherent and apparent optical properties such remote sensing reflectance, water absorption and scattering, concentration of optical water constituents and attenuation. Particle characterization group focused on different methods of characterization of quantity and quality (community composition) of particles in the water column. Rates working group focused on rates of change of different biogeochemical stocks, encompassing different estimates of production and removal. Lastly, Exports working group focused on vertical fluxes of carbon, and other biogeochemical tracers.

The main goal of the parameter groups was to compile all the methods and protocols used during the EXPORTS field campaigns. Such documents, here named as protocol documents, define the method, targeted deliverable parameters, dependencies on other parameters measured or modeled during the field campaigns and uncertainties associated with deliverables. Ultimately, protocol documents have listings of parameter names, as submitted to the databases - SeaBASS and BCO-DMO. Protocols were written prior to the North Pacific experiment and finalized within the year following the cruise. In addition to being the ultimate reference place for all collected measurements during the EXPORTS field campaign, protocols provided a path to post cruise synthesis work and facilitated answering of the EXPORTS science questions (Siegel et al., 2016). This connection to overarching goals of the EXPORTS 
was highlighted in the reports that each of the parameter groups produced; reports collated in this technical memorandum. 
Table 1.1 Summary of the parameter groups objectives and measurements

\begin{tabular}{|c|c|c|}
\hline $\begin{array}{l}\text { Parameter } \\
\text { Group }\end{array}$ & Team objectives & Type of measurements/instruments \\
\hline $\begin{array}{l}\text { Stocks, Proxies } \\
\text { \& Context } \\
\text { (Chapter 2) }\end{array}$ & $\begin{array}{l}\text { Provide documentation to help } \\
\text { EXPORTS investigators } \\
\text { understand, access, and utilize } \\
\text { stock, proxy, and context } \\
\text { observations }\end{array}$ & $\begin{array}{l}\text { Stocks are biogeochemical measurements in quantity per volume or mass } \\
\text { seawater (e.g., DOC and dissolved oxygen). } \\
\text { Proxies are synthesized observations created by mapping one variable onto } \\
\text { another (e.g., POC derived from optical backscatter). Context observations } \\
\text { include all physical / sensor measurements from the EXPORTS assets (i.e., ships, } \\
\text { autonomous vehicles, floats, moorings and remote sensing observations) }\end{array}$ \\
\hline $\begin{array}{l}\text { Optics } \\
\text { (Chapter 3) }\end{array}$ & $\begin{array}{l}\text { Provide high quality optical } \\
\text { data that can be used to } \\
\text { characterize the various ocean } \\
\text { constituents and that can be } \\
\text { further used to translate the } \\
\text { EXPORTS data into satellite- } \\
\text { derived algorithms. }\end{array}$ & $\begin{array}{l}\text { Apparent optical properties (e.g., radiance, irradiance and reflectance). } \\
\text { Inherent optical properties (e.g., attenuation coefficient, absorption coefficient, } \\
\text { volume scattering function, fluorescence). } \\
\text { The direct imaging devices, although optical measurements, were included in the } \\
\text { Particle Characterization group. } \\
\text { Measurements include those from ship underway system, ship-deployed profilers, } \\
\text { above water radiometer, gliders, Lagrangian BGC Argo floats and wirewalker. }\end{array}$ \\
\hline $\begin{array}{l}\text { Particle } \\
\text { Characterization } \\
\text { (Chapter 4) }\end{array}$ & $\begin{array}{l}\text { Provide high quality } \\
\text { measurements of the } \\
\text { abundance, composition and } \\
\text { size distribution of suspended } \\
\text { particles (including live } \\
\text { organisms) in the water } \\
\text { column. }\end{array}$ & $\begin{array}{l}\text { Optical and imaging instruments were used for enumeration, sizing and } \\
\text { classification of particles (e.g., plankton taxonomy and functional groups, biomass, } \\
\text { biovolume, abundance, size distribution). } \\
\text { Measurements were complemented with (1) metagenomics and DNA barcoding, } \\
\text { (2) microscopic image analyses of particles, and (3) characterization of particles } \\
\text { collected on polyacrylamide gels in sediment traps. } \\
\text { Instrumentation includes epifluorescence microscopy, flow cytometry, Imaging } \\
\text { FlowCytoBot-IFCB, MOCNESS/Zooscan, Underwater Video Profiler, LISST, } \\
\text { Coulter counter, etc. }\end{array}$ \\
\hline $\begin{array}{l}\text { Rates } \\
\text { (Chapter 5) }\end{array}$ & $\begin{array}{l}\text { Provide high quality } \\
\text { measurements of primary } \\
\text { production, bacterial and } \\
\text { community respiration, } \\
\text { secondary production, and } \\
\text { grazing rates. }\end{array}$ & $\begin{array}{l}\text { Primary productivity (GPP, NPP, NCP): incorporation of isotopes (stable and } \\
\text { radioactive) over } 6 \text { hr and } 24 \text { hr incubations to measure uptake of dissolved } \\
\text { inorganic carbon. The production of biogenic gases (e.g., oxygen) to estimate } \\
\text { PP. New production estimated through stable isotope NO3 incorporation. Diatom- } \\
\text { specific production estimated through uptake of silicon. } \\
\text { Respiration: Bacterial and Community respiration measured by O2 drawdown } \\
\text { assays and DOC remineralization assays. Zooplankton respiration assessed by } \\
\text { O2 drawdown, analysis of Electron Transport System (ETS) enzyme activity, and } \\
\text { converting community composition and biomass measurements to community } \\
\text { respiration. Measurements also include bacterial production, secondary } \\
\text { production and grazing, aggregation and sinking rates, and nutrient uptake rates. }\end{array}$ \\
\hline $\begin{array}{l}\text { Exports } \\
\text { (Chapter 6) }\end{array}$ & $\begin{array}{l}\text { Understand the mechanisms } \\
\text { controlling the magnitude and } \\
\text { attenuation of fluxes to depth } \\
\text { (biological and physical export } \\
\text { pathways out of the euphotic } \\
\text { zone and flux pathways below } \\
\text { the euphotic zone). }\end{array}$ & $\begin{array}{l}\text { High magnification microscope images of polyacrylamide gel collectors on } \\
\text { sediment traps are used to enumerate, characterize and determine the distribution } \\
\text { of sinking particles. The presence or absence of particles collected with the } \\
\text { Marine Snow Catcher. The biological composition determined by genetic } \\
\text { sequencing and proportional contributions to bulk traps of amino } \\
\text { acids. Respiration rates on sinking particles, determined using RESPIRE traps } \\
\text { and experimentally with particles from the Marine Snow Catcher. Profiled } \\
\text { Underwater Vision Profiler (UVP) images and LISST particle size distributions are } \\
\text { analyzed to identify aggregates and their water column size distribution. } \\
\text { Aggregate dynamics and coagulation modeling. Depth- and time-dependent } \\
\text { distribution of zooplankton biomass are determined using the MOCNESS and } \\
\text { UVP, with semi-automated image analysis to identify taxa. Vertical and horizontal } \\
\text { variability in zooplankton migratory distributions are characterized qualitatively } \\
\text { with acoustics systems on the survey ship, and on the autonomous platforms. } \\
\text { Fecal pellet production rates determined experimentally. }\end{array}$ \\
\hline
\end{tabular}

Following the protocols developed by the working groups. Please note that the protocols are organized around the five main topics and some of the protocols may be listed multiple times as they may answer the questions under several topics targeted by EXPORTS. 


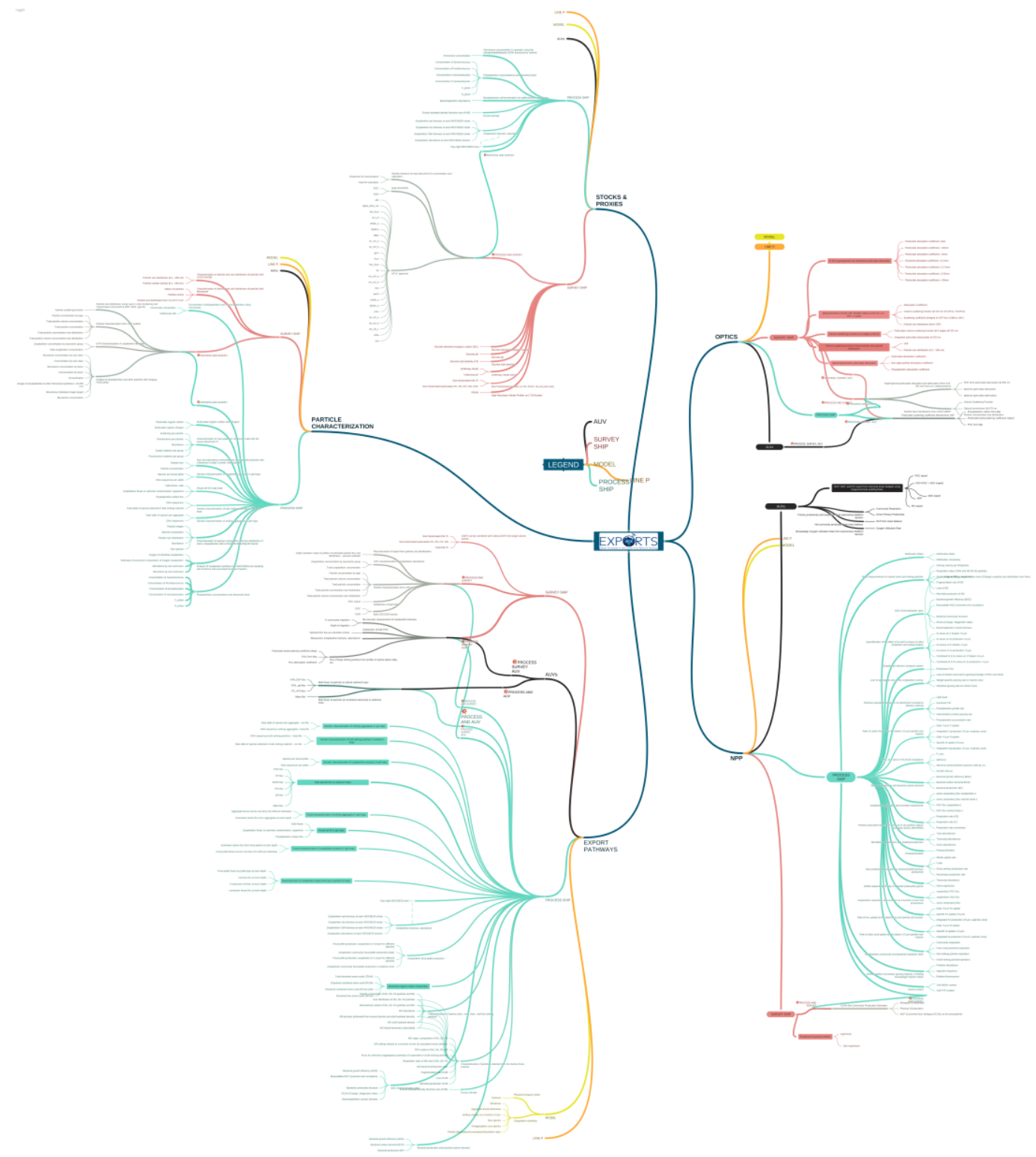

Figure 1-2 EXPORTS data tree (https://coggle.it/diagram/Wq85Q8GZiy3bfOxO/t/exports/37265e74477f7634f4fc76c10dc391269b84fbc01c36d48797 6f4b3155e4e742) 


\section{Chapter 2 Stocks, Proxies and Context (SPC) Working Group Report}

Sasha Kramer, University of California - Santa Barbara, Santa Barbara, California I sasha.kramer@lifesci.ucsb.edu Craig Lee, University of Washington, Seattle,Washington/craiglee@uw.edu Norman Nelson, University of California - Santa Barbara,California /normannelson@ucsb.edu Mary Jane Perry, University of Maine, Orono, Maine / perrymj@maine.edu David Siegel, University of California - Santa Barbara, Santa Barbara, California / david.siegel@ucsb.edu Brandon Stephens, University of California - Santa Barbara, Santa Barbara, California I bstephens@ucsb.edu Ivona Cetinić, GESTAR/Universities Space Research Association, Columbia, Maryland / ivona.cetinic@nasa.gov

\section{Overview}

The goal of the Stocks, Proxies and Context Working Group (SPC WG) is to provide documentation to help EXPORTS investigators understand, access, and utilize Stocks, Proxy and Context observations from the NE Pacific EXPORTS Field Campaign. The other Parameter WGs are focused on specific aspects of the field program's measurement suite; Optics, Rates, Export Pathways, and Particle Characterization. Hence, one of the foci for the SPC WG is ensuring that there are no gaps in measurements among the five working groups.

\section{Definitions and parameter tables}

Definitions for Stocks, Proxy and Context measurements are as follows:

Stocks - Stocks are defined here as any measurement of biogeochemical significance measured in quantity per volume or mass seawater. For example, DOC and dissolved oxygen are Stocks, while salinity is not (salinity will be defined as a Context measurement). Hence, Stocks are the measurements that contribute to the boxes in the EXPORTS wiring diagram (Fig. 2.1). For convenience, all taxa-specific information can be found under the report of the Particle Characterization Working Group (Chapter 4), while chemical composition information (either on particles or dissolved constituents) is covered in this chapter. Similarly, genomics-based determinations are not Stocks, so measurements such as OTUs/volume are covered by the Particle Characterization Working Group (Chapter 4). All optics measurements are considered in the Optics WG report (Chapter 3). Stocks measurements are primarily ship-based observations from the cruise and as such will be largely static in time once an analysis is run (compared with Proxies whose implementation will be more fluid, based on the updates provided by post-cruise analyses). 


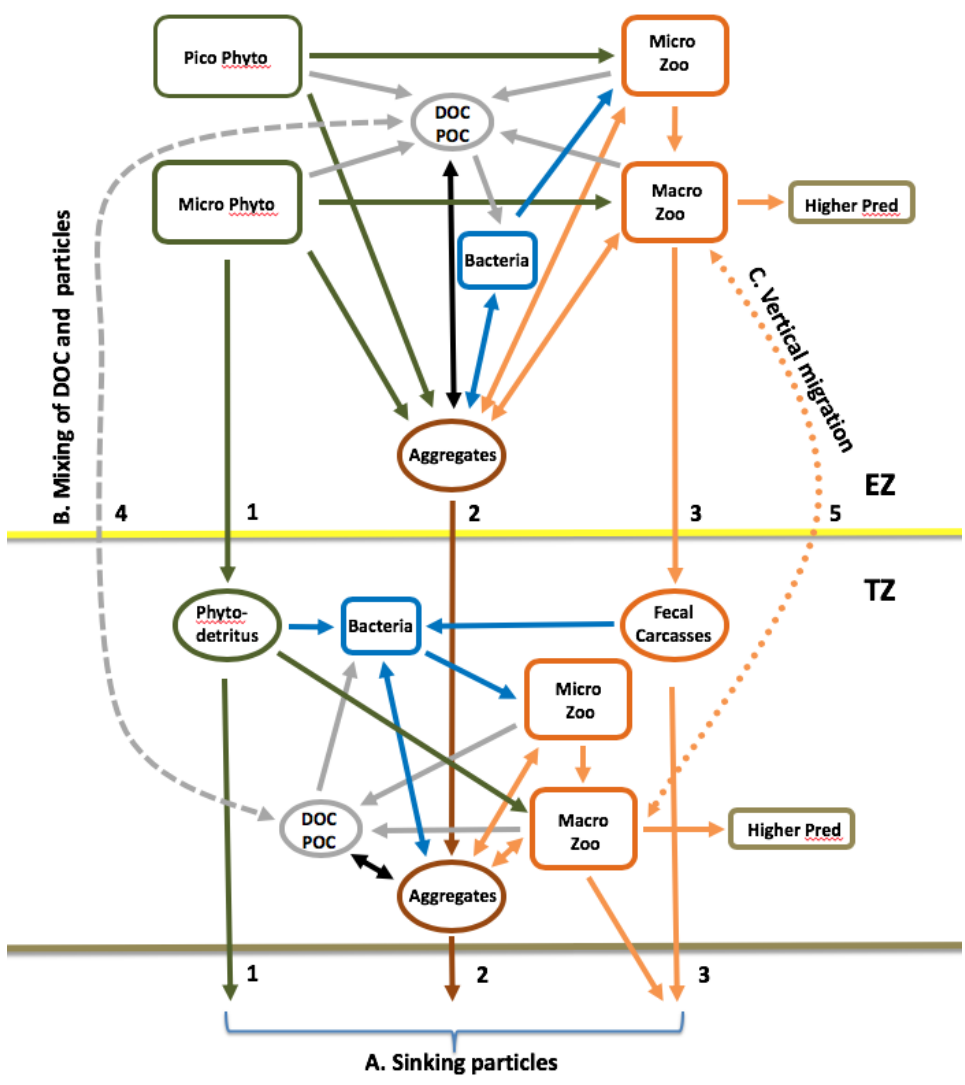

Figure 2-1 EXPORTS Wiring Diagram (modified from EXPORTS Science Plan, Siegel et al. (2016)).
Stocks protocol documents describe analyses performed and provide measures of uncertainty for each parameter. It is likely that many, if not most, of the protocol documents will be "owned" by another Parameter WG. Finally, when appropriate, protocols will include intercalibration information amongst variables (assessing variations among various $\mathrm{POC}$ or Chl-a determinations made).

Proxies - Proxies are defined here as synthesized observations created by mapping one variable onto another. Development of proxies usually serves the purpose of increasing the spatial / temporal resolution of a discrete measurement using a sensorbased measurement and typically a simple algorithm linking them. For example, using optical backscatter to represent POC is a proxy using a derived empirical relationship

between the two parameters. Furthermore, to ensure consistency across the platforms, precruise instrument intercalibration was performed (Chapter 3 ), and during the cruise numerous planed and serendipitous in field intercalibration exercises were performed. Due to their derived nature, it is unlikely that the process creating these proxies will be locked down early in the analysis phase. The Proxy Measurement Table (Table 2.1) is included here to illustrate our intent in creating the table. It is likely that this activity will not be complete by the time these WG reports are completed. Again, protocol documents will describe the methods used to derive the proxy measurements and provide measures of uncertainties for each.

Context - Context observations are useful for understanding the context of the observations made during EXPORTS. These include physical / sensor measurements from the EXPORTS ships' sampling systems (i.e., CTD/rosettes, ADCP, UW, echo sounders), all autonomous assets (SeaGlider, BioARGO floats, Lagrangian float, etc.) as well as measurements made by nearby (PMEL, OOI moorings, Line P, etc.) and remote observations (MODIS and VIIRS imagery, merged altimetry, etc.). When appropriate, short documents will describe analyses used to process the observations into data sets and how to access them. 


\section{Stock, Proxy and Context Measurement Tables}

Table 2.1 Stocks as defined in EXPORTS, with associated information. Platforms are $P$ - process ship (R/V Revelle), $S$ - survey (R/V Sally Ride),_uw - underway,_CTD - rosette,_pumps - pumps, _exp - measurement for experiment. Complete table can be found at: https://drive.google.com/open?id=1Kzvzna3bDEU9DyD9EJeR9EFsQi1polzG8SG0M35RjTs

\begin{tabular}{|c|c|c|c|c|}
\hline Parameter & $\begin{array}{c}\text { Parameter } \\
\text { name in } \\
\text { database } \\
\text { (SeaBASS) }\end{array}$ & $\begin{array}{c}\text { Units } \\
\text { (SeaBASS) }\end{array}$ & Platform & Parameter document \\
\hline Oxygen (discrete, continuous) & $\begin{array}{l}\text { Oxygen, } \\
\text { oxygen_kg }\end{array}$ & $m L L^{\wedge}-1$, umol $/ \mathrm{kg}$ & $S \_C T D, P \_C T D, W W, L F, S G$ & Oxygen \\
\hline $\begin{array}{l}\text { Macronutrients (NO3, NO2, } \mathrm{SiO} 4, \\
\text { PO4) }\end{array}$ & $\begin{array}{l}\mathrm{NO} 3, \mathrm{NO} 2 \\
\mathrm{SiO} 4, \mathrm{PO} 4\end{array}$ & $\mathrm{mmol} / \mathrm{m}^{\wedge} 3$ & P_CTD, S_CTD & $\begin{array}{c}\text { Inorganic_nutrients_protoc } \\
\text { ol_UCSB }\end{array}$ \\
\hline Nitrate (continuous) & NO3 & $\mathrm{mmol} / \mathrm{m}^{\wedge} 3$ & S_uw, S_CTD & BGC SUMO + ISUS \\
\hline Ammonia [NH4+] & $\mathrm{NH} 4$ & $\mathrm{mmol} / \mathrm{m}^{\wedge} 3$ & $P \_C T D$ & Santoro_ammoniumOPA \\
\hline \begin{tabular}{|l} 
Particulate Organic Carbon and \\
Particulate Organic Nitrogen
\end{tabular} & POC, PON & $\mathrm{mg} / \mathrm{m}^{\wedge} 3$ & P_CTD, S_CTD, S_uw, P_uw & Three or 4 methods \\
\hline Particulate Inorganic Carbon & $\mathrm{PIC}$ & $\mathrm{mol} / \mathrm{m}^{\wedge} 3$ & P_CTD, S_CTD, & $\begin{array}{c}\text { Particulate_Inorganic_Carb } \\
\text { on }\end{array}$ \\
\hline Biogenic Silica & Bsi & $\mathrm{mmol} / \mathrm{m}^{\wedge} 3$ & P_CTD, S_CTD & $\begin{array}{c}\text { Psi protocol Teflon } \\
\text { Tubes_BrzezinskiLab }\end{array}$ \\
\hline Dissolved Organic Carbon & DOC_L, DOC & umol L-1, umol/kg & P_CTD, S_CTD & $\mathrm{DOC}$ \\
\hline $\begin{array}{l}\text { Size fractionated }(1,20,50 \text { um }) \\
\text { Particulate organic Carbon, Particulate } \\
\text { Nitrogen, Total Particulate Phosphates }\end{array}$ & POC, PN, PTP & $\begin{array}{c}\mathrm{mg} / \mathrm{m}^{\wedge} 3, \mathrm{mg} / \mathrm{m}^{\wedge} 3 \\
\mathrm{mmol} / \mathrm{m}^{\wedge} 3\end{array}$ & S_pump & size fractionated particles \\
\hline $\begin{array}{l}\text { Size fractionated (1, 20,50 um) } \\
\text { Particulate Inorganic Carbon }\end{array}$ & $\mathrm{PIC}$ & $\mathrm{mol} / \mathrm{m}^{\wedge} 3$ & S_pump & size fractionated particles \\
\hline $\begin{array}{l}\text { Size fractionated }(1,20,50 \mathrm{um}) \\
\text { Biogenic Silica }\end{array}$ & Bsi & $\mathrm{mmol} / \mathrm{m}^{\wedge} 3$ & S_pump & size fractionated particles \\
\hline HPLC pigments (including $\mathrm{Ch} / \mathrm{a}$ ) & $\begin{array}{c}\text { Chl_a and many } \\
\text { other }\end{array}$ & $\mathrm{mg} / \mathrm{m}^{\wedge} 3$ & $\begin{array}{c}P_{-} C T D, S_{\text {_CTD }} S_{\text {S_lpumps }} u w, P_{-} u w, \\
\end{array}$ & Final_method_HPLC \\
\hline Fluorometric $\mathrm{Chl}$ a (acetone extraction) & $\mathrm{Chl}$ & $\mathrm{mg} / \mathrm{m}^{\wedge} 3$ & P_CTD, S_CTD & $\begin{array}{c}\text { Chlorophyll_analysis_Roesl } \\
\text { er }\end{array}$ \\
\hline $\begin{array}{l}\text { Fluorometric Chl a (methanol } \\
\text { extraction) }\end{array}$ & Chl_experiment & $\mathrm{mg} / \mathrm{m}^{\wedge} 3$ & P_exp & $\begin{array}{c}\text { Chlorophyll } \\
\text { extraction_Menden-Deuer }\end{array}$ \\
\hline Phytoplankton abundance & Abun_phyto & Cells/L & $P \_C T D, S \_C T D, S \_u w, P \_u w$ & yes \\
\hline Bacterioplankton abundances & $\begin{array}{c}\text { Abun_bacteriopl } \\
\text { ankton }\end{array}$ & Cells/L & $P \_C T D$ & Bacterial abundance \\
\hline Small Zooplankton (<63 um) & $\begin{array}{c}\text { Conc_particles_ } \\
\text { id }\end{array}$ & Particles/L & $P$ _other & 63 micron net \\
\hline Zooplankton & $\begin{array}{c}\text { Conc_particles_ } \\
\text { id }\end{array}$ & Particles/L & P_other & Zooplankton + MOCNESS \\
\hline Aggregates & $\begin{array}{c}\text { Conc_particles_ } \\
\text { id }\end{array}$ & Particles/L & P_other & Snowcatcher, density \\
\hline TEP & $\begin{array}{l}\text { TEP_bottle, } \\
\text { TEP_MSC }\end{array}$ & $\begin{array}{c}\text { ug_Gxan_equiv } \\
/ L\end{array}$ & P_CTD, $P$ _other & Snowcatcher \\
\hline $\mathrm{DIC} / \mathrm{TA}$ & $\begin{array}{c}\text { DIC, } \\
\text { total_alkalinity }\end{array}$ & umol/kg, none & S_CTD, S_uw & Discrete TA + Discrete DIC \\
\hline $\mathrm{pH}$ & $\mathrm{pH}$ & None & S_CTD, S_uw & BGC SUMO + Discrete pH \\
\hline Lipids & & & P_CTD & $\begin{array}{c}\text { Lipidomics_method_for_EX } \\
\text { PORTS }\end{array}$ \\
\hline $234^{\text {Th }}$ & Conc_Th_234 & $\mathrm{Dpm} / \mathrm{L}$ & P_CTDs & $\begin{array}{l}\text { Buesseler Thorium export } \\
\text { pathways protocol briefs }\end{array}$ \\
\hline
\end{tabular}


Table 2.2 Proxy measurements developed during North Pacific EXPORTS. Complete table can be found at https://docs.google.com/spreadsheets/d/16dqUOWHnOwMyYbZxD7Z1jcNoa2OhSICgbUhky6BKTrQ/edit\#gid=0

\begin{tabular}{|c|c|c|c|c|}
\hline 'Parameter' & $\begin{array}{c}\text { Ship-based water sample } \\
\text { measurement }\end{array}$ & Simple sensor & $\begin{array}{c}\text { AUV } \\
\text { measurement }\end{array}$ & Protocol \\
\hline Phytoplankton Chl & Chl, HPLC Chl & Ch/F;a(676) & $\mathrm{Ch} / \mathrm{F}$ & $\begin{array}{l}\text { Chlorophyll } \\
\text { proxies for } \\
\text { AUVs }\end{array}$ \\
\hline Phytoplankton Chl & Chl, HPLC Chl & $\mathrm{Ed}(412,442,553)$ & $\operatorname{Ed}(412,442,553)$ & $\begin{array}{l}\text { Chlorophyll } \\
\text { proxies for } \\
\text { AUVs }\end{array}$ \\
\hline Phytoplankton C & $\begin{array}{c}\text { plankton C from imaging, FCM, } \\
\text { and/or sorting }\end{array}$ & $b_{b p}$ & $b_{b p}$ & $\begin{array}{c}\text { POC proxies for } \\
\text { AUVs }\end{array}$ \\
\hline $\begin{array}{l}\text { Plankton community } \\
\text { composition }\end{array}$ & $\begin{array}{l}\text { FCM\& imaging }\left(1^{\circ}\right) \\
\operatorname{HPLC}\left(2^{\circ}\right)\end{array}$ & $C h / F / b_{b p}$ & $C h / F / b_{b p}$ & \\
\hline $\mathrm{POC}$ & POC & $c_{p}, b_{b p}$ & $c_{p}, b_{b p}$ & \\
\hline Nitrate & Chemical nitrate & $\mathrm{N} / \mathrm{A}$ & Suna & $\begin{array}{c}\text { Fassbender_un } \\
\text { derway_nitrate_- } \\
\text { pH }\end{array}$ \\
\hline Oxygen & Winkler & SBE 43 & Optode & \\
\hline Aggregate abundance & $\mathrm{N} / \mathrm{A}$ & $\begin{array}{l}\text { optical spikes } c_{p}, b_{b p} \\
\text { LISST \& UVP on CTD }\end{array}$ & optical spikes $c_{p}, b_{b p}$ & $\begin{array}{c}\text { OmandPerry_O } \\
\text { pticalSpikes_1p } \\
\text { age }\end{array}$ \\
\hline Zooplankton stock & Zooplankton from MOCNESS & $\begin{array}{c}\text { MOCNESS with } \\
\text { ADCP }\end{array}$ & ADCP & \\
\hline
\end{tabular}

Table 2.3 Context Measurement Summary

\begin{tabular}{l}
\hline EXPORTS NP \\
\hline CTD-SIO (Revelle \& Ride), CTD-TNC (Revelle), CTD-MOCNESS (Revelle) \\
\hline UW-SIO (Revelle \& Ride) \\
\hline ADCP (Revelle \& Ride) \\
\hline EK80 echo sounder (Ride) \\
\hline Mets (Revelle \& Ride) \\
\hline SeaGlider (AUV team) \\
\hline Lagrangian Float (AUV team) \\
\hline BioARGO floats (AUV team) \\
\hline OOI UW measurements \\
\hline Line P \\
\hline Bottle Files \& CTD profiles (recent and historical) \\
\hline Station P Infrastructure \\
\hline PMEL Mooring Mets, Fluxes and University of Washington Observations \\
\hline OOI Subsurface Moorings \& Gliders \\
\hline APL Waverider Mooring \\
\hline SST (thermal \& microwave) \\
\hline
\end{tabular}




\section{Relationship to EXPORTS science questions}

Stock concentrations play into all EXPORTS Science Questions. In particular, changes in biogeochemical stocks relate to changes in process. Some of the stocks can be derived, by using proxies from in situ optical measurements, or with algorithms from ocean color measurements. Hence, these fundamental measurements need to be monitored continuously. 


\section{Chapter 3 Exports Optics Working Group Report}

Xiaodong Zhang, University of Southern Mississippi, Mississippi / Xiaodong.Zhang@usm.edu Ivona Cetinić, GESTAR/Universities Space Research Association, Columbia, Maryland / ivona.cetinic@nasa.gov Inia Soto Ramos, GESTAR/Universities Space Research Association, Columbia, Maryland / inia.m.sotoramos@nasa.gov

Emmanuel Boss, University of Maine, Orono, Maine / emmanuel.boss@ maine.edu Collin Roesler, Bowdoin College, Brunswick, Maine / croesler@bowdoin.edu Mary Jane Perry, University of Maine, Orono, Maine / perrymj@maine.edu Deric Gray, Naval Research Laboratory, Washington, DC / deric.gray@nrl.navy.mil Jason Graff, Oregon State University, Corvallis, Oregon /jrgraff@science.oregonstate.edu Norman Nelson, University of California - Santa Barbara, Santa Barbara, California I normannelson@ucsb.edu Antonio Mannino, NASA Goddard Space Flight Center, Greenbelt, Maryland / Antonio.mannino-1@nasa.gov Scott Freeman, Science Systems and Applications Inc, Lanham, Maryland / scott.a.freeman@nasa.gov Susanne E. Craig, GESTAR/Universities Space Research Association, Columbia, Maryland / susanne.e.craig@nasa.gov

Melissa M. Omand, University of Rhode Island, Narragansett, Rhode Island / momand@uri.edu Eric D'Asaro, University of Washington, Washington / dasaro@apl.washington.edu

\section{Overview}

The underlying hypothesis of the EXPORTS is that changes in community composition in the surface ocean observed using satellite remote sensing can be used to quantify the export and fate of upper ocean net primary production (NPP). Fundamentally, ocean optics investigate a) the way the light field is changing in the ocean due to the nature and geometry of the ambient light field and ocean itself, also known as apparent optical properties (AOPs); and b) the way that oceanic constituents interact with light which depends on the nature of the medium solely, also known as inherent optical properties (IOPs). While both offer insight into the physical nature of the light in the ocean and provide an insight about the quantity and quality of light available for NPP, EXPORTs optical measurements, either collected from the satellites, in-situ platforms, or used on discrete samples collected in field give an opportunity to measure different pools of biogeochemical parameters and their changes on frequencies and scales not accessible by other means. This is achieved by developing relationships between AOPs and IOPs and targeted parameters, either through the development of Proxies (see Chapter 2 ) or ocean color algorithms.

\section{Measured parameters and associated methods}

Main goal of EXPORTS field campaign is to provide the critical information for quantifying the export and fate of upper ocean net primary production (NPP) using satellite observations and state of the art ocean technologies. Optical measurements, collected as part of EXPORTS, offer 
a direct connection to the satellite observations, and a way to extrapolate measurements of stocks and rates to the larger spatial and temporal scales covered by the AUV-based observations. Optical instrumentation was present on almost all of the observational platforms deployed during EXPORTS, making it (following the contextual measurements of the physical properties) most data abundant subsection of EXPORTS observations.

The main goal of this report is to summarize the EXPORTS Science Team's optical observations made during the 2018 North Pacific Ocean cruise onboard R/V Roger Revelle and Sally Ride, as well as the AUVs deployed as part of this experiment, and catalogize the protocols used to obtain these observations. The optical observations covered in this document include those that measure the AOPs - apparent optical properties (e.g., radiance, irradiance, and reflectance), and the inherent optical properties (e.g., attenuation coefficient, absorption coefficient, volume scattering function, fluorescence), and are shown in Table 3.1 and 3.2. While each of the methods used has an outlined parameter write up (linked in the Tables 3.1 and 3.2, and collated in the end of this technical memorandum), it is important to note that methods used were followed available community standards (e.g. in-line systems on both vessels, operated by PIs Roesler and Boss followed recommendations by Boss et al. (2019)).

Table 3.1 List of instrumentation used, during the EXPORTS NP, to collect Apparent Optical Properties (AOPs). Platforms are $P$ - Process ship, $S$ - Survey ship, LF - Lagrangian Float, WW - Wirewalker, SG - Seaglider.

\begin{tabular}{|c|c|c|c|c|c|}
\hline Instrument & $\begin{array}{l}\text { Parameter(s) } \\
\text { measured }\end{array}$ & $\begin{array}{l}\text { Parameter name } \\
\text { in database } \\
\text { (SeaBASS) }\end{array}$ & $\begin{array}{l}\text { Units } \\
\text { (SeaBASS) }\end{array}$ & Platform & $\begin{array}{l}\text { Parameter } \\
\text { document }\end{array}$ \\
\hline \multirow{4}{*}{$\begin{array}{l}\text { C-OPS (Compact- } \\
\text { Optical Profiling } \\
\text { System) at } 19 \\
\text { wavelengths }\end{array}$} & \multirow{4}{*}{$\begin{array}{l}\text { In-water radiometry } \\
\text { (Upwelling radiance, } \\
\text { downwelling irradiance, } \\
\text { downwelling surface } \\
\text { irradiance, diffuse } \\
\text { attenuation coefficient) }\end{array}$} & Lu & $\mathrm{uW} / \mathrm{cm}^{\wedge} 2 / \mathrm{nm} / \mathrm{sr}$ & \multirow{4}{*}{$\begin{array}{l}P, S, S G(E d \\
\text { only) }\end{array}$} & \\
\hline & & Es & $\mathrm{uW} / \mathrm{cm}^{\wedge} 2 / \mathrm{nm}$ & & \\
\hline & & Ed & $\mathrm{uW} / \mathrm{cm}^{\wedge} 2 / \mathrm{nm}$ & & \\
\hline & & $\mathrm{Kd}$ & $\mathrm{uW} / \mathrm{cm}^{\wedge} 2 / \mathrm{nm}$ & & \\
\hline HyperSAS & $\begin{array}{l}\text { Above-water radiometry } \\
\text { (water-leaving radiance) }\end{array}$ & $\begin{array}{l}\text { Lw, Lu, } \\
\text { Es }\end{array}$ & $\begin{array}{l}\mathrm{uW} / \mathrm{cm}^{\wedge} 2 / \mathrm{nm} / \mathrm{sr} \\
\mathrm{uW} / \mathrm{cm}^{\wedge} 2 / \mathrm{nm}\end{array}$ & $P, S$ & \\
\hline \multirow[t]{2}{*}{ HTSRB } & \multirow{2}{*}{$\begin{array}{l}\text { Above-water radiometry in } \\
\text { floating mode }\end{array}$} & Lu & $\mathrm{W} / \mathrm{cm}^{\wedge} 2 / \mathrm{nm} / \mathrm{sr}$ & \multirow[t]{2}{*}{$\mathrm{P}, \mathrm{S}$} & \\
\hline & & Ed & $\mathrm{uW} / \mathrm{cm}^{\wedge} 2 / \mathrm{nm}$ & & \\
\hline C-OPS & $\begin{array}{l}\text { Photosynthetic available } \\
\text { radiation }\end{array}$ & PAR & $\mathrm{uE} / \mathrm{cm}^{\wedge} 2 / \mathrm{s}$ & $P, S$ & \\
\hline $\begin{array}{l}\text { PAR instrument on } \\
\text { CTD/glider }\end{array}$ & $\begin{array}{l}\text { Photosynthetic available } \\
\text { radiation }\end{array}$ & PAR & $\mathrm{uE} / \mathrm{cm}^{\wedge} 2 / \mathrm{s}$ & $P, S, S G$ & \\
\hline Surface PAR & $\begin{array}{l}\text { Photosynthetic available } \\
\text { radiation }\end{array}$ & PAR & $\mathrm{uE} / \mathrm{cm}^{\wedge} 2 / \mathrm{s}$ & $P$ & \\
\hline $\begin{array}{l}\text { PAR on wirewalker/ } \\
\text { Seaglider }\end{array}$ & $\begin{array}{l}\text { Photosynthetic available } \\
\text { radiation }\end{array}$ & PAR & $\mathrm{uE} / \mathrm{cm}^{\wedge} 2 / \mathrm{s}$ & WW, SG, P & \\
\hline
\end{tabular}


Table 3.2 List of IOPS measured during the EXPORTS NP. Platforms are $P$ - Process ship, $S$ - Survey ship, LFLagrangian Float, WW - Wirewalker, SG - Seaglider, OOI-G-OOI glider, BCG-A -biogeochemical argo. Modes are I - inline, $v$ - profile, $d$-discrete.

\begin{tabular}{|c|c|c|c|c|c|}
\hline $\begin{array}{l}\text { Parameter(s) } \\
\text { measured }\end{array}$ & Instrument & $\begin{array}{l}\text { Parameter } \\
\text { name in } \\
\text { database } \\
\text { (SeaBASS) }\end{array}$ & $\begin{array}{l}\text { Units } \\
\text { (SeaBASS) }\end{array}$ & $\begin{array}{l}\text { Platform } \\
\text { (mode) }\end{array}$ & $\begin{array}{l}\text { Parameter } \\
\text { document }\end{array}$ \\
\hline \multirow{3}{*}{$\begin{array}{l}\text { (Hyper)Spectral } \\
\text { absorption } \\
\text { (particulate, } \\
\text { dissolved total), } \\
\text { Particulate } \\
\text { attenuation }\end{array}$} & \multirow[t]{3}{*}{ Ac-S/Ac-9 } & ap & $1 / \mathrm{m}$ & $\begin{array}{l}P(I, v), S \\
(i, v)\end{array}$ & \multirow[t]{3}{*}{ Boss and Roesler } \\
\hline & & ad & $1 / \mathrm{m}$ & $\begin{array}{l}S(i, v), \\
P(v)\end{array}$ & \\
\hline & & $\mathrm{cp}$ & $1 / m$ & $\begin{array}{l}P(I, v), S \\
(i, v)\end{array}$ & \\
\hline $\begin{array}{l}\text { Absorption } \\
\text { (particulate, } \\
\text { phytoplankton, } \\
\text { dissolved) }\end{array}$ & Discrete & ap, aph, ad & $1 / \mathrm{m}$ & $\begin{array}{l}S(d) \\
P(d)\end{array}$ & Roesler, Nelson \\
\hline \multirow{4}{*}{$\begin{array}{l}\text { Particulate } \\
\text { attenuation } \\
(\text { single } \lambda)\end{array}$} & LISST-Deep & $\mathrm{cp}$ & $1 / \mathrm{m}$ & $\mathrm{S}(\mathrm{v}), \mathrm{P}(\mathrm{v})$ & McDonnel \\
\hline & C-star & $\mathrm{cp}$ & $1 / \mathrm{m}$ & $\mathrm{S}(\mathrm{v}), \mathrm{P}(\mathrm{v})$ & Hydro \\
\hline & C-Star & $\mathrm{cp}$ & $1 / \mathrm{m}$ & WW & Omand/hydro \\
\hline & LISST-VSF & $\mathrm{cp}$ & $1 / \mathrm{m}$ & $S(d)$ & Zhang \\
\hline \multirow{11}{*}{$\begin{array}{l}\text { Spectral } \\
\text { backscattering } \\
(\lambda, \varphi) \text {, as } \\
\text { derived from } \\
\text { Volume } \\
\text { Scattering } \\
\text { Function }\end{array}$} & Eco-Triplet (BB3) & bbp & $1 / \mathrm{m}$ & $\mathrm{S}(\mathrm{i}), \mathrm{P}(\mathrm{i})$ & Boss, Roesler \\
\hline & FLBBRTD & bbp & $1 / \mathrm{m}$ & $\mathrm{S}(\mathrm{v}), \mathrm{P}(\mathrm{v})$ & CTD \\
\hline & BBFL2b & $\mathrm{bbp}$ & $1 / \mathrm{m}$ & $\mathrm{S}(\mathrm{i})$ & Roesler \\
\hline & HS-6 & bbp & $1 / \mathrm{m}$ & $\mathrm{P}(\mathrm{v})$ & Boss \\
\hline & ECO-BB9 & bbp & $1 / \mathrm{m}$ & $\mathrm{P}(\mathrm{v})$ & Boss \\
\hline & BBFL2SSC & bbp & $1 / \mathrm{m}$ & WW & Omand \\
\hline & FLBBCDSLC & $\mathrm{bbp}$ & $1 / \mathrm{m}$ & OOI G & Roo \\
\hline & FLNTU & $\mathrm{bbp}$ & $1 / \mathrm{m}$ & LF & D'Asaro \\
\hline & Hydroscat 6 & $\mathrm{bbp}$ & $1 / \mathrm{m}$ & $P(v)$ & Boss \\
\hline & MCOMSC & bbp & $1 / \mathrm{m}$ & BCG-A & Fassbender \\
\hline & ECO-BB9 & $\mathrm{bbp}$ & $1 / \mathrm{m}$ & $\mathrm{P}(\mathrm{v}), \mathrm{S}(\mathrm{v})$ & Boss, Scott \\
\hline \multirow{8}{*}{$\begin{array}{l}\text { Chlorophyll } \\
\text { Fluorescence }\end{array}$} & ALFA & Chl_stimf & $\mathrm{mg} / \mathrm{m}^{\wedge} 3$ & $\mathrm{P}(\mathrm{i})$ & Boss \\
\hline & Eco-Triplet & Chl_stimf & $\mathrm{mg} / \mathrm{m}^{\wedge} 3$ & $\mathrm{~S}(\mathrm{i})$ & Roesler \\
\hline & FLBBRTD & Chl_stimf & $\mathrm{mg} / \mathrm{m}^{\wedge} 3$ & $\mathrm{~S}(\mathrm{v}), \mathrm{P}(\mathrm{v})$ & Hydro team \\
\hline & MCOMSC & Chl_stimf & $\mathrm{mg} / \mathrm{m}^{\wedge} 3$ & BCG-A & Fassbender \\
\hline & BBFL2SSC & Chl_stimf & $\mathrm{mg} / \mathrm{m}^{\wedge} 3$ & WW & Omand \\
\hline & FLBBCDSLC & Chl_stimf & $\mathrm{mg} / \mathrm{m}^{\wedge} 3$ & $\mathrm{OOIG}$ & Roo \\
\hline & FLNTU & Chl_stimf & $\mathrm{mg} / \mathrm{m}^{\wedge} 3$ & LF & D'Asaro \\
\hline & FLBBRTD & Chl_stimf & $\mathrm{mg} / \mathrm{m}^{\wedge} 3$ & $\mathrm{~S}(\mathrm{v}), \mathrm{P}(\mathrm{v})$ & CTD \\
\hline \multirow{3}{*}{$\begin{array}{l}\text { CDOM } \\
\text { fluorescence }\end{array}$} & ALFA & $\mathrm{cdmf}$ & $\mathrm{mg} / \mathrm{m}^{\wedge} 3$ & $\mathrm{P}(\mathrm{v})$ & Boss \\
\hline & Eco-Triplet & cdmf & $\mathrm{mg} / \mathrm{m}^{\wedge} 3$ & $\mathrm{~S}(\mathrm{i})$ & Roesler \\
\hline & HORIBA_JY_Fluoromax4 & cdmf & $\mathrm{ppb}$ & $\mathrm{S}(\mathrm{d}), \mathrm{P}(\mathrm{d})$ & Nelson \\
\hline \multirow{7}{*}{$\begin{array}{l}\text { Volume } \\
\text { Scattering } \\
\text { Function }(\lambda, \varphi)\end{array}$} & FLNTU & VSF & $1 / \mathrm{m} / \mathrm{sr}$ & LF & D'Asaro \\
\hline & VSF -9 & VSF & $1 / \mathrm{m} / \mathrm{sr}$ & $\mathrm{S}(\mathrm{v})$ & Freeman \\
\hline & LISST - Deep & VSF & $1 / \mathrm{m} / \mathrm{sr}$ & $\mathrm{S}(\mathrm{v})$ & McDonnel \\
\hline & LISST-100X(B) & VSF & $1 / \mathrm{m} / \mathrm{sr}$ & $\mathrm{S}(\mathrm{d}), \mathrm{P}(\mathrm{i})$ & Gray, Boss \\
\hline & MVSM & VSF & $1 / \mathrm{m} / \mathrm{sr}$ & $\mathrm{S}(\mathrm{d})$ & Gray \\
\hline & LISST-VSF & VSF & $1 / \mathrm{m} / \mathrm{sr}$ & $\mathrm{S}(\mathrm{d})$ & Zhang \\
\hline & ECO-BB9 & VSF & $1 / \mathrm{m} / \mathrm{sr}$ & $\mathrm{P}(\mathrm{v}), \mathrm{S}(\mathrm{v})$ & Boss, Scott \\
\hline \multirow{3}{*}{$\begin{array}{l}\text { Particle size } \\
\text { distribution }\end{array}$} & LISST-100X(B) & PSD_DNSD & number/m^3/um & $\mathrm{S}(\mathrm{d}), \mathrm{P}(\mathrm{i})$ & Gray, Boss \\
\hline & LISST-Deep & PSD_DNSD & number/m^3/um & $\mathrm{S}(\mathrm{v}), \mathrm{P}(\mathrm{v})$ & McDonnel \\
\hline & Coulter Counter & PSD_DNSD & number/m^3/um & $\mathrm{S}(\mathrm{d}), \mathrm{P}(\mathrm{d})$ & \\
\hline $\begin{array}{l}\text { Variable } \\
\text { fluorescence }\end{array}$ & ALFA & $\overline{F V \_m}$ & Unitless & $\mathrm{P}(\mathrm{i})$ & Boss \\
\hline
\end{tabular}


The direct imaging devices, such as those taking images or videos, though in general belong to optical observation and play an important role in achieving the EXPORTS goal, are NOT covered in this Chapter, and can be found in report from the EXPORTS Particle Characterization working group (Chapter 4). As mentioned before, certain optical observations will be used, in conjunction with discrete measurements of biogeochemical stocks, to develop a suite of biogeochemical proxies (Table 2.2, Chapter 2). Ultimate goal is that some of the optical parameters collected here will be used for the development of the ocean color algorithms that can support biological carbon pump research, targeting specifically new generation of hyperspectral satellites (PACE, Werdell et al. (2019)).

\section{Inter-instrument calibration}

As visible from the Table 3.2, there was a large number of small instruments measuring bakscattering $\left(b_{b p}\right)$ and Chlorophyll Fluorescence $(C h / F)$. As these will be the primary instruments used to develop and extrapolate stock measurements of Particulate Organic Carbon and Chlorophyll a, prior to cruise Optics working group conducted a laboratory intercomparison. First, all sensors were taped with electrical tape and immersed in filtered seawater to estimate their dark counts/dark voltage. These dark counts measurements, together with the in-situ profiles with taped sensors (for some instruments) will be ultimately compared with the laboratory (factory) calibrations. Following, $b_{b p}$ sensors were immersed in serial dilution with beads, and Ch/F sensors were immersed in the serial dilution of algal culture and seawater. Actual bead and phytoplankton concentrations are irrelevant, as the comparison was used to compare the linearity of the instrument response in after-cruise intercalibration. 


\section{Chapter 4 EXPORTS Particle Characterization working group}

Lee Karp-Boss, University of Maine, Orono, Maine /lee.karp-boss@maine.edu

Tatiana Rynearson, University of Rhode Island, Narragansett, Rhode Island / rynearson@uri.edu Sasha Kramer, University of California - Santa Barbara, Santa Barbara, California I sasha.kramer@lifesci.ucsb.edu Heidi Sosik, Woods Hole Oceanographic Institution, Woods Hole, Massachusetts / hsosik@whoi.edu Jason Graff, Oregon State University, Corvallis, Oregon/jrgraff@science.oregonstate.edu Susanne Menden-Deuer, University of Rhode Island, Narragansett, Rhode Island / smenden@uri.edu Andrew McDonnell, The University of Alaska Fairbanks, Fairbanks, Alaska / amcdonnell@alaska.edu Emmanuel Boss, University of Maine, Orono, Maine / emmanuel.boss@maine.edu Collin Roesler, Bowdoin College, Brunswick, Maine / croesler@bowdoin.edu Xiaodong Zhang, University of Southern Mississippi, Mississippi / xiaodong.zhang@usm.edu Amy Maas, Bermuda Institute of Ocean Sciences, St.George's, Bermuda / amy.Maas@bios.edu Deborah Steinberg, Virginia Institute of Marine Science, Virginia / debbies@vims.edu Meg Estapa, Skidmore College, Saratoga Springs, New York/mestapa@skidmore.edu Colleen Durkin, Moss Landing Marine Laboratories, Moss Landing, California / cdurkin@mlml.calstate.edu Scott Gifford, The University of North Carolina at Chapel Hill, Chapel Hill, North Carolina I sgifford@email.unc.edu Craig Carlson, University of California Santa Barbara, California / craig.carlson@lifesci.ucsb.edu Melissa M. Omand, University of Rhode Island, Narragansett, Rhode Island / momand@uri.edu Ivona Cetinić, GESTAR/Universities Space Research Association, Columbia, Maryland I ivona.cetinic@nasa.gov Bethany Jenkins, University of Rhode Island, Narragansett, Rhode Island / bjenkins@uri.edu Alyson Santoro, University of California - Santa Barbara, California / asantoro@ucsb.edu

\section{Overview}

High quality measurements of the abundance, composition and size distribution of suspended particles in the water column are central for addressing all three science questions (and associated sub-questions) of the EXPORTS program. An impressive suite of optical and imaging instruments, covering the full spectrum of particle size in the ocean, were deployed for enumeration, sizing and classification of particles (e.g., according to taxonomy or functional groups) during the North Pacific cruise in August-September 2018. These measurements were augmented with (1) metagenomics and DNA barcoding of whole seawater samples (to increase resolution depth of taxonomic composition and functional genes), (2) microscopy/Zooprocess analyses of particles recovered from plankton nets, and (3) characterization of particles collected on polyacrylamide gels in sediment traps.

The instruments and methods that were used to characterize particles differ in their fundamental measurement principles, as well as their size ranges, sensitivities, and selectivity of particle 
detection. The comparability of data provided by different instruments and methodologies (e.g., different particle sizers, imaging/microscopy vs. metagenomics, etc.) and the integration of data across many technological platforms have not been fully evaluated yet (but see Boss et al., 2018) and will be examined during the data processing phase. The goal of this document is to provide an overview of the different measurements, to facilitate their integration with emerging research questions, and to facilitate validation of remote sensing algorithms and ecosystem models. Some of the products are in formats easily handled by SeaBASS while data from other sensors/methodologies require integration with other platforms (e.g., imaging, metagenomics).

\section{Summary of measurements to characterize particles:}

\section{Concentrations (abundances) of particles}

Table 4.1. Measurements of abundances

\begin{tabular}{|c|c|c|c|}
\hline Particle type & Platform & Units & Contact \\
\hline Bacterioplankton & Epifluorescence microscopy & cells $\times 10^{\wedge} 9 \mathrm{~L}^{-1}$ & Carlson, Hansell \\
\hline Synechococcus & Influx/Guava flow cytometer & Cells $\mathrm{L}^{-1}$ & Graff, Menden Deuer \\
\hline Prochlorochoccus & Influx/Guava flow cytometer & Cells $\mathrm{L}^{-1}$ & Graff, Menden Deuer \\
\hline Picoeukaryotes & Influx/Guava flow cytometer & Cells $\mathrm{L}^{-1}$ & Graff, Menden Deuer \\
\hline Nano-phytoplankton & Influx/Guava flow cytometer & Cells $L^{-1}$ & Graff, Menden Deuer \\
\hline $\begin{array}{l}\text { Nano- and } \\
\text { microphytoplankton (total and } \\
\text { by taxon) }\end{array}$ & IFCB & Cells $\mathrm{mL}^{-1}$ & $\begin{array}{l}\text { Sosik/Roesler, Karp- } \\
\text { Boss/Boss }\end{array}$ \\
\hline $\begin{array}{l}\text { Zooplankton abundance (by } \\
\text { size and taxon) }\end{array}$ & MOCNESS net/ ZOOSCAN & Individuals $\mathrm{m}^{-3}$ & Maas/ Steinberg \\
\hline Non-living particles & UVP & Individuals $\mathrm{m}^{-3}$ & McDonnell, Boss/Karp-Boss \\
\hline Zooplankton (by taxon) & UVP & Individuals $\mathrm{m}^{-3}$ & McDonnell, Boss/Karp-Boss \\
\hline
\end{tabular}

\section{Other biomass measurements:}

Cphyto (Influx flow cytometer; Graff)

Nphyto (Influx flow cytometer; Graff)

POC (Nelson, Graff, Roesler)

PON (Nelson, Graff, Roesler)

\section{Particle Size Distribution (PSD)}

Suspended particles in the ocean span 5 orders of magnitude in size, ranging from a few $\mathrm{nm}$ to large aggregates that reach a few $\mathrm{cm}$ in dimension. Particle size is often expressed in terms of an equivalent spherical diameter which is derived from either the particle's volume or its crosssectional area. PSD is usually derived by counting the number of particles within a given size class and normalizing that number by the width of the size class and the volume sampled; thus, accurate measurements of both size and concentrations are needed. Different instruments for 
detecting and sizing particles in seawater are based on different principles and sensitivities to size descriptors (Table 4.2) and encompass different parts of the particle size spectrum (Figure 4.1).

Table 4.2 Commercially available particle sizing instruments and their measurement principles, leading to potential discrepancies.

\begin{tabular}{|l|l|l|l|}
\hline \multicolumn{2}{|l}{ Approach } & Measurement & \multicolumn{1}{l}{$\begin{array}{l}\text { Principle associated particle } \\
\text { characteristic }\end{array}$} \\
\hline Electrical impedance & resistivity & Volume & Coulter Counter, Elzone Counter \\
\hline Optical & light scattering & axis dimension (e.g. diameter) & MVSM, LISST, flow cytometers \\
\hline Imaging & image & cross-sectional dimensions & IFCB, FlowCAM, UVP, ZooScan \\
\hline
\end{tabular}

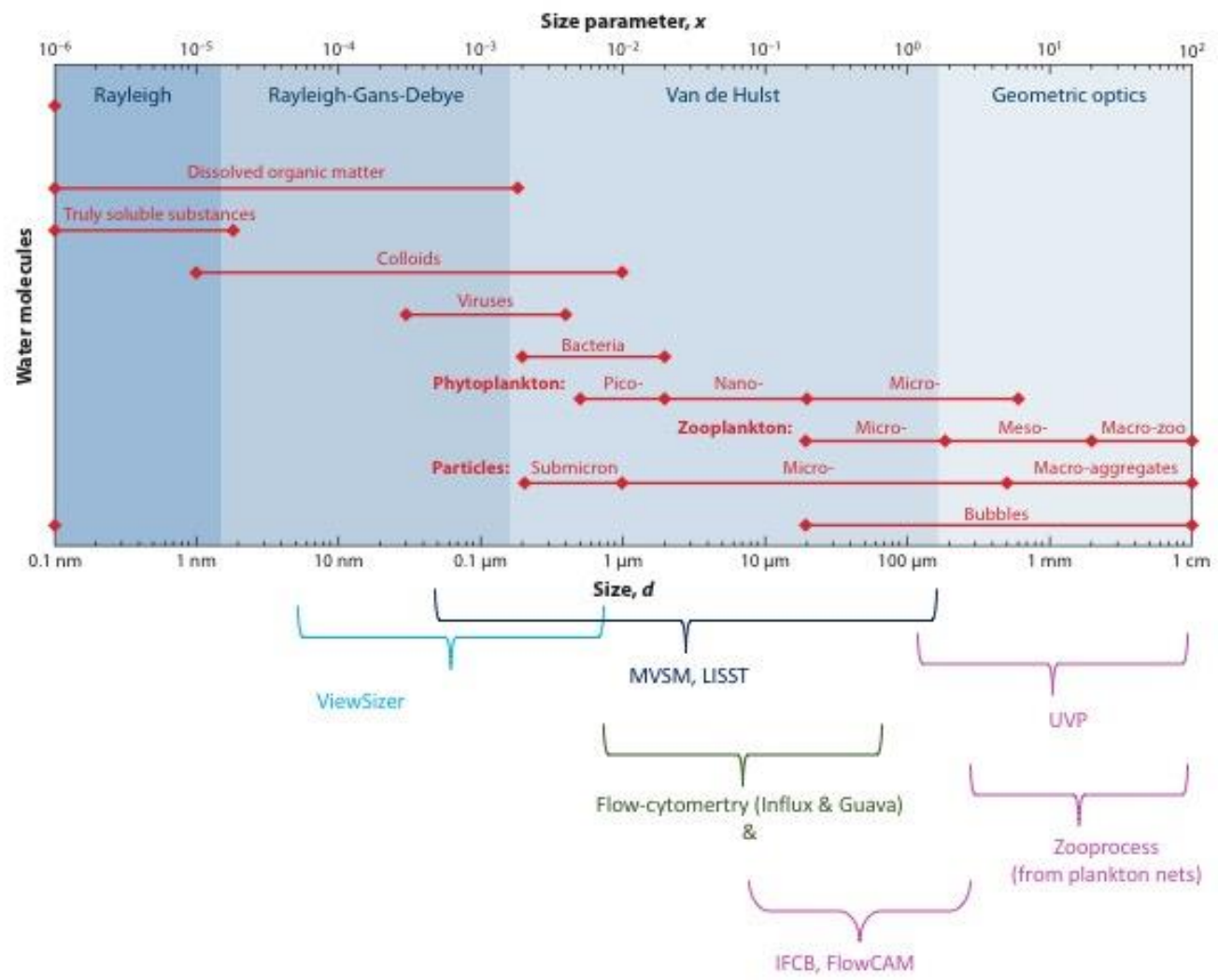

Figure 4-1 Particle size distribution (modified from Stemmann and Boss 2012) and the different PSD measurements during Exports. Identification of overlapping regions between instruments and evaluation of associated uncertainties will allow to reconstruct PSD across a broad range of particle size.

Measurements of PSD will be obtained at different spatial and temporal resolutions, depending on the instrument and its mode of deployment (Table 4.3). 
Table 4.3 A summary of PSD measurements, sampling frequency, and mode of deployment.

\begin{tabular}{|c|c|c|c|c|}
\hline $\begin{array}{l}\text { PSD } \\
\text { measurement }\end{array}$ & Platform & $\begin{array}{l}\text { Mode of operation/frequency of } \\
\text { sampling }\end{array}$ & Size range & $\begin{array}{l}\text { Contact for data } \\
\text { products }\end{array}$ \\
\hline ViewSizer & Survey ship & Discrete samples from Niskin bottles & $\sim 100-700 \mathrm{~nm}$ & Zhang \\
\hline $\begin{array}{l}\text { Multispectral Volume } \\
\text { Scattering Meter } \\
\text { (MVSM) }\end{array}$ & Survey ship & Discrete samples from Niskin bottles & $\sim 0.02-200 \mu \mathrm{m}$ & Zhang \\
\hline $\begin{array}{l}\text { Flow cytometer } \\
\text { (Heidi?) }\end{array}$ & Survey ship & $\begin{array}{l}\text { discrete samples from in line and Niskin } \\
\text { bottles }\end{array}$ & $0.5-80 \mu \mathrm{m}$ & Sosik/Roesler \\
\hline $\begin{array}{l}\text { Flow cytometer } \\
\text { (Influx) }\end{array}$ & Process ship & Discrete samples from Niskin bottles & $\sim 0.5-80 \mu \mathrm{m}$ & Graff \\
\hline $\begin{array}{l}\text { Flow cytometer } \\
\text { (Guava) }\end{array}$ & Process ship & Discrete samples from Niskin bottles & $\sim 1-30 \mu \mathrm{m}$ & $\begin{array}{l}\text { Menden-Deuer/ } \\
\text { Rynearson }\end{array}$ \\
\hline FlowCAM & Process ship & $\begin{array}{l}\text {-Subsamples from marine snow catcher } \\
\text { deployments } \\
\text {-Subsamples from zooplankton net tows }\end{array}$ & $\sim 10-200 \mu \mathrm{m}$ & $\begin{array}{l}\text { Menden-Deuer/ } \\
\text { Rynearson/ Passow }\end{array}$ \\
\hline IFCB & $\begin{array}{l}\text { Survey ship \& } \\
\text { Process ship }\end{array}$ & $\begin{array}{l}\text { Inline: surface }(5 \mathrm{~mL} / 20 \mathrm{~min}) \text { and discrete } \\
\text { sample from Niskin bottles }\end{array}$ & $\begin{array}{l}\sim 5-150 \mu \mathrm{m} \\
\text { (minimum } \\
\text { dimension; } \\
\text { elongated targets } \\
\text { up to } \sim 300 \mu \mathrm{m} \text { in } \\
\text { length) }\end{array}$ & $\begin{array}{l}\text { Sosik/ Roesler } \\
\text { Zhang/Huot } \\
\text { Karp-Boss }\end{array}$ \\
\hline LISST 100X (B) & Process ship & $\begin{array}{l}\text { Inline: surface; } 1 \text { sample per } \sim 10 \mathrm{~s} \text { (with } \\
0.2-\mu \mathrm{m} \text { FSW every hour to account for drift } \\
\text { and blank) }\end{array}$ & $\begin{array}{l}1.25-250 \mu \mathrm{m} \\
\text { (based on } \\
\text { manufacturer) }\end{array}$ & Boss \\
\hline LISST DEEP (B) & $\begin{array}{l}\text { Survey ship \& } \\
\text { Process ship }\end{array}$ & Profiling mode & $\begin{array}{l}1.25-250 \mu \mathrm{m} \\
\text { (based on } \\
\text { manufacturer) }\end{array}$ & McDonnell/Siegel \\
\hline UVP & $\begin{array}{l}\text { Survey ship } \\
\text { Process ship }\end{array}$ & CTD rosette. Volume imaged: $\sim 1 \mathrm{~L}$ & $>50 \mu \mathrm{m}$ & $\begin{array}{l}\text { McDonnell } \\
\text { Karp-Boss }\end{array}$ \\
\hline Gel traps & process ship & $\begin{array}{l}\text { NBST and STT, } 5 \text { discrete depths, 3-5 day } \\
\text { flux integrations }\end{array}$ & $\sim 10-10000 \mu \mathrm{m}$ & Durkin \\
\hline $\begin{array}{l}\text { Zooscan } \\
\text { (MOCNESS) }\end{array}$ & Process ship & Discrete samples from MOCNESS & $\begin{array}{l}>200 \mu \mathrm{m} \text { for } \\
\text { MOCNESS } \\
\text { Whatever we } \\
\text { image! (UVP) }\end{array}$ & Maas/Steinberg \\
\hline
\end{tabular}

\section{Other size proxies:}

Spectral slope of beam attenuation and scattering (links to optics working group)

Size groups derived from HPLC (pico-, nano-, micro-)

Size fractionated optical properties (in line ACS, $b_{b p}$, fluorometry) 


\section{Composition: morphology and genomics}

Table 4.4 Approaches used to study the community/particle composition during EXPORTS.

\begin{tabular}{|c|c|c|c|c|c|}
\hline Approach & Platform & $\begin{array}{l}\text { Mode of } \\
\text { operation/frequency } \\
\text { of sampling and } \\
\text { sampling volume }\end{array}$ & $\begin{array}{l}\text { Target } \\
\text { organisms } \\
\text { /particles }\end{array}$ & Information & Contact \\
\hline $\begin{array}{l}\text { DNA } \\
\text { sequencing }\end{array}$ & $\begin{array}{l}\text { Process \& } \\
\text { Survey }\end{array}$ & $\begin{array}{l}\text { filtered biomass from } \\
0.2-10 \mathrm{~L} \text { water from } \\
\text { Niskin bottles, flow } \\
\text { through system \& } \\
\text { marine snow catchers. }\end{array}$ & $\begin{array}{l}\text { Whole community } \\
(>0.2 \mu \mathrm{m}) \text { and } \\
\text { size fractionated } \\
(0.2-5 \mu \mathrm{m} \&>5 \\
\mu \mathrm{m})\end{array}$ & $\begin{array}{l}\text { Taxonomy, prokaryotes \& } \\
\text { eukaryotes }\end{array}$ & $\begin{array}{l}\text { Gifford (16S, } \\
\text { metagenomics), } \\
\text { Cassar (18S), } \\
\text { Rynearson(18S), } \\
\text { Durkin (18S), Siegel } \\
\text { (18S), } \\
\text { Jenkins (18S) } \\
\text { Santoro (16S), } \\
\text { Carlson (16S) }\end{array}$ \\
\hline IFCB & $\begin{array}{l}\text { Process \& } \\
\text { Survey }\end{array}$ & $\begin{array}{l}\text { Inline: surface }(5 \mathrm{~mL} / 20 \\
\text { min) and discrete } \\
\text { sample from Niskin } \\
\text { bottles }\end{array}$ & $\begin{array}{l}\text { Phytoplankton } \\
\text { and associated } \\
\text { chlorophyll } \\
\text { containing } \\
\text { organisms and } \\
\text { particles } \\
\end{array}$ & $\begin{array}{l}\text { Taxonomy, functional } \\
\text { groups/traits, Abundance } \\
\text { Biovolume (and other size } \\
\text { measures) }\end{array}$ & $\begin{array}{l}\text { Sosik } \\
\text { Karp-Boss }\end{array}$ \\
\hline FlowCAM & Process & $\begin{array}{l}\text { Subsamples of marine } \\
\text { snow catcher } \\
\text { deployments. } \\
\text { Zooplankton: } 63 \text { micron } \\
\text { net tows - } 2 \text { day/night } \\
\text { pairs per epoch }\end{array}$ & $\begin{array}{l}\text { Chl-a containing } \\
\text { organisms/particle } \\
\text { s; limited } \\
\text { zooplankton } \\
\text { composition 63- } \\
200 \mu \mathrm{m}\end{array}$ & $\begin{array}{l}\text { Taxonomy, functional } \\
\text { groups/traits, } \\
\text { Abundance Biovolume (and } \\
\text { other size measures) }\end{array}$ & $\begin{array}{l}\text { Menden-Deuer, } \\
\text { Rynearson, Passow, } \\
\text { Maas, Steinberg }\end{array}$ \\
\hline UVP & $\begin{array}{l}\text { Process \& } \\
\text { Survey }\end{array}$ & $\begin{array}{l}\text { CTD rosette. Volume } \\
\text { imaged: } \sim 1 \mathrm{~L}\end{array}$ & $\begin{array}{l}\text { Zooplankton, } \\
\text { particularly } \\
\text { gelatinous } \\
\text { zooplankton, } \\
\text { Rhizaria, large } \\
\text { aggregates, } \\
\text { marine snow, and } \\
\text { fecal pellets }\end{array}$ & $\begin{array}{l}\text { Taxonomy (course resolution), } \\
\text { functional groups/traits, } \\
\text { Abundance } \\
\text { Biovolume (and other size } \\
\text { measures) }\end{array}$ & $\begin{array}{l}\text { McDonnell } \\
\text { Karp-Boss }\end{array}$ \\
\hline Microscopy & Process & $\begin{array}{l}200 \mathrm{ml} \text { from Niskin } \\
\text { bottles (focus on } \\
\text { grazing except T0 and } \\
\text { TF) }\end{array}$ & $\begin{array}{l}\text { Phytoplankton (>5 } \\
\mu \mathrm{m}) \text { and } \\
\text { microzooplankton }\end{array}$ & $\begin{array}{l}\text { Taxonomy, functional } \\
\text { groups/traits, } \\
\text { Abundance, } \\
\text { Biovolume) }\end{array}$ & Menden-Deuer \\
\hline $\begin{array}{l}\text { Microscopy } \\
\text { (MOCNESS, } \\
\text { other nets) }\end{array}$ & Process & $\begin{array}{l}\text { MOCNESS: } 6 \text { day/night } \\
\text { paired tows } \\
\text { Other nets: variable- } \\
\text { animals used in } \\
\text { experiments }\end{array}$ & $\begin{array}{l}\text { Zooplankton } \\
\text { (metazoans, } \\
\text { primarily }>200 \\
\text { um) }\end{array}$ & $\begin{array}{l}\text { Taxonomy, functional } \\
\text { groups/traits, } \\
\text { Abundance, } \\
\text { biomass) }\end{array}$ & Steinberg \\
\hline $\begin{array}{l}\text { Zooscan } \\
\text { (MOCNESS) }\end{array}$ & Process & Variable & $\begin{array}{l}\text { Zooplankton } \\
\text { (metazoans, } \\
\text { primarily }>200 \\
\text { um) }\end{array}$ & $\begin{array}{l}\text { Taxonomy, functional } \\
\text { groups/traits } \\
\text { Abundance } \\
\text { Biovolume (and other size } \\
\text { measures) }\end{array}$ & Maas/Steinberg \\
\hline RNAlater traps & Process & Flux reaching traps & $\begin{array}{l}\text { eukaryotes, } \\
\text { bacteria, archaea } \\
\text { in sinking particles }\end{array}$ & Taxonomy (18S and 16S) & $\begin{array}{l}\text { Durkin (18S) and } \\
\text { Santoro (16S) }\end{array}$ \\
\hline $\begin{array}{l}\text { Gel traps } \\
\text { (microscopy) }\end{array}$ & Process & Flux reaching traps & $\begin{array}{l}\text { phytoplankton and } \\
\text { protists }\end{array}$ & Taxonomy & Durkin \\
\hline Gel traps (DNA) & Process & $\begin{array}{l}\text { individual particles } \\
\text { picked out from gel } \\
\text { traps }\end{array}$ & $\begin{array}{l}\text { eukaryotes, } \\
\text { bacteria, archaea } \\
\text { in aggregates, } \\
\text { fecal pellets }\end{array}$ & Taxonomy (18S and 16S) & $\begin{array}{l}\text { Durkin (18S) and } \\
\text { Santoro (16S) }\end{array}$ \\
\hline
\end{tabular}


A combination of imaging tools (IFCB, FlowCAM, UVP, Zooprocess), microscopy, and DNA sequence analysis provides information on community composition for both eukaryotes and prokaryotes. The taxonomic depth that can be achieved with any one of the approaches depends on the size range of the target organisms, the degree of morphological variation among species, and the level of detail available in databases or taxonomic identification guides. The ability to capture and detect rare or delicate organisms depends on the volume analyzed and the mode of sampling (e.g., niskin vs. flow through). The integration of different approaches, with their different strengths, will likely yield a thorough understanding of plankton composition. Details are described in Table 4.4.

Other sources of information for particle characterization

HPLC - functional groups (pico, nano, micro phytoplankton)

Flow cytometry - functional groups (pico-eukaryotes, Synecochoccus and Prochlorococcus) 


\title{
Chapter 5 EXPORTS Rates Working Group Report
}

\author{
Adrian Marchetti, The University of North Carolina at Chapel Hill, Chapel Hill, North Carolina I \\ amarchetti@unc.edu (primary lead) \\ Amy Maas, Bermuda Institute of Ocean Sciences, St.George's, Bermuda / amy.Maas@bios.edu (primary lead) \\ Heather McNair, University of Rhode Island, Narragansett, Rhode Island / hmcnair@uri.edu (co-lead) \\ Alex Niebergall, Duke University, Durham, North Carolina / alexandria.niebergall@duke.edu (co-lead) \\ James Fox, Oregon State University, Corvallis, Oregon / james.fox@oregonstate.edu (co-lead) \\ Scott Gifford, The University of North Carolina at Chapel Hill, Chapel Hill, North Carolina I \\ sgifford@email.unc.edu \\ Nicolas Cassar,Duke University, Durham,NC/nicolas.cassar@duke.edu \\ Susanne Menden-Deuer, University of Rhode Island, Narragansett, Rhode Island / smenden@uri.edu \\ Kim Halsey, Oregon State University, Corvallis, Oregon / halseyk@science.oregonstate.edu \\ Eric D'Asaro, University of Washington, Washington / dasaro@apl.washington.edu \\ Shuting Liu, University of California - Santa Barbara, Santa Barbara, California / shuting.liu@ucsb.edu \\ Deborah K Steinberg, Virginia Institute of Marine Science, Gloucester Point, VA / debbies@vims.edu \\ Tatiana Rynearson, University of Rhode Island, Narragansett, Rhode Island / rynearson@ uri.edu \\ Craig Carlson, University of California - Santa Barbara, Santa Barbara, California I \\ craig.carlson@lifesci.ucsb.edu \\ Jason Graff, Oregon State University, Corvallis, Oregon /jrgraff@science.oregonstate.edu \\ Michael Behrenfeld, Oregon State University, Corvallis,OR / mjb@science.oregonstate.edu \\ Craig Lee, University of Washington, Seattle, Washington / craiglee@uw.edu \\ Melissa M. Omand, University of Rhode Island, Narragansett, Rhode Island / momand@uri.edu \\ Uta Passow, Memorial University, St. John's, Canada / uta.passow@mun.ca \\ David Nicholson, Woods Hole Oceanographic Institution, Woods Hole, Massachusetts / dnicholson@whoi.edu \\ Bethany Jenkins, University of Rhode Island, Narragansett, Rhode Island / bjenkins@uri.edu \\ Mark Brzezinski, University of California - Santa Barbara, Santa Barbara, California I \\ mark.brzezinski@lifesci.ucsb.edu \\ Kristen Buck, University of South Florida, St. Petersburg, Florida / kristenbuck@usf.edu \\ Alyson Santoro, University of California - Santa Barbara, Santa Barbara, California / asantoro@ ucsb.edu
}

The overall goal of the EXPORTS program is to develop a predictive understanding of the export and fate of global ocean primary production (PP) and its implications for present and future climates. To accomplish this, a coordinated, process-oriented approach will be taken that includes a robust field campaign where the majority of parameters known to influence the formation, transformation and fate of organic matter synthesized via net primary production (NPP) will be measured. Although quantification of the stock of PP and the amount of flux in various pathways provides an instantaneous snapshot of the system's state, to move on to predictive modeling, it is necessary to determine the rates at which PP is accumulated, transformed, remineralized and sinks to depth as well as the chemical and hydrographic parameters modulating these rates.

The objective of this document is to describe the EXPORTS Science Team's conceptual framework and methods for determining these rates within an ecosystem/carbon cycle state. This will serve as a resource for identifying transformations and modulating factors that are not well characterized by the EXPORTS Science Team, and will hopefully serve as a resource for future and international programs exploring flux. In section A we describe the major processes 
that contribute to the transfer of carbon in the upper water column. These have been summarized in a figure that details the rate based processes depicted in the EXPORTS "wire diagram" (Figure 5.1). In section B, descriptions of rate measurements determined in the EXPORTS program are provided in the context of whether they are involved in the formation, alteration or remineralization of organic matter. These have been divided into five categories, which are: 1) Primary Production, 2) Respiration, 3) Organic carbon transformations and 4) Aggregation/Sinking and 5) Nutrient Uptake. The protocol briefs then provide detailed descriptions of each method, their uncertainties, key data products, and related references to facilitate data management, coordination and transparency. Rate measurements are given as a change in standing stock of a particular parameter (e.g., phytoplankton biomass, DOC, etc.) over time and can be used to estimate turnover and/or fluxes.

\section{Overview}

Primary production by phytoplankton fixes approximately $50 \mathrm{Pg}$ carbon (C) annually (Field et al., 1998). Rapid consumption and remineralization of this food source removes most of this carbon, leaving only an estimated 5 to $12 \mathrm{Pg}$ (10 to 24\%) for export out of the euphotic zone (Li and Cassar, 2016;Siegel et al., 2016). Export of the remaining carbon from the surface waters is mediated by aggregation and sinking processes in both the euphotic zone (EZ) and the deeper water column, which is referred to as the twilight zone (TZ) in the EXPORTS paradigm. In this midwater region repackaging and consumption of surface flux by midwater organisms modify both the total carbon export as well as the aggregation and sinking rates. This net reduction in vertical transfer of $\mathrm{C}$ is referred to as attenuation.

Understanding and predicting central paradigms of ocean ecosystem function, including export production and responses to environmental change requires recognition of grazing and inclusion of this dominant loss factor in global biogeochemical, ecosystem and cross-biome comparison models (e.g. Stock and Dunne (2010)). In all ocean ecosystems, grazing by herbivorous protists (i.e. micro-zooplankton) constitutes the single largest loss factor of marine primary production (PP) and alters the abundance and size spectra of particles (Banse, 2013;Worden et al., 2015;Steinberg and Landry, 2017). Global estimates of herbivorous protist grazing across major biogeochemical provinces in the ocean range from $49 \%$ to $77 \%$ primary production removed, with an overall average of $62 \%$ (Schmoker et al., 2013). Currently the trophic linkages and transfer efficiencies among microzooplankton, mesozooplankton and macrozooplankton remain poorly characterized, making analyses of grazing rate and secondary production of the mesozooplankton a large source of uncertainty (Steinberg and Landry, 2017). The transfer to higher trophic levels is even more poorly constrained (Burd et al., 2016).

Once grazed, around half of the $\mathrm{C}$ consumed by the zooplankton is respired as $\mathrm{CO}_{2}$ while the remainder contributes to growth and secondary production. In surface waters respiration acts as remineralization of $\mathrm{PP}$, while midwater zooplankton respiration after consumption of particle flux is a source of flux attenuation. In contrast, the respiration of diel vertical migratory zooplankton, which consume organic particles in the surface waters at night and metabolize (i.e., respiring, excreting, egesting) surface-ingested POM in the mesopelagic zone during the day, is one of the major pathways of export flux. This component of the biological pump is referred to as "active" transport, as opposed to the passive sinking from surface waters of particles such as 
fecal pellets. The largest component of the active transport of $C$ by vertical migrators is the respiratory flux (respiration of $\mathrm{CO}_{2}$ at depth), which scales positively with migrant animal biomass. Current estimates suggest that $31-40 \%$ of the PP in the euphotic zone is respired by microzooplankton, $21 \%$ by mesozooplankton and $50-90 \%$ is respired by bacteria (Anderson and Ducklow, 2001;Rivkin and Legendre, 2001). Mesozooplankton respiration through the full water column accounts for an estimated 17-32\% of global PP (Steinberg and Landry, 2017).

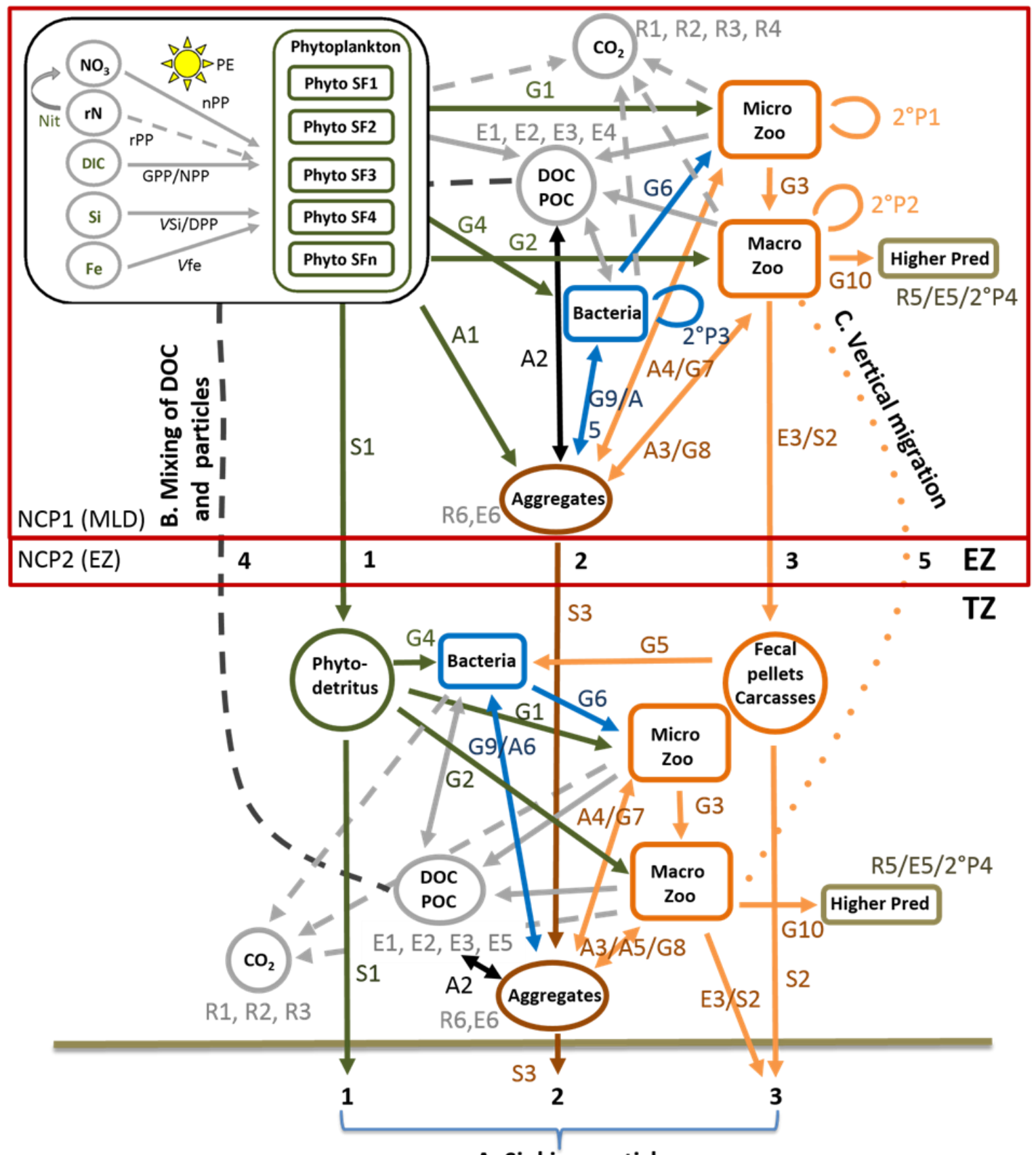

A. Sinking particles

Figure 5-1 EXPORTS "rates" wire diagram. A: aggregation, E: egestion (production of waste), G: grazing, R: respiration, $S$ : sinking, $2^{\circ} \mathrm{P}$ : Secondary production (growth/reproduction). POC: particulate organic carbon, DOC: dissolved organic carbon, nPP: NO3-based new production, rPP: Regenerated production, GPP: Gross primary production, NPP: Net 
primary production, Vsi/DPP: Si uptake rates/Diatom-based primary production, Vfe/NPP9: Fe uptake rates/Fe-based primary production, Nit: Nitrification, PE: Photosynthesis-irradiance curves, NCP1: Net community production - mixed layer, NCP2: Net community production - euphotic zone.

\section{Subgroup Primary Production}

Primary production in marine pelagic environments is the amount of dissolved carbon dioxide fixed by photosynthesis over time. In the euphotic zone, the vast amount of primary production is carried out by autotrophic single-celled prokaryotes and eukaryotes (collectively termed phytoplankton). Rates of primary production in the ocean vary spatially and temporally and are largely a function of the physical and chemical environment that influences phytoplankton composition, abundance and physiology.

A. Gross primary productivity (GPP): GPP is the total quantity of organic carbon that is fixed by photosynthesis.

B. Net primary productivity (NPP): NPP is equal to gross primary productivity minus losses due to respiration by autotrophs.

C. Net community productivity (NCP): NCP is equal to GPP minus community respiration (CR), or NPP minus heterotrophic respiration (HR). Negative NCP (i.e. net heterotrophic conditions) is associated with remineralization of $\mathrm{POC}$ and DOC. Conversely, a positive NCP (i.e. net autotrophic conditions) leads to a net production of POC and DOC at the ocean surface, which can either accumulate or be exported. Accordingly, NCP is equal to export production and new production (see below) when the POC and DOC inventories are at steady-state.

$$
\begin{gathered}
\mathrm{CO}_{2}+\mathrm{H}_{2} \mathrm{O} \underbrace{\underset{N C P}{\stackrel{G P P}{H}} \stackrel{H R}{\longrightarrow}}_{N P P} \text { Organic matter }+\mathrm{O}_{2} \\
\text { Export production }=\mathrm{NCP}-\mathrm{MLD} \times \frac{d(P O C+D O C)}{d t}
\end{gathered}
$$

Li \& Cassar 2017

D. New production: New production refers to primary production fueled by allochthonous (external) nutrient supply (e.g., vertical mixing of nutrient to the ocean surface, atmospheric nutrient deposition, and $\mathrm{N}_{2}$ fixation). Under steady-state conditions, new production can also be used as a proxy for export production (Eppley and Peterson 1979).

E. Regenerated production: Regenerated production refers to primary production fueled by the remineralization of nutrients at the ocean surface. Taken together, the ratio of new production divided by the total production (i.e., new plus regenerated production) yields the f-ratio, which is often used as a way to describe the export flux of organic matter from the surface ocean by way of the carbon biological pump.

F. Diatom production: Diatom production is the amount of dissolved inorganic carbon fixed specifically by diatom photosynthesis.

Primary productivity will be measured using multiple approaches that will estimate gross and net primary productivity as well as net community productivity. Both the incorporation of isotopes 
(stable and radioactive) over short ( $6 \mathrm{hr}$ ) and long (24 hr) incubations will be used to measure uptake of dissolved inorganic carbon. In addition, the production of biogenic gases (e.g., oxygen) will also be measured and used to estimate PP. New production is estimated through stable isotope $\mathrm{NO}_{3}$ incorporation. Diatom-specific production will be estimated through uptake of silicon.

\section{Subgroup Respiration}

Respiration is the cellular metabolic processes used to generate energy via the oxidation of organic matter and the release of waste products. In the context of EXPORTS the term is used to characterize the aerobic conversion of organically fixed $C$ (PP) to energy (in the form of ATP) and $\mathrm{CO}_{2}$. It is one of the major transformation pathways of PP and, depending on where it occurs in the water column, can contribute to flux or to the attenuation of flux.

Here we divide respiration into three categories: bacterial, community, and zooplankton.

A. Bacterial Respiration (BR): BR is the remineralization of organic matter by free-living microbes and microbes associated with particles passing through a $5 \mu \mathrm{m}$ pore size filter.

B. Community Respiration (CR): CR is the remineralization of organic matter by all members of the bacterioplankton, phytoplankton, and zooplankton communities. This measurement provides a holistic approximation of total heterotrophic respiration (HR). This measure underestimates mesozooplankton, fish and nekton contributions to community respiration due to methodological constraints.

C. Zooplankton Respiration (ZR): Estimates of total ZR are made of the $>200 \mu \mathrm{m}$ zooplankton community sampled comparing daytime and nighttime vertically stratified net tows (MOCNESS). Smaller metazoans that are not retained in the nets $(<200 \mu \mathrm{m})$ are sampled with a $63 \mu \mathrm{m}$ mesh net and the community composition and biovolume will be used to calculate the ZR of this size-fraction. Very large mobile zooplankton, fish and nekton respiration are underestimated by current EXPORTS protocols.

Bacterial and Community respiration will be measured in two complimentary ways: $\mathrm{O}_{2}$ drawdown assays and DOC remineralization assays. Zooplankton respiration will also be assessed in two ways 1) analysis of the Electron Transport System (ETS) enzyme activity and 2) converting community composition (from ZooScan analysis) and biomass measurements to community respiration. The latter will be accomplished using experimentally measured individual respiration rates as well as the published equations based on temperature and scaling coefficients (Ikeda 2014).

\section{Subgroup Organic Carbon transformations}

Carbon transformations are the conversion of NPP into the biomass of other prokaryotic or eukaryotic organisms via heterotrophy. This conversion can have different efficiencies depending on the carbon source (i.e. food quality)-characterizing the rate of growth based on photosynthetic community and DOM pool is critical for understanding how community composition influences export versus recycling.

A. Bacterial production 
We will determine the flux of the most labile fraction of DOC to bacterioplankton (i.e., bacterial carbon demand; BCD) from independent measurements of heterotrophic bacterial production (BP) and estimates of bacterial growth efficiency (BGE). The most labile fraction of DOC (LDOC) is rapidly consumed, supporting the metabolic energy and nutrient demands of heterotrophic prokaryotes, with turnover rates on time scales of hours to days. Bacterial carbon demand (BCD) best represents the flux of LDOC, with greater than $50 \%$ of net PP flowing through the labile DOM pool on a daily basis (Ducklow, 1999;Williams, 2000). Determining the flux of LDOC will constrain the respiratory fate of a large fraction of NPP.

We will also conduct DOC remineralization experiments to directly assess the fraction of the accumulated DOC that is available to bacterial production vs respiration. Simultaneous measurements of the change in bacterial biomass and DOC in microbial dilution cultures will allow us to estimate bacterial growth efficiency (BGE) of the natural microbial assemblages (Carlson et al., 2004) as follows:

$$
\mathrm{BGE}=\Delta \mathrm{BB} / \triangle \mathrm{DOC}
$$

where $\triangle \mathrm{BB}$ and $\triangle \mathrm{DOC}$ represent the change in bacterial carbon biomass and $\mathrm{DOC}$ removal through stationary growth in the microbial remineralization experiments. Estimates of water column BCD (0-500 m), or the gross flux of carbon to heterotrophic bacterioplankton, will be determined from BP profiles ( ${ }^{3} \mathrm{H}$-Leu incorp) and BGE estimates from the $\mathrm{EZ}$ and $\mathrm{MZ}$ determined on the Lagrangian cruise: $B C D=B P / B G E$

\section{B. Secondary production/Grazing}

To quantify predation and secondary production effects on export production, particle abundance and size distribution will be measured as a function of co-occurring environmental and biological conditions. Herbivorous grazing rates on specific groups of phytoplankton in the euphotic zone will be quantified using a two-point dilution method (Morison and Menden-Deuer, 2017) and flowcytometry. To achieve high-resolution grazing rate measurements, on time scales similar to the capacity of autonomous or remote sensors, we are developing novel ecogenomic tools that will open an entirely new field for remotely sensed products that assess zooplankton grazing (see proposed genomic methods by Menden-Deuer). Moreover, long-term incubations where predators have been concentrated to increased grazing signal will be used to resolve feeding potential and transformations of organic matter below the euphotic zone. Secondary production and feeding of higher trophic levels (mesozooplankton, nekton and fish) are not measured by EXPORTS protocols.

\section{Subgroup Aggregation/Sinking rates}

As particles sink through the water column they can coagulate (aggregate) to form (larger) aggregates, which may be fragmented (disaggregated) due to both physical and biological processes. The sinking of aggregates serve as one of the main export flux pathways, while disaggregation is a major driver of attenuation processes in the midwater. Aggregates are complex particles made up of phytodetritus, resident eukaryotic and prokaryotic communities, fragmented fecal pellets, organic polymers, detritus, mineral particles, and other compounds that become connected as they sink through the water column. The EXPORTS interest in these processes are to determine the size class and composition of various particle types throughout 
the water column, and to estimate their sinking, aggregation and disaggregation rates as well as other attenuation mechanisms (grazing). Aggregation will be studied both by comparing particles captured at various depths (trap, bottle, Marine Snow Catcher) as well process studies on various particle types. Sinking and respiration rates of particular particle types will be measured, while disaggregation and loss due to feeding will be assessed using grazing studies.

\section{Subgroup Nutrient (Si, Fe, N) Uptake rates}

It is well known that environmental factors can modify the physiological rates of all of the processes of interest to the EXPORTS program. The N Pacific is known to be nutrient (iron) limited, so it is valuable to determine how changes in the nutrient field will influence the physiology and associated rates of the primary producers. The primary hypothesis to be tested during EXPORTS is that differences in the type ( $\mathrm{Si}, \mathrm{Fe}, \mathrm{N})$ and degree of nutrient stress experienced by co-occurring phytoplankton (diatom) taxa can predict the export pathways that each will follow through the food web. Short term incubations using isotopically traced nutrients, will be conducted to measure changes in the rate of primary productivity and assess stoichiometry of nutrient use and a second set of longer duration incubation experiments will be carried out to find transcriptomic markers of nutrient stress. These two process studies will be linked with analyses of the vertical structure of the natural community composition and physiology to connect measured rates and transcriptomic tracers of nutrient stress with observed changes in natural assemblages as a function of depth and nutrient fields. 
Table 5.1 Summary of Protocol Briefs. This table provides a cross reference between the rate measured, the rate depicted on the rates wiring diagram (Figure 5.1) and the protocol descriptions associated with this working group and associated subgroups (SGs) ( $P$ = production, $R=$ respiration, $T=$ transformation (Corg-->Corg), $A=$ aggregation, $N=$ Nutrient Rate Processes).

\begin{tabular}{|c|c|c|c|c|c|}
\hline Rate & $\begin{array}{l}\text { Wire Diagram } \\
\text { Abbreviation }\end{array}$ & SG: & Lead PI & Contact Person & Method protocol \\
\hline $\mathrm{NCP}$ & & $\mathrm{P}, \mathrm{R}$ & Lee & Nicholson & $\begin{array}{c}\mathrm{O} 2, \mathrm{NO}, \text { rate of } \\
\text { change of } \mathrm{C} \text { from } \\
\text { backscatter }\end{array}$ \\
\hline $\mathrm{NCP}$ & & $\mathrm{P}, \mathrm{R}$ & Estapa & Omand & diel cp and oxygen \\
\hline NCP & NCP1 & $\mathrm{P}, \mathrm{R}$ & Marchetti & Cassar & $\mathrm{O} 2 / \mathrm{Ar}$ \\
\hline NO3 Uptake & $\mathrm{nPP}$ & $\mathrm{N}, \mathrm{P}$ & Marchetti & Marchetti & $\begin{array}{c}\text { Na15NO3, } 6 \text { hr and } 24 \\
\text { hr incubation }\end{array}$ \\
\hline $\begin{array}{l}\text { Metatranscriptomics of } \\
\text { eukaryotic plankton }\end{array}$ & & $P, R$ & Marchetti & Marchetti & $\begin{array}{l}\text { mRNA sequencing of } \\
\text { poly-A selected genes }\end{array}$ \\
\hline $\begin{array}{l}\text { Metatranscriptomics of } \\
\text { prokaryotic plankton }\end{array}$ & & $P, R$ & Marchetti & Gifford & $\begin{array}{l}\text { mRNA sequencing of } \\
\text { genes }\end{array}$ \\
\hline GPP & GPP & $P$ & Marchetti & Marchetti & $\begin{array}{l}\mathrm{H} 13 \mathrm{CO} 3,6 \mathrm{hr} \\
\text { incubation }\end{array}$ \\
\hline GPP/CR & & $P$ & Lee & Nicholson & diel oxygen \\
\hline NPP & & $P$ & Behrenfeld & Halsey & $\begin{array}{l}\mathrm{H} 14 \mathrm{CO} 3-24 \mathrm{hr} \\
\text { incubation }\end{array}$ \\
\hline NPP & NPP1 & $P$ & Marchetti & Marchetti & $\begin{array}{l}\mathrm{H} 13 \mathrm{CO} 3,24 \mathrm{hr} \\
\text { incubation }\end{array}$ \\
\hline NPP & & $P$ & Lee & Nicholson & $\begin{array}{c}\text { chlorophyll and PE } \\
\text { curve }\end{array}$ \\
\hline NPP & & $P$ & Menden-Deuer & Menden-Deuer & $\begin{array}{c}\text { phytoplankton } \\
\text { growth/heterotrophic } \\
\text { protist grazing dilution } \\
\text { experiments }\end{array}$ \\
\hline NPP & & $P$ & Estapa & Omand & diel cp and oxygen \\
\hline $\begin{array}{l}\text { Photosynthesis-irradiance } \\
\text { relationships }\end{array}$ & & $P$ & Behrenfeld & Halsey & $\begin{array}{c}\text { photosynthetron, 14C, } \\
2 \mathrm{hr} \text { incubations }\end{array}$ \\
\hline Photoacclimation & & $\mathrm{P}$ & Behrenfeld & Graff & $\begin{array}{c}\text { Chlorophyll and } \\
\text { fluorescence changes } \\
24 \text { hour }\end{array}$ \\
\hline O2 respiration & $\mathrm{R} 1-6$ & $\mathrm{R}$ & Lee & Nicholson & $\begin{array}{c}\mathrm{O} 2, \mathrm{NO} 3, \text { rate of } \\
\text { change of } \mathrm{C} \text { from } \\
\text { backscatter }\end{array}$ \\
\hline O2 respiration & $\mathrm{R} 1, \mathrm{R} 2, \mathrm{R} 4$ & $\mathrm{R}$ & Marchetti & Gifford & $\begin{array}{c}\text { O2 drawdown, } \\
\text { measuring every } 6 \\
\text { hours }\end{array}$ \\
\hline $\begin{array}{l}\text { Zooplankton respiration } \\
\text { and excretion }\end{array}$ & R3, E3 & $\mathrm{R}$ & Steinberg & Maas & $\begin{array}{l}\text { function of size and } \\
\text { temperature }\end{array}$ \\
\hline $\begin{array}{l}\text { Zooplankton respiration } \\
\text { and excretion }\end{array}$ & R3, E3 & $\mathrm{R}$ & Steinberg & Maas & incubations \\
\hline $\begin{array}{l}\text { Zooplankton electron } \\
\text { transport system }\end{array}$ & R3 & $\mathrm{R}$ & Steinberg & Maas & ETS assay \\
\hline DOC remineralization & $\mathrm{R} 1,2^{\circ} \mathrm{P} 3$ & $\mathrm{R}$ & Carlson & Carlson & $\begin{array}{l}\text { Microbial remin days to } \\
\text { weeks incubation }\end{array}$ \\
\hline $\begin{array}{l}\text { Bacterial Production on } \\
\text { MS }\end{array}$ & $\mathrm{G} 9,2^{\circ} \mathrm{P} 2$ & $P$ & Siegel/ Carlson & Passow/Carlson & $\begin{array}{c}\text { 3H-Leucine uptake } \\
\text { carlson }\end{array}$ \\
\hline $\begin{array}{l}\text { O2 respiration of marine } \\
\text { snow (and non-sinking, } \\
\text { fast and slow sinking } \\
\text { particles) }\end{array}$ & $\mathrm{R} 1$ & $\mathrm{R}$ & Siegel & Passow/ Gifford & $\begin{array}{c}\text { O2 change incubation } \\
+ \text { gifford }\end{array}$ \\
\hline
\end{tabular}




\begin{tabular}{|c|c|c|c|c|c|}
\hline $\begin{array}{l}\text { Sinking velocity of marine } \\
\text { snow \& estimates for } \\
\text { small particles }\end{array}$ & S3 & $\bar{A}$ & Siegel & Passow & $\begin{array}{c}\text { MSC collection allows } \\
\text { for the separation of } \\
\text { particles sinking at }<\text { or } \\
>18 \mathrm{~m} / \mathrm{d} \text { or not sinking } \\
\text { at all. Incubations for } \\
\text { MS }\end{array}$ \\
\hline $\begin{array}{l}\text { grazing and } \\
\text { fragmentation rate of } \\
\text { zooplankton on marine } \\
\text { snow }\end{array}$ & A3/G8 & $\mathrm{T}$ & Siegel & Passow/Steinberg & incubations \\
\hline Bacterial Production & $2^{\circ} \mathrm{P} 3$ & $\mathrm{~T}$ & Carlson & Carlson & 3H-Leucine uptake \\
\hline $\begin{array}{l}\text { Phytoplankton loss } \\
\text { processes, via } \\
\text { microzooplankton/protist } \\
\text { grazing }\end{array}$ & G1, G6, G7 & $\mathrm{T}$ & Menden-Deuer & Menden-Deuer & $\begin{array}{l}\text { incubation vs. in situ } \\
\text { Chl a accumulation } \\
\text { rates }\end{array}$ \\
\hline Grazing rate marker & G1, G6, G7 & $\mathrm{T}$ & Menden-Deuer & Rynearson & Biomass filtration \\
\hline $\begin{array}{l}\text { Mesopelagic grazing rate } \\
\text { potential }\end{array}$ & G1, G6, G7 & $\mathrm{T}$ & Menden-Deuer & Menden-Deuer & incubation \\
\hline Mesozooplankton grazing & G2, G3 & $\mathrm{T}$ & $\begin{array}{l}\text { Steinberg/Menden- } \\
\text { Deuer }\end{array}$ & $\begin{array}{c}\text { Menden- } \\
\text { Deuer/Steinberg/Mass }\end{array}$ & incubation \\
\hline NPP & VSi/DPP & $\mathrm{P}, \mathrm{N}$ & Jenkins & Brzezinski & $\begin{array}{c}\text { 32Si uptake } 0.6-5.0 \& \\
>5.0 \text { um size fractions } \\
24 \mathrm{~h}\end{array}$ \\
\hline NPP & $\begin{array}{l}\text { VSi/DPP; VFe } \\
\text { (NPP9); nPP; } \\
\text { GPP/NPP 1-8 }\end{array}$ & $\mathrm{P}, \mathrm{N}$ & Jenkins & Brzezinski & $\begin{array}{c}\text { Nurient stress } \\
\text { assessments. Effects } \\
\text { of } \mathrm{Fe} \text { and } \mathrm{Si} \text { on rates of } \\
\mathrm{C}, \mathrm{Si} \text { and } \mathrm{N} \text { use (dawn } \\
\text { to dusk) }\end{array}$ \\
\hline Nitrification & Nit & $\mathrm{R}, \mathrm{T}$ & Santoro & Santoro & 15NH4 addition \\
\hline $\begin{array}{l}\text { Particle-associated } \\
\text { respiration }\end{array}$ & $\mathrm{R} 6$ & $\mathrm{R}, \mathrm{T}$ & Santoro & Santoro & $\begin{array}{l}\text { in situ incubation } \\
\text { chamber (RESPIRE } \\
\text { trap) }\end{array}$ \\
\hline $\mathrm{NCP}(\mathrm{POC}+\mathrm{DOC})$ & & P-R & Fassbender & Fassbender & $\begin{array}{l}\text { BGC tracer budgets } \\
\text { (DIC, TA, NO3, O2) }\end{array}$ \\
\hline CaCO3 Production (PIC) & & $P-R$ & Fassbender & Fassbender & $\begin{array}{l}\text { BGC tracer budgets } \\
\text { (DIC, TA, NO3, O2) }\end{array}$ \\
\hline NPP & VSi/DPP & $\mathrm{N}$ & Jenkins & Brzezinski & $\begin{array}{c}\text { 32Si uptake } 0.6-5.0 \& \\
>5.0 \text { um size fractions } \\
24 \mathrm{~h}\end{array}$ \\
\hline Fe uptake & VFe (NPP9) & $\mathrm{N}$ & Jenkins & Buck & $\begin{array}{l}\text { 57FeCl3 uptake into } \\
\text { diatom size fraction }\end{array}$ \\
\hline particle aggregation & $\begin{array}{l}\text { Sum of } A 1, A 2, \\
A 3, A 4 \text { and } A 6\end{array}$ & A & Lam & Lam & $\begin{array}{c}\text { lithogenic particle } \\
\text { concentration analysis } \\
\text { followed by inverse } \\
\text { modeling }\end{array}$ \\
\hline particle disaggregation & $\begin{array}{l}\text { Sum of A5 and } \\
\text { physical \& } \\
\text { bacterial } \\
\text { diaggregation } \\
\text { (not in the } \\
\text { diagram) } \\
\end{array}$ & A & Lam & Lam & $\begin{array}{c}\text { lithogenic particle } \\
\text { concentration analysis } \\
\text { followed by inverse } \\
\text { modeling }\end{array}$ \\
\hline particle remineralization & $\begin{array}{l}\text { Sum of G1, G2, } \\
\text { G3, G4 and G6 }\end{array}$ & $\mathrm{R}, \mathrm{T}$ & Lam & Lam & $\begin{array}{c}\text { lithogenic particle } \\
\text { concentration analysis } \\
\text { followed by inverse } \\
\text { modeling }\end{array}$ \\
\hline $\begin{array}{l}\text { sinking velocity of } \\
\text { aggregates }\end{array}$ & $\begin{array}{c}\text { Sum of } \mathrm{S} 1, \mathrm{~S} 2, \\
\text { and } \mathrm{S} 3\end{array}$ & A & Lam & Lam & $\begin{array}{c}\text { lithogenic particle } \\
\text { concentration analysis } \\
\text { followed by inverse } \\
\text { modeling }\end{array}$ \\
\hline
\end{tabular}




\section{Chapter 6 Export Pathways Working Group Report}

Meg Estapa, Skidmore College, Saratoga Springs, New York/mestapa@ skidmore.edu (lead) Claudia Benitez-Nelson, University of South Carolina, Columbia, South Carolina / cbnelson@geol.sc.edu Ken Buesseler, Woods Hole Oceanographic Institution, Woods Hole, Massachusetts / kbuesseler@whoi.edu Adrian Burd, University of Georgia, Athens, Georgia / adrianb@uga.edu Craig Carlson, University of California - Santa Barbara, Santa Barbara, California I craig.carlson@lifesci.ucsb.edu Hilary Close, University of Miami, Coral Gables, Florida / hclose@ rsmas.miami.edu Eric D’Asaro, University of Washington, Seattle, Washington / dasaro@apl.washington.edu Colleen Durkin, Moss Landing Marine Laboratories, Moss Landing, California / cdurkin@mlml.calstate.edu Lionel Guidi, Laboratoire d'Océanographie de Villefranche-sur-Mer, Villefranche-sur-Mer, France I lguidi@obs-vlfr.fr Dennis Hansell, University of South Florida, St. Petersburg, Florida / d.hansell@ miami.edu Phoebe Lam, University of California - Santa Cruz, Santa Cruz, California / pjlam@ucsc.edu Jong-mi Lee, University of California - Santa Cruz, Santa Cruz, California /jlee377@ ucsc.edu Amy Maas, Bermuda Institute of Ocean Sciences, St.George's, Bermuda / amy.Maas@bios.edu Olivier Marchal, Woods Hole Oceanographic Institution, Woods Hole, Massachusetts / omarchal@whoi.edu Andrew McDonnell, The University of Alaska Fairbanks, Fairbanks, Alaska / amcdonnell@alaska.edu Melissa M. Omand, University of Rhode Island, Narragansett, Rhode Island / momand@uri.edu Uta Passow, Memorial University, St.John's, Newfoundland, Canada / uta.passow@mun.ca Mary Jane Perry, University of Maine, Orono, Maine / perrymj@maine.edu Brian Popp, University of Hawaii, Honolulu, Hawaii / popp@ hawaii.edu Montserrat Roca-Martí, Woods Hole Oceanographic Institution, Woods Hole, Massachusetts / mrocamarti@whoi.edu Alyson Santoro, University of California - Santa Barbara, California / asantoro@ ucsb.edu David Siegel, University of California - Santa Barbara, California / davesiegel@ucsb.edu Karen Stamieszkin, Virginia Institute of Marine Science, Gloucester Point, Virginia / karens@vims.edu Deborah K Steinberg, Virginia Institute of Marine Science, Gloucester Point, Virginia / debbies@vims.edu Andrew Thompson, California Institute of Technology, Pasadena, California / andrewt@caltech.edu Benjamin Van Mooy, Woods Hole Oceanographic Institution, Woods Hole, Massachusetts / bvanmooy@whoi.edu

\section{Overview}

Critical to the EXPORTS program goal of estimating biological carbon fluxes from satellite observations is understanding of mechanisms controlling the magnitude and attenuation of those fluxes to depth in the ocean. The main goal of this document is to describe the EXPORTS Science Team's observational methods that are used to distinguish between (i) biological and physical export pathways out of the euphotic zone and (ii) flux pathways below the euphotic zone. It is our intention that this document will serve as a resource not only for Science Team members, but also for other scientists contributing to other programs with similar goals. This report also outlines a plan for integrating and performing internal consistency checks (i.e., achieving closure) among the various measurements of biological carbon fluxes, and gives an overview of observational and model uncertainties. Thus we hope it will also be a useful resource for data managers. The remainder of this overview defines key concepts and their 
relationships to the main EXPORTS science questions. The document then summarizes measurement techniques contributing to determination of each of the five export pathways, and describes the plan for achieving measurement-measurement closure. Finally, a series of protocol briefs describe each method, its uncertainties, key data products, and related references.

The biological and physical pathways that govern the export of carbon from the euphotic zone and its attenuation with depth vary across space and time in the ocean. The EXPORTS program's overarching scientific goal is to determine how satellite-observable surface properties of both the ocean ecosystem and ocean circulation control the relative importance of these pathways. The EXPORTS Science Plan defines five export pathways:

1. Gravitational settling of intact phytoplankton cells

2. Gravitational settling of aggregates

3. Gravitational settling of zooplankton products

4. Active transport of carbon by diurnally or ontogenetically migrating zooplankton

5. Net vertical transport of suspended particulate or dissolved carbon by physical and microbial processes

The EXPORTS "wiring diagram" (Figure 6.1) illustrates the relationships among these pathways, and the expected variations in the relative importance of the pathways in different locations and times. 


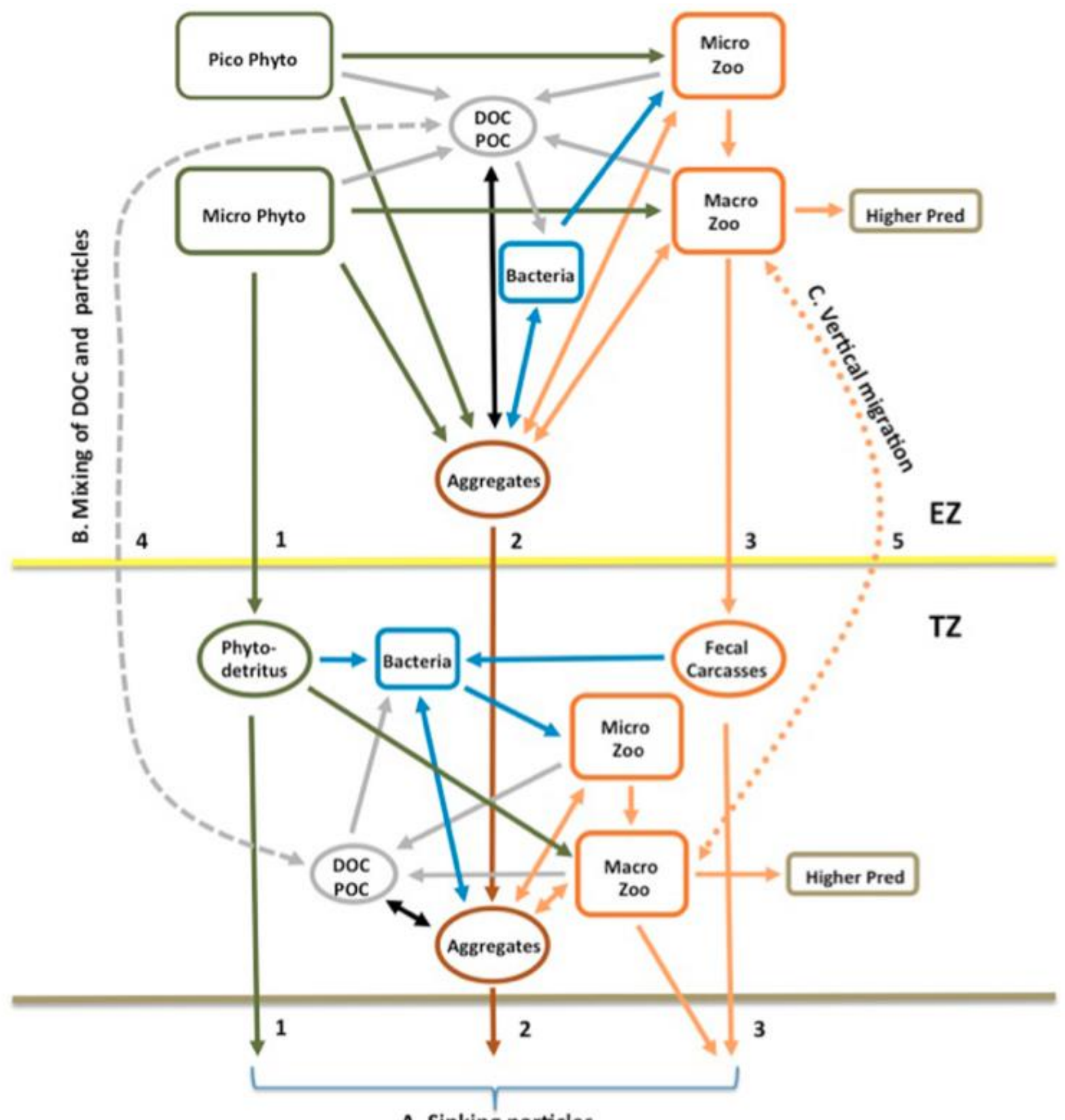

A. Sinking particles

Figure 6-1 The EXPORTS "wiring diagram" illustrating relationships among export pathways and the food web. "EZ" = euphotic zone; "TZ" = twilight zone. Reproduced from Fig. 4 of Siegel et al. (2016).

The goal of the EXPORTS field campaigns is to characterize export via each of these pathways over operationally-defined time periods - referred to as "epochs" or "ecosystem and carbon cycling (ECC) states", equivalent to the time necessary for sinking particles to exit the euphotic zone and enter sediment traps in the upper $500 \mathrm{~m}$. In the North Pacific field campaign, each of the measurement techniques described below was repeated during three 8-day states. Work was conducted aboard two ships: a "Process Ship" operating in a water parcel-following Lagrangian mode, and a "Survey Ship" in a gridded survey mode. Additionally, autonomous 
platforms (gliders and floats or "AUVs") were used to increase the spatiotemporal coverage of some measurements.

Flux measurements are made within a vertical reference frame where the base of the "well-lit surface ocean" (as defined in the EXPORTS Science Questions, below), or "export reference depth", is theoretically defined as the depth where new production equals export production (Buesseler and Boyd, 2009). Prior to obtaining direct observations of production, we operationally estimate this as the depth where in vivo chlorophyll fluorescence drops to $10 \%$ of its subsurface maximum (Owens et al., 2015). Flux measurements are made at the export reference depth as well as $50 \mathrm{~m}$ and $100 \mathrm{~m}$ below it, in order to capture processes that typically result in rapid flux attenuation at the shallowest depths. Diel vertical migration of zooplankton influences multiple export pathways and so a fourth measurement depth targets the deep biomass maximum. The fifth and deepest flux measurement may be constrained by the operational limits of sediment traps but targets seasonal zooplankton migrators where possible.

The main EXPORTS Science Questions are:

1. How do upper-ocean ecosystem characteristics determine the vertical transfer of carbon from the well-lit surface ocean?

2. What controls the efficiency of vertical transfer of carbon below the well-lit surface ocean?

3. How can the knowledge gained be used to reduce uncertainties in contemporary and future estimates of the export and fates of global ocean net primary production (NPP)?

Observations of export pathways at the base of the euphotic zone or mixed layer contribute directly to EXPORTS Science Question 1 by establishing the magnitude of the vertical transfer of carbon from the well-lit surface ocean. By further establishing which pathways are responsible for the vertical transfer, these observations allow connections to be made to characteristics of the upper ocean ecosystem. Similarly, measurements at depths below the euphotic zone and mixed layer directly address Science Question 2 by quantifying the transfer efficiency of different pathways. Observations of the relative importance of the different export pathways under different surface ecosystem states will be useful in addressing Science Question 3.

\section{Summary of measurements by export pathway}

Pathway 1 (sinking, single phytoplankton cells) is characterized using high magnification microscope images of polyacrylamide gel collectors on sediment traps, and estimating $\mathrm{C}$ per cell using literature values and shipboard measurements (see "Stocks and Proxies" and methods for determination of phytoplankton carbon). The presence or absence of phytoplankton cells in the non-sinking, slow sinking or fast sinking category of particles (e.g. the partitioning of cells between these pools) as collected with the Marine snow catcher addresses the importance of this pathway.

Pathway 2 (sinking aggregates) is characterized by synthesizing four methods. As with Pathway 1 , microscope images of gel traps are used to enumerate, visually characterize, and determine the size distribution of sinking aggregates. The biological composition of the aggregates in gel traps are determined by genetic sequencing of representative aggregate types and by the 
proportional contributions to bulk traps of amino acids due to phytodetritus, microbes, and fecal pellets. Rapidly-sinking aggregates are also sampled using Marine Snow Catchers and, if present, characterized for size distribution, carbon content, biomineral content, porosity, density, sinking velocity and respiration loss. Respiration rates on sinking particles, determined using RESPIRE traps and experimentally with particles from the Marine Snow Catcher, provide information on the mechanisms driving attenuation of Pathway 2 flux with depth. Profiled Underwater Vision Profiler (UVP) images and LISST particle size distributions are analyzed to identify aggregates and their water column size distribution. Finally, aggregate dynamics and coagulation modeling are used to synthesize the size distributions of suspended and sinking aggregates, their compositions, and physical properties to provide a size-resolved estimate of aggregate-mediated $\mathrm{C}$ fluxes as a function of depth.

Pathway 3 (sinking zooplankton products) is determined in three ways. First, zooplankton products are identified in gel traps and their $\mathrm{C}$ and $\mathrm{N}$ contents are estimated using published and on-board measurements. In addition, zooplankton excretion rate experiments are carried out on board to measure dissolved organic $\mathrm{C}$ and $\mathrm{N}$ (protocols are documented under Biological Rates working group). The rates determined by these experiments will be applied to measures of zooplankton biomass and community composition to generate estimates of total export via sinking zooplankton products. Partitioning of fecal pellets between non-sinking, slow sinking or fast sinking category of particles, as determined using the marine snow catcher, assesses the relative importance of fecal pellet sinking. Genetic characterization of sinking fecal pellets collected in the gel traps, as well as compound-specific amino acid composition of zooplankton and their food sources, provide qualitative evidence of ecosystem interactions contributing to Pathway 3.

Pathway 4 (zooplankton active transport) is determined by applying analyses of zooplankton metabolic rates to estimates of migratory biomass. First, the depth- and time-dependent distribution of zooplankton biomass are determined using the MOCNESS and UVP, with semiautomated image analysis to identify taxa. Vertical and horizontal variability in zooplankton migratory distributions are characterized qualitatively with acoustics systems on the survey ship, and on the autonomous platforms. These biomass calculations are converted to active transport in three ways, via application of 1) metabolic respiration rates (respiration of $\mathrm{CO}_{2}$, excretion of DOC, egestion of POC as fecal pellets) determined experimentally on board the ship 2) estimates of metabolicrespiration rate calculated from organism size and temperature coefficients and 3) electron transport system enzymatic activity measurements on the MOCNESS samples that are used to estimate the depth-resolved $\mathrm{CO}_{2}$ production by zooplankton respiration. Both the ETS and metabolicrespiration rate protocols are documented by Biological Rates working group.

Pathway 5 (physical transfer of POC and DOC) is comprised of advective and turbulent diffusive transfer of POC and DOC to depth, along and across density surfaces, as well as microbial processes acting upon $\mathrm{POC}$ and DOC. Characterization of this pathway requires quantifying POC and DOC stocks and lability, determining rates of microbial utilization, and describing the physical transport and mixing of these pools over a range of spatiotemporal scales, from submesoscale motions up to annual vertical mixing. Certain smaller-scale circulation processes 
are parameterized in terms of larger-scale hydrographic and biogeochemical properties captured by both satellite observations and EXPORTS measurements.

In addition to measurements of single export pathways described above, the EXPORTS program also utilizes methods characterizing the sum of two or more pathways. For instance, spikes in profiles of optical scattering and fluorescence serve as a proxy for the abundance of particles large enough to occlude optical sensing volumes (large aggregates and zooplankton products) and provide an estimate of fluxes due to the sum of Pathways 2 and 3. Several bulk methods provide estimates of fluxes due to all sinking particles (the sum of Pathways 1-3), including bulk fluxes to sediment traps and marine snow catchers, and optical attenuance fluxes to optical sediment traps and gel traps. Measurements of flux derived from ${ }^{234} \mathrm{Th}$ and ${ }^{210} \mathrm{Po}$ disequilibria represent the sum of Pathways 1-4 -- all sinking-particle and zooplankton-mediated pathways -- over the preceding weeks $\left({ }^{234} \mathrm{Th}\right)$ and months $\left({ }^{210} \mathrm{Po}\right)$. Particle stocks collected with size-fractionated filtration through large volume pumps provide estimates of the composition of large particles that are likely sinking via pathways $1-4$. Inversion of ${ }^{234}$ Th activities, and organic and lithogenic particle stocks will provide estimates of aggregation, disaggregation, and remineralization rates of particulate material present in two operational size classes that together represent pathways 1-4. Two qualitative but information-rich methods, compoundspecific isotopic analysis of amino acids, and environmental lipidomics, are used to qualitatively describe sources and biological drivers of particle fluxes in pathways 1-4. ${ }^{210} \mathrm{Po}$ disequilibrium from ${ }^{210} \mathrm{~Pb}$ in seawater will be used in a similar way to ${ }^{234} \mathrm{Th}$, but at a lower spatial resolution, to estimate fluxes on a seasonal scale. And finally, geochemical budgets measured through longterm monitoring of $\mathrm{O}_{2}, \mathrm{NO}_{3}$, and carbon pools from moorings and profiling floats will independently constrain all 5 pathways over longer seasonal and annual scales.

\section{Closure of $\mathrm{C}$ flux budgets}

By measuring each of the export pathways using multiple methods, as well as measuring combinations of more than one pathway, we will rigorously constrain uncertainties in flux estimates. Even in cases where independent methods do not give the same result for a given pathway, we can use relationships among different techniques to inform our understanding of driving processes. These measurements and flux estimates will need to be evaluated in the context of larger-scale characteristics of the ecosystem and circulation as observed from in situ autonomous array and remote sensing platforms during the EXPORTS field program. Table 6.1 summarizes sets of measurements that we can use to constrain uncertainties in this way. 
Table 6.1 Possible closure schemes (aka things that should add up), ignoring issues of time/space averaging scales

\begin{tabular}{|c|c|c|}
\hline Pathway(s) & Method(s) 1 & Method(s) 2 \\
\hline 3 (sinking zooplankton products) & Gel trap fecal pellet/C contents & $\begin{array}{l}\text { Biomass distribution/egestion } \\
\text { excretion rate experiments }\end{array}$ \\
\hline 4 (zooplankton active transport) & Biomass distribution/ETS activity & $\begin{array}{l}\text { Biomass distribution/respiration rate } \\
\text { experiments }\end{array}$ \\
\hline Sum of 1, 2, 3 (sinking particles) & $\begin{array}{l}\text { Bulk fluxes to sediment traps and in } \\
\text { marine snow catchers }\end{array}$ & $\begin{array}{l}\text { Sum of independent measurements } \\
\text { of pathways } 1-3\end{array}$ \\
\hline Sum of 1, 2, 3 (sinking particles) & $\begin{array}{l}\text { Attenuation with depth of sinking } \\
\text { particle fluxes in traps and marine } \\
\text { snow catchers }\end{array}$ & $\begin{array}{l}\text { Respiration rates on sinking } \\
\text { particles from RESPIRE traps and } \\
\text { marine snow catcher experiments }\end{array}$ \\
\hline Sum of $1,2,3$ (sinking particles) & \multicolumn{2}{|c|}{$\begin{array}{l}\text { Inversion of bulk fluxes through reconstruction modeling approaches to give } \\
\text { particle size, composition, settling velocity -- for bulk fluxes and possibly for } \\
\text { pathways } 1-3 \text { independently }\end{array}$} \\
\hline Sum of 1, 2, 3 (sinking particles) & \multicolumn{2}{|c|}{ Source partitioning from compound-specific stable isotopes, lipidomics } \\
\hline Sum of 2, 3 (large, sinking particles) & $\begin{array}{l}\text { Optical spike fluxes and fluxes of } \\
\text { large particles sinking }>18 \mathrm{~m} / \mathrm{d} \text { in } \\
\text { marine snow catchers }\end{array}$ & $\begin{array}{l}\text { Sum of independent measurements } \\
\text { of pathways } 2 \text { and } 3\end{array}$ \\
\hline $\begin{array}{l}\text { Sum of } 1,2,3,4 \text { (sinking particles + } \\
\text { zooplankton) }\end{array}$ & $\begin{array}{l}{ }^{234} \mathrm{Th} \text { flux/C:Th ratios and }{ }^{210} \mathrm{Po} \\
\text { flux/Po:C ratios of large particles }\end{array}$ & $\begin{array}{l}\text { Sum of independent measurements } \\
\text { of pathways } 1-4\end{array}$ \\
\hline $\begin{array}{l}\text { Sum of } 1,2,3,4 \text { (sinking } \\
\text { particles+zooplankton) }\end{array}$ & $\begin{array}{l}\text { Inversion of size-fractionated POC, } \\
234 T h \text {, lithogenic particle } \\
\text { concentrations and bulk fluxes to } \\
\text { estimate bulk aggregation, } \\
\text { disaggregation, and remineralization } \\
\text { rates }\end{array}$ & $\begin{array}{l}\text { Sum of independent measurements } \\
\text { of pathways } 1-4\end{array}$ \\
\hline Sum of all pathways (1-5) & $\begin{array}{l}\text { Geochemical budget estimates of } \\
\operatorname{NCP}\left(\mathrm{O}_{2} / \mathrm{Ar}, \mathrm{DIC}, \mathrm{NO}_{3} \text { others? }\right)\end{array}$ & $\begin{array}{l}\text { Sum of independent measurements } \\
\text { of pathways } 1-5\end{array}$ \\
\hline Sum of all pathways (1-5) & $\begin{array}{l}\text { Biological rate estimates of NCP } \\
\text { (GPP-R) }\end{array}$ & $\begin{array}{l}\text { Sum of independent measurements } \\
\text { of pathways } 1-5\end{array}$ \\
\hline
\end{tabular}

Complementing the pathway-specific estimates of flux described in this document, net community production will be independently determined using geochemical budgets and biological rate measurements. These methods are detailed in the Biological Rates Working Group report. If the overarching hypothesis is correct, that the total carbon flux is the sum of carbon fluxes via the five pathways defined in the EXPORTS Science Plan, then estimates of total export from the surface ocean should be in agreement with NCP measurements when averaged over appropriate scales of space and time. With closure of flux budgets achieved, the importance of each export pathway to the total can be related to the ecosystem characteristics and remote sensing observables of each ECC state. 
Table 6.2 Protocol briefs (This list of protocol briefs may contain some overlaps with other working groups.)

Pathway 1

1. Visual cell ID in gel traps

Pathway 2

2. Characterization of Sinking Particles from Marine Snow Catcher samples

3. Visual characterization of sinking aggregates in gel traps

4. Genetic characterization of sinking aggregates in gel traps

5. Particle characterization from UVP profiles (merged with \#15, below)

6. Coagulation modeling

Pathway 3

7. Visual characterization of zooplankton products in gel traps

8. Genetic characterization of zooplankton products in gel traps

9. Characterization of feces in the different categories collected with the Marine snow catcher

10. Zooplankton fecal pellet production

11. Compound-specific stable isotope analysis of zooplankton

12. Reconstruction of zooplankton product export from gel traps

Pathway 4

13. Day-night MOCNESS tows

14. Zooplankton biomass, abundance

15. UVP characterization of zooplankton abundance (merged with \#5, above)

16. Bio-acoustic measurement of zooplankton biomass

Pathway 5

17. Bulk DOC/TDN stocks

18. Bulk POC stocks - reference to BGC stocks WG doc

19. Dissolved combined amino acids

20. Subduction of bulk DOC

21. Subduction of bulk POC

22. Physical modeling protocol

Large sinking particle pathways $(2,3)$

23. Flux of large sinking particles from profiles of optical spikes (bb, $c p)$ - reference to Stocks \& Proxies WG doc

Sinking particle pathways $(1,2,3)$

24. Bulk fluxes of particles (\& constituent elements) to sediment traps

25. Bulk fluxes of particles to optical sediment traps

26. Genetic characterization of bulk sinking particles in sediment traps

27. Bulk fluxes of rapidly-sinking particles in marine snow catcher samples

28. Reconstruction of export from particle size distributions

29. Lipidomics markers for particle sources and biological drivers

30. Compound-specific isotopic markers for particle sources and biological drivers

Particle and zooplankton pathways $(1,2,3,4)$

31. Compositions of large particles collected with in situ pumps 
32. ${ }^{234} \mathrm{Th}$ survey combined with $\mathrm{C}(\mathrm{etc}):{ }^{234} \mathrm{Th}$ from large volume pumps

33. ${ }^{210} \mathrm{Po}$ and $\mathrm{C}(\mathrm{etc}):{ }^{210} \mathrm{Po}$ from large volume pumps

34. Rates from inversion of size-fractionated particle stocks and ${ }^{234} \mathrm{Th}$ activities

Relevant biological rate measurements (see Bio. Rates Working Group Report)

Total fluxes from geochemical budgets

Total fluxes from biological rate measurements 


\section{References:}

Anderson, T.R., and Ducklow, H.W. (2001). Microbial loop carbon cycling in ocean environments studied using a simple steady-state model. Aquatic Microbial Ecology 26, 37-49.

Banse, K. (2013). Reflections about chance in my career, and on the top-down regulated world. Annual review of marine science 5, 1-19.

Boss, E., Haëntjens, N., Ackleson, S.G., Balch, B., Chase, A., Dall'olmo, G., Freeman, S., Liu, Y., Loftin, J., Neary, W., Nelson, N., Novak, M., Slade, W., Proctor, C., Tortell, P., and Westberry, T. (2019). "IOCCG Ocean Optics and Biogeochemistry Protocols for Satellite Ocean Colour Sensor Validation Inherent Optical Property Measurements and Protocols: Best Practices for the Collection and Processing of Ship-Based Underway Flow-Through Optical Data (v4.0)". OCCG Protocol Series).

Buesseler, K.O., and Boyd, P.W. (2009). Shedding light on processes that control particle export and flux attenuation in the twilight zone of the open ocean. Limnology and Oceanography 54, 1210-1232.

Burd, A., Buchan, A., Church, M., Landry, M., Mcdonnell, A., Passow, U., Steinberg, D., and Benway, H. (Year). "Towards a transformative understanding of the ocean's biological pump: Priorities for future research", in: Report of the NSF Biology of the Biological Pump Workshop), 19-20.

Carlson, C.A., Giovannoni, S.J., Hansell, D.A., Goldberg, S.J., Parsons, R., and Vergin, K. (2004). Interactions among dissolved organic carbon, microbial processes, and community structure in the mesopelagic zone of the northwestern Sargasso Sea. Limnology and Oceanography 49, 1073-1083.

Ducklow, H.W. (1999). The bacterial component of the oceanic euphotic zone. FEMS Microbiology Ecology 30, 1-10.

EXPORTS Science Definition Team (2016). "EXPORTS Implementation Plan". https://oceanexports.org/docs_implementation_plan.html

EXPORTS Writing Team (2015). "EXport Processes in the Ocean from RemoTe Sensing (EXPORTS): A Science Plan for a NASA Field Campaign". http://cce.nasa.gov/cce/pdfs/EXPORTS_Science_Plan_May18_2015_final.pdf

Field, C.B., Behrenfeld, M.J., Randerson, J.T., and Falkowski, P. (1998). Primary Production of the Biosphere: Integrating Terrestrial and Oceanic Components. Science 281, 237-240.

$\mathrm{Li}, \mathrm{Z}$, and Cassar, N. (2016). Satellite estimates of net community production based on O2/Ar observations and comparison to other estimates. Global Biogeochemical Cycles 30, 735-752. 
Morison, F., and Menden-Deuer, S. (2017). Doing more with less? Balancing sampling resolution and effort in measurements of protistan growth and grazing-rates. Limnology and Oceanography: Methods 15, 794-809.

Owens, S.A., Pike, S., and Buesseler, K.O. (2015). Thorium-234 as a tracer of particle dynamics and upper ocean export in the Atlantic Ocean. Deep Sea Research Part II: Topical Studies in Oceanography 116, 42-59.

Rivkin, R.B., and Legendre, L. (2001). Biogenic carbon cycling in the upper ocean: effects of microbial respiration. Science 291, 2398-2400.

Schmoker, C., Hernández-León, S., and Calbet, A. (2013). Microzooplankton grazing in the oceans: impacts, data variability, knowledge gaps and future directions. Journal of Plankton Research 35, 691-706.

Siegel, D.A., Buesseler, K.O., Behrenfeld, M.J., Benitez-Nelson, C.R., Boss, E., Brzezinski, M.A., Burd, A., Carlson, C.A., D'asaro, E.A., Doney, S.C., Perry, M.J., Stanley, R.H.R., and Steinberg, D.K. (2016). Prediction of the Export and Fate of Global Ocean Net Primary Production: The EXPORTS Science Plan. Frontiers in Marine Science 3.

Steinberg, D.K., and Landry, M.R. (2017). Zooplankton and the ocean carbon cycle. Annual Review of Marine Science 9, 413-444.

Stock, C., and Dunne, J. (2010). Controls on the ratio of mesozooplankton production to primary production in marine ecosystems. Deep Sea Research Part I: Oceanographic Research Papers 57, 95-112.

Werdell, P.J., Behrenfeld, M.J., Bontempi, P.S., Boss, E., Cairns, B., Davis, G.T., Franz, B.A., Gliese, U.B., Gorman, E.T., Hasekamp, O., Knobelspiesse, K.D., Mannino, A., Martins, J.V., Mcclain, C.R., Meister, G., and Remer, L.A. (2019). The Plankton, Aerosol, Cloud, Ocean Ecosystem Mission: Status, Science, Advances. Bulletin of the American Meteorological Society 100, 1775-1794.

Williams, P. (2000). "Heterotrophic bacteria and the dynamics of dissolved organic material," in Microbial ecology of the oceans.).

Worden, A.Z., Follows, M.J., Giovannoni, S.J., Wilken, S., Zimmerman, A.E., and Keeling, P.J. (2015). Rethinking the marine carbon cycle: factoring in the multifarious lifestyles of microbes. Science 347, 1257594. 


\section{Chapter 7 Protocols}

Following is the collection of the "one page" protocols, as developed by the EXPORTS Science team during the preparations for the North Pacific Field Campaign. Some of the protocols here were submitted as part of the SeaBASS dataset submission. Final version of the protocols, as well as the update status of the submitted data is can be found at: https://sites.google.com/view/oceanexports/home 
Method: Derive hyperspectral reflectance measuring downwelling irradiance, and upwelling radiance, in buoy mode.

Document author and contact info: Emmanuel Boss (emmanuel.boss@maine.edu)

NB: This document is largely based on Rudick (2017).

\section{Brief description of protocol:}

This buoy approach includes two methods:

1. Above water radiometry with Skylight-Blocked Approach (Fig. 1)

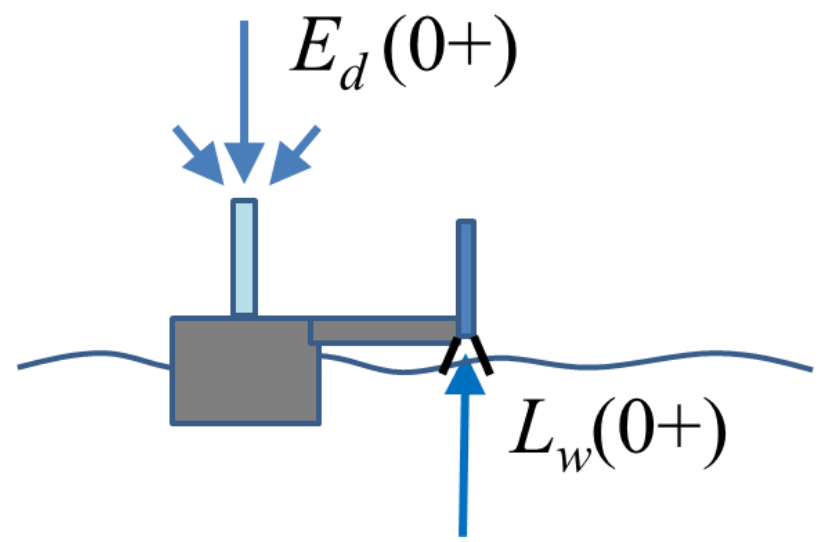

Fig. 1. Measuring reflectance by measuring above water leaving radiance and downwelling irradiance.

Upwelled radiance needs to be corrected for self-shading (by cone and by buoy) and insure that sensor is not touching the water surface nor is it covered with drops. Reflectance is computed from:

$$
R_{r S}(\lambda)=\frac{L_{w}\left(\lambda, 0^{+}\right)}{E_{d}\left(\lambda, 0^{+}\right)}
$$

2. Above and below water radiometry (Fig. 2)

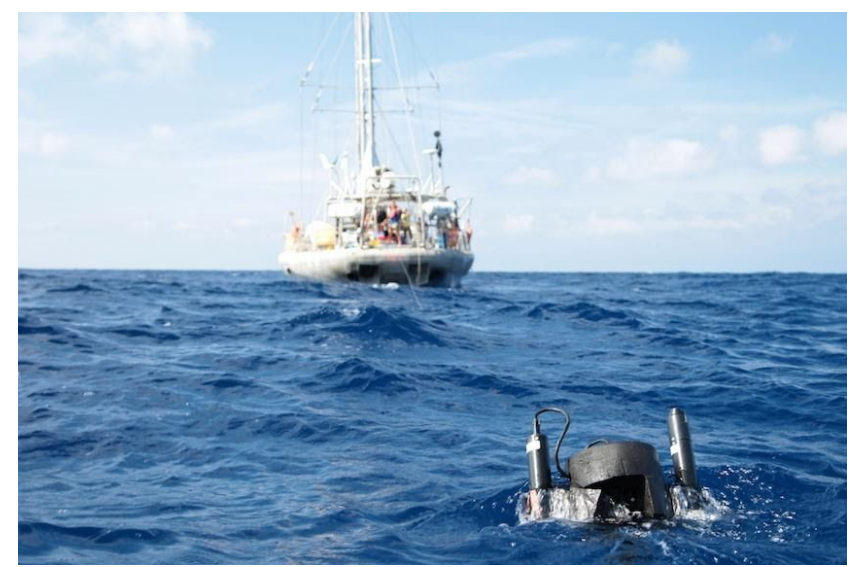

Fig. 2. Measuring reflectance by measuring below water upwelling radiance and downwelling irradiance and propagating the measurement above the surface. 
Upwelled radiance needs to be propagated across the interface and corrected for self-shading (by sensor and buoy). This is done using IOPs measured locally or estimated from the upwelled radiance (e.g. Zibordi et al., 2012).

Reflectance is computed from:

$$
R_{r S}(\lambda)=\frac{L_{w}\left(\lambda, 0^{+}\right)}{E_{d}\left(\lambda, 0^{+}\right)}
$$

\section{Deployment methodologies:}

Buoy is tethered to vessel but needs to be sufficiently far to not be affected by boat shadow.

\section{Derived parameters:}

Remote sensing reflectance (ocean color) from which additional parameters can be obtained (IOPs as well as biogeochemical parameters).

\section{Uncertainties and quality control concerns: \\ For both methods:}

Sensor calibration uncertainty.

Long enough averaging to obtain sufficient number of realization (usually about a minute) as well as average wave focusing. If uncertainties due to spatial heterogeneity are of interest, leave system in water for longer.

Need to get far away from large research vessel to avoid effects due to its shadow. Ideally towards the direction of the sun. Avoid data taken with instrument tilted (need high frequency measurements form which tilted measurements can be removed).

\section{For above water radiometry with Skylight-Blocked Approach:}

The uncertainties and correction associated with self-shading have been estimated by (Shang et al. 2017), who propose also a correction scheme.

\section{For above and below water radiometry:}

Non-exponential attenuation with depth (Li et al., 2016, Voss et al., 2017) introduces uncertainty. Self-shading (Gordon and Ding, 1992). Uncertainty in depth of downwelling sensor, Fresnel coefficients (Voss and Flora, 2017)

\section{Key method references}

Li, L., D. Stramski, and R. A. Reynolds. 2016. "Effects of Inelastic Radiative Processes on the Determination of Water-Leaving Spectral Radiance from Extrapolation of Underwater near-Surface Measurements." Applied Optics 55 (25):7050. https://doi.org/10.1364/AO.55.007050.

Gordon, H. R., and K. Ding. 1992. "Self-Shading of in-Water Optical Instruments.” Limnology and Oceanography 37 (3):491-500. https://doi.org/10.4319/10.1992.37.3.0491.

Shang, Z., Z. Lee, Q. Dong, and J. Wei. 2017. "Self-Shading Associated with a Skylight-Blocked Approach System for the Measurement of Water-Leaving Radiance and Its Correction." Applied Optics 56 (25):7033. https://doi.org/10.1364/AO.56.007033. 
Rudick, K., 2017, Technical Report TR- 1 "Measurement Requirements and Protocols when Operating Fiducial Reference Measurement (FRM) Ocean Colour Radiometers (OCR) used for Satellite Validation".

Voss, K. J., and S. J. Flora. 2017. "Spectral Dependence of the Seawater-Air Radiance Transmission Coefficient." Journal of Atmospheric and Oceanic Technology, 1203-5.

Voss, K. J., Gordon, H. R., Flora, S., C. Johnson, B., Yarbrough, M., Feinholz, M., \& Houlihan, T. (2017). A Method to extrapolate the diffuse upwelling radiance attenuation coefficient to the surface as applied to the Marine Optical Buoy (MOBY). Journal of Atmospheric and Oceanic Technology, 34(7), 1423-1432. DOI: 10.1175/JTECH-D-16-0235.1

Zibordi, G., K. Ruddick, I. Ansko, G. Moore, S. Kratzer, J. Icely, and A. Reinart. 2012. "In Situ Determination of the Remote Sensing Reflectance: An Inter-Comparison." OCEAN SCIENCE 8 (4):567-86. https://doi.org/10.5194/os-8-567-2012. 
Method: Derive hyperspectral reflectance measuring downwelling irradiance, downwelling radiance and upwelling radiance, removing sky contribution from upwelling radiance.

Document author and contact info: Emmanuel Boss (emmanuel.boss@maine.edu)

NB: This document is largely based on Rudick (2017).

\section{Brief description of protocol:}

Three measurements of radiance are made including downwelling irradiance, downwelling radiance and upwelling radiance (Fig. 1).

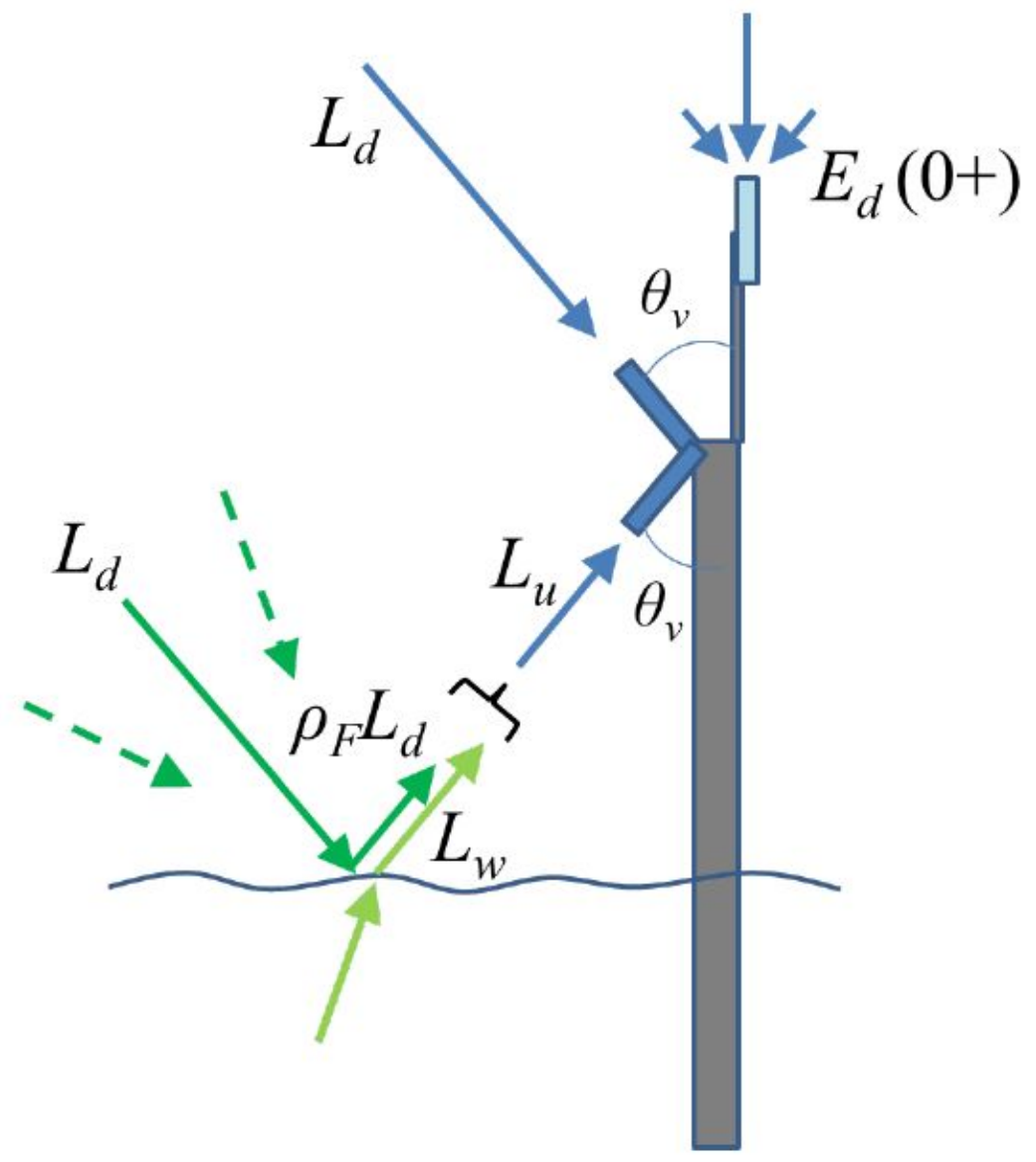

Figure 1. Schematic of above water radiometry with sky radiance measurement and skyglint removal (from Rudick, 2017). $L_{d}$ represent the sky contribution to upwelling radiance in the direction of the downlooking radiometer, $L_{u}$ the downwelling radiance in the symmetric direction to the viewing angle as will contribute if the ocean was perfectly flat. $E_{d}$ is the downwelling irradiance.

The spectrum of the water leaving radiance is estimated from:

$$
L_{w}\left(\lambda ; \theta_{v^{-}}, \varphi\right)=L_{u}\left(\lambda ; \theta_{v^{-}}, \varphi\right)-\rho L_{d}\left(\lambda ; \theta_{v^{+}}, \varphi\right)
$$

and the remote-sensing reflectance $\left(R_{r s}\right)$ from:

$$
R_{r s}(\lambda)=\frac{L_{w}\left(\lambda ; \theta_{v^{-}}, \varphi\right)}{E_{d}(\lambda)} .
$$


$\rho$ denotes the fraction of skylight that is reflected into the down-looking sensor, $\varphi$ the azimuth angle $\theta_{v^{-}}$, the downward zenith angle and $\theta_{v^{+}}$. Mobley (1999) recommends $\varphi=\mp 135^{\circ}$ and $\theta_{v \mp}=40^{\circ}, 120^{\circ}$.

\section{Deployment methodologies:}

On board the deck of the ship with compass and tilt sensors and automatic mechanism to insure correct pointing directions.

\section{Derived parameters:}

Remote sensing reflectance (ocean color) from which additional parameters can be obtained (IOPs as well as biogeochemical parameters).

\section{Uncertainties and quality control concerns:}

Sensor calibration uncertainty.

The most critical aspect of above water measurements of $L_{w}$ lies in the removal of skylight reflected at the air-sea interface, represented by the coefficient $\rho$. It is well understood that any modulation of the sea surface will result in from contributions from the sky in directions not viewed with the $L_{d}$ sensor (hence patchy clouds can bias the measurements). Approach includes using values from Mobley's $(1999,2015)$ published tables, choosing $\rho$ such that there is zero reflectance at the NIR (Morel, 1980) or choosing $\rho$ such as to minimize atmospheric signals (as observed in atmospheric absorption bands) in the resulting reflectance (Simis and Olsson, 2013). Various attempt to model $\rho$ which are not conclusive (See: Rudick, 2017). One method for estimation of uncertainties associated with this method is to consider the spectral consistency of $R_{r S}(\lambda)$ in the near infrared. For clear waters and at sufficiently long wavelength $R_{r S}(\lambda)$ can be assumed zero and any offset in measurements can be used as an estimator of total measurement uncertainty, provided this information has not already been used to perform a "residual correction" of data (Hooker and Morel, 2003).

Need to insure not to view boat's wake or shadow and that irradiance sensor is not shaded by vessel.

\section{Key method references}

Hooker, S.B., and A. Morel. 2003. "Platform and Environmental Effects on Above-Water Determinations of Water-Leaving Radiances." Journal of Atmospheric and Oceanic Technology 20:187-205.

Mobley, C.D. Estimation of the remote-sensing reflectance from above surface measurements. Applied Optics 1999, 38(36): 7442-7455.

Mobley, C.D. Polarized reflectance and transmittance properties of wind-blow sea surfaces. Applied Optics 2015, 54(15): 4828-4849.

Morel, A. 1980. "In-Water and Remote Measurements of Ocean Colour." Boundary Layer Meteorology 18:177-201.

Rudick, K., 2017, Technical Report TR- 1 "Measurement Requirements and Protocols when Operating Fiducial Reference Measurement (FRM) Ocean Colour Radiometers (OCR) used for Satellite Validation". 
LISST-100X setting when in-line:

Method: Near forward particulate VSF at $670 \mathrm{~nm}$ is derived from measurements of nearforward scattering of a laser. Measurements are inverted to obtain a PSD.

Document author and contact info: Emmanuel Boss (emmanuel.boss@maine.edu)

\section{Deployment methodology:}

Sensors is calibrated at the manufacturer and checked with NIST-traceable beads (Slade and Boss, 2006. Sensors is deployed in-line and is cleaned daily (including measurements of DIW that are not used except for tracking. ). Z-scat (blank) is determined based on VSF at the last 2 min of the $10 \mathrm{~min}$ long $0.2 \mu \mathrm{m}$ filtered period at the end of each hour and interpolated inbetween (Boss et al., 2018).

\section{Processing data:}

Z-scat (blank) is determined based on VSF at the last 2 min of the $10 \mathrm{~min}$ long $0.2 \mu \mathrm{m}$ filtered period. Median-average total scattered data over $10 \mathrm{~min}$ to obtain one 'robust' near forward scattering spectra and variance around it. Blank for particulate VSF is the interpolated value between two consecutive Z-scats. Compute particulate scattering substracting the Z-scat to the total data. Invert particulate scattering to PSD using Mie inversion (using the 'natural particle' we get significantly bigger deviations from Coulter Counter data). Beam attenuation is also computed.

All the raw data is saved in case we need to reprocess in the future.

Processing code is available at: https://github.com/OceanOptics/InLineAnalysis

\section{Derived parameters:}

Near forward VSF at 670nm.

Beam attenuation at $670 \mathrm{~nm}$ and $0.0269^{\circ}$ acceptance angle.

Particulate size distribution

\section{Uncertainties and quality control concerns:}

Uncertainty in VSF stems from:

1. Uncertainties in calibration - these are assessed with beads and corrected (in particular the assumed ring area).

2. Potential for changes in particles within the flow-through system.

Uncertainty in PSD stems from:

1. Assumption regarding particle's shape. We found that in the open ocean the Mie theory (Agrawal and Pottsmith, 2000) based inversion matched best data from Coulter counter. 2. 'Contamination' by particles outside the inverted region - dealt with by removing first and last 3 size bins (Traykovsky et al., 1999).

SeaBASS fields and units:

/fields=PSD_DNSD_\#\#\#umsize or PSD_DVSD_\#\#\#umsize, VSF_670_\#\#\#ang /units=TBD 


\section{References}

Agrawal Y. C. and H. C. Pottsmith, "Instruments for particle size and settling velocity observations in sediment transport," Mar. Geol. 168, 89-114 (2000).

Boss, E., N. Haentjens, T. K. Westberry, L. Karp-Boss, and W. Slade, 2018. Validation of the particle size distribution obtained with the laser in-situ scattering and transmission (LISST) meter in flow-through mode. Optics Express, 26(9), 11125-11136.

https://doi.org/10.1364/OE.26.011125

Sequoia Scientific, Inc., "Processing LISST-100 and LISST-100X data in MATLAB," https://www.sequoiasci.com/article/processing-lisst-100-and-lisst-100x-data-in-matlab/. 15. P. Slade, W.H. and E. Boss, 2006. Calibrated Near-Forward Volume Scattering Function Obtained from the LISST Particle Sizer. Optics Express, Vol. 14, No. 8, pp. 3602-3615

Traykovski, R. J. Latter, and J. D. Irish, "A laboratory evaluation of the laser in situ scattering and transmissometery instrument using natural sediments," Mar. Geol. 159, 355-367 (1999). 
Method: Particulate backscattering coefficient at one wavelength derived from VSF measurement in one wavelength in the back direction.

Document author and contact info: Emmanuel Boss (emmanuel.boss@maine.edu)

\section{Brief description of protocol:}

Sensors are calibrated with NIST-traceable beads (Sullivan et al., 2013). Salt water contribution is removed using salinity measurements (Zhang and al., 2009). Dark reading are measured on platform instrument is deployed on. Conversion from one angle VSF to the backscattering coefficient is based on literature values (Sullivan et al., 2013)

\section{Deployment methodologies:}

Sensors are deployed on profiling packages as well as using a special container in the flow-through system. In flow-through system contribution of box to signal needs to be measured (with DIW) and, by running $0.2 \mathrm{u}$ m filtered water, the dissolved contribution can be assessed.

\section{Derived parameters:}

Particulate backscattering coefficient at wavelength of measurement. POC from $b_{b p}$ (e.g. Cetinic et al., 2012).

Phytoplankton carbon from $b_{b p}$ (e.g. Graf et al., 2015).

\section{Uncertainties and quality control concerns:}

Uncertainty in $\mathrm{b}_{\mathrm{bp}}$ stem from:

1. Uncertainties in calibration (actual angular response of sensor and inhomogeneity of illumination (hot spot of LED).

2. Uncertainties in conversion factor from one angle VSF in the back-direction to backscattering. Based on comparison with instrument using different calibration.

Comparison between instrument calibrated differently result in $<10 \%$ uncertainty (Boss et al., 2004). Recent comparison between instrument of different angles in back direction showed differences on the $\mathrm{O}(50 \%)$ (Poteau et al., 2017). This was traced back to a problem with calibration coefficient provided by the manufacturer. After correction the uncertainties are $\mathrm{O}(10 \%)$ (Barnard, personal communication, 2017). Uncertainties in POC and phytoplankton carbon will be established based on regression with samples from project.

\section{SeaBASS fields and units:}

/fields=bbp,POC_cp, phyto_carbo

/units $=1 / \mathrm{m}, \mathrm{mg} / \mathrm{m}^{\wedge} 3, \mathrm{ug} / \mathrm{L}$

Key method references

1. Boss E. and W.S. Pegau, 2001. Relationship of light scattering at an angle in the backward direction to the backscattering coefficient. Applied Optics, 40, 5503-5507.

2. Sullivan, J., M. Twardowski, J.R.V. Zaneveld, and C. Moore. 2013. Measuring optical backscattering in water, In: A. Kokhanovsky (Ed), Light Scattering Reviews 7: Radiative Transfer and Optical Properties of Atmosphere and Underlying Surface, Springer Praxis Books, DOI 10.1007/978-3-642-21907-8_6, pp. 189-224. 
3. Zhang, X., L. Hu, and M. He, ;Scattering by pure seawater: Effect of salinity; 2009.

Optics Express 17, 5698-5710.

4. Cetinić, I., Perry, M.J., Briggs, N.T., Kallin, E., D’Asaro, E.A., Lee, C.M., 2012. Particulate organic carbon and inherent optical properties during 2008 North Atlantic Bloom Experiment. J. Geophys. Res. Oceans 117 (C6), C06028.

5. Graff, J. R. , T. K. Westberry, A. J. Milligan, M. B. Brown, G. Dall'Olmo, V. van Dongen-Vogels, K. M. Reifel and M. J. Behrenfeld, "Analytical phytoplankton carbon measurements spanning diverse ecosystems," Deep Sea Res. I, 102, 16-25 (2015).

6. Boss E., W.S. Pegau, M. Lee, M.S. Twardowski, E. Shybanov, G. Korotaev, and F. Baratange, 2004. Particulate backscattering ratio at LEO 15 and its use to study particles composition and distribution. J. Geophys. Res., 109, C1, C0101410.1029/2002JC001514

7. Poteau, A., E. Boss, and H. Claustre (2017), Particulate concentration and seasonal dynamics in the mesopelagic ocean based on the backscattering coefficient measured with

Biogeochemical-Argo floats, Geophys. Res. Lett., 44, doi:10.1002/2017GL073949. 
This document describes how we processed the CDOM absorption spectra from the Slow descent rate optical package (SLOW-DROP) for the EXPORTS 01 cruise (RR1318).

Emmanuel Boss (emmanuel.boss@maine.edu) and Bentley Simpson, 2019-12-05

Sensors:

The CDOM absorptions were measured using different AC-S sensors:

From start to 8-17: used 301.

From 8-18 to 8-19: used 24.

From 8-20 until the end used 298.

Delay:

Based of plotting graphs and comparing temperature sensitive wavelengths we determined that AC-S were, on average, 6.5second lagging compared to the temperature (and pressure) of the CTD (measured outside the water stream). This delay was applied to the AC-S data. We only use the a-side from the AC-S as it was less sensitive to bubbles and provided more stable values compared to the c-side.

Salinity:

The Temperature-Salinity relationship is very tight for EXPORTS and the top 110m (where we deployed the IOP package). Because we had problems with the salinity sensor of our CTD we decided to use the relationship established from the ship's CTD to compute salinity. Hence the salinity we report and use for correction is:

$\mathrm{S}=32.3+(14-\mathrm{T}) / 32$ if $\mathrm{T}>6$

$\mathrm{S}=32.55+0.9 *(6-\mathrm{T})$ if $\mathrm{T}<6$

Where $\mathrm{T}$ is the temperature measured with our CTD

Pressure:

We tarred the pressure at the surface (lowest pressure recorded was taken as offset).

Decent rates:

Varied from $15-30 \mathrm{~cm} / \mathrm{s}$.

Spike removal:

A 5pt median filter was applied to remove spikes.

Binning:

We median-binned the data into $1 \mathrm{~m}$ bins.

Calibration:

We calibrated the sensors daily on the package. We chose the calibration file within two days of each cast, that when applied to our data, resulted in spectra that were least different from an exponential function, over all the wavelengths (least absolute difference). We added a function for salinity and temperature so those were corrected before the absolute difference was measured. Calibration spectra used are provided in their own files. 
Quality control:

1. We expected spectra to be exponential within uncertainty of $\sim 0.005 \mathrm{~m}^{-1}$. Spectra that were widely different were removed.

2. We compared (by eye) the trace of a_g(440) to the voltage recorded by an analogue flowthrough CDOM fluorometer (WETLabs, Wetstar). The traces were very similar in all cases.

Uncertainty estimate:

We estimate the uncertainty in CDOM to be smaller than $0.005 \mathrm{~m}^{-1}$ based on the manufacturer uncertainty $\left(0.01 \mathrm{~m}^{-1}\right)$, our binning (typically $\sim 15$ scans binned per $\mathrm{m}$ ), and the variability in successive calibrations (based on the above procedure). 
Measurements: Size fractionated (0.6-5.0 \& $>5.0 \mathrm{um})$ assessment of $\mathrm{Si}$ and Fe limitation of silica and primary production

Document author and contact information: Mark Brzezinski, mark.brzeinski@lifesci.ucsb.edu

Brief description of protocol and relation to export pathways: Seawater is collect from 2 depths from within the euphotic zone. At each depth the rate of silica production and primary production are measured in unaltered seawater (controls) and in the same water that has been augmented with $20 \mu \mathrm{m}$ silicic acid, $1 \mathrm{nM}$ Fe or both $20 \mu \mathrm{m}$ silicic acid and $1 \mathrm{nM} \mathrm{Fe}$. Rates of silica production and primary production in all controls and treatments are measured in the 0.65.0 and the $>5.0 \mu \mathrm{m}$ size fractions following protocols Size fractionated ${ }^{14} \mathrm{C}$ carbon uptake Brzezinski and Size fractionated ${ }^{32} \mathrm{Si}$ silicic acid uptake Brzezinski protocol one pagers.

Other contributing protocols: Determination of $0.6-5.0 \&>5 \mu \mathrm{m}$ POC (combustion elemental analysis) and BSi (sodium hydroxide digestion), Par profiles.

Uncertainties and quality control concerns: The light field in deck incubators only approximates the light experience of captured diatom cells in situ. Extrapolation of rates measured from dawn to dusk to daily rates. Costs prohibit routine replication.

\section{Data product originating from this measurement}

\section{Parameter}

Rate $+\mathrm{Si} /$ control

Rate + F3/control

Rate $+\mathrm{Fe}+\mathrm{Si} /$ control

\section{Units}

unitless

unitless

unitless

\section{BCO-DMO Fields:}

Cruise,Date_Zulu,Time_Zulu,Event_num,Activity,Station,Cast,Latitude,Longitude,Rosette_Bott le,Target_Depth,pent_lo,TRMT,PO4,PO4_flag,SiO4,SiO4_flag,NO2,NO2_flag,NO2_NO3,NO2 _NO3_flag,POC,POC_flag,PON,PON_flag,BSi_0_6umfilt_5umprefilt,BSi_- 5 umfilt,rate_32Si_u ptake_24hr_0_6umfilt_5umprefilt,rate_32Si_uptake_specific_24hr_0_6umfilt_5umprefilt,rate_3 2Si_uptake_24hr_5umfilt,rate_32Si_uptake_specific_24hr_5umfilt,rate_14C_uptake_24hr_0_6u mfilt_5umprefilt,rate_14C_uptake_24hr_5umfilt,ISO_DateTime_UTC

\section{$\underline{\text { Key method references }}$}

Brzezinski MA, Phillips DR, Chavez FP, Friederich GE, Dugdale RC (1997). Silica production in the Monterey, California upwelling system. Limnol Oceanogr 42: 1694-1705. 
Measurements: Size fractionated primary production $(0.6-5.0 \&>5.0 \mathrm{um})$

Document author and contact information: Mark Brzezinski, mark.brzeinski@lifesci.ucsb.edu

Brief description of protocol and relation to export pathways: The rate of inorganic carbon fixation into the $>5 \mu \mathrm{m}$ particle size fraction is measured in seawater samples from the euphotic zone. The radioisotope 14C (bicarbonate) is added to seawater and each sample incubated in deck incubators (24h) screened with neutral density screening to simulate the light intensity at the depth of collection. Particles are recovered by filtration onto $5 \mu \mathrm{m}$ polycarbonate filters, fumed with $\mathrm{HCl}$ to remove carbonates and analyzed for ${ }^{14} \mathrm{C}$ content by liquid scintillation counting. The spiked seawater is sampled at the end of the incubation to determine total tracer added. The method is used alongside measures of 32Si uptake to determine the degree to which silicic acid and iron limit silica production and the rate of primary production.

Other contributing protocols: Determination of $0.6-5.0 \&>5 \mu \mathrm{m}$ POC (combustion elemental analysis), Par profiles.

Uncertainties and quality control concerns: The light field in deck incubators only approximates the light experience of captured diatom cells in situ. Extrapolation of rates measured from dawn to dusk to daily rates. Costs prohibit routine replication.

Data product originating from this measurement

Parameter Units

Daily 0.6-5.0 \& >5 $\mu \mathrm{m} \mathrm{C}$ uptake $\quad \mathrm{mol} \mathrm{C} \mathrm{L}^{-1} \mathrm{~d}^{-1}$

\section{BCO_DMO fields:}

Cruise,Date_Zulu,Time_Zulu,Event_num,Activity,Station,Cast,Latitude,Longitude,Rosette_Bott le,Target_Depth,pcnt_lo,PO4,PO4_flag,SiO4,SiO4_flag,NO2,NO2_flag,NO2_NO3,NO2_NO3 flag,BSi_0_6umfilt_5umprefilt,BSi_5umfilt,rate_32Si_uptake_24hr_0_6umfilt 5umprefilt,rate_ 32Si_uptake_specific_24hr_0_6umfilt_5umprefilt,rate_32Si_uptake_24hr_5umfilt,rate_32Si_upt ake_specific_24hr_5umfilt,ISO_DateTime_UTC

\section{Key method references}

Brzezinski, M. A. and L. Washburn. 2011. Phytoplankton primary productivity in the Santa Barbara Channel: Effects of wind-driven upwelling and mesoscale eddies. Journal of Geophysical Research 116:C12013. 
Measurements: Size fractionated silicic acid uptake

Document author and contact information: Mark Brzezinski, mark.brzeinski@lifesci.ucsb.edu

Brief description of protocol and relation to export pathways: The rates of silicic acid uptake into the $>5 \mu \mathrm{m}$ and in the $0.6-5.0$ particle size fraction are measured in seawater samples from multiple depths spanning the euphotic zone in profile mode. The radioisotope ${ }^{32} \mathrm{Si}(\mathrm{OH})_{4}$ is added to seawater and each sample incubated in deck incubators (dawn to dusk) screened with neutral density screening to simulate the light intensity at the depth of collection. Particles are recovered by serial filtration through 5 and $0.6 \mu \mathrm{m}$ polycarbonate filters, each filter is mounted on a planchette and the ${ }^{32} \mathrm{Si}$ activity measured by low level beta counting. The rates obtained will be combined with parallel measures of the rate of $\mathrm{C}, \mathrm{N}$ and $\mathrm{Fe}$ incorporation to 1) understand the stoichiometry of particle production in the diatom size fraction, 2) provide a baseline rate for assessing the level of nutrient stress in diatoms. The ultimate goal is to relate the nutrient status of diatoms to the specific 'sinking particle' pathways (pathways $1,2,3$ ) that different diatom taxa follow.

Other contributing protocols: Determination of $>5$ and $0.6-5.0 \mu \mathrm{m}$ biogenic silica concentration ( $\mathrm{NaOH}$ digestion), silicic acid concentration.

Uncertainties and quality control concerns: The light field in deck incubators only approximates the light experience of captured diatom cells in situ. Extrapolation of rates measured from dawn to dusk to daily rates. Costs prohibit routine replication.

\section{Data product originating from this measurement}

Parameter

Daily $>5 \&$ 0.6-5.0 $\mu \mathrm{m}$ Si uptake

Specific Si uptake $(>5 \&$ 0.6-5.0 $\mu \mathrm{m})$

Integrated Si production

(>5 \& 0.6-5.0 $\mu \mathrm{m}$, euphotic zone)
Units

mol Si L $\mathrm{L}^{-1}$

$\mathrm{d}^{-1}$

mmol Si m-2 $\mathrm{d}^{-1}$

\section{BCO_DMO fields:}

Cruise,Date_Zulu,Time_Zulu,Event_num,Activity,Station,Cast,Latitude,Longitude,Rosette_Bott le,Target_Depth,pcnt_lo,PO4,PO4_flag,SiO4,SiO4_flag,NO2,NO2_flag,NO2_NO3,NO2_NO3_ flag,BSi_0_6umfilt_5umprefilt,BSi_5umfilt,rate_32Si_uptake_24hr_0_6umfilt 5umprefilt,rate_ 32Si_uptake_specific_24hr_0_6umfilt_5umprefilt,rate_32Si_uptake_24hr_5umfilt,rate_32Si_upt ake_specific_24hr_5umfilt,ISO_DateTime_UTC

\section{Key method references}

Brzezinski, M. A. and D. R. Phillips. 1997. Evaluation of ${ }^{32} \mathrm{Si}$ as a tracer for measuring silica production rates in marine waters. Limnology and Oceanography 42:856-865. 
Krause, J. W., M. A. Brzezinski, and J. L. Jones. 2011. Application of low-level beta counting of ${ }^{32} \mathrm{Si}$ for the measurement of silica production rates in aquatic environments. Marine Chemistry 127:40-47. 


\section{Method: Size fractionated particles}

Document author and contact info: Ken Buesseler kbuesseler@whoi.edu

Brief description of protocol and relation to export pathways: To understand the sources and fate of carbon associated with the biological pump, sampling of particles is needed. To collect enough material to obtain relevant data on the concentrations of $\mathrm{C}$ and associated elements on the rarer, larger suspended particles, in-situ pumping is commonly used to filter upwards of $1000 \mathrm{~L}$. We will be deploying battery powered in-situ pumps (McLane Industries) whereby water entering the pump passes first through two screens ( 51 micron followed by 5 micron nominal pore size) followed by a $1 \mu \mathrm{m}$ nominal pore-size QMA (quartz based) filter (all are $142 \mathrm{~mm}$ diameter). The QMA can be readily subsampled with "punches" of varying size for different analytes as particle distribution is even across the filter (Lam et al. 2015). For the screens, we have considerable experience in rinsing particles gently off these screens on to a $25 \mathrm{~mm}$ diameter $1 \mu \mathrm{m}$ pore size silver filter that is dried and beta counted at sea for ${ }^{234} \mathrm{Th}$, and subsequently recounted on shore for ${ }^{234} \mathrm{Th}$ prior to splitting by weight into subfractions for CHN, PIC and bSi (Lamborg et al. 2008). As in GEOTRACES, the screens will be cut into "pizza" wedges for ${ }^{234} \mathrm{Th},{ }^{210} \mathrm{Po}-{ }^{210} \mathrm{~Pb}$ and $\mathrm{Ba}$ analysis (only at 3 stations). Given the sampling of 6 depths ( 5 trap depths plus $50 \mathrm{~m}$ ) at 12 stations, this generates 72 samples for each of the three size classes. Moreover, we will have three dip blanks for each filter type, i.e. screens (51 and $5 \mu \mathrm{m}$ ) and QMA filters loaded in a filter holder that will be deployed with the deepest pump down to $500 \mathrm{~m}$ three times during the cruise. Samples will be generally dried except for other protocols (HPLC, organic isotopes, and phosphorous for a subset of QMA punches).

Other contributing protocols: Determine $\mathrm{C}$ or other element to ${ }^{234} \mathrm{Th}$ ratios to convert water column-derived ${ }^{234} \mathrm{Th}$ fluxes into $\mathrm{C}$ and other elemental flux estimates, as well as element to ${ }^{210} \mathrm{Po}$ ratios; comparisons of filtration derived particle size and stocks results to other optical PSD data, such as from UVP and other camera systems; comparison to direct estimates of sinking particle fluxes using sediment traps and optical flux traps; look for links between spatial variability in particle abundance and size to community structure and other variables.

Uncertainties and quality control concerns: Particle data will have uncertainties derived from sample processing, blanks and other steps determined by standards and variability among replicate analyses. Each ${ }^{234} \mathrm{Th}$ and ${ }^{210} \mathrm{Po}$ measurement includes an associated analytical counting uncertainty.

Sample Analyses Summary and Units

\begin{tabular}{|l|l|}
\hline Analyses type & Units \\
\hline Size fractionated particulates & $>1-5 ; 5-51 ;>51$ micron pore size \\
\hline $\mathrm{PC}, \mathrm{PN}, \mathrm{PIC}, \mathrm{bSi}$ & $\mu \mathrm{mol} / \mathrm{L}$ \\
\hline${ }^{234} \mathrm{Th}$ & $\mathrm{dpm} / \mathrm{L}$ \\
\hline${ }^{210} \mathrm{~Pb} ;{ }^{210} \mathrm{Po}$ & $\mathrm{dpm} / 100 \mathrm{~L}$ \\
\hline $\mathrm{Ba}$ & $\mathrm{pM}$ \\
\hline $\begin{array}{l}\delta^{138 / 134} \mathrm{Ba} \text { NIST (particulate } \mathrm{Ba}-\text { isotopic } \\
\text { compositions) }\end{array}$ & Unitless (ratio quantity) \\
\hline
\end{tabular}

* POC is determined by PC-PIC

\section{SeaBASS submission fields and units:}

/fields=sample,R2R_Event,date,time,lat,lon,station,depth,conc_Th_234_1umfilt_5umprefilt,conc_Th_234_1umfilt 5umprefilt_unc,conc_Th_234_5umfilt_51umprefilt,conc_Th_234_5umfilt_51umprefilt_unc,conc_Th_234_51umfilt ,conc_Th_234_51umfilt_unc,PC_1umfilt_5umprefilt,PC_1umfilt_5umprefilt_unc,PC_5umfilt_51umprefilt,PC_5um filt_51 umprefilt_unc,PC_51umfilt,PC_51 umfilt_unc,PC_51umfilt_quality,PIC_1umfilt_5umprefilt,PIC_1umfilt_5u mprefilt_unc,PIC_5umfilt_51umprefilt,PIC_5umfilt_51umprefilt_unc,PIC_51umfilt,PIC_51umfilt_unc,PN_mmol_ 1umfilt_5umprefilt,PN_mmol_1umfilt_5umprefilt_unc,PN_mmol_5umfilt_51umprefilt,PN_mmol_5umfilt_51umpr 
efilt_unc,PN_mmol_5umfilt_51umprefilt_quality,PN_mmol_51umfilt,PN_mmol_51umfilt_unc,PN_mmol_51umfilt quality,bSi_0.8umfilt_51umprefilt,bSi_0.8umfilt_51umprefilt unc,bSi_5umfilt_51umprefilt,bSi_5umfilt_51umpre filt unc,bSi 51 umfilt,bSi 51umfilt unc,PTP 1umfilt 5umprefilt,PTP $\overline{1}$ umfilt $\overline{5}$ umprefilt unc,PTP 5umfilt 51 um prefilt,PTP_5umfilt_51umprefilt_unc,PTP_51umfilt,PTP_51umfilt_unc,conc_Ba_total_1umfilt_5umprefilt,conc_Ba total_1umfilt_5umprefilt_unc,conc_Ba_total_5umfilt_51umprefilt,conc_Ba_total_5umfilt_51umprefilt_unc,conc $\bar{B}$ a total_51umfilt,conc_Ba total_51umfilt_unc,Ba_138_134_d_delta_1umfilt 5umprefilt, $\bar{B} a \_138 \_134 \_$d_delta_1u mfilt 5umprefilt_unc,Ba_138_134_d_delta_5umfilt_51umprefilt,Ba_138_134_d_delta_5umfilt_51umprefilt_unc,B a_138_134_d_delta_51umfilt,Ba_138_134_d_delta_51umfilt_unc,conc_Po_210_1umfilt_5umprefilt,conc_Po_210_ 1umfilt 5umprefilt unc,conc_Po_210_5umfilt 51umprefilt,conc_Po 210 5umfilt 51umprefilt_unc,conc_Po_210 51umfilt,conc_Po_210_51umfilt_unc,conc_Pb_210_1umfilt_5umprefilt,conc_Pb_210_1umfilt_5umprefilt_unc,con c_Pb_210_5umfilt_51umprefilt,conc_Pb_210_5umfilt_51umprefilt_unc,conc_Pb_210_51umfilt,conc_Pb_210_51u mfilt_unc

/units=none,none,yyyymmdd,hh:mm:ss, degrees,degrees,none,m,dpm/L,dpm/L,dpm/L,dpm/L,dpm/L,dpm/L,mmol/ $\mathrm{m}^{\wedge} 3, \mathrm{mmol} / \mathrm{m}^{\wedge} 3, \mathrm{mmol} / \mathrm{m}^{\wedge} 3, \mathrm{mmol} / \mathrm{m}^{\wedge} 3, \mathrm{mmol} / \mathrm{m}^{\wedge} 3, \mathrm{mmol} / \mathrm{m}^{\wedge} 3$, none, $\mathrm{mol} / \mathrm{m}^{\wedge} 3, \mathrm{~mol} / \mathrm{m}^{\wedge} 3, \mathrm{~mol} / \mathrm{m}^{\wedge} 3, \mathrm{~mol} / \mathrm{m}^{\wedge} 3, \mathrm{~mol}^{\wedge} / \mathrm{m}^{\wedge} 3$, $\mathrm{mol} / \mathrm{m}^{\wedge} 3, \mathrm{mmol} / \mathrm{m}^{\wedge} 3, \mathrm{mmol} / \mathrm{m}^{\wedge} 3, \mathrm{mmol} / \mathrm{m}^{\wedge} 3, \mathrm{mmol} / \mathrm{m}^{\wedge} 3$, none, $\mathrm{mmol} / \mathrm{m}^{\wedge} 3, \mathrm{mmol} / \mathrm{m}^{\wedge} 3$, none, $\mathrm{mmol} / \mathrm{m}^{\wedge} 3, \mathrm{mmol} / \mathrm{m}^{\wedge} 3, \mathrm{~mm}$ $\mathrm{ol} / \mathrm{m}^{\wedge} 3, \mathrm{mmol} / \mathrm{m}^{\wedge} 3, \mathrm{mmol} / \mathrm{m}^{\wedge} 3, \mathrm{mmol} / \mathrm{m}^{\wedge} 3, \mathrm{mmol} / \mathrm{m}^{\wedge} 3, \mathrm{mmol} / \mathrm{m}^{\wedge} 3, \mathrm{mmol} / \mathrm{m}^{\wedge} 3, \mathrm{mmol} / \mathrm{m}^{\wedge} 3, \mathrm{mmol} / \mathrm{m}^{\wedge} 3, \mathrm{mmol} / \mathrm{m}^{\wedge} 3, \mathrm{nmol}$ /L,nmol/L,nmol/L,nmol/L,nmol/L,nmol/L,per_mil,per_mil,per_mil,per_mil,per_mil,per_mil,dpm/L,dpm/L,dpm/L,d $\mathrm{pm} / \mathrm{L}, \mathrm{dpm} / \mathrm{L}, \mathrm{dpm} / \mathrm{L}, \mathrm{dpm} / \mathrm{L}, \mathrm{dpm} / \mathrm{L}, \mathrm{dpm} / \mathrm{L}, \mathrm{dpm} / \mathrm{L}, \mathrm{dpm} / \mathrm{L}, \mathrm{dpm} / \mathrm{L}$

\section{Key analytical methods references}

Maiti, K., Buesseler, K.O., Pike, S.M., Benitez-Nelson, C.R., Cai, P., Chen, W., Cochran, K., Dai, M., Dehairs, F. and Gasser, B., 2012. Intercalibration studies of short-lived thorium-234 in the water column and marine particles. Limn. \& Ocean., Methods, 10: 631-644

Lam, P.J., Ohnemus, D.C. and Auro, M.E., 2015. Size-fractionated major particle composition and concentrations from the US GEOTRACES North Atlantic Zonal Transect. Deep Sea Research Part II: Topical Studies in Oceanography, 116: 303-320

Lamborg, C.H., Buesseler, K.O., Valdes, J., Bertrand, C.H., Bidigare, R., Manganini, S., Pike, S., Steinberg, D., Trull, T. and Wilson, S., 2008. The Flux of Bio- and Lithogenic Material Associated with Sinking Particles in the Mesopelagic "Twilight Zone" of the Northwest and North Central Pacific Ocean. Deep-Sea Research II, 55(14-15): 1540-1563 


\section{Export Pathways Working Group "protocol briefs"}

\section{1. ${ }^{234}$ Th survey combined with particulate Element: ${ }^{234}$ Th ratios from large volume pumps}

\section{Ken Buesseler, kbuesseler@whoi.edu}

\section{Brief protocol description and how it relates to export pathways.}

We will use the particle-reactive tracer, thorium-234 (half-life $=24.1 \mathrm{~d}$ ) to quantify the spatio-temporal variability in particle flux from the well-lit surface layer, and its attenuation with depth below. The disequilibrium in ${ }^{234} \mathrm{Th}$ from its soluble parent, uranium-238, provides quantitative information on where particle export and remineralization occurs. The link from ${ }^{234} \mathrm{Th}$ to $\mathrm{C}$ or other elemental fluxes is based upon determining the ratio of particulate ${ }^{234} \mathrm{Th}$ to $\mathrm{C}$ (will be done here also for particulate nitrogen, biogenic silica and particulate inorganic $\mathrm{C}$ ) measured on depth resolved profiles of size-fractionated particles ( $>1$ to 50-100 $\mu \mathrm{m}$ range) collected using in-situ pumps (subsamples will be shared). The fluxes derived from this approach include all of the sinking particle pathways, as well as net removal of surface ocean particles (EXPORTS pathways 1, 2, 3), if removed by diel migrating zooplankton and released after they return to depth (pathway 4).

4. Other contributing protocols: Direct estimate of sinking particle fluxes using sediment traps and optical flux traps; comparisons to fluxes derived from particle stocks, such as from UVP and other camera systems; comparisons of Th derived flux to zooplankton and DOM mixing pathways; link between spatial variability from Th compared to community structure

5. Uncertainties and quality control concerns: Each ${ }^{234} \mathrm{Th}$ measurement includes an associated analytical counting uncertainty. Particle data will have uncertainties derived from sample processing, blanks and other steps determined by variability among replicate analyses. The ${ }^{234} \mathrm{Th}$ flux is derived from a model, and here we will estimate these terms by measuring local and time-varying transport terms, and by sampling in a Lagrangian mode, non-steady state terms can be assessed. Propagated model and analytical errors will be included in derived flux fields.

6. Data products originating with this method

A. Sample Analyses

\begin{tabular}{|l|l|}
\hline Analyses type & Units \\
\hline Total ${ }^{234} \mathrm{Th}$ & $\mathrm{dpm} / \mathrm{L}$ \\
\hline & \\
\hline Size fractionated particulates & $>1-20 ; 20-53 ;>53$ micron pore size \\
\hline $\mathrm{PC}, \mathrm{PN}, \mathrm{PIC}, \mathrm{bSi}$ & $\mu \mathrm{M} / \mathrm{L}$ \\
\hline${ }^{234} \mathrm{Th}$ & $\mathrm{dpm} / \mathrm{L}$ \\
\hline
\end{tabular}

*note- size classes of particulates tbd and may vary from 53 micron.

** POC is determined by PC-PIC

\section{SeaBASS submission fields and units:}

/fields=sample,R2R_Event,date,time,lat,lon,station,station_alt_id,bottle,depth,conc_U_238,conc_Th_234,conc_Th 234_se,flux_Th_234,flux_Th_234_se,sal,Wt,pressure,sigmaT,sigma_theta,flux_sampling_method,flux_submethod,f lux_calibration_method,flux_sinking_speed_method

/units=none,none,yyyymmdd,hh:mm:ss,degrees,degrees,none,none,none, $\mathrm{m}, \mathrm{dpm} / 1, \mathrm{dpm} / 1, \mathrm{dpm} / \mathrm{l}, \mathrm{dpm} \_\mathrm{m}^{\wedge}-2 \_\mathrm{d}^{\wedge} \_$ 1,dpm_m^-2_d^-1,psu,degreesC,dbar, $\mathrm{kg} / \mathrm{m}^{\wedge} 3, \mathrm{~kg} / \mathrm{m}^{\wedge} 3$, none, none,none,none

\section{B. Derived products}

We will combine ${ }^{234} \mathrm{Th}$ data with satellite products and results from a 3D high-resolution coupled physicalbiogeochemical model with ${ }^{234} \mathrm{Th}$ dynamics to produce synthesized flux data products.

\section{Key analytical methods references}

Buesseler, K.O., Benitez-Nelson, C., Rutgers Van Der Loeff, M., Andrews, J., Ball, L., Crossin, 
G. and Charette, M., 2001. An intercomparison of small- and large-volume techniques for thorium-234 in seawater. Mar. Chem., 74(1): 15-28.

Pike, S., Buesseler, K.O., Andrews, J.A. and Savoye, N., 2005. Quantification of ${ }^{234}$ Th recovery in small volume sea water samples by inductively coupled plasma mass spectrometry.

J. of Radioanal. and Nuc. Chem., 263(2): 355-360.

Maiti, K., Buesseler, K.O., Pike, S.M., Benitez-Nelson, C.R., Cai, P., Chen, W., Cochran, K., Dai, M., Dehairs, F. and Gasser, B., 2012. Intercalibration studies of short-lived thorium-234

in the water column and marine particles. Limn. \& Ocean., Methods, 10: 631-644 


\section{Export Pathways Working Group "protocol briefs"}

\section{1. ${ }^{210} \mathrm{~Pb}$ and ${ }^{210} \mathrm{Po}$ survey combined with particulate Element: ${ }^{210} \mathrm{Po}$ ratios from large volume pumps}

\section{Ken Buesseler, kbuesseler@whoi.edu; Montserrat Roca-Martí, mrocamarti@whoi.edu}

\section{Brief protocol description and how it relates to export pathways}

Both polonium-210 (half-life $=138.4 \mathrm{~d}$ ) and its parent lead-210 (half-life $=22.3 \mathrm{y}$ ) have a strong affinity for particle surfaces. However, ${ }^{210} \mathrm{Po}$ is also incorporated into the cytoplasm of bacteria and phytoplankton (Cherrier et al., 1995; Fisher et al., 1983) and is preferentially assimilated by zooplankton with respect to ${ }^{210} \mathrm{~Pb}$ (Stewart and Fisher, 2003). This results in a disequilibrium in ${ }^{210} \mathrm{Po}$ from its parent in seawater that can be used to quantify biogenic particle flux from the well-lit surface layer and its attenuation with depth below, in a similar way to ${ }^{234} \mathrm{Th}$. Due to its half-life, ${ }^{210} \mathrm{Po}$ integrates a time scale of several months prior to the sampling. Export estimates from ${ }^{210} \mathrm{Po}$ will be compared to other methods with shorter time scales, ${ }^{234} \mathrm{Th}$ (weeks) and sediment traps (days), with the aim to provide more insights into the export and attenuation of sinking particle fluxes below the euphotic zone. The link from ${ }^{210} \mathrm{Po}$ to particulate organic carbon (POC) and other elemental fluxes (particulate nitrogen, particulate inorganic carbon and biogenic silica) is based upon determining the ratio of particulate ${ }^{210} \mathrm{Po}$ to the corresponding element measured on depth resolved profiles of size-fractionated particles ( $>1$ to 50-100 $\mu \mathrm{m}$ range) collected using in-situ pumps. The fluxes derived from this approach include all the sinking particle pathways (EXPORTS pathways 1,2,3), as well as net removal of surface ocean particles by diel migrating zooplankton (pathway 5).

4. Other contributing protocols: Comparison to direct and other indirect estimates of sinking particle fluxes, including sediment traps, ${ }^{234} \mathrm{Th}$, and fluxes derived from particle stocks, such as UVP and other optical systems; link between spatial variability from ${ }^{210} \mathrm{Po}$ compared to community structure.

5. Uncertainties and quality control concerns: The uncertainties associated with ${ }^{210} \mathrm{~Pb}$ and ${ }^{210} \mathrm{Po}$ measurements are mainly due to the counting of polonium isotopes by alpha spectrometry and the determination of both the ${ }^{209} \mathrm{Po}$ activity and the recovery of stable $\mathrm{Pb}\left({ }^{209} \mathrm{Po}\right.$ and $\mathrm{Pb}$ are used as internal tracers to monitor losses of $\mathrm{Po}$ and $\mathrm{Pb}$ during sample processing). These uncertainties will be quantified appropriately following Rigaud et al. (2013). ${ }^{210}$ Poderived fluxes will have uncertainties derived from both data and modeling assumptions.

\section{Data products originating with this method}

A. Sample Analyses

\begin{tabular}{|l|l|}
\hline Analyses type & Units \\
\hline Total ${ }^{210} \mathrm{~Pb} ;$ Total ${ }^{210} \mathrm{Po}$ & $\mathrm{dpm} 100 \mathrm{~L}^{-1}$ \\
\hline Size fractionated particulates & \\
\hline $\mathrm{PC}, \mathrm{PN}, \mathrm{PIC}, \mathrm{bSi}$ & $>1-5 ; 5-51 ;>51-$ micron pore size \\
\hline${ }^{210} \mathrm{~Pb} ;{ }^{210} \mathrm{Po}$ & $\mu \mathrm{M} \mathrm{L}^{-1}$ \\
\hline
\end{tabular}

* POC is determined by PC-PIC

\section{B. Derived products}

Export flux estimates of POC $\left(\mathrm{mmol} \mathrm{C} \mathrm{m} \mathrm{m}^{-2} \mathrm{~d}^{-1}\right)$ and other elements at different depths in the upper $500 \mathrm{~m}$ of the water column.

\section{Key analytical methods references}

Flynn, W. W. (1968), The determination of low levels of polonium-210 in environmental materials, Anal. Chim. Acta, 43(2), 221-227, doi: 10.1016/S0003-2670(00)89210-7.

Fleer, A. P., and M. P. Bacon (1984), Determination of ${ }^{210} \mathrm{~Pb}$ and ${ }^{210} \mathrm{Po}$ in seawater and marine particulate matter, Nucl. Instruments Methods Phys. Res., 223(2-3), 243-249, doi:10.1016/0167-5087(84)90655-0.

Church, T. et al. (2012), Intercalibration studies of ${ }^{210} \mathrm{Po}$ and ${ }^{210} \mathrm{~Pb}$ in dissolved and particulate seawater samples, Limnol. Oceanogr. Methods, 10, 776-789, doi: 10.4319/lom.2012.10.776. 
Rigaud, S., V. Puigcorbé, P. Cámara-Mor, N. Casacuberta, M. Roca-Martí, J. Garcia-Orellana, C. R. BenitezNelson, P. Masqué, and T. Church (2013), A methods assessment and recommendations for improving calculations and reducing uncertainties in the determination of ${ }^{210} \mathrm{Po}$ and ${ }^{210} \mathrm{~Pb}$ activities in seawater, Limnol. Oceanogr. Methods, 11(10), 561-571, doi:10.4319/lom.2013.11.561.

Masqué, P., Puigcorbé, V., Roca-Martí, M (2018), ${ }^{210} \mathrm{Po}$ and ${ }^{210} \mathrm{~Pb}$ radiochemistry in seawater samples - Co-APDC chelate co-precipitation, RiO5 Cookbook - Method 15, https://cmer.whoi.edu/wp-content/uploads/2018/01/15-Po$\mathrm{Pb}$-210-in-sewater_Co-APDC.pdf 


\section{Export Pathways Working Group "protocol briefs"}

\section{Abundance and isotopic composition of barium}

2. Ken Buesseler, kbuesseler@whoi.edu; Montserrat Roca-Martí, mrocamarti@whoi.edu; Tristan Horner, tristan.horner@whoi.edu

\section{Brief protocol description and how it relates to export pathways}

How do upper ocean ecosystems characteristics determine the vertical transfer of organic matter from the well-lit surface ocean? This question will be tackled by measuring the abundance and isotopic composition of barium - an emerging geochemical proxy for organic carbon oxidation - in seawater and particulate samples from the upper mesopelagic $(\leq 500 \mathrm{~m})$. Earlier work has shown that barite $\left(\mathrm{BaSO}_{4}\right)$ micro-crystals precipitate inside biogenic aggregates in association with heterotrophic bacterial production, reflecting remineralization of organic matter (e.g., Dehairs et al., 2008; Martinez-Ruiz et al., 2018). However, our knowledge about barite cycling in seawater is limited. We are primarily interested in quantifying the relationship between organic matter remineralization and barite precipitation (and the Ba-isotopic composition thereof) in the context of the quantitative rate information derived from radionuclide proxies $\left({ }^{234} \mathrm{Th} /{ }^{238} \mathrm{U}\right.$ and $\left.{ }^{210} \mathrm{Po} /{ }^{210} \mathrm{~Pb}\right)$. Such a study has not been conducted before and can be extremely beneficial in terms of understanding how Ba cycling relates to carbon remineralization. Ba-isotopic fractionation in seawater and marine particles $\left(\delta^{138 / 134} \mathrm{Ba}\right.$ NIST) and a new tracer, Ba* (defined as the difference between expected and observed Ba; e.g., Horner et al., 2015; Bates et al., 2017) will be used to investigate particle cycling and the biogeochemical processes that govern $\mathrm{Ba}$ distributions in seawater. Ba-derived data will be compared to heterotrophic respiration rates and flux attenuation estimates from sediment traps, besides radionuclidederived data.

4. Other contributing protocols: Comparison to direct and indirect estimates of particle flux attenuation, including sediment traps, ${ }^{234} \mathrm{Th}$ and ${ }^{210} \mathrm{Po}$, as well as carbon respiration rates by bacteria and zooplankton.

\section{Uncertainties and quality control concerns:}

Long-term uncertainties for total and particulate Ba concentration measurements are estimated at $\pm 2 \%$ (RSD; relative standard deviation; e.g., Horner et al., 2015). Similarly, uncertainties for Ba-isotopic measurements of samples with unknown composition have been estimated as $\pm 0.03 \%$ (Horner et al., 2015; Bates et al., 2017). Data accuracy is monitored via processing and analysis of international reference materials as part of each batch of samples (e.g., GEOTRACES GSP, GSC, D1). Lastly, blanks - extraneous Ba added during sample processing-are monitored via processing and analyzing of sub-ng aliquots of an isotopic double spike $\left({ }^{135} \mathrm{Ba}-{ }^{136} \mathrm{Ba}\right)$ through all sample purification procedures. Analyses of samples processed in batches with unreasonably high blank Ba concentrations will be discarded and the offending samples re-processed.

6. Data products originating with this method

A. Sample Analyses

\begin{tabular}{|l|l|}
\hline Analyses type & Units \\
\hline$[\mathrm{Ba}]$ (total Ba concentrations) & $\mathrm{nM}$ \\
\hline$\delta^{138 / 134}$ BanIst (total Ba-isotopic compositions) & Unitless (ratio quantity) \\
\hline $\mathrm{p}[\mathrm{Ba}]$ (particulate Ba concentrations) & $\mathrm{pM}$; determined for $>1-5,5-51$, and $>51 \mu \mathrm{m}$ size fractions \\
\hline$\delta^{138 / 134}$ Banist (particulate Ba-isotopic compositions) & $\begin{array}{l}\text { Unitless (ratio quantity); determined for }>1-5,5-51, \text { and } \\
>51 \mu \mathrm{m} \text { size fractions }\end{array}$ \\
\hline
\end{tabular}

\section{B. Derived products}

Total: Ba concentrations, $\Omega_{\text {barite, }} \mathrm{Ba}^{*}$, and Ba-isotopic compositions. Particulate: Ba concentrations and Ba-isotopic compositions for three size fractions.

\section{Key analytical methods references}

Horner, T. J., C. W. Kinsley, and S. G. Nielsen. 2015. Barium-isotopic fractionation in seawater mediated by barite cycling and oceanic circulation. Earth Planet. Sci. Lett. 430: 511-522. doi:10.1016/J.EPSL.2015.07.027

Horner, T. J., H. V. Pryer, S. G. Nielsen, P. W. Crockford, J. M. Gauglitz, B. A. Wing, and R. D. Ricketts. 2017. 
Pelagic barite precipitation at micromolar ambient sulfate. Nat. Commun. 8: 1342. doi:10.1038/s41467-01701229-5 


\section{EXPORTS Coagulation Modeling}

\section{Adrian Burd, adrianb@uga.edu}

The aim of the coagulation model is to model bio-physical processes affecting the particle size distribution with depth in the water column. The model is primarily an inverse-model that will be used to obtain rate parameters that are difficult or impossible to obtain from field observations or experiments (e.g. aggregation and disaggregation rates etc.). Two types of models will be used to minimize the effects of model uncertainty. The first model has been used in multiple studies before and represents the size spectrum with a high-resolution in particle size. This model assumes that particles are homogeneous and so cannot differentiate between particle types or particles of different composition. However, the model has the advantage of being well-established. The second model is under development and will be able to accommodate particles of multiple compositions. One version of this model has already been developed and used to successfully predict the amounts of oil, organic carbon, and mineral ballast in sedimenting particles. A second, more computationally efficient version of this model is currently being developed.

Model Input Data:

UVP and optically derived particle size distributions will be used as data for the inverse model, along with relevant zooplankton and fecal pellet concentrations, and microbial rates. Particle concentration by type will be used as data for determining particle production rates. Model output will also be compared with export flux measurements from the field.

\section{Model Output:}

Model output will consist primarily of particle size spectra, particle composition, and rate parameters including aggregation, disaggregation and consumption rates, particle stickiness, aggregate fractal dimension, and particle settling velocity.

Model Quality Control and Parameter Uncertainties:

The model code will be developed, documented and made publicly available using current best practices (e.g. unit and regression testing etc.)

Parameter uncertainties will be determined using, for example, Monte Carlo simulations and using inter-model comparisons.

Units of model input/output variables are:

- stickiness - unitless

- Aggregate fractal dimension - unitless

- Settling velocity of aggregates $-\mathrm{m} \mathrm{d}^{-1}$

- Particle size spectra $-\mathrm{m}^{-4}$

- Particle degradation/consumption/dissolution rates - $\mathrm{mg} \mathrm{C} \mathrm{d}^{-1}$

- Particle aggregation/disaggregation rates $-\mathrm{d}^{-1}$ 
Method: Bulk DOC and DON stocks

Document author and contact info: Craig Carlson, carlson@lifesci.ucsb.edu

Brief description of protocol and relation to export pathways: Samples for the determination of bulk DOC and DON concentrations were collected over the surface $1000 \mathrm{~m}$ to capture DOM variability through the euphotic and mesopelagic zones on both survey (each station; spatial resolution) and process cruises (at least once per day; temporal resolution). Additional DOM profiles were collected and will continue to be collected from cruises deploying and recovering autonomous assets, or through collaborations with Line P PIs providing higher resolution of DOM seasonality. Water was passed through in-line GF/F filters into combusted EPA vials, then acidified to $\mathrm{pH} 3$ with $4 \mathrm{~N} \mathrm{HCL}$ and stored. DOC concentrations will be determined by the high temperature combustions method ashore using a Shimadzu TOC-V or TOC-L (Carlson et al., 2010). Total dissolved nitrogen (TDN) is determined on the same instruments but with a detector for NO by chemiluminescence (Walsh, 1989). DON is calculated as the difference between TDN and DIN (the latter measured on samples collected by the EXPORTS hydro team). We hypothesized that net DOC production is a fairly regular fraction of NCP. Bulk DOC stock analysis will provide the mechanistic foundations to constrain DOC net production efficiency as well as its persistence.

Other contributing protocols: DIN (nutrient analysis by hydro team)

Uncertainties and quality control concerns: The systems' responses are standardized daily with a four-point calibration curve of glucose or nitrate solution in Nanopure water. Each analytical run includes a set of deep and surface seawater "working" reference materials calibrated with DOC and TDN consensus reference material (CRM) (Hansell 2005). All samples are systematically referenced every $6-8$ analyses throughout a run and generally have a coefficient of variation ranging between 1-3\% over the 3-7 independent analyses (number of references depends on size of the run).

Data products originating with this method:

\begin{tabular}{ll}
\hline Parameter & Units \\
\hline DOC & $\mu \mathrm{mol} \mathrm{L} \mathrm{L}^{-1}, \mu \mathrm{mol} \mathrm{kg}$ \\
DON & $\mu \mathrm{mol} \mathrm{L}$
\end{tabular}

\section{SeaBASS submission fields and units:}

/fields=R2R_Event,date,sample,bottle,depth,sigma_theta,DOC_L,DOC_L_sd,DOC_L_q uality,DOC,DOC_sd,TOC_L,TOC_L_sd,TOC_L_quality, TOC,TOC_sd,TDN,TDN_sd, T DN_quality,TDN_kg,TDN_kg_sd

/units=none,yyyymmdd,none,none, $\mathrm{m}, \mathrm{kg} / \mathrm{m}^{\wedge} 3$, umol $/ \mathrm{L}$,umol/L,none,umol $/ \mathrm{kg}$,umol $/ \mathrm{kg}, \mathrm{um}$ $\mathrm{ol} / \mathrm{L}, \mathrm{umol} / \mathrm{L}$,none,umol $/ \mathrm{kg}, \mathrm{umol} / \mathrm{kg}, \mathrm{umol} / \mathrm{L}, \mathrm{umol} / \mathrm{L}$, none,umol $/ \mathrm{kg}, \mathrm{umol} / \mathrm{kg}$ 


\section{Key method references:}

1. Carlson, C. A., D. A. Hansell, N. B. Nelson, D. A. Siegel, W. M. Smethie, S. Khatiwala, M. M. Meyers and E. Halewood (2010). Dissolved organic carbon export and subsequent remineralization in the mesopelagic and bathypelagic realms of the North Atlantic basin. Deep Sea Research II 57: 1433-1445.

2. Walsh, T. W. (1989). Total dissolved nitrogen in seawater: a new-hightemperature combustion method and a comparison with photo-oxidation. Marine Chemistry 26: 295-311.

3. Hansell, D. A. (2005). Dissolved organic carbon reference material program. EOS, Transactions, American Geophysical Union 86(35): 318-319. 
Method: DOC Remineralization Experiments

Document author and contact info: Craig Carlson, carlson@lifesci.ucsb.edu

Brief description of protocol and relation to export pathways: Microbial remineralization culture experiments were set up as seawater dilution cultures in which a source microbial assemblage (EZ or MZ) was inoculated into a naturally occurring seawater media i.e. $0.2 \mu \mathrm{m}$ filtrate (EZ or MZ; DOM and nutrients) (Carlson et al. 2004). The culture was incubated at in situ temperatures (maintained in upright incubators) in the dark for days to weeks. Samples monitoring changes in bacterioplankton abundance, DOM concentrations and dissolved combined amino acid or dissolved combined neutral concentrations were collected from experiments at regular intervals for periods of days to weeks. Bacterial growth efficiency (BGE) will be obtained from concomitant changes in DOC concentration and bacterial carbon (Wear et al, 2015). DNA and RNA samples were also collected to assess changes in microbial community and function (in conjunction with S. Gifford).

Data generated from microbial remineralization experiments are relevant to Question SQ1a and SQ1b and essential to quantify the fraction of seasonally accumulated DOM that is bioavailable to microbial remineralization at surface versus how much survives degradation and is available for export during physical mixing (i.e. export potential). In addition, microbial remineralization experiments with mesopelagic microbes and surface accumulated DOM will simulate/investigate microbial responses to export events.

Other contributing protocols: $\mathrm{O}_{2}$ respiration measurements (Scott Gifford), 16S rRNA gene phylogeny and transcriptomics (Scott Gifford), DNA sample collection, bulk DOC stocks, DOM composition and bacterial abundances.

Uncertainties and quality control concerns: All experimental treatments for microbial remineralization experiments will be replicated and each experiment will be conducted at least three times per Lagrangian cruise to assess variability among ECC states.

Data products originating with this method:

\begin{tabular}{|c|c|}
\hline Parameter & Units \\
\hline DOC Removal Rate (over incubation) & $\mu \mathrm{mol} \mathrm{C} \mathrm{L}{ }^{-1}$ day $^{-1}$ \\
\hline Bioavailable DOC (over incubation) & $\mu \mathrm{mol} \mathrm{C} \mathrm{L} \mathrm{L}^{-1}$, and $\%$ of total DOC \\
\hline $\begin{array}{l}\text { DCAA or DCNS (Change / diagenetic } \\
\text { index) }\end{array}$ & nmol L-1, relative contribution \\
\hline Bacterioplankton counts & Cells L ${ }^{-1}$ \\
\hline BGE & $\%$ \\
\hline Bacterial community structure & Relative contribution of OTUs \\
\hline
\end{tabular}




\section{SeaBASS submission fields and units:}

/fields=R2R_Event,date,depth,DNA,associated_files,associated_file_types

/units=none,yyyymmdd, $\mathrm{m}, \mathrm{mg} / \mathrm{m}^{\wedge} 3$, none,none

\section{Key method references:}

1. Carlson, C. A., S. J. Giovannoni, D. A. Hansell, S. J. Goldberg, R. Parsons and K. Vergin (2004). Interactions among dissolved organic carbon, microbial processes, and community structure in the mesopelagic zone of the northwestern Sargasso Sea.

Limnology and Oceanography 49(4): 1073-1083.

2. Wear, E. K., C. A. Carlson, A. K. James, M. A. Brzezinski, L. A. Windecker and C. E. Nelson (2015). Synchronous shifts in dissolved organic carbon bioavailability and bacterial community responses over the course of an upwelling-driven phytoplankton bloom. Limnol and Oceanogr 60: 657-677. 
Method: Dissolved organic matter composition

Document author and contact info: Craig Carlson, carlson@lifesci.ucsb.edu

Note: Whether either DCAA or DCNS product is used for the full suite of EXPORTS samples is currently under evaluation.

Dissolved Combined Amino Acid (DCAA) Analysis: Seawater was passed through inline $\mathrm{GF} / \mathrm{F}$ filters and stored at $-20^{\circ} \mathrm{C}$. Dissolved free amino acids (DFAA) will be analyzed as o-phthaldialdehyde (OPA) derivatives in high performance liquid chromatography (Lindroth and Mopper, 1989). Total dissolved amino acids (TDAA) will be analyzed in the same way as DFAA but after hydrolysis in $6 \mathrm{M} \mathrm{HCl}$ in sealed ampoules for $20 \mathrm{~h}$ at $110^{\circ} \mathrm{C}$ (Henrichs, 1991; Kaiser and Benner 2009). DCAA will be calculated as the difference between TDAA and DFAA. Concentrations of DCAA will be measured and normalized to bulk DOC concentrations to produce the DCAA yield index. The DCAA yield and the mole ratio of individual amino acids reveal diagenetic patterns of DOM production and subsequent consumption in the epipelagic and mesopelagic zones.

Dissolved Combined Neutral Sugars (DCNS): The same principle of a diagenetic status index of DOM as identified for DCAA yield has also been applied to DCNS (Goldberg et al., 2009) with slightly differing isolation methods for DCNS as follows. Polymers of DOM are acid hydrolyzed $(0.85 \mathrm{M} \mathrm{H} 2 \mathrm{SO} 4)$ for $20 \mathrm{~h}$ at $100{ }^{\circ} \mathrm{C}$ to produce monomers that are detectable by pulsed amperometric detection high performance liquid chromatography (PAD-HPLC). DCNS yields are then normalized to DOC concentrations to produce a diagenetic index for DOM.

Other contributing protocols: DOC analysis

Uncertainties and quality control concerns: All of the field measurements will have had their measurement uncertainties quantified and standard errors reported for all variables. Certified standards are utilized to calibrate amino acids and neutral sugars with each sample being run in duplicate to triplicate to assess analytical error.

\section{Data products originating with this method:}

\begin{tabular}{ll}
\hline Parameter & Units \\
\hline DCAA & $\mathrm{nmol} \mathrm{L}{ }^{-1}$ \\
DCAA yield & $\%$ \\
\multicolumn{1}{c}{ Or } & \\
DCNS & $\mathrm{nmol} \mathrm{L}{ }^{-1}$ \\
DCNS yield & $\%$ \\
\hline
\end{tabular}




\section{SeaBASS submission fields and units:}

/fields=r2r_event,depth,aa_aspartic_acid,aa_glutamic_acid,aa_histidine,aa_serine,aa_argi nine,aa_threonine,aa_glycine,aa_taurine,aa_beta-

alanine,aa_tyrosine,aa_alanine,aa_gamma_amino_butyric_acid,aa_methionine,aa_valine, aa_phenylalanine,aa_isoleucine,aa_leucine,aa_lysine,DCAA

/units=none,m,nM,nM,Nm,nM,nM,Nm,nM,nM,Nm,nM,nM,Nm,nM,nM,Nm,nM,nM,

\section{Key method references:}

1. Henrichs, S.M. (1991). Methods of sample handling and analysis for dissolved and particulate amino acids and carbohydrates in seawater. In: Hurd, D.C., Spencer, D.W. (Eds.), Marine Particles: Analysis and Characterization.

Geophysical Monograph Series. American Geophysical Union, Washington, pp. 139-149.

2. Goldberg, S. J., C. A. Carlson, D. A. Hansell, N. B. Nelson, D. A. Siegel (2009). Temporal dynamics of dissolved combined neutral sugars and the quality of dissolved organic matter in the Northwestern Sargasso Sea. Deep-Sea Research I 56: $672-685$.

3. Kaiser, K., R. Benner (2009). Biochemical composition and size distribution of organic matter at the Pacific and Atlantic time-series stations. Marine Chemistry 113, 63-77.

4. Lindroth, P., K. Mopper (1979). High performance liquid chromatographic determination of subpicomole amounts of amino acids by precolumn fluorescence derivatization with o-phthaldialdehyde. Analytical Chemistry 51, 1667-1674. 
Method: ${ }^{3} \mathrm{H}$ - Leucine incorporation rate as a proxy for net heterotrophic bacterial production

Document author and contact info: Craig Carlson, carlson@lifesci.ucsb.edu

Brief description of protocol and relation to export pathways: The flux of the most labile fraction of DOC to bacterioplankton requires independent measurements of net heterotrophic bacterial production (BP) and estimates of bacterial growth efficiency (BGE). Net BP was estimated by ${ }^{3} \mathrm{H}$-Leucine incorporation (20nM addition; SA $60 \mathrm{Ci} / \mathrm{mmol}$ ) using a modified version of the microcentrifuge method (Smith and Azam, 1992; Halewood et al 2012). Samples were collected on all SIO Cast profiles for depths spanning the surface to $500 \mathrm{~m}$ and were incubated in the dark for 2-4 hr at in situ temperatures. The ${ }^{3} \mathrm{H}$ - Leu incorporation rates can be converted to bacterial carbon production (BP) using common conversion factors as described in Simon and Azam (1989; i.e. $1.5-3 \mathrm{~kg} \mathrm{C}$ (mol leucine $)^{-1}$ ). To convert net BP to bacterial carbon demand (BCD) requires estimates of BGE from the literature or derived from independent remineralization experiments (see DOC Remineralization protocol) in which simultaneous measurements of the change in bacterial biomass and DOC in microbial dilution cultures are used to estimate BGE. BCD is determined as net BP / BGE and best represents the net flux of labile DOC (LDOC) through heterotrophic bacterioplankton. Determining the flux of LDOC will constrain the respiratory fate of a large fraction of NPP.

Other contributing protocols: Bacterial growth efficiency (BGE) from microbial remineralization experiments (see DOC remineralization experiments).

Uncertainties and quality control concerns: ${ }^{3} \mathrm{H}$ - Leu incorporation rates were determined for 12 depths from euphotic to mesopelagic $(1-500 \mathrm{~m})$ waters using replicate incubations with killed controls. BGE will be obtained from duplicate treatment incubations of microbial remineralization experiments.

Data products originating with this method:

\begin{tabular}{ll}
\hline Parameter & Units \\
\hline${ }^{3}$ H- Leu incorporation rate & pmol L L $^{-1} \mathrm{~h}^{-1}$
\end{tabular}

\section{SeaBASS submission fields and units:}

/fields=R2R_Event,date,sample,bottle,depth,sigma_theta,3H_Leu_L,3H_Leu_L_sd,3H_ Leu_L_quality,3H_Leu,3H_Leu_sd

/units=none,yyyymmdd,none,none, $\mathrm{m}, \mathrm{kg} / \mathrm{m}^{\wedge} 3, \mathrm{pmol} / \mathrm{L} / \mathrm{hr}, \mathrm{pmol} / \mathrm{L} / \mathrm{hr}$,none,pmol/kg/hr,pmo $1 / \mathrm{kg} / \mathrm{hr}$ 


\section{Key method references:}

1. Halewood, E. R., C. A. Carlson, M. A. Brzezinski, D. C. Reed, and J. Goodman. 2012. Annual cycle of organic matter partitioning and its availability to bacteria across the Santa Barbara Channel continental shelf. Aquat. Microb. Ecol. 67: 189209, doi:10.3354/ame01586

2. Smith, D. C. and F. Azam (1992). A simple, economical method for measuring bacterial protein synthesis rates in seawater using $3 \mathrm{H}-$ leucine. Marine Microbial Food Webs 6: 107-114.

3. Simon, M. and F. Azam (1989). Protein content and protein synthesis rates of planktonic marine bacteria. Mar. Ecol. Prog. Ser. 51: 201-213. 
Method: Bacterioplankton Cell Enumeration

Document author and contact info: Craig Carlson, carlson@lifesci.ucsb.edu

Epifluorescence microscopy protocol: The epifluorescence microscopy method described below enumerates total prokaryotic abundance but is not able to differentiate between bacterial and archaeal domains. The cell density of the combined bacterial and archaeal domains is often referred to as bacterioplankton abundance (BA) in the literature (Glockner et al. 1999). The principle of analysis is that bacterioplankton are preserved with particle free formalin (at final concentration of 3.7\%), stained with a 4'-6'diamidino-2-phenylidole (DAPI) concentrated onto a blacked (acid black dye) polycarbonate $0.2 \mu \mathrm{m}$ filter and enumerated with an epifluorescence microscope (60X; Porter and Feig 1980). Individual cells were identified on 10 images captured from the microscope and were counted using automated algorithms developed using ImageJ software (Bankhead, 2014). ImageJ software was used to determine BA as well as cell maximum and minimum length dimension to estimate cell biovolume (Baldwin and Bankston, 1988) of DAPI stained samples. The epifluorescence microscopy assay is appropriate for measuring bacterioplankton abundance within the dynamic range of $10^{7}$ $10^{9}$ cells $\mathrm{L}^{-1}$. These data will be used to estimate the variability of bacterioplankton stocks over specific depth horizons as well as throughout dissolved organic carbon (DOC) remineralization experiments. Cell abundance can be converted to $\mathrm{C}, \mathrm{N}$ and $\mathrm{P}$ units using conversion factors from the literature or by independent analyses.

Flow cytometry protocol: Flow cytometric analyses of bacterioplankton stained with nucleic acid binding fluorochrome (SYBR-Green; Fisher Scientific) (Noble and Fuhrman, 1998) were used to enumerate bacterioplankton in remineralization experiments. SYBR-Green stain was added to formalin-preserved samples at a 1000-fold final dilution and allowed to rest for 10 minutes before analysis by a Guava easyCyte 5HT HPL Flow Cytometer (Blue 488 nm 150 mW laser; EMD Millipore). Stained bacterioplankton cells were enumerated using gating that excluded regions known to contain background noise previously identified by SYBR-stained HPLC-grade water.

Uncertainties and quality control concerns: Slides were spot checked at sea to ensure loading density and slide preparation quality and a subset of samples were prepared in triplicate as a check for reproducibility. Flow cytometry and epifluorescence microscopy output will be intercalibrated for direct comparison.

\section{Data products originating with this method:}

\begin{tabular}{ll}
\hline Parameter & Units \\
\hline $\begin{array}{l}\text { Bacterioplankton } \\
\text { Abundance }\end{array}$ & Cells E9 L \\
&
\end{tabular}


Mean cell volume $\quad \mu \mathrm{m}^{3}$

\section{SeaBASS submission fields and units:}

/fields=R2R_Event,date,sample,bottle,depth,sigma_theta,abun_bacterioplankton,abun_ba cterioplankton_sd,quality,biovol_bacterioplankton,biovol_bacterioplankton_sd,associated _files,associated_file_types

/units=none,yyyymmdd,none,none, $\mathrm{m}, \mathrm{kg} / \mathrm{m}^{\wedge} 3$, cells/L,cells/L, none, um^3/cell,um³/cell,n one, none

/associated_archives=EXPORTSNP_Bact_Abund_Profiles.tar.gz /associated_archive_types=imaging_epifluorescence

\section{Key method references:}

1. Baldwin, W. W. and P. W. Bankston (1988). Measurement of live bacteria by Nomarksi interference microscopy and stereologic methods as tested with macroscopic rod-shaped models. Applied and Environmental Microbiology 54(1): 105-109.

2. Bankhead P. (2014). Analyzing fluorescence microscopy images with ImageJ.

3. Glockner, F. O., B. M. Fuchs, \& R. Amann (1999). Bacterioplankton compositions of lakes and oceans: a first comparison based on fluorescence in situ hybridization. Applied and Environmental Microbiology 65: 3721-3726.

4. Porter, K. G. and Y. S. Feig (1980). The use of DAPI for identifying and counting aquatic microflora. Limnol. Oceanogr 25(5): 943-948. 
Method: DOC export

Document author and contact info: Craig Carlson, carlson@lifesci.ucsb.edu

Brief description of protocol and relation to export pathways: Estimates of the annual DOM export out of the surface $100 \mathrm{~m}$ and into the mesopelagic zone will be constrained by assessing changes in mesopelagic DOC inventories associated with physical measurements of subduction and deep convective mixing (Carlson et al. 1994, Hansell and Carlson 2002). For annual estimates of export flux we will leverage DOM collection from EXPORTS asset deployment/ recovery cruises and time series cruises to Station Papa. High resolution sampling on survey ship will provided coincident measure of submesoscale physical variability along with DOM variability. Sensors on autonomous assets remaining after cruises will provide additional temporal variability of T, S, density used evaluated physical subduction of surface water to depth as well as changes in mixed layer depth (MLD). In summary, measurements of changes in mesopelagic DOM inventories from cruises and extended time series samples along with and estimates of subduction and maximal vertical mixing, observed with Bio-Argo floats, together provide insights on DOM export from the euphotic zone.

Other contributing protocols: autonomous sensor data for Temperature, salinity, density and MLD estimates.

Uncertainties and quality control concerns: All of the field measurements for DOC will have had their measurement uncertainties quantified and standard errors reported for all variables. Our laboratories use consensus and calibrated reference materials 3- 4 times in every analytical run to ensure comparability between analytical runs within and between UCSB and U Miami laboratories. We will draw replicate 10\% of DOC samples for our measurements enabling precision to be quantified. The glider and float sensors will be calibrated (by other groups) with discrete bottle samples collected upon deployment and upon occupation during "spatial" and "Lagrangian" campaigns.

\section{Data products originating with this method:}

\begin{tabular}{ll}
\hline Parameter & Units \\
\hline DOC export & $\mu \mathrm{mol} \mathrm{L} \mathrm{L}^{-1} \mathrm{y}^{-1}$
\end{tabular}

Key method references:

1. Carlson, C. A., H. W. Ducklow and A. F. Michaels (1994). Annual flux of dissolved organic carbon from the euphotic zone in the northwestern Sargasso Sea. Nature 371: 405-408.

2. Hansell, D. A. and C. A. Carlson (2001). Biogeochemistry of total organic carbon and nitrogen in the Sargasso Sea: Control by Convective Overturn. Deep Sea Research II 48: $1649-1667$. 
Method: Winkler titrations for total dissolved $\mathrm{O}_{2}$ concentration and saturation

Document authors and contact info: Nicolas Cassar, nicolas.cassar@,duke.edu, David Nicholson,dnicholson@,whoi.edu.

Brief description of protocol and relation to biogeochemical stocks: The $\mathrm{O}_{2}$ concentration and saturation in seawater reflect a multitude of biological and physical processes, including photosynthesis, respiration, bubble injection through breaking waves, mixing of water masses, temperature and atmospheric pressure changes. The method for determining $\mathrm{O}_{2}$ concentration in seawater was originally presented by Winkler (1888). We use the modified version of Carpenter (1965) as outlined in the WOCE Standard Operating Procedures Manual (Dickson, 1996). Briefly, $\mathrm{O}_{2}$ in a known volume of sample oxidizes iodide ions $\left(\mathrm{I}^{-}\right)$to iodine $\left(\mathrm{I}_{2}\right)$. The amount of iodine generated through this reaction is quantitatively titrated with a standard of thiosulfate $\left(\mathrm{S}_{2} \mathrm{O}_{3}{ }^{-2}\right)$ using an automated potentiometric end-point titrator. The conversion stoichiometry is four moles of thiosulfate for every mole of $\mathrm{O}_{2}$. This assay is appropriate for measuring $\mathrm{O}_{2}$ concentration in seawater under most oceanic conditions when hydrogen sulfide is not present. These data will be used to measure $\mathrm{O}_{2}$ concentration and saturation and most importantly to calibrate the $\mathrm{O}_{2}$ sensors (optodes).

Other contributing protocols: This is complementary to the Equilibrator Inlet Mass Spectrometer measurements which specifically measures the biological $\mathrm{O}_{2}$ saturation and concentration. From these two methods, the physical $\mathrm{O}_{2}$ supersaturation can be derived.

Uncertainties and quality control concerns: Samples for $\mathrm{O}_{2}$ analyses will be collected at multiple stations. The main purpose is to calibrate and validate the $\mathrm{O}_{2}$ sensors data on the ships and the autonomous platforms. Samples will be collected in triplicates to check replication error and precision. Precision and accuracy of dissolved $\mathrm{O}_{2}$ concentration measurements should be $0.2 \%$ of air saturation or better (coefficient of variation). Air saturation values are calculated relative to the salinity and temperature dependent solubility of oxygen in seawater (Garcia and Gordon, 1992).

\section{Data products originating with this method:}

\begin{tabular}{ll}
\hline Parameter & Units \\
\hline $\begin{array}{l}\text { Dissolved } \mathrm{O}_{2} \\
\text { concentration }\end{array}$ & $\mu \mathrm{mol} \mathrm{kg} \mathrm{kg}^{-1}$ \\
& \\
Total $\mathrm{O}_{2}$ & $\%$ \\
saturation & \\
\hline
\end{tabular}

During the 2018 EXPORTS North Pacific cruise, Winkler titrations were conducted on the R/V Sally Ride by Weiyi Tang, Duke University with assistance from Alex Niebergall, Duke University using reagents and equipment provided by the Nicholson 
Lab at WHOI. Over the course of the cruise, 287 individual Winkler bottle samples from calibration casts were titrated. Titrations on five calibration casts were conducted for the Seaglider, four for the Lagrangian Float, three for the BGC Argo float and one for the Wirewalker. Most were sampled as sets of triplicates with each replicate drawn from a different Niskin bottle fired at the same depth. Of the 287 samples, 3 were flagged as unexplained outliers and 6 were flagged due to identified problems that included Niskin misfires, a broken flask, and a software crash. Subsequent results are reported for the remaining 278 samples. Oxygen concentration ranged from $16.5 \mu \mathrm{mol} \mathrm{kg} \mathrm{kg}^{-1}$ to $300.9 \mu \mathrm{mol}$ $\mathrm{kg}^{-1}$. The median standard deviation for triplicate samples was $0.52 \mu \mathrm{mol} \mathrm{kg} \mathrm{kg}^{-1}(0.2 \%$ of saturation).

Oxygen concentration were determined in units of $\mu \mathrm{mol} \mathrm{kg} \mathrm{kg}^{-1}$ and subsequently converted to units of $\mathrm{ml} \mathrm{L}^{-1}$ as required by SeaBASS using the equation:

$\mathrm{O}_{2}(\mathrm{ml} / \mathrm{L})=\mathrm{O}_{2}(\mu \mathrm{mol} / \mathrm{kg}) * 22.392 *\left(\sigma_{\theta}+1000\right) * 10^{-6}$

where 22.392 is the virial molar volume of oxygen $\left(\mathrm{L} \mathrm{mol}^{-1}\right)$ and $\sigma_{\theta}$ is potential density. The equilibrium dissolved oxygen concentration $\left(\mathrm{O}_{2} \mathrm{eq}\right)$ was calculated using the TEOS

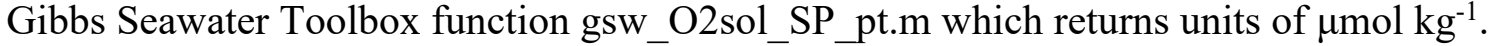
Dissolved oxygen saturation is then calculated as:

$\mathrm{O}_{2}$ saturation $=100 * \mathrm{O}_{2}(\mu \mathrm{mol} / \mathrm{kg}) / \mathrm{O}_{2} \mathrm{eq}$

\section{SeaBASS fields and units:}

/fields=r2r_event,station,bottle,year,month,day,hour,minute,second,pressure,depth,lat,lon ,sal,Wt,sigma_theta,oxygen,oxygen_saturation,oxygen_quality

/units=none,none,none,yyyy,mo,dd,hh,mn,ss,dbar,m,degrees,degrees,psu,degreesc, $\mathrm{kg} / \mathrm{m}^{\wedge}$ $3, \mathrm{ml} / \mathrm{L}, \%$,none

\section{Key method references:}

1. Winkler, L.W. (1888). Die Bestimmung des in Wasser gelösten Sauerstoffen. Berichte der Deutschen Chemischen Gesellschaft, 21: 2843-2855.

2. Carpenter, J.H. (1965). The Chesapeake Bay Institute Technique for the Winkler Dissolved Oxygen Method. Limnology and Oceanography, 10(1), 141-143. https://doi.org/10.4319/lo.1965.10.1.0141

3. Strickland, J.D.H., and Parsons, T.R. (1968). Determination of dissolved oxygen. in A Practical Handbook of Seawater Analysis. Fisheries Research Board of Canada, Bulletin, 167, 71-75.

4. Dickson, A (1996) Determination of dissolved oxygen in sea water by Winkler titration, Accessed at: https://www.nodc.noaa.gov/woce/woce_v3/wocedata_1/whp/manuals/pdf/91_1/di ckson2.pdf 
5. Garcia, H. E., \& Gordon, L. I. (1992). Oxygen solubility in seawater: Better fitting equations. Limnology and Oceanography, 37(6), 1307-1312. https://doi.org/10.4319/1o.1992.37.6.1307 
Method: $\mathrm{O}_{2} /$ Ar Net Community Production Estimates

Document author and contact info: Nicolas Cassar, nicolas.cassar@duke.edu

Brief description of protocol and relation to export pathways: Export production is believed to be a function of NCP which is defined as the balance between net primary production and heterotrophic respiration, or the difference between gross primary production and community respiration. If the organic matter pool (POC+DOC) in the ML is at steady state, export production is equal to NCP. Export may lag production, in which case NCP is expected to be greater than export. Conversely, without allochthonous sources of organic matter, if the organic matter inventory in the ML decreases, export production will be predicted to be transiently greater than NCP. We can account for the lack of steady-state by measuring changes in the $\mathrm{O}_{2}$ and POC and DOC pools over time. We derive NCP from the ratio of $\mathrm{O}_{2}$ to the inert gas argon (Ar). The biological $\mathrm{O}_{2}$ supersaturation can be estimated from $\mathrm{O}_{2} / \mathrm{Ar}$ because $\mathrm{O}_{2}$ and Ar have similar solubility properties (Craig and Hayward 1987). $\Delta \mathrm{O}_{2} / \mathrm{Ar}$ is measured underway from the ship's flow-through seawater line by Equilibrator Inlet Mass Spectrometry (EIMS) as described in Cassar et al. (2009). NCP in units of $\mathrm{mmol} \mathrm{O}_{2} \mathrm{~m}^{-2}$ day-1 is calculated from $\Delta \mathrm{O}_{2} / \mathrm{Ar}$ and other factors, including a gas transfer velocity for $\mathrm{O}_{2}\left(\mathrm{~m} \mathrm{day}^{-1}\right)$ and a wind speed parameterization and a gas exchange weighting. $\mathrm{NCP}$ for $\mathrm{O}_{2}$ is then converted to carbon (mmol $\mathrm{C} \mathrm{m}^{-2}$ day $\left.^{-1}\right)$.

Other contributing protocols: DNA sequencing for $16 \mathrm{~S}$ and $18 \mathrm{~S}$.

Uncertainties and quality control concerns: Lack of steady-state (can be accounted for in Lagrangian mode), vertical mixing/exchange with other water masses, gas exchange parameterization, conversion factor $\mathrm{O}_{2} / \mathrm{C}$. See Cassar et al. (2014) for a thorough description of the uncertainties.

Data products originating with this method:

\begin{tabular}{ll}
\hline Parameter* & Units \\
\hline Biological $\mathbf{O}_{2}$ saturation & $\%$ \\
Physical $\mathrm{O}_{2}$ saturation & $\%$ \\
NCP $(*)$ & $\mathrm{mmol}-\mathrm{C} \mathrm{m}^{-2} \mathrm{~d}^{-1}$ \\
\hline${ }^{*}$ Converted from biological $\mathrm{O}_{2}$ flux to the atmosphere.
\end{tabular}

\section{SeaBASS submission fields and units:}

/fields=date,time,H2O_amps,N2_amps,O2_amps,Ar_amps,CO2_amps, $13 \mathrm{CO} 2 \_$amps,pressure_i nstrument,N2_Ar_ratio,O2_Ar_ratio,N2_O- 2 _ratio, quality, oxygen_saturation, $\overline{\mathrm{W}} \mathrm{t}, \mathrm{At}$

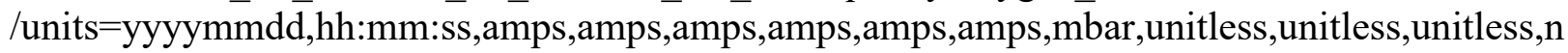
one, $\%$,degreesC, degreesC

/fields=date,time,lat,lon,O2_Ar_ratio,Wt,Z_MLD,sal,piston_velocity,NCP_O2_Ar_ratio_contin uous

/units=yyyymmdd,hh:mm:ss,degrees,degrees,unitless,degreesC,m,PSU,m/d,mmol/m^2/d 


\section{Key method references}

Cassar, N., B. A. Barnett, M. L. Bender, J. Kaiser, R. C. Hamme, and B. Tilbrook. 2009. Continuous High-Frequency Dissolved $\mathrm{O}_{2} /$ Ar Measurements by Equilibrator Inlet Mass Spectrometry. Analytical Chemistry 81:1855-1864.

Cassar, N., C. D. Nevison, and M. Manizza. 2014. Correcting oceanic $\mathrm{O}_{2} /$ Ar-net community production estimates for vertical mixing using $\mathrm{N}_{2} \mathrm{O}$ observations. Geophysical Research Letters 41:8961-8970.

Craig, H., and T. Hayward. 1987. Oxygen supersaturation in the ocean - biological versus physical contributions. Science 235:199-202. 
Method: Compound-specific isotope analysis of amino acids (AA-CSIA) isolated from sinking particles, size-fractionated particles, and zooplankton fecal pellets

Document author and contact info: Hilary G. Close (hclose@rsmas.miami.edu)

\section{Brief description of protocol and relation to export pathways:}

Sinking particles will be collected via sediment traps. Two size fractions of particles $(0.8-51 \mu \mathrm{m}$, $>51 \mu \mathrm{m})$ and subsamples of $1-5 \mu \mathrm{m}$ particles will be collected via in situ pumps. Four size fractions of particles $(0.3-1 \mu \mathrm{m}, 1-6 \mu \mathrm{m}, 6-51 \mu \mathrm{m},>51 \mu \mathrm{m})$ will be collected at a subset of depths. Fecal pellets will be harvested from zooplankton incubations. Filters may be subsampled for sizefractionated total particulate carbon, particulate organic carbon, and total particulate nitrogen concentrations and isotope ratios. Fourteen protein-forming amino acids will be analyzed for compound-specific $\mathrm{C}$ and $\mathrm{N}$ isotope analysis and quantitation and enantiomer ratios. From this data, several parameters will be calculated that can distinguish the extent to which microbial and metazoan heterotrophy have acted upon detrital particles and/or contributed secondary biomass. We will use a multivariate statistical framework to estimate phytoplankton, heterotrophic microbe, and fecal pellet contributions to particles and thus to size-fractionated particle flux. We anticipate coordinating with several projects to refine our statistical framework and eventually to construct a dynamical model of organic matter sources and transformations.

Other contributing protocols: AA-CSIA of size-fractionated zooplankton, microbial and zooplankton community characterization/quantification, microbial and zooplankton respiration, fecal pellet production and flux, visual particle characterization, particle size distributions, thorium-derived size-fractionated carbon and nitrogen flux, particle fluxes from sediment traps, particle aggregation/disaggregation rates.

Uncertainties and quality control concerns: Blank "dipped" filters as full-process blanks. Synthetic amino acids added to samples as internal isotope and recovery standards. Suites of amino acid standards prepared and analyzed with sample batches as external standards for quantitation, mass-balance correction for derivative carbon, and racemization correction. Cross-lab standard material prepared and analyzed with sample batches. Triplicate analysis, propagation of analytical uncertainty in calculated parameters. Propagated uncertainty in $\delta^{13} \mathrm{C}_{\mathrm{AA}}$ from analysis of derivatization standards. Estimated uncertainty in filtered volumes and thus concentrations.

\section{Data products originating with this method}

\begin{tabular}{|l|l|}
\hline Parameter & Units \\
\hline $\begin{array}{l}\text { Individual and total hydrolysable amino acid concentrations, } \\
\text { size fractionated particles ([THAA]) }\end{array}$ & nmol L-1 \\
\hline $\begin{array}{l}\text { Natural-abundance nitrogen isotope ratios of individual amino } \\
\text { acids, size fractionated particles and incubated fecal pellets }\end{array}$ & Values of $\delta^{15} \mathrm{~N}$ (air) \\
\hline $\begin{array}{l}\text { Natural-abundance carbon isotope ratios of individual amino } \\
\text { acids, size fractionated particles and incubated fecal pellets }\end{array}$ & Values of $\delta^{13} \mathrm{C}$ (VPDB) \\
\hline D:L enantiomer ratio of alanine, size fractionated particles & $\mathrm{mol} / \mathrm{mol}^{-1}$ \\
\hline *Bulk nitrogen concentration, size fractionated particles ([PN]) & $\mu \mathrm{mol} \mathrm{L} \mathrm{L}^{-1}$ \\
\hline *Natural-abundance bulk nitrogen isotope ratios, size & Values of $\delta^{15} \mathrm{~N}$ (air) \\
\hline
\end{tabular}




\begin{tabular}{|l|c|}
\hline fractionated particles $\left(\delta^{15} \mathrm{~N}_{\mathrm{PN}}\right)$ & \\
\hline $\begin{array}{l}* \text { Bulk total carbon concentration, size fractionated particles } \\
([\mathrm{PC}])\end{array}$ & $\mu \mathrm{mol} \mathrm{L}{ }^{-1}$ \\
\hline $\begin{array}{l}* \text { Natural-abundance bulk carbon isotope ratios, size } \\
\text { fractionated particles }\left(\delta^{13} \mathrm{C}_{\mathrm{PC}}\right)\end{array}$ & Values of $\delta^{13} \mathrm{C}(\mathrm{VPDB})$ \\
\hline $\begin{array}{l}* \text { Bulk organic carbon concentration, size fractionated particles } \\
([\mathrm{POC}])\end{array}$ & $\mu \mathrm{mol} \mathrm{L}{ }^{-1}$ \\
\hline $\begin{array}{l}* \text { Natural-abundance bulk organic carbon isotope ratios, size } \\
\text { fractionated particles }\left(\delta^{13} \mathrm{C}_{\mathrm{POC}}\right)\end{array}$ & Values of $\delta^{13} \mathrm{C}(\mathrm{VPDB})$ \\
\hline$*$ PC:PN and POC:PN ratios, size fractionated particles & $\mathrm{mol} / \mathrm{mol}^{\mathrm{P}}$ \\
\hline
\end{tabular}

*As sample size permits and where not redundant

\section{Key method references}

Hannides CCS, Popp BN, Landry MR, Graham BS (2009) Quantification of zooplankton trophic position in the North Pacific Subtropical Gyre using stable nitrogen isotopes. Limnology and Oceanography, 54, 50-61.

Kaiser K, Benner R (2008) Major bacterial contribution to the ocean reservoir of detrital organic carbon and nitrogen. Limnology and Oceanography, 53, 99-112.

McMahon KW, McCarthy MD, Sherwood OA, Larsen T, Guilderson TP (2015) Millennial-scale phytoplankton regime shifts in the subtropical North Pacific Ocean. Science, 350, 1530-1533.

Ohkouchi N, Chikaraishi Y, Close HG, Fry B, Larsen T, Madigan DJ, McCarthy MD, McMahon KW, Nagata T, Naito YI, Ogawa NO, Popp BN, Steffan S, Takano Y, Tayasu I, Wyatt ASJ, Yamaguchi YT, Yokoyama Y (2017) Advances in the application of amino acid nitrogen isotopic analysis in ecological and biogeochemical studies. Organic Geochemistry, 113, 150174.

Popp BN, Graham BS, Olson RJ, Hannides CCS, Lott MJ, López-Ibarra GA, Galván-Magña F, Fry B, (2007) Insight into the trophic ecology of yellowfin tuna, Thunnes albacares, from compound-specific nitrogen isotope analysis of proteinaceous amino acids, in: Dawson TD, Siegwolf RTW (Eds.), Stable isotopes as indicators of ecological change. Elsevier, San Diego, pp. 173-190. 
Method: Genetic characterization of bulk sinking particles in sediment traps

Document author and contact info: Colleen Durkin, cdurkin@mlml.calstate.edu

Brief description of protocol and relation to export pathways: Each sediment trap will include 1 tube containing RNAlater preservative. Particles in the RNAlater will be collected onto a filter and frozen. DNA will be extracted and the V4 hyper-variable region of the 18S and 16S rRNA DNA markers will be amplified using primer sets modified by Apprill et al. 2015 and Penna et al. 2017. Amplified PCR products will be sequenced on an Illumina MiSeq with a 300 bp paired end run. DNA sequence identities will be assigned by comparing to sequence databases. This analysis contributes to export pathways 1,2, and 3 by specific organisms with particle export. When combined with particle-specific DNA sequencing data, the organisms only exported in small particles can be inferred.

Other contributing protocols: Genetic characterization of zooplankton products in sediment traps, genetic characterization of surface plankton communities, genetic characterization of aggregates in sediment traps.

Uncertainties and quality control concerns: While the presence of a DNA sequence confirms the link between an organism or its remains with sinking particles, the absence of a DNA sequence does not confirm the absence of this link. It is possible for organic matter to be exported without any DNA evidence of its organismal source. To relate these data to surface phytoplankton communities, it is critical that the same PCR primers are used to amplify $16 \mathrm{~S}$ and $18 \mathrm{~S}$ rRNA of surface plankton communities.

Data products originating with this method:

Data table of species detected in bulk sinking material - csv file

DNA sequences - fasta file

SeaBASS submission fields and units:

/fields=abun, namespace_manual, identification_manual, biotic_group, DNA_counts, associated_files, associated_file_type

/units $=\%$,none, $\mathrm{TBD}$

Key method references:

Apprill, A., McNally, S., Parsons, R. and Weber, L., 2015. Minor revision to V4 region SSU rRNA 806R gene primer greatly increases detection of SAR11 bacterioplankton. Aquat Microb Ecol, 75, pp.129-137.

Penna, A., Casabianca, S., Guerra, A.F., Vernesi, C. and Scardi, M., 2017. Analysis of phytoplankton assemblage structure in the Mediterranean Sea based on high-throughput sequencing of partial 18S rRNA sequences. Marine Genomics. 
Method: Genetic characterization of sinking aggregates in gel traps

Document author and contact info: Colleen Durkin, cdurkin@mlml.calstate.edu

Brief description of protocol and relation to export pathways: Jars containing polyacrylamide gel layers will be deployed in 1 tube of each deployed sediment trap. Sinking particles and organisms that settle into the gel layer remain distinctly separated, preserving original characteristics of size and quantity and constituents. Individual aggregates will be pipetted out of the gel layer and frozen in cryovials immediately after trap recovery. DNA will be extracted and the V4 hyper-variable region of the $18 \mathrm{~S}$ and $16 \mathrm{~S}$ rRNA DNA markers will be amplified using primer sets modified by Apprill et al. 2015 and Penna et al. 2017. Amplified PCR products will be sequenced on an Illumina MiSeq with a 300 bp paired end run. DNA sequence identities will be assigned by comparing to sequence databases. This analysis contributes to export pathway 2 by connecting specific organisms with transport by sinking aggregates.

Other contributing protocols: Genetic characterization of bulk particles in sediment traps, genetic characterization of surface plankton communities.

Uncertainties and quality control concerns: This analysis is performed on the largest particles in the gel but sequences that are specific to the small sinking particles can be inferred by identifying differences between individual particles and the bulk trap material sequence compositions. While the presence of a DNA sequence confirms the link between an organism or its remains with aggregates, the absence of a DNA sequence does not confirm the absence of this link. It is possible for organic matter to be exported without any DNA evidence of its organismal source. Additionally, particles will degrade over the course of the deployment period, and may alter the DNA sequences detected. The extent of these changes is currently being examined. To relate these data to surface phytoplankton communities, it is critical that the same PCR primers are used to amplify $16 \mathrm{~S}$ and $18 \mathrm{~S}$ rRNA of surface plankton communities.

\section{Data products originating with this method:}

Data table of species per aggregate - csv file

DNA sequences - fasta file

\section{SeaBASS submission fields and units:}

/fields=abun, namespace_manual, identification_manual, biotic_group, DNA_counts, associated_files, associated_file type

/units $=\%$, none, TBD

Key method references:

Apprill, A., McNally, S., Parsons, R. and Weber, L., 2015. Minor revision to V4 region SSU rRNA 806R gene primer greatly increases detection of SAR11 bacterioplankton. Aquat Microb Ecol, 75, pp.129-137.

Penna, A., Casabianca, S., Guerra, A.F., Vernesi, C. and Scardi, M., 2017. Analysis of phytoplankton assemblage structure in the Mediterranean Sea based on high-throughput sequencing of partial 18S rRNA sequences. Marine Genomics. 
Method: Genetic characterization of zooplankton products in gel traps

Document author and contact info: Colleen Durkin, cdurkin@mlml.calstate.edu

Brief description of protocol and relation to export pathways: Jars containing polyacrylamide gel layers will be deployed in 1 tube of each deployed sediment trap. Sinking particles and organisms that settle into the gel layer remain distinctly separated, preserving original characteristics of size and quantity and constituents. Individual fecal pellets will be pipetted out of the gel layer and frozen in cryovials immediately after trap recovery. DNA will be extracted and the V4 hyper-variable region of the 18S and 16S rRNA DNA markers will be amplified using primer sets modified by Apprill et al. 2015 and Penna et al. 2017. Amplified PCR products will be sequenced on an Illumina MiSeq with a 300 bp paired end run. DNA sequence identities will be assigned by comparing to sequence databases. This analysis contributes to export pathway 3 by connecting specific organisms with transport by sinking fecal pellets.

Other contributing protocols: Genetic characterization of bulk particles in sediment traps, genetic characterization of surface plankton communities.

Uncertainties and quality control concerns: This analysis is performed on the largest fecal pellets in the gel but sequences that are specific to the small sinking particles can be inferred by identifying differences between individual particles and the bulk trap material sequence compositions. While the presence of a DNA sequence confirms the link between an organism or its remains with fecal pellets, the absence of a DNA sequence does not confirm the absence of this link. It is possible for organic matter to be exported without any DNA evidence of its organismal source. Additionally, particles will degrade over the course of the deployment period, and may alter the DNA sequences detected. The extent of these changes is currently being examined. To relate these data to surface phytoplankton communities, it is critical that the same PCR primers are used to amplify $16 \mathrm{~S}$ and $18 \mathrm{~S}$ rRNA of surface plankton communities.

\section{Data products originating with this method:}

Data table of species per fecal pellet - csv file

DNA sequences - fasta file

\section{SeaBASS submission fields and units:}

/fields=abun, namespace_manual, identification_manual, biotic_group, DNA_counts, associated_files, associated_file type

/units $=\%$, none, TBD

Key method references:

Apprill, A., McNally, S., Parsons, R. and Weber, L., 2015. Minor revision to V4 region SSU rRNA 806R gene primer greatly increases detection of SAR11 bacterioplankton. Aquat Microb Ecol, 75, pp.129-137.

Penna, A., Casabianca, S., Guerra, A.F., Vernesi, C. and Scardi, M., 2017. Analysis of phytoplankton assemblage structure in the Mediterranean Sea based on high-throughput sequencing of partial 18S rRNA sequences. Marine Genomics. 
Method: Visual cell ID in gel traps

Document author and contact info: Colleen Durkin, cdurkin@mlml.calstate.edu

Brief description of protocol and relation to export pathways: Jars containing polyacrylamide gel layers will be deployed in 1 tube of each deployed sediment trap. Sinking particles and organisms that settle into the gel layer remain distinctly separated, preserving original characteristics of size and quantity and constituents. Gel jars will be visually examined by microscopy to quantify the flux and identity of individually-sinking organisms. To detect the large and potentially rare organisms (phytoplankton and zooplankton), the entire gel layer will be surveyed at low magnification $(30 \mathrm{x}-50 \mathrm{x})$ with a stereomicroscope and all visible organisms will be identified and counted. To quantify smaller cells, a gridded transparency will be placed underneath the gel and all cells within $\geq 20$ grid squares $\left(0.25 \mathrm{~cm}^{2}\right.$ area per square $)$ will be identified and counted at $115 x$ under darkfield illumination. Cell fluxes will be calculated by dividing the total number of cells counted by the area examined and further divided by the deployment time (number $\mathrm{m}^{-2} \mathrm{~d}^{-1}$ ). Approximate cell volumes will be calculated and number fluxes will be converted to carbon flux using the equations of Menden-Deuer and Lessard 2000.

\section{Other contributing protocols:}

Uncertainties and quality control concerns: The uncertainty of fluxes can be estimated by the square root of the number of counts. The carbon per cell is an estimate based on an empirically derived equation.

\section{Data products originating with this method:}

Cells fluxes: cells $\mathrm{m}^{-2} \mathrm{~d}^{-1}$

Zooplankton fluxes or swimmer contamination: organisms $\mathrm{m}^{-2} \mathrm{~d}^{-1}$

Phytoplankton carbon flux: mmol $\mathrm{C} \mathrm{m}^{-2} \mathrm{~d}^{-1}$

\section{SeaBASS submission fields and units:}

/id_fields_definitions=1id:passive,2id:aggregate,3id:long_fp,4id:dense_detritus,5id:1arge_loose,6 id:short_fp,7id:mini_pellet,8id:salp_pellet,9id:phyto,10id:foraminifera,11id:rhizaria,12id:fiber,1 3id:copepod,14id:pteropod,15id:amphipod,16id:other_zooplankton,17id:zooplankton_part,18id: unidentifiable

/fields=R2R_Event,sample,SN,station,depth,date,time,date_start,time_start,date_end,time_end,d ate_resurface,time_resurface,date_recovery,time_recovery,e-elapsed_time,lat,lon, ,lat_end,lon_end,lat_resurface,lon_resurface,lat_recovery,lon_recovery,bin_diameter_center,bin _diameter_upper,bin_diameter_lower,flux_particles_1id,flux_particles_1id_unc,bincount_lid,flu x_particles_2id,flux_particles_2id_unc,bincount_2id,flux_particles_3id,flux_particles_3id_unc,b

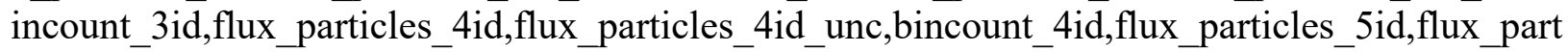
icles_5id_unc,bincount_5id,flux_particles_6id,flux_particles_6id_unc,bincount_6id,flux_particle

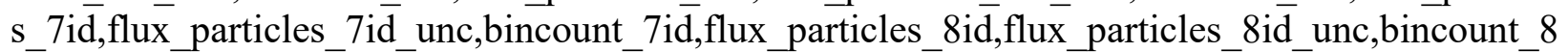

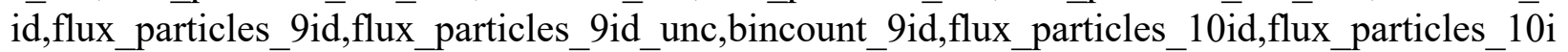
d_unc,bincount_10id,flux_particles_11id,flux_particles_11id_unc,bincount_11id,flux_particles_ 
12id,flux_particles_12id_unc,bincount_12id,flux_particles_13id,flux_particles_13id_unc,bincou nt_13id,flux_particles_14̄id,flux_particles_14id_unc,bincount_14id,flux_particles_15id,flux_par ticles_15id_unc,bincount_15id,flux_particles_16id,flux_particles_16id_unc,bincount_16id,flux_

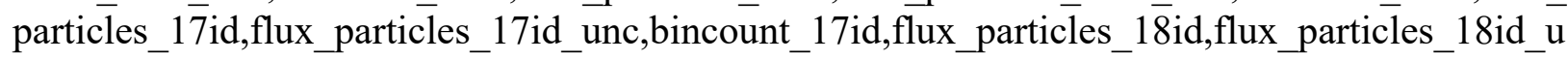
nc,bincount_18id

/units=none,none,none,none,m,yyyymmdd,hh:mm:ss,yyyymmdd,hh:mm:ss,yyyymmdd,hh:mm:s s,yyyymmdd,hh:mm:ss,yyyymmdd,hh:mm:ss, seconds, degrees, degrees, degrees, degrees, degrees, d egrees,degrees,degrees, degrees, degrees, $m, m, m$,particles $/ \mathrm{m}^{\wedge} 2 / \mathrm{d}$, particles $/ \mathrm{m}^{\wedge} 2 / \mathrm{d}$, none,particles $/ \mathrm{m}$ ${ }^{\wedge} 2 / \mathrm{d}$,particles $/ \mathrm{m}^{\wedge} 2 / \mathrm{d}$,none,particles $/ \mathrm{m}^{\wedge} 2 / \mathrm{d}$,particles $/ \mathrm{m}^{\wedge} 2 / \mathrm{d}$,none,particles $/ \mathrm{m}^{\wedge} 2 / \mathrm{d}$,particles $/ \mathrm{m}^{\wedge} 2 / \mathrm{d}$, none,particles $/ \mathrm{m}^{\wedge} 2 / \mathrm{d}$,particles $/ \mathrm{m}^{\wedge} 2 / \mathrm{d}$,none,particles $/ \mathrm{m}^{\wedge} 2 / \mathrm{d}$,particles $/ \mathrm{m}^{\wedge} 2 / \mathrm{d}$,none,particles $/ \mathrm{m}^{\wedge} 2 / \mathrm{d}$, particles $/ \mathrm{m}^{\wedge} 2 / \mathrm{d}$,none,particles $/ \mathrm{m}^{\wedge} 2 / \mathrm{d}$,particles $/ \mathrm{m}^{\wedge} 2 / \mathrm{d}$,none,particles $/ \mathrm{m}^{\wedge} 2 / \mathrm{d}$,particles $/ \mathrm{m}^{\wedge} 2 / \mathrm{d}$, none, particles $/ \mathrm{m}^{\wedge} 2 / \mathrm{d}$,particles $/ \mathrm{m}^{\wedge} 2 / \mathrm{d}$,none,particles $/ \mathrm{m}^{\wedge} 2 / \mathrm{d}$,particles $/ \mathrm{m}^{\wedge} 2 / \mathrm{d}$, none,particles $/ \mathrm{m}^{\wedge} 2 / \mathrm{d}$,partic les $/ \mathrm{m}^{\wedge} 2 / \mathrm{d}$,none,particles $/ \mathrm{m}^{\wedge} 2 / \mathrm{d}$,particles $/ \mathrm{m}^{\wedge} 2 / \mathrm{d}$,none,particles $/ \mathrm{m}^{\wedge} 2 / \mathrm{d}$,particles $/ \mathrm{m}^{\wedge} 2 / \mathrm{d}$,none,partic les $/ \mathrm{m}^{\wedge} 2 / \mathrm{d}$,particles $/ \mathrm{m}^{\wedge} 2 / \mathrm{d}$,none,particles $/ \mathrm{m}^{\wedge} 2 / \mathrm{d}$,particles $/ \mathrm{m}^{\wedge} 2 / \mathrm{d}$, none,particles $/ \mathrm{m}^{\wedge} 2 / \mathrm{d}$,particles $/ \mathrm{m}$ $\wedge 2 / \mathrm{d}$,none,particles $/ \mathrm{m}^{\wedge} 2 / \mathrm{d}$,particles $/ \mathrm{m}^{\wedge} 2 / \mathrm{d}$, none

\section{Key method references:}

Durkin, C. A., B. A. S. Van Mooy, S. T. Dyhrman, K. O. Buesseler. 2016. Sinking phytoplankton associated with carbon flux in the Atlantic Ocean. Limnology and Oceanography 61: $1172-1187$

Menden-Deuer, S., and E. J. Lessard. 2000. Carbon to volume relationships for dinoflagellates, diatoms, and other protist plankton. Limnology and Oceanography 45: 569-579. 
Method: Visual characterization of zooplankton products in gel traps

Document author and contact info: Colleen Durkin, cdurkin@mlml.calstate.edu

Brief description of protocol and relation to export pathways: Jars containing polyacrylamide gel layers will be deployed in 1 tube of each deployed sediment trap. Sinking particles and organisms that settle into the gel layer remain distinctly separated, preserving original characteristics of size, quantity, and constituents. A process blank gel is prepared and remains on the ship to quantify background particle contamination. Gel layers are imaged under a stereomicroscope at multiple magnifications (e.g. 7x, 20x, 50x, 115x), in multiple focal planes, and under brightfield and oblique lighting sources. Image data are processed using a python script that isolates, counts, measures, and saves images of individual particles. Particle size distribution (PSD) (number $\mathrm{m}^{-2}$ ) is calculated for log-transformed size bins spanning optimal magnification ranges. Each sample PSD is blank-corrected by subtracting the average of all process blank PSDs and converted to flux by dividing by deployment time (number $\mathrm{m}^{-2} \mathrm{~d}^{-1}$ ). Every detected particle is manually assigned an identity (e.g. fecal pellet, aggregate) using a python-based graphical user interface that allows rapid identity assignment of thousands of images. The percent of fecal pellets in each size bin is multiplied by the total particle number flux to determine fecal pellet number fluxes across size bins. Fecal pellet number fluxes will be converted to fecal pellet carbon fluxes using conversions measured directly from concurrent zooplankton grazing experiments $\left(\mathrm{mmol} \mathrm{C} \mathrm{m}^{-2} \mathrm{~d}^{-1}\right)$. This analysis contributes to export path 3 by calculating the quantity of fecal pellets that are contributing the carbon flux at each depth.

Other contributing protocols: Zooplankton fecal pellet production, Visual characterization of aggregates in gel traps

Uncertainties and quality control concerns: The uncertainty of fluxes can be estimated by the square root of the number of counts. Oblique lighting enables detection of translucent particles and can resolve smaller size bins, whereas brightfield lighting is more comparable to optical instruments like the Optical Sediment Trap.

Data products originating with this method:

Fecal pellet fluxes across size bins (10-1000 um diameter): pellets $\mathrm{m}^{-2} \mathrm{~d}^{-1}$

Estimated carbon flux from fecal pellets at each depth: mmol $\mathrm{C} \mathrm{m}^{-2} \mathrm{~d}^{-1}$

\section{SeaBASS submission fields and units:}

/fields=flux_carbon_fecalpellet

/units $=$ mmol $\mathrm{C}$ m-2 $\overline{\mathrm{d}}-1$

\section{Key method references:}

Durkin, C.A., Estapa, M.L. and Buesseler, K.O., 2015. Observations of carbon export by small sinking particles in the upper mesopelagic. Marine Chemistry, 175, pp.72-81. 
Method: Bulk particle flux to sediment traps

Document author and contact info: Meg Estapa, mestapa@skidmore.edu

Brief description of protocol and relation to export pathways: Sediment traps are used to directly collect sinking particles at discrete, sub-mixed layer depths. Collected particles are analyzed for particulate carbon (PC), particulate inorganic carbon (PIC), biogenic silica (bSi), ${ }^{234} \mathrm{Th},{ }^{210} \mathrm{Po},{ }^{210} \mathrm{~Pb}, \mathrm{Ba}$, and mass and converted to fluxes by normalizing to the trap collection area and length of deployment. POC flux is determined as the difference between PC and PIC fluxes. Bulk compositional analysis does not discriminate among sinking particles from different export pathways (single cells, aggregates, zooplankton products) so this method provides an estimate of the sum of all "sinking particle" pathways (1,2, and 3). EXPORTS field measurements use two different sediment trap platform designs (one neutrally-buoyant, the other surface-tethered) both carrying cyclindrical trap tubes with closing lids. Other analytes not described here may be analyzed by other contributing groups.

Other contributing protocols: Analytical determination of PC (combustion elemental analysis), PIC (coulometry), bSi (alkaline digestion and spectrophotometric determination), ${ }^{234} \mathrm{Th}$ (low level $\beta$ emission), ${ }^{210} \mathrm{Po}$ (alpha spectrometry), ${ }^{210} \mathrm{~Pb}, \mathrm{Ba}$, and particle mass (gravimetry).

Uncertainties and quality control concerns: Influence of hydrodynamic biases which depend upon trap design; zooplankton "swimmer" presence in samples; sample solubilization during deployment; intra-platform (i.e. "tube-to-tube") variability; inter-platform (i.e. "trap-to-trap") variability; handling (process) blanks for all analytes; mechanical issues with traps during deployments (e.g. depth variability, lid closures)

\section{Data products originating with this method:}

\begin{tabular}{|c|c|}
\hline Parameter ${ }^{*}$ & Units \\
\hline PC flux & mmol-C m m $^{-2} \mathrm{~d}^{-1}$ \\
\hline POC flux & mmol-C m-2 $\mathrm{d}^{-1}$ \\
\hline PIC flux & mmol-C m ${ }^{-2} \mathrm{~d}^{-1}$ \\
\hline bSi flux & mmol-Si m ${ }^{-2} \mathrm{~d}^{-1}$ \\
\hline${ }^{234}$ Th flux & $\mathrm{dpm} \mathrm{m}^{-2} \mathrm{~d}^{-1}$ \\
\hline${ }^{210}$ Po flux & $\mathrm{dpm} \mathrm{m}^{-2} \mathrm{~d}^{-1}$ \\
\hline${ }^{210} \mathrm{~Pb}$ flux & $\mathrm{dpm} \mathrm{m}^{-2} \mathrm{~d}^{-1}$ \\
\hline $\begin{array}{l}\text { Ba flux } \\
\text { mass flux }\end{array}$ & $\begin{array}{l}\text { mmol-Ba m-2 } \mathrm{d}^{-1} \\
\mathrm{mg} \mathrm{m}^{-2} \mathrm{~d}^{-1}\end{array}$ \\
\hline
\end{tabular}

${ }^{*}$ Each to be reported separately for surface-tethered and neutrally-buoyant sediment traps, and as a function of depth

SeaBASS submission fields and units:

/fields=flux_PC, flux_PN, flux_POC, flux_PIC, flux_bSi, flux_Th_234, flux_mass,flux_pb_210,flux_Po_210,flux_ba, flux_P

/units = mmol m-2 d-1, mmol m-2 d-1, mmol m-2 d-1, mmol m-2 d-1, mmol m-2 d-1, dpm m-2 d-1, mg m-2 d-1, dpm m-2 d-1, dpm m-2 d-1, mmol m-2 d-1, mmol m-2 d-1 


\section{Key method references}

1.Buesseler, K. O. et al. An assessment of the use of sediment traps for estimating upper ocean particle fluxes. Journal of Marine Research 65, 345-416 (2007).

2.Lamborg, C. H. et al. The flux of bio-and lithogenic material associated with sinking particles in the mesopelagic "twilight zone" of the northwest and North Central Pacific Ocean. Deep Sea Research Part II: Topical Studies in Oceanography 55, 1540-1563 (2008).

3.Owens, S. A. et al. A new time series of particle export from neutrally buoyant sediments traps at the Bermuda Atlantic Time-series Study site. Deep Sea Research Part I: Oceanographic Research Papers 72, 34-47 (2013). 
Method: Particle flux to optical sediment traps

Document author and contact info: Meg Estapa, mestapa@skidmore.edu

Brief description of protocol and relation to export pathways: An upward-looking optical attenuance sensor (either bulk or imaging) or optical sediment trap (OST) is deployed on a quasiLagrangian platform and used to measure the accumulation rate of sinking particles while the platform drifts on a neutral surface. The rate of increase in accumulated particles' attenuance (ATN ${ }_{\text {OST }}$ flux) is converted to a particulate carbon flux ( $\mathrm{PC}_{\mathrm{ATN}}$ flux) using an empirical calibration function. These calibration data are generated by co-deploying OSTs on the same

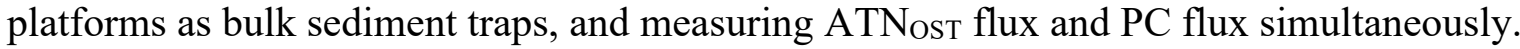
Independent estimates of attenuance flux will also be determined from brightfield microscopy on polyacrylamide gel sediment traps carried on these platforms. In EXPORTS, C-Rover 2000 beam transmissometers (WETlabs, specs here: http://www.seabird.com/c-rover-2000) will be used as bulk OSTs in the first (N. Pacific) field campaign, and imaging sensors will be added in the second (N. Atlantic) campaign. $\mathrm{PC}_{\mathrm{ATN}}$ flux is an estimate of the sum of all "sinking particle" pathways $(1,2$, and 3$)$.

Other contributing protocols: Bulk PC fluxes to sediment traps, visual characterization of sinking particles in gel traps.

Uncertainties and quality control concerns: Platform-flow interactions biasing collection of particles by size; integration of $F_{\mathrm{ATN}}$ measurement over sufficient area and time to achieve statistical confidence; inter-platform variability

Data products originating with this method:

\begin{tabular}{ll}
\hline Parameter & Units \\
\hline ATNost flux & $\mathrm{m}^{2} \mathrm{~m}^{-2} \mathrm{~d}^{-1}$ \\
ATN $_{\text {gel }}$ flux & $\mathrm{m}^{2} \mathrm{~m}^{-2} \mathrm{~d}^{-1}$ \\
PC $_{\text {ATN }}$ flux & $\mathrm{mmol}^{-} \mathrm{C} \mathrm{m}^{-2} \mathrm{~d}^{-1}$ \\
\hline
\end{tabular}

SeaBASS submission fields and units:

$/$ fields $=$ flux_ATN

/units $=\mathrm{m} 2 \mathrm{~m}-2 \mathrm{~d}-1$

\section{Key method references}

1. Estapa, M., Durkin, C., Buesseler, K., Johnson, R. \& Feen, M. Carbon flux from bio-optical profiling floats: Calibrating transmissometers for use as optical sediment traps. Deep Sea Research Part I: Oceanographic Research Papers 120, 100-111 (2017).

2. Bishop, J. K. B., Fong, M. B. \& Wood, T. J. Robotic observations of high wintertime carbon export in California coastal waters. Biogeosciences 13, 3109-3129 (2016). 
Method: Net community production, net primary production, and particulate inorganic carbon export from chemical tracer budgets using biogeochemical profiling floats

Document author and contact info: Andrea Fassbender, fassbender@mbari.org

Brief description of protocol and relation to export pathways: Float observations are used to evaluate bulk nitrate, dissolved oxygen (DO), dissolved inorganic carbon (DIC), and total alkalinity (TA) transformations throughout the water column and close chemical tracer budgets to estimate carbon export. Nitrate, $\mathrm{DO}$, and $\mathrm{pH}$ are directly measured by the floats while TA is estimated from salinity, temperature, and oxygen measurements and used with $\mathrm{pH}$ to calculate DIC. Additionally, float $\mathrm{pH}$ is used to estimate the partial pressure of carbon dioxide $\left(p \mathrm{CO}_{2}\right)$ at the ocean surface [Williams et al., 2017] to calculate air-sea $\mathrm{CO}_{2}$ exchange that contributes to the DIC budget. By closing multiple tracer budgets, it is possible to quantify the export of particulate and dissolved organic carbon (POC \& DOC) and particulate inorganic carbon (PIC) when integrated over the annual cycle, assuming steady state [Fassbender et al., 2016; Plant et al., 2016]. Net primary production (NPP) will also be estimated from float bio-optical sensors and regional chlorophyll fluorescence-particle backscattering-NPP relationships determined during the EXPORTS cruise.

Other contributing protocols: Analytical determination of: POC (combustion elemental analysis) and PIC (by difference using acidified filter); DOC and TOC (combustion catalytic oxidation), achieving POC by difference; absorption coefficient of CDOM (UV/Vis spectrophotometry); DIC (NDIR spectrophotometry), TA (open cell titration), and $\mathrm{pH}$ (UV/Vis spectrophotometry); empirical backscatter-POC relationships; and empirical chlorophyll fluorescence-particle backscattering-NPP relationships.

Uncertainties and quality control concerns: Unresolved physics, application of a TA algorithm in a calcium carbonate production region, $\mathrm{C}: \mathrm{N}$ and $\mathrm{C}: \mathrm{O}$ ratios applied in chemical tracer budgets, POC-backscatter relationship, NPP-chlorophyll relationship.

\section{Data products originating with this method:}

\begin{tabular}{ll}
\hline Parameter $^{*}$ & Units \\
\hline POC export & mol-C m $^{-2} \mathrm{yr}^{-1}$ (or day) \\
PIC export & mol-C m $\mathrm{yr}^{-1}$ (or day) \\
DOC export & mol-C m $\mathrm{yr}^{-1}$ (or day) \\
NCP (POC + DOC export) & mol-C m $\mathrm{yr}^{-1}$ (or day) \\
NPP & mol-C m $\mathrm{yr}^{-1}$ (or day)
\end{tabular}

${ }^{*}$ These parameters will be estimated every $\sim 3$ days during the EXPORTS cruise, and every $\sim 10$ days otherwise for an anticipated 3-5 years; however, the most robust results may come from integration over the seasonal/annual cycle.

Data quality control and access: Float sensor data quality control procedures are outlined in Johnson et al., 2017. Float data are available in near real time from the MBARI FloatViz and Argo websites: 
- https://www.mbari.org/science/upper-ocean-systems/chemical-sensor-group/floatviz/

- http://www.argodatamgt.org/Access-to-data/Description-of-all-floats2

Float 0949 (Dory) WMO \#: 5905988

Float 0948 (Nemo) WMO \#: TBD. The float has exhibited serious problems since the December 2018 redeployment. As a result, we may report data from the EXPORTS deployment, at which time the float will be issued a WMO number.

\section{Key method references}

Fassbender, A. J., C. L. Sabine, and M. F. Cronin (2016), Net community production and calcification from 7 years of NOAA Station Papa Mooring measurements, Global Biogeochem. Cycles, 30(2), 250-267, doi:10.1002/2015GB005205.

Johnson, K. S. et al. (2017), Biogeochemical sensor performance in the SOCCOM profiling float array, J. Geophys. Res. Ocean., 122(8), 6416-6436, doi:10.1002/2017JC012838.

Plant, J. N., K. S. Johnson, C. M. Sakamoto, H. W. Jannasch, L. J. Coletti, S. C. Riser, and D. D. Swift (2016), Net community production at Ocean Station Papa observed with nitrate and oxygen sensors on profiling floats, Glob. Biogeochem. Cycles, 30, 859-879, doi:10.1002/2015GB005349.

Williams, N. L. et al. (2017), Calculating surface ocean $p \mathrm{CO}_{2}$ from biogeochemical Argo floats equipped with pH: An uncertainty analysis, Global Biogeochem. Cycles, in press, 1-14, doi:10.1002/2016GB005541. 
Method: Discrete dissolved inorganic carbon (DIC) $-\left(\mu \mathrm{mol} \mathrm{kg}{ }^{-1}\right)$

Document author and contact info: Andrea Fassbender, fassbender@mbari.org

Brief description of protocol and relation to export pathways: Discrete DIC samples were collected into $500 \mathrm{~mL}$ and $250 \mathrm{~mL}$ borosilicate bottles and preserved with $200 \mu \mathrm{L}$ and $100 \mu \mathrm{L}$, respectively, of saturated mercuric chloride for later analysis at the Monterey Bay Aquarium Research institute (MBARI). A custom analysis system was used in which a Kloehn V6 syringe pump ( $5 \mathrm{~mL}$ syringe) handles fluid control, delivering $1.75 \mathrm{~mL}$ of sample to a custom designed $\mathrm{CO}_{2}$ stripping chamber. $200 \mu \mathrm{L}$ of $5 \%$ phosphoric acid $\left(\mathrm{H}_{3} \mathrm{PO}_{4}\right)$ is subsequently added to the $\mathrm{CO}_{2}$ stripping chamber for acidification of the sample. $\mathrm{CO}_{2}$-free gas is then bubbled through the acidified sample and the evolved $\mathrm{CO}_{2(\mathrm{~g})}$ is delivered to a LiCOR 7000 Nondispersive Infrared gas analyzer for measurement. Carrier gas flow rate is controlled using a mass flow controller. The DIC concentration of the sample is proportional to the integral of the $\mathrm{LiCOR} \mathrm{CO}_{2(\mathrm{~g})}$ sample peak. All samples were run in triplicate, and the results were averaged. Instrument performance was monitored by measuring Certified Reference Material (CRM; provided by Andrew Dickson at SIO) approximately every hour. The average accuracy of the instrument relative to CRMs is better than $1 \mu \mathrm{mol} \mathrm{kg}{ }^{-1}$.

The following systematic, concentration-dependent correction for samples analyzed on our laboratory instrumentation, was applied: $\mathrm{DIC}_{\text {Corrected }}=\mathrm{DIC}_{\text {Sample }}-\left(\mathrm{DIC}_{\text {Sample }}-\mathrm{CRM}\right) \times-0.023$. The standard error of the slope $(-0.023 \pm 0.002)$ results in correction uncertainties ranging from \pm 0.2 to $\pm 0.75 \mu \mathrm{mol} \mathrm{kg}{ }^{-1}$.

Discrete DIC samples are used to validate DIC values estimated from profiling float $\mathrm{pH}$ measurements and TA estimates. A biogeochemical tracer budget for DIC is used to quantify carbon export over the float lifetimes.

\section{Other contributing protocols:}

Uncertainties and quality control concerns: Measurement precision was estimated by analyzing sets of replicate samples drawn from the same Niskin bottle during rosette casts. The average standard deviation between replicate sets was found to be $\pm 0.02 \mu \mathrm{mol} \mathrm{kg}^{-1}(\mathrm{n}=2)$. Sampling reproducibility was estimated by analyzing sets of replicate samples drawn from different Niskin bottles during rosette casts. The average standard deviation between replicate pairs and was found to be $\pm 1.3 \mu \mathrm{mol} \mathrm{kg} \mathrm{kg}^{-1}(\mathrm{n}=22)$. Combining instrument accuracy, sampling reproducibility, and the concentration-dependent correction uncertainty, the estimate of overall measurement uncertainty is $\pm 1.8 \mu \mathrm{mol} \mathrm{kg} \mathrm{kg}^{-1}$.

\section{Key method references:}

Dickson, A. G., J. D. Afghan, and G. C. Anderson (2003), Reference materials for oceanic $\mathrm{CO}_{2}$ analysis: a method for the certification of total alkalinity, Mar. Chem., 80(2-3), 185-197, doi:10.1016/S0304-4203(02)00133-0.

Dickson, A. G., C. L. Sabine, and J. R. Christian (Eds.) (2007), Guide to best practices for ocean $\mathrm{CO}_{2}$ measurements, PICES Special Publication 3. 
O'Sullivan, D. W., and F. J. Millero (1998), Continual measurement of the total inorganic carbon in surface seawater, Mar. Chem., 60(1-2), 75-83, doi:10.1016/S0304-4203(97)00079-0. 
Method: Discrete $\mathrm{pH}-$ (no units)

Document author and contact info: Andrea Fassbender, fassbender@mbari.org

Brief description of protocol and relation to export pathways: Discrete samples for $\mathrm{pH}$ were collected into $250 \mathrm{~mL}$ borosilicate bottles and analyzed aboard the $R / V$ Sally Ride spectrophotometrically using an automated system designed after the one described in Carter et al., [2013]. The temperature of the sample was held constant at $20^{\circ} \mathrm{C}$ using a $10-\mathrm{cm}$ jacketed cell, and every sample was immersed in a $20^{\circ} \mathrm{C}$ water bath for at least 25 minutes before analysis. An indicator dye (purified m-cresol purple from Dr. Robert Byrne's lab) solution ( $2 \mathrm{mM}$ ) was used to assess sample $\mathrm{pH}$. The sample $\mathrm{pH}$ perturbation caused by dye addition was quantified by adding

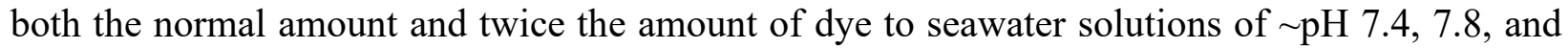
8.1. The dye perturbation was conducted prior to the cruise, during the cruise, and after the cruise yielding an average perturbation (relative to the isosbestic point, $\mathrm{A}_{\text {iso }}$ ) of: $\Delta \mathrm{pH} / \Delta \mathrm{A}_{\text {iso }}=-0.0462 \times$ $\mathrm{pH}+0.344$.

Multiple laboratory comparisons between the ZEISS MMS spectrophotometer used on the cruise and the standard, state-of-the-art Agilent 8453 spectrophotometer used in the laboratory yielded the following $\mathrm{pH}$ dependent correction: $\Delta \mathrm{pH}_{\text {Agilent-MMS }}=6.33 \times 10^{-3} \times \mathrm{pH}_{\text {Agilent }}-0.0406$.

Discrete $\mathrm{pH}$ samples were used to validate independent, algorithm approaches (e.g., Juranek et al., 2011; Carter et al., 2016, 2017; Sauzède et al., 2017; Bittig et al., 2018) for estimating pH to correct $\mathrm{pH}$ sensor drift on profiling floats throughout their lifetimes. Float $\mathrm{pH}$ observations are used with TA estimates to calculate dissolved inorganic carbon (DIC) for biogeochemical tracer budget assessment of carbon export. Additionally, float $\mathrm{pH}$ measurements and TA estimates are used to calculate sea surface $p \mathrm{CO}_{2}$ to quantify the air-sea exchange of carbon dioxide, which is relevant for the DIC tracer budget.

\section{Other contributing protocols: N/A.}

Uncertainties and quality control concerns: Measurement precision was estimated by analyzing sets of duplicate samples (same Niskin bottle) from each rosette cast $(n=45)$. The average standard deviation between duplicate pairs and was found to be \pm 0.0005 . Sampling reproducibility was estimated by analyzing sets of replicate samples (different Niskin bottle) from some rosette casts $(n=21)$. The average standard deviation between replicate pairs and was found to be \pm 0.0009 .

\section{Key method references:}

Bittig, H. C., T. Steinhoff, H. Claustre, B. Fiedler, N. L. Williams, R. Sauzède, A. Körtzinger, and J.-P. Gattuso (2018), An Alternative to Static Climatologies: Robust Estimation of Open Ocean CO2 Variables and Nutrient Concentrations From T, S, and O2 Data Using Bayesian Neural Networks, Front. Mar. Sci., 5(September), 1-29, doi:10.3389/fmars.2018.00328.

Carter, B. R., J. A. Radich, H. L. Doyle, and A. G. Dickson (2013), An automated system for spectrophotometric seawater pH measurements, Limnol. Oceanogr. Methods, 11(1), 16-27, doi:10.4319/lom.2013.11.16.

Carter, B. R., N. L. Williams, A. R. Gray, and R. A. Feely (2016), Locally interpolated alkalinity 
regression for global alkalinity estimation, Limnol. Oceanogr. Methods, 14(4), 268-277, doi:10.1002/lom3.10087.

Carter, B. R., R. A. Feely, N. L. Williams, A. G. Dickson, M. B. Fong, and Y. Takeshita (2017), Updated methods for global locally interpolated estimation of alkalinity, $\mathrm{pH}$, and nitrate, Limnol. Oceanogr. Methods, doi:10.1002/lom3.10232.

Juranek, L. W., R. A. R. A. Feely, D. Gilbert, H. J. Freeland, and L. A. Miller (2011), Real-time estimation of $\mathrm{pH}$ and aragonite saturation state from Argo profiling floats: Prospects for an autonomous carbon observing strategy, Geophys. Res. Lett., 38(17), n/a-n/a, doi:10.1029/2011GL048580.

Sauzède, R., H. C. Bittig, H. Claustre, O. Pasqueron de Fommervault, J.-P. Gattuso, L. Legendre, and K. S. Johnson (2017), Estimates of Water-Column Nutrient Concentrations and Carbonate System Parameters in the Global Ocean: A Novel Approach Based on Neural Networks, Front. Mar. Sci., 4, doi:10.3389/fmars.2017.00128. 
Method: Discrete total alkalinity $(\mathrm{TA})-\left(\mu \mathrm{mol} \mathrm{kg} \mathrm{kg}^{-1}\right)$

Document author and contact info: Andrea Fassbender, fassbender@mbari.org

Brief description of protocol and relation to export pathways: Discrete TA samples were collected into $500 \mathrm{~mL}$ and $250 \mathrm{~mL}$ borosilicate bottles and preserved with $200 \mu \mathrm{L}$ and $100 \mu \mathrm{L}$, respectively, of saturated mercuric chloride for later analysis at the Monterey Bay Aquarium Research institute (MBARI). TA was analyzed using a Metrohm 855 automated titrator following standard open cell alkalinity titration procedures. The titrant was comprised of $0.1 \mathrm{M}$ hydrochloric acid $(\mathrm{HCl})$ in a $0.7 \mathrm{M}$ sodium chloride $(\mathrm{NaCl})$ background solution. The titration temperature was held constant at $20.0 \pm 0.2{ }^{\circ} \mathrm{C}$ throughout the titration. The temperature of the sample is measured immediately upon delivery to the jacketed cell for later sample mass determination using density and volume. All samples were run in triplicate, and the results were averaged. Certified Reference Material (CRM; provided by Andrew Dickson at SIO) were run every 10 samples (approximately once every hour) to ensure accuracy. The average accuracy of the instrument relative to CRMs is better than $4 \mu \mathrm{mol} \mathrm{kg} \mathrm{k}^{-1}$.

Discrete TA samples were used to validate TA estimates derived from algorithms [Carter et al., 2016, 2017; Sauzède et al., 2017; Bittig et al., 2018] applied to profiling float observations that are used to close biogeochemical tracer budgets and quantify carbon export.

\section{Other contributing protocols:}

Uncertainties and quality control concerns: Measurement precision was estimated by analyzing sets of replicate samples drawn from the same Niskin bottle during rosette casts. The average standard deviation between replicate sets was found to be $\pm 0.04(n=2)$. Sampling reproducibility was estimated by analyzing sets of replicate samples drawn from different Niskin bottles during rosette casts. The average standard deviation between replicate pairs and was found to be \pm 2.0 ( $\mathrm{n}$ $=23$ ).

\section{Key method references:}

Bittig, H. C., T. Steinhoff, H. Claustre, B. Fiedler, N. L. Williams, R. Sauzède, A. Körtzinger, and J.-P. Gattuso (2018), An Alternative to Static Climatologies: Robust Estimation of Open Ocean CO2 Variables and Nutrient Concentrations From T, S, and O2 Data Using Bayesian Neural Networks, Front. Mar. Sci., 5(September), 1-29, doi:10.3389/fmars.2018.00328.

Carter, B. R., N. L. Williams, A. R. Gray, and R. A. Feely (2016), Locally interpolated alkalinity regression for global alkalinity estimation, Limnol. Oceanogr. Methods, 14(4), 268-277, doi:10.1002/lom3.10087.

Carter, B. R., R. A. Feely, N. L. Williams, A. G. Dickson, M. B. Fong, and Y. Takeshita (2017), Updated methods for global locally interpolated estimation of alkalinity, $\mathrm{pH}$, and nitrate, Limnol. Oceanogr. Methods, doi:10.1002/lom3.10232.

Sauzède, R., H. C. Bittig, H. Claustre, O. Pasqueron de Fommervault, J.-P. Gattuso, L. Legendre, and K. S. Johnson (2017), Estimates of Water-Column Nutrient Concentrations and Carbonate System Parameters in the Global Ocean: A Novel Approach Based on Neural Networks, Front. Mar. Sci., 4, doi:10.3389/fmars.2017.00128. 
Method: High-Resolution Nitrate Profiles on CTD Rosette $-\left(\mu \mathrm{mol} \mathrm{kg} \mathrm{kg}^{-1}\right)$

Document author and contact info: Andrea Fassbender, fassbender@mbari.org

Brief description of protocol and relation to export pathways: Vertical water column profiles of nitrate at $\sim 1 \mathrm{~m}$ resolution were obtained at each sampling station using an In Situ Ultraviolet Sensor (ISUS) for nitrate [Johnson and Coletti, 2002]. The instrument was custom built in the Chemical Sensor Laboratory at the Monterey Bay Aquarium Research Institute and calibrated in the laboratory prior to the cruise. The ISUS was mounted vertically on the rosette frame approximately $50 \mathrm{~cm}$ above the SeaBird Electronics 911 conductivity-temperature-depth sensor (CTD). Nitrate concentration was calculated from the ISUS ultraviolet absorbance spectra (200-240 nm) using an updated algorithm, where the bromide spectra is calculated from salinity [Sakamoto et al., 2009]. Corrections for the pressure dependence of bromide ultraviolet absorption were also included [Sakamoto et al., 2017]. The sensor collected data at approximately $1 \mathrm{~Hz}$. Raw ISUS nitrate data and contemporaneous, quality-controlled CTD data (time stamp matched) were used to compute the final nitrate values. Results from the downcast were binned at a $1 \mathrm{~m}$ interval to comprise the final profile data.

High-resolution nitrate profiles from ISUS sensor measurements on the CTD rosette were compared to nitrate profiles from two biogeochemical profiling floats in the region. The high-resolution nitrate profiles provide context about vertical nutrient gradients, which can be challenging to capture from lower-resolution (e.g., 5-10 m) observations, such as on the floats.

\section{Other contributing protocols:}

Uncertainties and quality control concerns: To be completed.

\section{Data products originating with this method: $\mathrm{NO3}\left(\mathrm{mmol} / \mathrm{m}^{\wedge} 3\right)$}

\section{Key method references}

1) Johnson, K. S., and L. J. Coletti (2002), In situ ultraviolet spectrophotometry for high resolution and long-term monitoring of nitrate, bromide and bisulfide in the ocean, Deep Sea Res. Part I Oceanogr. Res. Pap., 49(7), 1291-1305, doi:10.1016/S0967-0637(02)00020-1.

2) Sakamoto, C. M., K. S. Johnson, and L. J. Coletti (2009), Improved algorithm for the computation of nitrate concentrations in seawater using an in situ ultraviolet spectrophotometer, Limnol. Oceanogr. Methods, 7, 132-143.

3) Sakamoto, C. M., K. S. Johnson, L. J. Coletti, and H. W. Jannasch (2017), Pressure correction for the computation of nitrate concentrations in seawater using an in situ ultraviolet spectrophotometer, Limnol. Oceanogr. Methods, 15(10), 897-902, doi:10.1002/lom3.10209. 
Method: Underway Nitrate $\left(\mu \mathrm{mol} \mathrm{kg}^{-1}\right)$ and $\mathrm{pH}$ (unitless)

Document author and contact info: Andrea Fassbender, fassbender@mbari.org

Brief description of protocol and relation to export pathways: A prototype, dual nitrate-pH system was integrated into the ship's underway seawater line. Nitrate was measured using an In Situ Ultraviolet Sensor (ISUS) (1), and pH was measured using a Deep-Sea-Durafet (DSD) (2). A SeaBird Electronics 45 thermosalinograph was located directly downstream $(<10 \mathrm{~cm})$ of the system flowcell to make underway temperature and salinity measurements near the sensors. The instruments were powered through an isolation transformer to prevent ground loop issues. The system was polled using a LabView interface, and measurements were made every 15 to 20 seconds. The $\mathrm{pH}$ sensor was calibrated by taking discrete samples from the underway line $(\mathrm{n}=9)$ throughout the cruise.

Underway nitrate and $\mathrm{pH}$ measurements were used to identify fronts. Additionally, the underway observations were compared to those on two biogeochemical profiling floats deployed in the region.

Other contributing protocols: High-Resolution Nitrate Profiles on CTD Rosette

Uncertainties and quality control concerns: To be completed.

\section{Data products originating with this method: NO3 $\left(\mathrm{mmol} / \mathrm{m}^{\wedge} 3\right), \mathrm{pH}$ (none)}

\section{Key method references}

1) Johnson KS, Coletti LJ (2002) In situ ultraviolet spectrophotometry for high resolution and long-term monitoring of nitrate, bromide and bisulfide in the ocean. Deep Sea Res Part I Oceanogr Res Pap 49(7):1291-1305.

2) Johnson KS, et al. (2016) Deep-Sea DuraFET: A Pressure Tolerant pH Sensor Designed for Global Sensor Networks. Anal Chem 88(6):3249-3256. 


\section{NASA EXPORTS North Pacific - FRR \& PAR \\ R/V Roger Revelle, Aug-Sep 2018}

Prepared by: James Fox, Department of Microbiology, Oregon State University

Email: james.fox@oregonstate.edu

\section{Introduction}

This dataset contains Fast Repetition Rate (FRR) fluorescence data, incident Photosynthetically active radiation (PAR) data, and sea surface temperature data for NASA EXPORTS north pacific field campaign.

FRR and SST data were collected continuously during the cruise using sample water drawn from the ship's flow through seawater system.

PAR data reported here were collected with a Licor cosine collector positioned on the top rail of the port side aerosol van on the upper forward weather deck of the Atlantis, providing measurements relatively free of any ship shading. PAR data are reported in units of uM quanta/cm^2/s.

The FRR was characterized by the manufacturer, Zbignew Kolber. The Licor sensor was calibrated by Licor shortly before the cruise. Data submitted to SeaBASS from the FRR include initial fluorescence (FO), Maximum Fluorescence (Fm), Variable Fluorescence (Fv/Fm), and the functional cross section of photosystem II (Sigma-PSII). These properties were derived from the single turnover flash sequence from the FRR. 16 individual flash sequence results were averaged into each reported value. Seawater sample analyzed by the FRR was exposed to darkness from the time the water was drawn into the ship to the time of measurement (estimated as a few minutes). 
Method: Volume Scattering Function at 9 angles (VSF-9)

Document author and contact info: Scott Freeman (scott.freeman@nasa.gov)

Brief description of protocol: The ECO volume scattering function meter measures scattering at nine angles at $532 \mathrm{~nm}$. The vsf- 9 uses LEDs modulated at $1 \mathrm{kHz}$ for source light. The source light enters the water volume and scattered light is detected by a detector positioned such that the acceptance angle forms a specific intersection with the source beam.

\section{Calibration}

The calibration applied will be conducted by M. Twardowski and company using NIST-traceable microsphere beads. We will also have an intercalibration exercise before and after the cruise. The angles, in degrees, are: 62, 76, 80, 90, 110, 120, 140, 160, 170.

\section{Deployment Methodology}

The package is lowered to $5-10$ meters to thermally equilibrate and de-gas. The instrument is switched on after a time delay, then the package is brought to the surface and a slow descent $\left(\sim 0.3 \mathrm{~m}^{-1}\right)$ is started. Near the seafloor or approximately 100 meters, the package is held for a minute before being raised at $\sim 0.5 \mathrm{~m}^{-1}$ or faster. Only downcast data are used.

The VSF-9 is mounted to the FSG Wetlabs IOP cage, facing downward and positioned such that the cage reflects none of the light emitted by the LEDs. Data are stored in a Wetlabs DH-4 and offloaded after each deployment

\section{4) Derived Parameters}

Particulate VSF at 9 angles, $532 \mathrm{~nm}\left(\beta(\theta, 532)_{p}\right)$ [1/m/sr], after subtraction of VSF water (Zhang et al, 2009); and integrated particulate backscatter at $532 \mathrm{~nm}\left(b_{b p 532}\right)[1 / \mathrm{m}]$.

Uncertainties and quality control concerns:

Uncertainty is reported as standard deviation in a one-meter bin.

\section{5) References}

ECO user's manual. Retrieved from http://www.wetlabs.com/sites/default/files/documents/WetlabsECOTripletwEN.pdf

Sullivan, J.M., M.S. Twardowski, P.L. Donaghay, and S.A. Freeman, 2005. Using optical scattering to discriminate particle types in coastal waters, Applied Optics,44,1667-1680.

Sullivan, J., M. Twardowski, J.R.V. Zaneveld, and C. Moore. 2013. Measuring optical backscattering in water, In: A. Kokhanovsky (Ed), Light Scattering Reviews 7: Radiative Transfer and Optical Properties of Atmosphere and Underlying Surface, Springer Praxis Books, DOI 10.1007/978-3-642-21907-8_6, pp. 189-224.

Zhang, X., L. Hu, and M. He, "Scattering by pure seawater: Effect of salinity," 2009. Optics Express 17, 5698-5710. 
Method: Microbial metagenomics and metatranscriptomics

Document author and contact info: Scott Gifford, sgifford@email.unc.edu

Brief description of protocol and relation to export pathways: The primary objective is to characterize prokaryote community composition via metagenomics and microbes' physiological and metabolic responses to the carbon pool via community transcriptome sequencing (metatranscriptomics). Linkages between microbial community composition and metabolic activities with respiration, primary productivity, and net community production rate measurements will illuminate the underlying factors controlling carbon availability for export. Seawater samples (4L) will be fractioned between particle-associated and free-living bacterial communities by filtration through $5 \mu \mathrm{m}$ and $0.22 \mu \mathrm{m}$ filters, respectively, and then immediately flash freezing both filters in liquid nitrogen. DNA will be extracted using MoBio's DNA isolation kit. RNA extractions will use Ambion's mirVana kit. For both DNA and RNA samples, internal standards will be added just prior to extraction. Internal standard recovery efficiencies after sequencing will enable reads of gene or transcript abundances to be placed on a per cell or liter basis (Gifford et al., 2011, 2013). After extraction, DNA libraries will be prepared using KAPA Biosystem's Hyperplus kit with Roche barcodes. RNA samples will be rRNA depleted using the custom rRNA subtraction protocol of Stewart et al. (2010) and libraries prepared using EpiCentre's ScriptSeq v2 kit. After pooling, libraries will be sequenced via the Illumina HiSeq 4000 platform at UNC's High-Throughput Sequencing Facility. Metagenomes will be sequenced to a target depth of 50-100 million reads per sample. Metatranscriptomes will be sequenced to a target depth of 10-20 million reads per sample. After sequencing, reads will undergo quality control trimming and pairing using custom workflows on the Gifford lab's slipstream appliance. Metagenomic reads will assembled into contigs using MetaBAT (bitbucket.org/berkeleylab/metabat). Taxonomic identification and putative protein function will be annotated via Diamond homology searches against NCBI's nr and RefSeq database. Metatranscriptomic reads will be mapped to metagenomic contigs using Bowtie.

Other contributing protocols: DNA sequencing for $16 \mathrm{~S}$ and $18 \mathrm{~S}$, metagenomics and metatranscriptomics, bacterial abundance, DOC concentrations, marine snow characterization.

Uncertainties and quality control concerns: RNAs have short half-lives (minutes) and are highly susceptible to degradation by RNAases, which are ubiquitous in the environment. Per liter and per cell gene or transcript abundance estimates from meta-omic datasets requires good measurements of filtration volumes and stringent extraction protocols.

Data products originating with this method:

Parameter* Units

Taxa abundances

Transcript abundances $\quad$ Transcripts $\mathrm{L}^{-1}$ or Transcripts genome-equivalent ${ }^{-1}$

Gene abundances Genes L-1

\section{Key method references}

Gifford SM, Sharma S, Rinta-Kanto JM, Moran MA 2011. Quantitative analysis of a deeply sequenced marine microbial metatranscriptome. The ISME Journal 5(3):461-472.

Gifford SM, Satinsky BM, Moran MA 2013. Quantitative Microbial Metatranscriptomics. In Environmental Microbiology: Methods and Protocols, Second Edition. Springer Publ. p213-229. 
Method: $\mathrm{O}_{2}$ drawdown community and bacterial respiration rates

Document author and contact info: Scott Gifford, sgifford@email.unc.edu

Brief description of protocol and relation to export pathways: The primary objective is to measure carbon remineralization rates of the community and bacterioplankton in both the freeliving and particulate associated size fractions. These rates will help constrain the remineralization component of NCP and reduction in carbon export potential. Biological Oxygen Demand (BOD) bottles $(60 \mathrm{ml})$ containing PreSens oxygen optode sensors spots will be acid washed and triple rinsed with sample seawater before each incubation. The bottles will be filled with either whole (unfiltered) or $5 \mu \mathrm{m}$ filtered seawater directly from the Niskin bottles. After filling, the BOD bottles are capped with a glass stopper and submerged in a dark water bath set at in situ temperature. $\mathrm{O}_{2}$ concentrations will be measured every 4 to 6 hours for 48 hours using the PreSens Fibox Fiberoptic sensor to determine oxygen drawdown (Edwards et al. 2011). Using this technique, we have previously measured rates over a range of productivity gradients, from highly productive upwelling systems to open ocean oligotrophic systems, where respiration rates are often $1 \mu \mathrm{M} \mathrm{O}_{2} \mathrm{~d}^{-1}$ or less.

Other contributing protocols: DNA sequencing for $16 \mathrm{~S}$ and $18 \mathrm{~S}$, metagenomics and metatranscriptomics, bacterial abundance, DOC concentrations, marine snow characterization.

Uncertainties and quality control concerns: Low DOC standing stocks can introduce two issues: 1) Respiration rates $<1 \mu \mathrm{M}$ per day can be difficult to resolve. We have previously overcome this limitation by increasing the incubation time to 48 hours. However, one must ensure that drawdown is linear over this period and bottle effects are not biasing results. 2) DOC contamination: The low ambient DOC concentrations mean that even small amounts of carbon contamination can artificially increase rates.

$\begin{array}{ll}\begin{array}{l}\text { Data products originating with this method: } \\ \text { Parameter* }\end{array} & \text { Units } \\ \text { Community respiration } & \text { mmol-C m } \mathrm{m}^{-3} \mathrm{~d}^{-1} \\ \text { Free-Living bacterial respiration } & \mathrm{mmol}-\mathrm{C} \mathrm{m}^{-3} \mathrm{~d}^{-1} \\ \text { Non-sinking particle respiration } & \mathrm{mmol}-\mathrm{C} \mathrm{m}^{-3} \mathrm{~d}^{-1} \\ \text { Small-sinking particle respiration } & \mathrm{mmol}-\mathrm{C} \mathrm{m}^{-3} \mathrm{~d}^{-1}\end{array}$

\section{Key method references}

Edwards BR, Reddy CM, Camilli R, Carmichael CA, Longnecker K, Van Mooy BA (2011). Rapid microbial respiration of oil from the Deepwater Horizon spill in offshore surface waters of the Gulf of Mexico. Environmental Research Letters, 6(3), 035301

Pomeroy, LR, Sheldon JE, Sheldon, WM, Peters D (1995) Limits to growth and respiration of bacterioplankton in the Gulf of Mexico. Marine Ecology Progress Series Vol 117 p. 259 


\section{Method: Phytoplankton concentrations and elemental stocks}

Document author(s) and contact info: Jason Graff, jrgraff@science.oregonstate.edu, Michael Behrenfeld, mjb@science.oregonstate.edu

\section{Brief description of protocol and relation to export pathways:}

Phytoplankton cell concentrations for four major groups (Prochlorococcus, Synechococcus, picoeukaryotes, and nanoeukaryotes) will be determined using a Becton Dickinson Influx Cells Sorter (BD ICS) flow cytometer. Whole seawater samples will be analyzed for multiple depth profiles each day. At each depth, $4 \mathrm{ml}$ of seawater are to be collected into sterile $5 \mathrm{ml}$ polypropylene tubes (3x rinsed) and immediately stored at $\sim 40^{\circ} \mathrm{F}$ in the dark until analysis on the BD ICS. Groups specific identifications are determined based on fluorescence and scattering properties. Our ICS is equipped with a blue $(488 \mathrm{~nm})$ laser and four detectors; forward scatter (FSC) with enhanced small particle detection, side scatter (SSC), fluorescence at $692+/-40 \mathrm{~nm}$ (FL692) and fluorescence at $530+/-40 \mathrm{~nm}$ (FL530). Sample flow rates are required for normalizing cell counts collected over time to volume and are calculated from volumetric changes in a $1 \mathrm{ml}$ water sample over a known time (60 s or greater) using a pipettor to determine the volume of water lost. The ICS is calibrated with fluorescent beads following standard operating protocols (Spherotech, SPHERO ${ }^{\mathrm{TM}} 3.0 \mu \mathrm{m}$ Ultra Rainbow Calibration Particles and Drop Delay beads are used to calibrate instrument timing for cells sorting).

Our new method for measuring phytoplankton carbon and nitrogen $\left(\mathrm{C}_{\text {phyto }}, \mathrm{N}_{\text {phyto }}\right)$ involves separating phytoplankton from natural assemblages using the BD ICS, which is a particle sorting flow cytometer, and then performing elemental analysis on the sorted sample using a Shimadzu TOCN analyzer (full details are published in Graff et al. 2012 and Graff et al. 2015). Briefly, prior to sample analysis and sorting, whole seawater is passed through a $64 \mu \mathrm{m}$ screen to eliminate large, but generally rare, cells and particles that cannot pass through the $100 \mu \mathrm{m}$ nozzle that we typically use for this method. Sorted cells, and the associated sheath fluid in which the cells are passed to for analysis, are collected and then stored in LN or at $-80 \mathrm{C}$ until analysis. A 'blank' or correction sample of the carrier sheath fluid is collected immediately following sorting of each sample to account for non-target carbon and nitrogen. These samples are also frozen with the sorted cell samples until elemental analysis. Samples from the surface mixed layer and from specific depths will be targeted for direct phytoplankton elemental analysis. The contribution of larger cells to biomass can be made from size fractionated chlorophyll and carbon estimates of phytoplankton from the Imaging Flow Cytobot (IFCB). Net primary production and phytoplankton biomass $\left(\mathrm{C}_{\text {phyto }}\right.$ - in units of carbon per volume $)$ occupy the first step in the transfer of inorganic carbon to the diverse ecological pathways of organic carbon. Traditional approaches for quantifying phytoplankton biomass from retrievals of surface chlorophyll are compromised because of drastic seasonal changes in cellular chlorophyll:carbon (Chl:C) ratios (Westberry et al. 2016). This variability is driven by seasonality in mixed layer light conditions, severity of iron stress, and species compositional shifts, and it has significantly impacted our understanding of carbon cycling in the region. Our direct measurements of the community structure and biomass, coupled with optical proxies of carbon stocks, are the important first steps to understanding carbon pathways leading to export. 
Other contributing protocols: ${ }^{14} \mathrm{C}$ NPP and dilution experiment derived $\mu ; \mathrm{NPP} / \mu=$ $\mathrm{C}_{\text {phyto }}$, optical proxies for $\mathrm{C}_{\text {phyto }}$ - specifically particulate backscattering $\left(\mathrm{b}_{\mathrm{bp}}\right), \mathrm{IFCB}$ analysis of overlapping and larger phytoplankton

Uncertainties and quality control concerns: Multiple samples collected each day for cell counts and elemental analysis will constrain daily values and the characterization of changes occurring throughout each 8-day epoch planned for the EXPORTS field program.

Data products originating with this method: None - all currently exist within the SeaBASS framework.

\begin{tabular}{|l|l|}
\hline Parameter & Units \\
\hline Concentration of Synechococcus & cells L-1 \\
\hline Concentration of Prochlorococcus & cells L-1 \\
\hline Concentration of picoeukaryotes & cells L-1 \\
\hline Concentration of nanoeukaryotes & cells L-1 \\
\hline C_phyto & pg L-1 \\
\hline N_phyto & pg L-1 \\
\hline
\end{tabular}

\section{Key method references:}

Graff JR, Milligan AJ, Behrenfeld MJ. 2012. The measurement of phytoplankton biomass using flow-cytometric sorting and elemental analysis of carbon. Limnol Oceanogr Methods 10:910-920.

Graff, J.R., Westberry, T.K., Milligan, A.J., Brown, M.B., Dall'Olmo, G., van DongenVogels, V., Reifel, K.M. and Behrenfeld, M.J., 2015. Analytical phytoplankton carbon measurements spanning diverse ecosystems. Deep Sea Research Part I:

Oceanographic Research Papers, 102, pp.16-25. 
Method: Photoacclimation

Document author and contact info:

Jason Graff

jrgraff@science.oregonstate.edu

$541-737-4090$

\section{Brief description of protocol and relation to export pathways:}

Growth, grazing, and accumulation rates are targeted parameters in the EXPORTS program for relating surface plankton properties to carbon export to the deep ocean. Phytoplankton are able to rapidly respond to changes in mixed layer growth irradiance through a process known as photoacclimation and can skew rate estimates based on chlorophyll (Chl) if not properly taken into account. Our primary objective is to measure phytoplankton photoacclimation by observing changes in phytoplankton specific $\mathrm{Chl}$ to carbon $\left(\mathrm{C}_{\text {phyto }}\right)$ ratios or their proxies of fluorescence (FL) and forward scatter (FSC) from in-situ and incubated whole seawater samples. In-situ sampling and on-deck experiments, with and without iron additions, will be performed to track changes in Chl: $\mathrm{C}_{\text {phyto }}$ and FL:FSC ratios in response to different light treatments and in-situ changes in growth irradiance. Multiple light treatments in on-deck incubations allow us to determine the growth irradiance to which cells were acclimated at the time of collection and the change due to experimental light conditions. This is critical for correctly assessing the balance between $\mathrm{Chl}$ based phytoplankton growth rates and zooplankton grazing rates in on-deck incubations, e.g. dilution experiments. In-situ tracking of $\mathrm{Chl}: \mathrm{C}_{\text {phyto }}$ can provide corrections for net accumulation rates based on Chl or FL alone. Specific measurements that will be made include high performance liquid chromatography (HPLC) $\mathrm{Chl}, \mathrm{C}_{\text {phyto }}$ using cell sorting approaches, and phytoplankton FL and FSC parameters from flow cytometry.

Other contributing protocols: Establishing active mixing and/or mixed layer depths will be critical for evaluating the light environment experienced by cells. Contributing assets that do not include discrete measurements include optical parameters measured via in-line flow through seawater, water column profiles, and autonomous vehicles.

\section{Uncertainties and quality control concerns:}

TBD - these have yet to be addressed using this protocol and will be determined from recently completed experiments.

\section{Data products originating with this method}

Percent correction (+/-) for Chl based rates of phytoplankton accumulation in-situ and on-deck experiments.

\section{Key method references.}

Graff, J.R. and M.J. Behrenfeld. (in prep) Deep mixing and re-stratification events drive vertical differentiation in phytoplankton physiology (and accumulation) in the North Atlantic ocean

Graff, J.R., T. K. Westberry, A.J. Milligan, M.B. Brown, G. Dall'Olmo, K.M. Reifel, M.J. Behrenfeld. 2016. Photoacclimation of natural phytoplankton communities. Marine Ecology Progress Series 542, 51-62. doi://10.3354/meps11539 
Graff, J.R., T. K. Westberry, A.J. Milligan, M.B. Brown, G. Dall'Olmo, V. van Dongen-Vogels, K.M. Reifel, M.J. Behrenfeld. 2015. Analytical phytoplankton carbon measurements spanning diverse ecosystems.

Deep-Sea Research Part I 102, 16-25. 
Method: Volume Scattering Function measurements and particle size distributions.

Document Author and Contact Info: Deric Gray (deric.gray@nrl.navy.mil)

Brief Description of Instrument Protocol: The volume scattering function (VSF) of seawater will be measured with two instruments: the Multi-Spectral Volume Scattering Meter (MVSM), a prototype instrument developed at the Marine Hydrophysical Institute in Sevastopol, Crimea, and the LISST-100X (Sequoia Scientific). The MVSM measures the VSF in $0.25^{\circ}$ increments over the angles from $0.5-179^{\circ}$, and at eight wavelengths: $443,488,510,532,555,565,590$, and $620 \mathrm{~nm}$. The LISST (operating at $532 \mathrm{~nm}$ ) measures the VSF from $0.1-13^{\circ}$ in 32 angular intervals. The data from both instruments are combined to produce the VSF from 0.1 to $179^{\circ}$. The resulting VSF is then inverted to derive particle size distributions (PSD) from $0.02-200 \mu \mathrm{m}$.

Deployment Methodology: Discrete water samples will be collected from the CTD rosette and measured with the instruments in the lab. Approximately $10 \mathrm{~L}$ of water is needed from each depth, and measurements will take 20 minutes per depth. Water filtered through a $0.2 \mu \mathrm{m}$ filter from the deepest depth will be measured to establish a baseline for the LISST instruments, and additional baselines measured as needed. Surfaces measurements from the inline flow-through system will also be measured periodically throughout the cruise.

Data Products: The directly measured data are the volume scattering functions. Data from the LISST is inverted by the standard processing software (LISST-SOP 5.1) to provide particle size distributions from $1-250 \mu \mathrm{m}$. The complete VSF from the MVSM+LISST is also inverted to provide PSDs from $0.02-200 \mu \mathrm{m}$.

\begin{tabular}{lll}
\hline Parameter & Range & Units \\
\hline VSF & $0.1-179^{\circ}(443,490,510,532$, & $\mathrm{m}^{-1} \mathrm{Sr}^{-1}$ \\
& $555,565,590,620 \mathrm{~nm})$ & \\
\hline PSD & $0.02-200 \mu \mathrm{m}$ & $\mathrm{m}^{-3} \mu \mathrm{m}^{-3}$ \\
\hline
\end{tabular}

\section{Uncertainties:}

Instrument: The largest instrument uncertainties result from calibration errors and instrument drifts during long deployments. Instrument drifts will be monitored by periodic measurements of pure water during the deployment. The instruments will be calibrated pre- and post- cruise in laboratory, and also mid-cruise on the vessel. Measurement: Repeated measurements will be made of each water sample during the cruise to assess measurement uncertainties. Sample uncertainty will be minimized by mixing water from all Niskin bottles collected at each depth.

\section{Key Method References:}

Zhang, X., Gray, D., Huot, Y., You Y., Bi, Lei, “Comparison of optically derived particle size distributions: scattering over the full angular range versus diffraction at near forward angles," Appl. Opt. 51, 5085-5099 (2012). 


\section{EXPORTS 1 ACS data processing \\ Nils Haëntjens and Emmanuel Boss \\ January 5, 2019 \\ Updated: March 5, 2019}

Cruise name: EXPORTS 1

Cruise id: RR1813

Ship: R/V Roger Revelle

Location: Station Papa, North East Pacific

Dates at sea: $2018 / 08 / 11$ to $2018 / 09 / 12$ 01:00

Epoch 1:2018/08/14 4:30 to 2018/08/23 9:00

Epoch 2:2018/08/23 9:00 to 2018/08/31 9:00

Epoch 3:2018/08/31 9:00 to 2018/09/08 9:00

At Station P: 2018/08/14 0:00 to 2018/08/23 9:00

Operators: Nils Haëntjens and Emmanuel Boss

Group Leaders: Emmanuel Boss and Lee Karp-Boss

ACS serial numbers: 298 and 301

\section{Revision 2:}

Gamma in the file EXPORTS-EXPORTSNP_InLine-ACS-Products_20180811-20180912_R1 was not processed for the ACS 301 and was populated with $-9999(\mathrm{NaN})$ values. The bug was corrected and a beautiful diel cycle can now be observed for the entire campaign. Only the file EXPORTS-EXPORTSNP_InLine-ACS-Products_20180811-20180912_R2 is concerned by this revision. The processing stays identical.

We use a calibration independent technique (Slade et al., 2010) to obtain particulate absorption (ap) and attenuation (cp) by differencing measurements with a 0.2 um filter from measurements made with no filter. Dissolved absorption and attenuation are obtained by subtracting daily MilliQ run from .2um filtered measurements. Filters are exchanged weekly and flow-tubes are cleaned every day. Switching between filtered and unfiltered measurements is done every $60 \mathrm{~min}(50 \mathrm{~min}$ total, 10min dissolved). In addition, MilliQ water was run every day after the instrument cleaning through the instrument to obtain ag and cg spectrums.

Two ACS, serial number 298 and 301, are used during the campaign, ACS 298 was used from the beginning of the campaign to 2018/08/20 18:10 and ACS 301 was used from 2018/08/20 20:17 to the end of the expedition. The change in ACS is not related to any dysfunction of instrument on the InLine system but rather an issue with the ACS-301 when profiling, not affecting underway observations. Bad spectrums are removed manually and arise, generally due to bubbles going through the instrument.

For each minute, the remaining data between $15^{\text {th }}$ and $75^{\text {th }}$ percentiles are binned-averaged and their standard deviation is kept for reporting. The particulate bins are processed by subtracting the filtered measurements from the unfiltered measurements. Filtered values needed to obtain the particulate values are interpolated to the time of particulate measurements linearly. Dissolved bins are computed by differencing MilliQ and filtered data. The MilliQ values are linearly interpolated to match the filtered periods. 
The mismatch in spectral band positions between absorption and attenuation are corrected using interpolation. We use the 3rd method of Zaneveld et al., 1994 to correct for scattering with 730nm as the null wavelengths simultaneously performing a residual temperature correction (Slade et al., 2010). Attenuation is also corrected for residual temperature effect. Then, we perform a spectral unsmoothing based on the method in Chase, A., et al., 2013. We have left spectra with negative absorption in the blue regions, as these values are not significantly different from zero.

The device files are used for wavelength registration, to convert binary counts from the instruments into scientific units $(1 / \mathrm{m})$ independent of instruments temperature, and to indicate the last service of the instrument.

While the dissolved absorption and attenuation spectrums are available they must be used with caution and only a couple of hours a day might be valid due to bio-fueling of the instrument which can't be assessed with the current method. For more information please contact us (emmanuel.boss@maine.edu, nils.haentjens@maine.edu).

Additional products derived directly from the ap or $\mathrm{cp}$ spectrums are provided.

- Chlorophyll a (chl) is computed using the particulate absorption line height at $676 \mathrm{~nm}$ and the global relationship from Tara Ocean (Boss et al. 2013):

○ line $\_$height $=a \_p(676)-\left(39 / 65 \times a \_p(650)+26 / 65 \times a \_p(715)\right)$

$\circ \mathrm{chl}=157 \times$ line_height ${ }^{\wedge} 1.22$ (relationship NOT applied here, from Tara Ocean)

- The particulate organic carbon (POC) is computed using the particulate attenuation at 660 $\mathrm{nm}$ Using the global relationship from Gardner et al. (2006):

○ $\quad P O C=380 \times$ c $\_$p $(660)$

- Gamma is computed using the method of Boss et al. 2001.
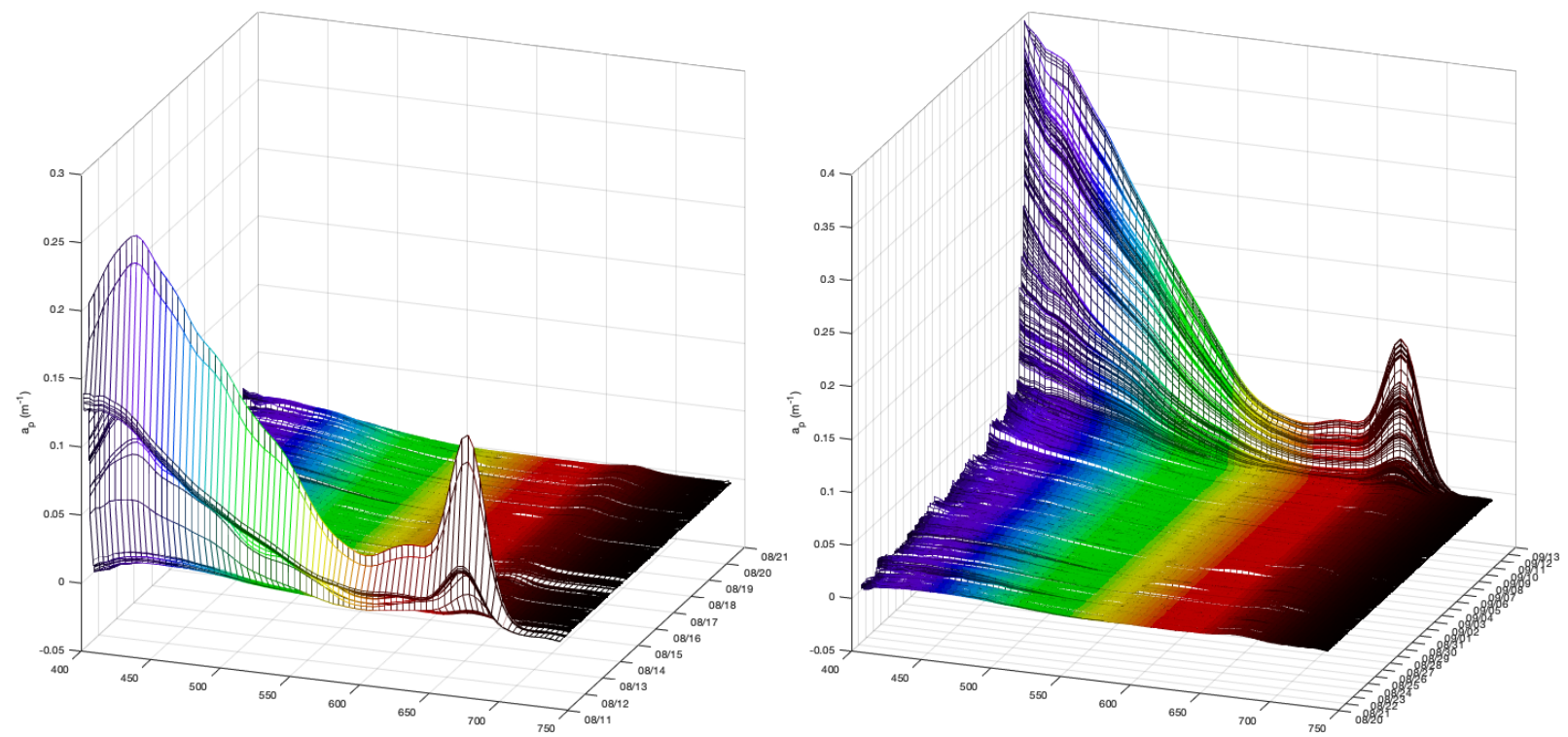

Figure 1. Particulate absorption spectrums during the entire expedition measured with ACS 298 (left) and ACS 301 (right). The higher absorptions at the beginning and the end of the expedition are in to coastal waters. 


\section{References:}

Boss, E., W.S. Pegau, W.D. Gardner, J.R.V. Zaneveld, A.H. Barnard., M.S. Twardowski, G.C. Chang, and T.D. Dickey, 2001. Spectral particulate attenuation and particle size distribution in the bottom boundary layer of a continental shelf. Journal of Geophysical Research, 106, 9509-9516.

Emmanuel Boss, Marc Picheral, Thomas Leeuw, Alison Chase, Eric Karsenti, Gabriel Gorsky, Lisa Taylor, Wayne Slade, Josephine Ras, Herve Claustre, 2013. The characteristics of particulate absorption, scattering and attenuation coefficients in the surface ocean; Contribution of the Tara Oceans expedition, Methods in Oceanography.

Chase, A., et al., 2013. Decomposition of in situ particulate absorption spectra. Methods in Oceanography $7,110-124$.

Gardner, W.D., Mishonov, A., Richardson, M.J., 2006. Global POC concentrations from in-situ and satellite data. Deep Sea Res. II 53, 718-740.

Slade, W.H, E. Boss, G. Dall'Olmo, M.R. Langner, J. Loftin, M.J. Behrenfeld, and C. Roesler, 2010. Underway and moored methods for improving accuracy in measurement of spectral particulate absorption and attenuation. Journal of Atmospheric and Oceanic Technology, 27:10, 1733-1746.

Zaneveld, J. R. V., J. C. Kitchen, and C. Moore, "The scattering error correction of reflecting-tube absorption meters," in Ocean Optics XII, S. G. Ackleson ed., Proc. SPIE 2258, 44-55 (1994). 


\section{EXPORTS 1 ALFA data processing \\ Nils Haëntjens and Emmanuel Boss \\ January 8, 2019}

Cruise name: EXPORTS 1

Cruise id: RR1813

Ship: R/V Roger Revelle

Location: Station Papa, North East Pacific

Dates at sea: 2018/08/11 to 2018/09/12 01:00

Epoch 1:2018/08/14 4:30 to 2018/08/23 9:00

Epoch 2:2018/08/23 9:00 to 2018/08/31 9:00

Epoch 3:2018/08/31 9:00 to 2018/09/08 9:00

At Station P: 2018/08/14 0:00 to 2018/08/23 9:00

Operators: Nils Haëntjens and Emmanuel Boss

Group Leaders: Emmanuel Boss and Lee Karp-Boss

ALFA Serial Number: 011

The WETLabs Aquatic Laser Fluorescence Analyzer, (ALFA) spectrofluorometer was mounted on the flow through system of the ship, after a vortex debubbler and switching system. The switching system automatically ran filtered seawater $(0.2 \mathrm{um})$ the first 10 minutes of every hour, unfiltered/total seawater was running through the instruments the rest of the time. The instrument was cleaned daily at night time with bleach and laboratory grade soap. A peristatic pump was used to pump the water through the instruments of the underway.

The data presented here was collected and preprocessed by the manufacturers software, manually quality checked (un-realistic values mainly being due to bubbles running through the system), and minute binned. Data collected when the water was filtered was removed from the dataset and not used in the processing but can be distributed per request to the data owner.

TSG, PAR, and the chlorophyll fluorometer (Wetlabs WS3S) data from the R/V Roger Revelle are added to the SeaBASS file to help for data analysis.

Parameters collected by the ALFA are:

- Chl_stimf_ex405: chlorophyll a fluorescence excited at $405 \mathrm{~nm}$

- Chl_stimf_ex514: chlorophyll a fluorescence excited at $514 \mathrm{~nm}$

- Fv_Fm_ex405: Fv/Fm value with $405 \mathrm{~nm}$ excitation

- Fv_Fm_ex514: Fv/Fm value with $514 \mathrm{~nm}$ excitation 


\section{EXPORTS 1 BB3 data processing}

Nils Haëntjens and Emmanuel Boss

January 5, 2019

Cruise name: EXPORTS 1

Cruise id: RR1813

Ship: R/V Roger Revelle

Location: Station Papa, North East Pacific

Dates at sea: 2018/08/11 to 2018/09/12 01:00

Epoch 1:2018/08/14 4:30 to 2018/08/23 9:00

Epoch 2:2018/08/23 9:00 to 2018/08/31 9:00

Epoch 3:2018/08/31 9:00 to 2018/09/08 9:00

At Station P: 2018/08/14 0:00 to 2018/08/23 9:00

Operators: Nils Haëntjens and Emmanuel Boss

Group Leaders: Emmanuel Boss and Lee Karp-Boss

ECO-BB3 serial numbers: 349

WetLabs ECO-BB3 serial number 349 was measuring the angular scatterance at $1 \mathrm{~Hz}$ at the three wavelength $(470,532,660 \mathrm{~nm})$. The data was logged with a home-grown data-loggger (Inlinino, http://inlinino.readthedocs.io/). The system is run on an hourly schedule of whole water for $50 \mathrm{~min}$ followed with 10min of filtered measurements (using a $0.2 \mu \mathrm{m}$ filter). In processing, the first 400 seconds data collected after switching from total filtered and vice-versa are ignored corresponding to the time it takes to renew the water in the BB-Box. 20-40 L of MilliQ water are run daily through the system to estimate the dissolved backscattering coefficient.

Period with obvious bad measurements are removed manually (most likely due to large clouds of bubbles or accumulation of big particles in coastal waters).

For each minute, the measurements between the $15^{\text {th }}$ and $75^{\text {th }}$ percentiles are averaged and their standard deviation is kept for reporting. Both the dissolved $\left(\beta_{\mathrm{g}}\right)$ and particulate $\left(\beta_{\mathrm{p}}\right)$ VSF are computed depending on switch position. The dissolved VSF is obtained by subtracting the MilliQ measurements from filtered measurements (interpolating in time between successive daily MiliQ values). The particulate VSF is obtained by subtracting the filtered from the total values (filtered values are linearly interpolated). Those differences take care of the dark and wall effects of the BB box. The slope coefficient used (table 1) comes from the latest calibration done by Jim Sullivan of FAU on 6/29/16. A temperature and salinity correction is performed on the dissolved using Zhang et al. 2009.

The particulate backscattering coefficient $\left(b_{b p}\right)$ is computed using $\chi=1.076$ (nominal angle 124, Sullivan et al, 2013). Note: the reported value for particulate backscattering does not include the contribution of the fraction below $0.2 \mathrm{um}$.

Table 1. Calibration coefficients of WetLabs ECO-BB3 349 on 6/29/16, wavelength were measured 09/23/2017 with a Satlantic Radiometer.

\begin{tabular}{|l|l|l|l|}
\hline Nominal Wavelength [nm] & Slope $\left[\mathrm{sr}^{-1}\right.$ count $\left.^{-1}\right]$ & Dark [counts] & Uncertainties \\
\hline 468.7 & $8.407 \mathrm{E}-6$ & 55.5 & $\operatorname{Max}(11 \%, 6 \mathrm{E}-5)$ \\
\hline 527 & $4.624 \mathrm{E}-6$ & 50.8 & $\operatorname{Max}(10 \%, 3 \mathrm{E}-5)$ \\
\hline 652 & $4.090 \mathrm{E}-6$ & 43.7 & $\operatorname{Max}(17 \%, 5-5)$ \\
\hline
\end{tabular}




\section{References}

Sullivan, J. M., M. S. Twardowski, J. Ronald, V. Zaneveld, and C. C. Moore (2013), Measuring optical backscattering in water, in Light Scattering Reviews 7, Springer Praxis Books, edited by A. A. Kokhanovsky, pp. 189-224, Springer, Berlin, doi:10.1007/978-3-642-21907-8 6.

Zhang, X., L. Hu, and M.-X. He, 2009. Scattering by pure seawater: effect of salinity, Opt. Express 17, 5698-5710 
Method: NPP, $24 \mathrm{~h}$ and $2 \mathrm{~h} \mathrm{H}^{14} \mathrm{CO}_{3}$ incubations

Document author and contact info: Kim Halsey, halseyk@science.oregonstate.edu, 541-7371831; James Fox, james.fox@oregonstate.edu

Brief description of protocol and relation to export pathways: Our primary objective is to measure ${ }^{14}$ carbon assimilation in seawater samples. These (A) 24 hour and (B) short-term (2 h) incubations will allow us to calculate net organic carbon production (NPP) and will yield information about the physiology of the phytoplankton community. NPP describes the rate of $\mathrm{CO}_{2}$ conversion into organic matter; the first step of the carbon cycle. A key goal of EXPORTS is to determine the fraction and rate of NPP that is transferred to the dark ocean. We will apply the commonly used ${ }^{14} \mathrm{C}$-uptake method (Steeman Nielsen, 1952). Seawater samples will be spiked with ${ }^{14} \mathrm{C}$-labeled bicarbonate, incubated at a range of light levels, filtered, acidified, and then measured by scintillation counter to determine the amount of ${ }^{14} \mathrm{C}$ incorporated into biomass. $24 \mathrm{~h}$ incubations will be conducted from dawn-to-dawn in on-deck temperature controlled incubators with and without screening to estimate NPP throughout the euphotic zone. Short term $(2 \mathrm{~h})$ incubations will be done in a photosynthetron.

Other contributing protocols: NPP can be normalized to a variety of different parameters (e.g., Chla, total absorption, $\mathrm{C}_{\text {phyto }}$ ) especially for use in linking to satellite retrievals. Estimates of light intensities with depth will be needed to match $I_{g}$ to incubation light exposures.

Uncertainties and quality control concerns: Duplicate measurements help constrain the uncertainty.

\section{Data products originating with this method:}

Short term incubations yield $\mathrm{P}_{\max }$ and alpha $(\alpha)$ which can be used to determine the maximum quantum yield $\phi_{\mathrm{m}}$ and possibly growth rate $(\mu)$.

\begin{tabular}{|c|c|}
\hline Parameter & Units \\
\hline $\mathrm{P}_{\max }$ & $\operatorname{mol~C}\left(m^{3} d\right)^{-1}$ \\
\hline $\operatorname{alpha}(\alpha)$ & mol C m² $\mathrm{s}$ (mol photons $\mathrm{d})^{-1}$ \\
\hline Maximum photosynthetic quantum yield $\left(\varphi_{\mathrm{m}}\right)$ & mol C (mol photons) \\
\hline Growth rate $(\mu)$ & $d^{-1}$ \\
\hline
\end{tabular}

\section{SeaBASS submission fields and units:}

/fields=depth,lightlevel,rate_14C_uptake_bottle_24hr_0.2umfilt,R2R_event,date,time /units $=\mathrm{m}, \%, \mathrm{~mol} / \mathrm{l} / \mathrm{d}$, none,yyyymmdd,hh:mm:ss 


\section{Key method references}

Steeman Nielsen (1952) The use of radioactive carbon (14C) for measuring organic production in the sea. J. Cons. Int. Explor. Mer 18:117-40

Fisher and Halsey (2016) Mechanisms that increase the growth efficiency of diatoms in low light. Photosynthesis Research. 129:183-197. doi: 10.1007/s11120-016-0282-6

Milligan, Halsey, and Behrenfeld (2015) Advancing interpretations of ${ }^{14} \mathrm{C}$-uptake measurements in the context of phytoplankton physiology and ecology. Journal of Plankton Research. 37:692698. 


\begin{tabular}{|l|l|}
\hline Variable & Biogenic Silica \\
\hline SeaBASS Name & Bsi \\
\hline Units & \\
\hline Sampling & Niskin bottle on rosette \\
\hline
\end{tabular}

Document author and contact information: Janice Jones, janice.jones@lifesci.ucsb.edu

\section{Particulate Si Determination}

\section{At Sea:}

1. Filter sample through a $0.6 \mathrm{~m}$ polycarbonate membrane filter at $<10 \mathrm{~mm} \mathrm{Hg}$, record volume filtered. Nalgene clamp towers work well with the thin PC filters.

2. Fold filter into quarters, place in a screw cap cryovial, cap loosely and dry at $65^{\circ}$. Once dry (in $\sim 2$ days) store at room temperature. Or cap tightly and freeze at $-20 \mathrm{C}$ and keep frozen until samples can be dried in a drying oven as above.

3. For every box of filters used, make 3 filter blanks - take a clean filter, fold in quarters, place in a cryovial and label BLANK. These blanks will go through the same procedure as the samples.

\section{In the Lab:}

\section{Reagents:}

\section{$0.2 \mathrm{~N} \mathrm{NaOH}$}

$1 \mathrm{~N} \mathrm{HCl}$

$0.2 \mathrm{~N} \mathrm{HF}(\mathrm{LSi})$

Saturated aqueous boric acid (LSi)

Deionized distilled water (Milli-Q or Nanopure)

Regents for colorimetric seawater silicate

4. $15 \mathrm{ml}$ Teflon centrifuge tubes are stored in $0.5 \mathrm{M} \mathrm{HF}$. Dump the rinse HF from a set of Teflon tubes into the HF reservoir (2L bottle). Rinse the tubes with Nanopure 3x. Transfer a dry filter from a microcentrifuge tube to the bottom of a $15 \mathrm{ml}$ tube keeping filter as open as possible. If necessary, use long forceps to open filter, exposing the surface for $\mathrm{NaOH}$ digestion. Rinse forceps well with Nanopure between samples.

5. Make 3 tube blanks - empty Teflon tubes. Treat blanks as you do all other vials with filters.

6. Cover filter with $4 \mathrm{ml}$ of $0.2 \mathrm{~N} \mathrm{NaOH}$. Plug and vortex. Be sure filter remains submerged. Cover each tube with a loose cap to keep condensation drips out of sample.

7. Place in water bath at $\underline{\underline{95}} \underline{\underline{C}}$ for :

- RoMP samples $=1 \mathrm{hr}$

- BATS samples $=2 \mathrm{hr}$

- JGOFS $=40 \mathrm{~min}$

- Plumes and Blooms $=30 \mathrm{~min}$

- $\mathrm{LTER}=40 \mathrm{~min}$

- $\quad$ EXPORTS = TBD 
8. Cool in ice water bath immediately. Remove foil while cooling. This should take about 3-5 minutes, then samples should be cool enough for acid addition.

9. Add $1.0 \mathrm{ml}$ of $1 \mathrm{~N} \mathrm{HCl}$ and vortex after each addition. This neutralizes the $\mathrm{NaOH}$ and along with the cooling stops the digestion. Work quickly to minimize the time difference between the first and last sample.

10. With a clean spatula or long forceps, gently crunch filter into bottom of tube. Rinse the spatula/forceps with Nanopure between samples. Scrunching the filter makes it easier to withdraw your sample later, but you will need to remove the filter eventually so be gentle.

11. Centrifuge for $10 \mathrm{~min}$ at setting 6 to drive the lithogenic Si particles to the bottom of the tube.

12. Withdraw $4 \mathrm{ml}$ of the $5 \mathrm{ml}$ in the Teflon tube and place in $30 \mathrm{ml}$ PP (polypropylene) bottle - be sure to take the sample from the top of the liquid, don't push the pipette tip down into the filter. Do this in front of the light - you can see the liquid level with the backlight. Add $18 \mathrm{ml}$ of Nanopure to the PP bottle for a total of $21 \mathrm{ml}$.

13. From the PP bottle containing $21 \mathrm{ml}$ of sample, transfer $10 \mathrm{ml}$ to another $30 \mathrm{ml}$ PP bottle for DSi analysis. Your dilution factor for this $10 \mathrm{ml}$ sample will be $(5 / 4)^{*}(21 / 10)=2.625$. If you need to dilute the sample, take an aliquot less than $10 \mathrm{ml}$ and make up to $10 \mathrm{ml}$ with Nanopure. Reflect the change in your dilution factor: i.e. if you only use $5 \mathrm{ml}$ of $21 \mathrm{ml}$ then $(5 / 4)^{*}(21 / 5)=5.25$.

14. If lithogenic silica concentrations are NOT to be determined skip to step 22.

15. To rinse the LSi sample, add $7 \mathrm{ml}$ Nano to the remaining $1 \mathrm{ml}$ of sample + filter in the Teflon tube. Plug tube, vortex and centrifuge for $10 \mathrm{~min}$ at setting 6 on clinical centrifuge (program 15 on new centrifuge).

If filter does NOT spin to the bottom of tube, push it down with clean poker and spin again for 10 minutes (remember we are trying to rid ourselves of any remaining dissolved silica from the BSi digestion not the particulate LSi). Aspirate to $1 \mathrm{ml}$ (BE SURE to rinse slurper tip before you use it!!)

16. Repeat rinse/aspirate step. Two rinses are necessary but do more if there was a lot of BSi.

17. Remove the plug from the Teflon tubes, cover with large clean Petri dishes (to allow drying while keeping dust out of tubes), and place in drying oven at $65^{\circ} \mathrm{C}$ until dry (takes approximately 48hours). Once dry, these filters can be stored at room temperature until you have time to continue - cover the tubes with plugs and caps then cover entire rack with plastic wrap if you're going to let them sit around.

\section{ONCE THE PMP TUBES FOR LSi ARE IN THE OVEN AND THE BSi SAMPLES ARE READY TO ENTER THE DSi PART OF THE ANALYSIS YOU CAN STOP FOR THE DAY. THE BSi SAMPLES SHOULD BE PROCESSED WITHIN 48 HOURS.}

18. When dry, remove filters from oven and let cool. Wear gloves when working with HF, and you may want to work in the hood but it's not necessary. Completely cover each filter with $0.2 \mathrm{ml}$ of $2.5 \mathrm{M} \mathrm{HF}$.

\section{BE SURE FILTER IS DRY AND COOL, DO NOT ADD HF TO WARM FILTERS}

19. Crunch the filter down into the bottom of the tube with the HF poker (teflon or plastic stirring rod or spatula), remove all air bubbles and completely submerge the filter ball under the HF. Rinse the poker well with Nanopure between samples. The filter will have to be removed from the tube later so you'll want to try and flip it over or lift it slightly off the bottom to make that removal easier!!.

\section{DO NOT USE GLASS OR METAL STIR RODS / FORCEPS / SPATULAS WITH HF}

20. Use plugs to tightly caps the tubes. Be sure to treat the tube and filter blanks with $0.2 \mathrm{ml} \mathrm{HF}$ and the $\mathrm{HF}$ poker as well. Let samples and blanks sit covered with HF for $\underline{\mathbf{4 8}}$ hours.

21. A couple of hours before the 48hour waiting period is over, the saturated boric acid solution $(\sim 1 \mathrm{M}$, $65 \mathrm{~g} / \mathrm{L}$ ) needs to be filtered. The $\mathrm{H}_{3} \mathrm{BO}_{3}$ MUST be freshly filtered prior to use. A total volume of $14.8 \mathrm{ml}$ per sample is required, plus $110 \mathrm{ml}$ for the standard curve plus enough to make dilutions if necessary. The saturated boric acid should be filtered through a $0.6 \mathrm{~mm} 47 \mathrm{~mm}$ PC membrane filter and collected in 
PSi protocol Teflon Tubes_Janice a clean bottle. Filter enough boric acid for all samples, standard curves and dilutions you might need it doesn't hurt to filter too much.

22. Vortex the tube to release the HF inside the crunched filter. Set the dispensette on the filtered boric acid to $7.4 \mathrm{ml}$ (CHECK VOLUME!!). Dispense $7.4 \mathrm{ml}$ of filtered boric acid into the tube, vortex to resuspend filter and transfer the boric acid, HF and scrunched filter to a $30 \mathrm{ml}$ PP bottle. Dispense a second $7.4 \mathrm{ml}$ aliquot of boric acid into the tube, vortex to rinse the tube and transfer volume to same $30 \mathrm{ml}$ bottle (you can do this in 3 aliquots totaling $14.8 \mathrm{ml}$ for better tube rinsing if you want). The total volume in the bottle is $15 \mathrm{ml}-14.8 \mathrm{ml}$ of filtered boric acid and $0.2 \mathrm{ml}$ of $2.5 \mathrm{M} \mathrm{HF}$.

23. Withdraw $10 \mathrm{ml}$ of the $15 \mathrm{ml}$ in the PP bottle and transfer to a clean $30 \mathrm{ml}$ PP bottle for the DSi reaction. The dilution factor here is $(15 / 10)=1.5$.

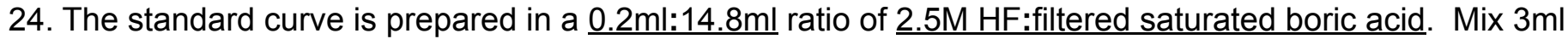
2.5M HF and $222 \mathrm{ml}$ filtered boric acid in a beaker, transfer $10 \mathrm{ml}$ of this solution to each of the standard curve bottles. DO NOT USE NANOPURE FOR THE LSi STANDARD CURVE. Use this solution for dilutions as well. If you'll have dilutions, make a larger volume - be sure to maintain the ratio!

25. Follow same protocol as for Dissolved Si Analysis - $4 \mathrm{ml}$ of the Acid/Moly reagent, wait 10 minutes to form silicomolybdic acid, add $6 \mathrm{ml}$ reducing reagent.

26. Tube blanks correct for signal generated by the effect of the $\mathrm{NaOH} \& \mathrm{HF}$ digestions on the tube. Filter blanks correct for signal generated by the effect of the digestions on the filter. When the signal from the tube blank gets too high $(<90 \% \mathrm{~T}$ for $1 \mathrm{~cm}$ cell, $<80 \%$ for $10 \mathrm{~cm}$ cell) the tubes need to be discarded usually they can only be used for HF approximately 10 times. Since the filter blank incorporates the tube blank, the signal from the filter blank is subtracted from the signal on all samples.

27. Calculate the LSi concentration in the original seawater sample (LSi). Correct the value based on the number of nanopure rinses in steps $14 / 15$. The calculation is as follows:

LSi umol/filter ${ }_{\text {corrected }}=$ LSi umol/filter $-\left((1 / 5)^{\star}(1 / 8)^{\star}(1 / 8)^{\star}\right.$ BSi umol/filter $)=$ LSi $-\left(0.003125^{\star} B S i\right.$ umol/filter $)$ 
Method: Estimation of particle (dis)aggregation and sinking rates based on size-fractionated lithogenic particle concentrations

Document author and contact info: Phoebe J. Lam (pjlam@ucsc.edu); Jong-Mi Lee (jm lee@ucsc.edu); Olivier Marchal (omarchal@,whoi.edu)

Brief description of protocol and relation to export pathways:

Size-fractionated particle samples will be collected in the upper water column at stations occupied during EXPORTS from in-situ filtration pumps (McLane Industries) whereby water entering the pump passes through two screens ( 51 micron followed by 0.8 micron nominal pore size). Subsamples of the 0.8-51 micron and $>51$ micron particles will be digested using $\mathrm{HNO}_{3}$ and $\mathrm{HF}$ (Cullen and Sherrell, 1999). The digested solutions will be diluted and run on the Inductively Coupled Plasma Mass Spectroscopy (ICPMS) to measure concentrations of various trace elements and REEs, including Ti which represents lithogenic particles in the samples.

In addition to this effort of sample collection and analysis, we will develop and apply a two-particle size class model of particle and thorium cycling in the oceanic water column. In this model, the particle size classes will coincide with those sampled at sea. Rates of particle aggregation, disaggregation, remineralization, and sinking at stations occupied during the EXPORTS and GEOTRACES programs will be estimated from a model fit to measurements of size-fractionated lithogenic particle and particulate organic carbon (POC) concentrations and ${ }^{234} \mathrm{Th}$ activity, provided by this and other research groups. A time-dependent version of the model will be applied to infer temporal variations in these rates from EXPORTS data (time series data), and a steadystate version of the model will be applied to infer horizontal variations in these rates from GEOTRACES data (transect data). For both model versions, the model fit to the data will be obtained from the application of inverse methods: methods of optimal estimation theory for the time-dependent version, and methods of total inversion or nonlinear programming for the steady version. Through this approach, we will be able to document variations in particle (dis)aggregation, remineralization, and sinking rates (for export pathways 1, 2, and 3) over the course of a bloom and across different pelagic environments in the open ocean, with due consideration for the uncertainties in the data and the model.

Other contributing protocols: Analytical determination of $\mathrm{POC}$ and ${ }^{234} \mathrm{Th}$, comparison to direct estimates of sinking particle fluxes using sediment traps and optical flux traps, comparison to particle size distribution data from UVP and other optical systems.

\section{Uncertainties and quality control concerns:}

Particle data will have uncertainties derived from blanks and other steps determined by standards. Rate constants will have uncertainties derived from both data and modeling errors.

\section{Data products originating with this method}

\begin{tabular}{ll}
\hline Parameter & Units \\
\hline size-fractionated $\mathrm{pTi}$ and other TEs and REEs concentrations & $\mathrm{nmol} / \mathrm{kg}$ \\
aggregation $(0.8-51 \mu \mathrm{m}$ to $>51 \mu \mathrm{m})$ rate constant & $\mathrm{d}^{-1}$ \\
disaggregation $(>51 \mu \mathrm{m}$ to $0.8-51 \mu \mathrm{m})$ rate constant & $\mathrm{d}^{-1}$ \\
sinking rate of $>51 \mu \mathrm{m}$ particles & $\mathrm{m} \mathrm{d}^{-1}$
\end{tabular}




\section{Key method references}

1. Cullen, J. T. and Sherrell, R. M. Techniques for determination of trace metals in small samples of size-fractionated particulate matter: Phytoplankton metals off central California, Mar. Chem. 67, 233-247 (1999).

2. Lam, P. J. and Marchal, O. Insights into particle cycling from thorium and particle data. Annu. Rev. Marine. Sci. 7, 159-184 (2015).

3. Lerner P., Marchal O., Lam P., Buesseler K., and Charette M., Kinetics of thorium and particle cycling along the U.S. GEOTRACES North Atlantic Transect, Deep-Sea Res. I, 125, 106128,2017

4. Marchal, O. and Lam, P.J. What can paired measurements of Th isotope activity and particle concentration tell us about particle cycling in the ocean? Geochim. Cosmochim. Acta 90, 126-149 (2012).

5. Waltz, R. A., J. L. Morales, J. Nocedal, and D. Orban (2006), An interior algorithm for nonlinear optimization that combines line search and trust region steps, Mat. Program. 107(3), 391-408. 
Method: Estimation of particle (dis)aggregation and sinking rates based on size-fractionated lithogenic particle concentrations

Document author and contact info: Phoebe J. Lam (pjlam@ucsc.edu); Jong-Mi Lee (jm_lee@ucsc.edu); Olivier Marchal (omarchal@whoi.edu)

\section{Brief description of protocol and relation to export pathways:}

Size-fractionated particle samples will be collected in the upper water column at stations occupied during EXPORTS from in-situ filtration pumps (McLane Industries) whereby water entering the pump passes through two screens (51 micron followed by 0.8 micron nominal pore size). Subsamples of the 0.8-51 micron and $>51$ micron particles will be digested using $\mathrm{HNO}_{3}$ and $\mathrm{HF}$ (Cullen and Sherrell, 1999). The digested solutions will be diluted and run on the Inductively Coupled Plasma Mass Spectroscopy (ICPMS) to measure concentrations of various trace elements and REEs, including Ti which represents lithogenic particles in the samples.

In addition to this effort of sample collection and analysis, we will develop and apply a two-particle size class model of particle and thorium cycling in the oceanic water column. In this model, the particle size classes will coincide with those sampled at sea. Rates of particle aggregation, disaggregation, remineralization, and sinking at stations occupied during the EXPORTS and GEOTRACES programs will be estimated from a model fit to measurements of size-fractionated lithogenic particle and particulate organic carbon (POC) concentrations and ${ }^{234} \mathrm{Th}$ activity, provided by this and other research groups. A timedependent version of the model will be applied to infer temporal variations in these rates from EXPORTS data (time series data), and a steady-state version of the model will be applied to infer horizontal variations in these rates from GEOTRACES data (transect data). For both model versions, the model fit to the data will be obtained from the application of inverse methods: methods of optimal estimation theory for the time-dependent version, and methods of total inversion or nonlinear programming for the steady version. Through this approach, we will be able to document variations in particle (dis)aggregation, remineralization, and sinking rates (for export pathways 1,2, and 3) over the course of a bloom and across different pelagic environments in the open ocean, with due consideration for the uncertainties in the data and the model.

Other contributing protocols: Analytical determination of POC and ${ }^{234} \mathrm{Th}$, comparison to direct estimates of sinking particle fluxes using sediment traps and optical flux traps, comparison to particle size distribution data from UVP and other optical systems.

\section{Uncertainties and quality control concerns:}

Particle data will have uncertainties derived from blanks and other steps determined by standards. Rate constants will have uncertainties derived from both data and modeling errors. 


\section{Data products originating with this method}

Parameter

size-fractionated $\mathrm{pTi}$ and other TEs and REEs concentrations

aggregation $(0.8-51 \mu \mathrm{m}$ to $>51 \mu \mathrm{m})$ rate constant

disaggregation ( $>51 \mu \mathrm{m}$ to $0.8-51 \mu \mathrm{m})$ rate constant

sinking rate of $>51 \mu \mathrm{m}$ particles

remineralization rate constant
Units

$\mathrm{nmol} / \mathrm{kg}$

$\mathrm{d}^{-1}$

$\mathrm{d}^{-1}$

$\mathrm{m} \mathrm{d}^{-1}$

$\mathrm{d}^{-1}$

\section{Key method references}

1. Cullen, J. T. and Sherrell, R. M. Techniques for determination of trace metals in small samples of size-fractionated particulate matter: Phytoplankton metals off central California, Mar. Chem. 67, 233-247 (1999).

2. Lam, P. J. and Marchal, O. Insights into particle cycling from thorium and particle data. Annu. Rev. Marine. Sci. 7, 159-184 (2015).

3. Lerner P., Marchal O., Lam P., Buesseler K., and Charette M., Kinetics of thorium and particle cycling along the U.S. GEOTRACES North Atlantic Transect, Deep-Sea Res. I, 125, 106-128, 2017

4. Marchal, O. and Lam, P.J. What can paired measurements of Th isotope activity and particle concentration tell us about particle cycling in the ocean? Geochim. Cosmochim. Acta 90, 126-149 (2012).

5. Waltz, R. A., J. L. Morales, J. Nocedal, and D. Orban (2006), An interior algorithm for nonlinear optimization that combines line search and trust region steps, Mat. Program. 107(3), 391408. 
Method: Bio-acoustic measurement of zooplankton biomass

\section{Document author and contact info:}

Amy Maas, Amy.Maas@bios.edu, Eric D’Asaro dasaro@apl.washington.edu

\section{Brief description of protocol and relation to export pathways:}

The day/night abundance, distribution and species composition of the mesozoooplankton control two of the main exports pathways: active transport and fecal pellet production. These communities can be quite patchy, and some members (particularly larger individuals) are capable of net avoidance. To better constrain the distribution and relative abundance of the zooplankton, and to examine both meso- and finer scale variability in migration behavior, analyses of the acoustic sound scattering layer (SSL) will be conducted. These will be used to inform the active flux pathway by providing information about the variability in the behavior.

During the cruise period, raw acoustic backscatter data will be collected by the Simrad EK80 on the R/V Ride at five frequencies $(18,38,70,120$ and $200 \mathrm{kHz})$. Raw data will be integrated over $0.1 \mathrm{~min}$ intervals and $1 \mathrm{~m}$ depth strata per frequency, then concatenated into daily sections (with Matlab code) to produce echograms from depths of a few meters to at least $400 \mathrm{~m}$. These data will be used to compute relative (qualitative) differences in mesoscale variability, timing of migration, migration depths, etc. based on visual scrutiny of the rate, timing, and amplitude of diel vertical migrations evident in the data. Additional, more quantitative analysis may be possible given the dominant zooplankton species as determined from MOCNESS and UVP data combined with acoustic backscattering models.

During the autonomous mission (July - December), a glider will carry a $1 \mathrm{MHz}$ Nortek Signature ADCP operated as a narrow band $\left(2.9^{\circ}\right)$ echosounder with a large number of narrow $(3 \mathrm{~mm})$ bins over a range of a few meters away from the glider. Each bin will sample $\sim 1 \mathrm{ml}$ of water so that each bin is likely to contain only one individual. The system will thus $i$ ) count animals, $i i$ ) measure the scattering cross-section of each animal and iii) roughly measure the size of animals bigger than $1 \mathrm{~mm}$. These measurements will be made many times per day along profiles extending from the surface to $1000 \mathrm{~m}$ and will thus be capable of observing diel migrations. Comparisons with more established methods will be made during the cruise period using the same model of ADCP operating as an internally recording, battery powered sampler. During MOCNESS tows, it will be mounted with a view of the net opening, so as to make direct measurements of the acoustic signatures of animals captured. During CTD measurements, it will be mounted with a view of the camera sampling volume so as to obtain simultaneous optical and acoustic measurements of the same animals.

Other contributing protocols: MOCNESS sampling and UVP sampling.

Uncertainties and quality control concerns: It is difficult to go from single or multi-beam echosounders to direct quantification of biomass as some species produce a louder backscatter relative to size and abundance (i.e. fish with swim bladders, pteropods, etc.). The use of a high-frequency, high resolution echo sounder to measure zooplankton has not been previously attempted, so its accuracy is not known.

Data products originating with this method:

Parameter Units




\begin{tabular}{lc}
\hline depth of migration & $\mathrm{m}$ \\
\% community migration & $\%$ \\
\hline
\end{tabular}

\section{Key method references}

Lavery, A.C., Wiebe, P.H., Stanton, T.K., Lawson, G.L., Benfield, M.C. and Copley, N., 2007. Determining dominant scatterers of sound in mixed zooplankton populations. The Journal of the Acoustical Society of America, 122(6), pp.3304-3326.

Lawson, Gareth L., Peter H. Wiebe, Carin J. Ashjian, Scott M. Gallager, Cabell S. Davis, and Joseph D. Warren. (2004). Acoustically-inferred zooplankton distribution in relation to hydrography west of the Antarctic Peninsula. Deep Sea Research Part II: Topical Studies in Oceanography 51, no. 17: 2041-2072.

Powell, J. R. and M. D. Ohman (2015). Changes in zooplankton habitat, behavior, and acoustic scattering characteristics across glider-resolved fronts in the Southern California Current System. Progress in Oceanography 134: 77-92 doi 10.1016/j.pocean.2014.12.011.

Powell, J. R. and M. D. Ohman (2012). Use of glider-class acoustic Doppler profilers for estimating zooplankton biomass. Journal of Plankton Research 34(6): 563-568 doi 10.1093/plankt/fbs023. 
Method: Zooplankton electron transport system

Document author and contact info: Amy Maas, Amy.Maas@bios.edu

\section{Brief description of protocol and relation to export pathways:}

Respiration of diel vertical migratory (DVM) zooplankton is one of the five export pathways. Although individual direct measurements of respiration and associated scaling via abundance and biomass provide one measure of this active flux they rely upon the assumption that experiments with a limited number of individual and species can characterize the fully community respiratory rate. Analysis of the Electron Transport System (ETS) captures diel changes in whole mesozooplankton community metabolism in discrete depth intervals throughout the water column. The ETS analysis measures the enzymatic capacity of a sample to transfer electrons to a terminal receptor. When performed on samples of mesozooplankton taken with net tows it is generally interpreted as the "potential respiration" of the organisms within a discrete vertical community (Gómez et al., 1996; Packard, 1971). Using a flash frozen fraction of the MOCNESS samples, enzymatic activity is measured on each vertical strata of all MOCNESS samples using the standard ETS methods (Gómez et al., 1996; Packard, 1971). The enzyme activity will be used to directly calculate the respiratory $\mathrm{CO}_{2}$ production (active transport; $\mu \mathrm{mol} \mathrm{CO} \mathrm{CO}^{-3} \mathrm{~h}^{-1}$ ) in each vertical strata using the equations detailed in Packard and Gómez (2013). These measures will capture both diel and ontogenetic variations in active flux.

Other contributing protocols: MOCNESS abundance and biomass sampling to provide biomass calculations.

Uncertainties and quality control concerns: This assay is a measure of "potential respiration" and is based on an assumption that the abundance of ETS relates directly to the respiration of a community (i.e. that an individual organism is always producing the maximum of ATP possible). This is an oversimplification of organismal physiology, but provides a good first approximation of whole community respiration rate. The calculation of active flux via the ETS method for respiration has been calculated to have an uncertainty of 31-38\% based on all sources of error (Packard and Gómez, 2013; Packard et al., 1988), while calculations of respiratory $\mathrm{C}$ demands of the mesopelagic organisms have a 40\% error (Packard and Gómez, 2013).

Data products originating with this method:

\begin{tabular}{ll}
\hline Parameter & Units \\
\hline respiratory flux & $\mathrm{mg}-\mathrm{C} \mathrm{m}^{-2} \mathrm{~d}^{-1}$ \\
\hline
\end{tabular}

\section{SeaBASS submission fields and units:}

/fields=date_start,station_alt_id,sample_1id,sample_2id,R2R_event,lat,lon,wt,net_interval,volfilt,sample_ 3id,sample_4id,weight_protein_sample,oxygen_consumption_tempcorr,weight_protein_community,rate_ respiration_carbon_zoop

/units=yyyymmdd,none,none,none,none,degrees, degrees,degreesC,m,L,none,none, $\mathrm{mg} / \mathrm{sample}, \mathrm{uL} / \mathrm{h}, \mathrm{mg} / \mathrm{m}$ $\wedge 3, \mathrm{mg} / \mathrm{m}^{\wedge} 2 / \mathrm{d}$

\section{Key method references}


Gómez, M., Torres, S. and Hernández-León, S. (1996). Modification of the electron transport system (ETS) method for routine measurements of respiratory rates of zooplankton. South African Journal of Marine Science 17, 15-20.

Packard, T. (1971). The measurement of respiratory electron transport activity in marine phytoplankton. J. mar. Res 29, 235-244.

Packard, T. T. and Gómez, M. (2013). Modeling vertical carbon flux from zooplankton respiration. Progress in Oceanography 110, 59-68.

Packard, T. T., Minas, H. J., Coste, B., Martinez, R., Bonin, M. C., Gostan, J., Garfield, P., Christensen, J., Dortch, Q. and Minas, M. (1988). Formation of the Alboran oxygen minimum zone. Deep Sea Research Part I: Oceanographic Research 35, 1111-1118. 
Method: Zooplankton biomass/abundance

Document author and contact info: Amy Maas, Amy.Maas@bios.edu

\section{Brief description of protocol and relation to export pathways:}

The day/night abundance, distribution and species composition of the mesozoooplankton control two of the main exports pathways: active transport and fecal pellet production. To characterize these communities biomass and abundance analyses of the water column will be conducted.

Biomass: Biomass analysis will be conducted following established protocols and will provide cross calibration of our results with other datasets (Madin et al. 2001; Steinberg et al. 2000, 2008), with the sample split poured through nested sieves (0.2-, 0.5-, 1-, 2-, and 5-mm mesh), and contents of each concentrated onto pre-weighed, 0.2-mm Nitex mesh filters and frozen on board at $-20^{\circ} \mathrm{C}$. Filters will be subsequently thawed, weighed to obtain wet weight, then dried for $24 \mathrm{~h}$ at $60^{\circ} \mathrm{C}$ and weighed again to obtain dry weight. Each dried sample will then be homogenized using a mortar and pestle, and a weighed subsample analyzed for $C \& N$ content using an elemental analyzer (Madin et al., 2001). From these measurements wet, dry, and C\&N biomass $\left(\mathrm{mg} \mathrm{m}^{-3}\right)$ will be calculated by dividing the biomass by the volume filtered through the net. In the event of a salp, doliolid, or other gelatinous zooplankton bloom, measured abundance, size, and biovolume from fresh samples will be converted to wet/dry weight and C\&N (Madin et al., 2001; Stone and Steinberg, 2014).

Abundance: To characterize mesozooplankton size distribution and taxonomic composition within each depth strata, we will use both the MOCNESS and UVP. The MOCNESS sample split will be preserved in buffered formaldehyde and an aliquot of each preserved sample will be imaged with a ZooSCAN optical imaging system (Hydroptic) using two size classes $(>2 \mathrm{~mm},<2 \mathrm{~mm}$ ) following established procedures (Gorsky et al., 2010; Picheral et al., 2017; Vandromme et al., 2012). Image analysis of at least 1000 particles per sample will be conducted via the widely used ZooProcess and EcoTaxa pipeline. UVP automated image analyses will be also done using ZooProcess and EcoTaxa. From both the ZooSCAN and UVP analyses, counts and biovolumes will be obtained by major taxon (copepods, euphausiids, doliolids, ostracods, etc). Certain taxa of interest (e.g., known ontogenetic migrators of the calanoid copepod families) will be identified to species using ZooSCAN or microscopy. Biovolumes from the ZooSCAN will be calculated by dividing the biovolumes per group by the split and volume filtered through the net. They will then be added together by animal size to directly compare to the size fractionated biomass measurements to provide an estimation of uncertainty using the equations of Davis \& Wiebe (1985).

Other contributing protocols: MOCNESS sampling.

Uncertainties and quality control concerns: Although the ZooScan and EcoTaxa pipeline are semiautomated, the quality of organismal identification via machine learning algorithms is variable. The learning set will be carefully cultivated and images quality-checked to optimize identification.

Data products originating with this method:

\begin{tabular}{ll}
\hline Parameter & Units \\
\hline zooplankton wet biomass $^{*}$ & $\mathrm{mg} \mathrm{m}^{-3} \mathrm{~d}^{-1}$ \\
zooplankton dry biomass $^{*}$ & $\mathrm{mg} \mathrm{m}^{-3} \mathrm{~d}^{-1}$ \\
zooplankton C\&N biomass $^{*}$ & $\mathrm{mg}-\mathrm{C}$ or $\mathrm{N} \mathrm{m}^{-3} \mathrm{~d}^{-1}$
\end{tabular}


zooplankton abundance** \# individuals taxonomic group ${ }^{-1} \mathrm{~m}^{-3}$

${ }^{*}$ Reported for each of 5 size fractions for each vertical strata of the MOCNESS during both day and night ** Reported for each vertical strata of the MOCNESS during both day and night

\section{SeaBASS fields and units:}

/fields=R2R_Event,date,time,depth,depth_start,depth_end,volfilt,zoop_biomass_wet_0200umfilt_0500u mprefilt,zoop_biomass_wet_0500umfilt_1000umprefilt,zoop_biomass_wet_1000umfilt_2000umprefilt,z oop_biomass_wet_2000umfilt_5000umprefilt,zoop_biomass_wet_5000umfilt,zoop_biomass_dry_0200u mfilt_0500umprefilt,zoop_biomass_dry_0500umfilt_1000umprefilt,zoop_biomass_dry_1000umfilt_2000 umprefilt,zoop_biomass_dry_2000umfilt_5000umprefilt,zoop_biomass_dry_5000umfilt

/units=none,yyyymmdd,hh:mm:ss, $\mathrm{m}, \mathrm{m}, \mathrm{m}, 1, \mathrm{mg} / \mathrm{m}^{\wedge} 3, \mathrm{mg} / \mathrm{m}^{\wedge} 3, \mathrm{mg} / \mathrm{m}^{\wedge} 3, \mathrm{mg} / \mathrm{m}^{\wedge} 3, \mathrm{mg} / \mathrm{m}^{\wedge} 3, \mathrm{mg} / \mathrm{m}^{\wedge} 3, \mathrm{mg} / \mathrm{m}^{\wedge} 3$, $\mathrm{mg} / \mathrm{m}^{\wedge} 3, \mathrm{mg} / \mathrm{m}^{\wedge} 3, \mathrm{mg} / \mathrm{m}^{\wedge} 3$

\section{Key method references}

Gorsky, G., Ohman, M. D., Picheral, M., Gasparini, S., Stemmann, L., Romagnan, J.-B., Cawood, A., Pesant, S., Garcia-Comas, C. and Prejger, F. (2010). Digital zooplankton image analysis using the ZooScan integrated system. Journal of Plankton Research 32, 285-303.

Madin, L. P., Horgan, E. F. and Steinberg, D. K. (2001). Zooplankton at the Bermuda Atlantic Timeseries Study (BATS) station: diel, seasonal and interannual variation in biomass, 1994-1998. Deep Sea Research Part II: Topical Studies in Oceanography 48, 2063-2082.

Steinberg, D.K., C.A. Carlson, N.R. Bates, S.A. Goldthwait, L.P. Madin, and A.F. Michaels. (2000). zooplankton vertical migration and the active transport of dissolved organic and inorganic carbon in the Sargasso Sea. Deep-Sea Research I 47: 137-158

Steinberg, D. K.,J. S. Cope, S. E. Wilson, and T. Kobari. (2008). A comparison of mesopelagic mesozooplankton community structure in the subtropical and subarctic North Pacific Ocean. DeepSea Research II 55(14-15): 1615-1635.

Stone, J. P. and Steinberg, D. K. (2014). Long-term time-series study of salp population dynamics in the Sargasso Sea. Mar. Ecol. Prog. Ser 510, 111-127. 
Method: Zooplankton respiration, excretion, and egestion experiments

Document author and contact info: Amy Maas, Amy.Maas@bios.edu

\section{Brief description of protocol and relation to export pathways:}

Respiration of diel vertical migratory (DVM) zooplankton is one of the five export pathways, while excretion of DOC and egestion of POC as fecal pellets at depth may also contribute to "active flux". We will perform live respiration and excretion experiments on dominant migratory species to provide measurements of key species' contribution to community active $\mathrm{C}$ flux during each ecosystem state sampled. Oxygen consumption will be measured and will serve as a proxy for respiratory $\mathrm{CO}_{2}$ excretion while DOC excretion and POC egestion will be measured directly. These will be scaled to community level export using the biomass measures and DVM species identification made with the MOCNESS.

Incubations will be carried out for $12 \mathrm{~h}$, in the dark, in filtered seawater, and at daytime residence depth temperature to mimic time spent and conditions (non-feeding, cold) at depth. Prior to incubation, $20 \mathrm{~L}$ of water will be collected, filtered $(0.2 \mu \mathrm{m})$, and stored in an incubator at in situ mesopelagic temperature and in darkness for $<8 \mathrm{~h}$ prior to use in respiration experiments.

Migrators are collected from the EZ at night. Individuals of each of the dominant migratory groups (e.g., euphausiids, Metridia spp, Calanus/Neocalanus spp., and hyperiid amphipods) will be gently selected using a wide-bore pipette or small ladle. Effort is also made to obtain more rare migratory organisms (gelatinous species, decapods). Individuals are selected to provide a large within-species range of sizes, with at least 10 replicates for each dominant species sampled over the course of each ecosystem state. Immediately following collection, individuals are placed into custom $20-250 \mathrm{~mL}$ chambers (dependent upon organism size) containing $0.2 \mu \mathrm{m}$ filtered seawater (Saba et al., 2011; Schnetzer and Steinberg, 2002). Each chamber contains an optical sensing spot to allow for semi-continuous measurements of oxygen using a multi-channel FireSting optical oxygen meter (PyroScience, Aachen Germany; Maas et al., 2016). Chambers are maintained in the dark in onboard incubators at in situ mesopelagic temperature. Chambers without animals serve as controls. Separate incubations will also be set up to determine the contribution of bacterial respiration associated with any egested fecal pellets. Incubations are monitored semi-continuously, with measurements of oxygen concentration taken at $2 \mathrm{~h}$ intervals for a total of $12 \mathrm{~h}$. At the end of the incubation individuals are removed and frozen in liquid N. Upon return to land these individuals are imaged for biovolume cross-calibration, dried, and weighed on a Mettler Toledo Microbalance. A sample of incubation water will then be collected for DOC and analyzed post-cruise using a Shimadzu TOC analyzer 5000A (Peltzer et al., 1996; Sharp et al., 2002). Both individual and weight-specific respiration, excretion, and egestion are calculated for each dominant migratory species. Regressions for each species, along with 95\% confidence intervals are reported for allometric scaling results. Species counts from net tows are used to scale up individual rates to community respiration, excretion, and egestion, and active transport for dominant species (Steinberg et al., 2000).

Other contributing protocols: MOCNESS abundance and biomass sampling to scale individual respiration and excreta experiments to community export.

Uncertainties and quality control concerns: Physiological effect of net capture and incubation; circadian patterns in physiology; effect of pressure (which is not controlled for). When scaling - the effects of zooplankton patchiness and variation in species physiology. 
Data products originating with this method:

\begin{tabular}{|c|c|}
\hline Parameter & Units \\
\hline $\begin{array}{l}\text { active (respiratory) flux } \\
\text { zooplankton }^{-1 *}\end{array}$ & mg-C $(\mathrm{mg} \text { body } \mathrm{C})^{-1} \mathrm{~d}^{-1}$ \\
\hline $\begin{array}{l}\text { active (respiratory) flux } \\
\text { vertical strata }^{-1}\end{array}$ & $\mathrm{mg}-\mathrm{C} \mathrm{m} \mathrm{m}^{-2} \mathrm{~d}^{-1}$ \\
\hline $\begin{array}{l}\text { active DOC flux } \\
\text { zooplankton }^{-1 *}\end{array}$ & $\operatorname{mg}-\mathrm{C}(\mathrm{mg} \text { body } \mathrm{C})^{-1} \mathrm{~d}^{-1}$ \\
\hline $\begin{array}{l}\text { active DOC flux vertical } \\
\text { strata }^{-1}\end{array}$ & 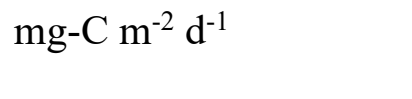 \\
\hline
\end{tabular}

\section{SeaBASS submission fields and units:}

/fields=sample_1id,sample_2id,lat,lon,namespace_manual,identification_manual,biotic_group,abundance ,station_alt_id,date,sample_3id,sample_4id,sample_5id,volume,elapsed_time,weight_wet,weight_dry,Wt, rate_respiration_O2_ind,rate_respiration_C_ind,rate_production_DOC_ind

/units=none,none,degrees, degrees,none,none,none,none,none,yyyymmdd,none,none,none,L,seconds,mg, $\mathrm{mg}$,degreesC,umol/ind/h,mg/mg_body_C/d,mg/mg_body_C/d

/id_fields_definitions=1id:respiration_id,2id:DOC_id,3id:exp_id,4id:id_number,5id:net_tow_id

Key method references

Peltzer, E. T., Fry, B., Doering, P. H., McKenna, J. H., Norrman, B. and Zweifel, U. L. (1996). A comparison of methods for the measurement of dissolved organic carbon in natural waters. Marine Chemistry 54, 85-96.

Schnetzer, A. and Steinberg, D. K. (2002). Active transport of particulate organic carbon and nitrogen by vertically migrating zooplankton in the Sargasso Sea. Marine Ecology Progress Series 234, 71-84.

Steinberg, D. K., Carlson, C. A., Bates, N. R., Goldthwait, S. A., Madin, L. P. and Michaels, A. F. (2000). Zooplankton vertical migration and the active transport of dissolved organic and inorganic carbon in the Sargasso Sea. Deep Sea Research Part I 47, 137-158. 
Method: Zooplankton respiration, excretion, and egestion as a function of size and temperature

Document author and contact info: Amy Maas, Amy.Maas@bios.edu

\section{Brief description of protocol and relation to export pathways:}

Respiration of diel vertical migratory (DVM) zooplankton at depth is one of the five export pathways, while excretion of DOC and egestion of POC as fecal pellets at depth may also contribute to "active flux".

The biomass and abundance measurements from the MOCNESS and UVP sampling are used to calculate downward active flux of respiratory $\mathrm{CO}_{2}$ by migrant zooplankton $\left(\mathrm{mg} \mathrm{C} \mathrm{m}^{-2} \mathrm{~d}^{-1}\right)$ as by Al-Mutairi \& Landry (2001) uzsing respiration rates calculated from published empirical allometric relationships based on zooplankton taxon, weight, and temperature (Ikeda, 1985; Ikeda, 2014). Migrants are assumed to reside below the EZ $12 \mathrm{~h}$ during the day, with equal time spent in the surface waters at night, and the average temperature experienced by migrants at depth during the day for each tow is applied (Dam et al. 1995, Steinberg et al. 2000, 2008a or b, 2012, Al-Mutairi \& Landry 2001, Hannides et al. 2009). Downward active flux of DOC excreted, and POC egested as fecal pellets, by migrant zooplankton (mg C $\mathrm{m}^{-2} \mathrm{~d}^{-1}$ ) are each calculated as $31 \%$ of downward active flux of $\mathrm{CO}_{2}$, based on experimental results from previous studies (Steinberg et al. 2000, Schnetzer \& Steinberg 2002, Goldthwait \& Steinberg 2008). Weight-specific respiration, excretion, and egestion rates are scaled up (for each size fraction) to the entire migrating biomass (night minus day biomass in EZ or mixed layer).

Other contributing protocols: MOCNESS abundance and biomass sampling and environmental parameters. UVP sampling of the gelatinous community. Ground truth of respiratory demand, DOC and POC production from experiments.

Uncertainties and quality control concerns: Application of scaling factors assumes that biomass and temperature are the main constraints on respiratory and excreta rate, if there are species specific differences or variations in physiology due to some other factor (food availability, oxygen, circadian rhythm, etc), they will not be accounted for. The factors used in allometric equations to calculate metabolic rates (temperature, taxonomic group, size and depth habitat) characterize $\sim 93 \%$ of the variance in respiration data (Ikeda, 2014).

Data products originating with this method:

\begin{tabular}{ll}
\hline Parameter & Units \\
\hline $\begin{array}{l}\text { zooplankton active POC } \\
\text { flux }\end{array}$ & $\mathrm{mg}-\mathrm{C} \mathrm{m}^{-2} \mathrm{~d}^{-1}$ \\
zooplankton active DOC & $\mathrm{mg}-\mathrm{C} \mathrm{m}^{-2} \mathrm{~d}^{-1}$ \\
flux & \\
$\begin{array}{l}\text { zooplankton active } \\
\text { respiratory flux }\end{array}$ & $\mathrm{mg}-\mathrm{C} \mathrm{m}^{-2} \mathrm{~d}^{-1}$ \\
\hline
\end{tabular}

\section{Key method references}

Ikeda, T. (2014). Respiration and ammonia excretion by marine metazooplankton taxa: synthesis toward a global-bathymetric model. Marine Biology 161, 2753-2766. 
Al-Mutairi, H. and Landry, M. R. (2001). Active export of carbon and nitrogen at Station ALOHA by diel migrant zooplankton. Deep Sea Research Part II: Topical Studies in Oceanography 48, 2083-2103. 
Document author and contact info: Amy Maas (BIOS), amy.maas@bios.edu

Measurement and instrument: Analysis of zooplankton particles from MOCNESS net sampling with ZooScan and associated EcoTaxa Pipeline

A brief description of the method: A sample split from each net of all MOCNESS tows was preserved in buffered formaldehyde and an aliquot from each was imaged with a ZooSCAN optical imaging system (Hydroptic) using two size classes $(>2 \mathrm{~mm},<2 \mathrm{~mm}$ ) following established procedures (Gorsky et al. 2010, Bachiller et al. 2012, Vandromme et al. 2012, Lebourges-Dhaussy et al. 2014). Briefly the sample was passed through a sieve to create the two size fractions and then split to attain $\sim 1000-1500$ particles. The subsample was poured into the ZooSCAN then particles were manually separated. An image was then taken at 4800 dpi. All images were processed using the pipeline described below.

Data processing: Image analysis of at least 1000 particles per MOCNESS sample was conducted via the widely used ZooProcess and EcoTaxa pipeline. The software automatically separates particles and measures their major dimensions. They images were then loaded into a database where machine learning algorithms compare the images to other validated zooplankton images, assigning a taxonomic group to the image. This was validated manually. Counts were then be obtained for major taxon (copepods, euphausiids, doliolids, ostracods, etc) and biovolumes calculated using taxon specific equations and measurements. Biovolumes from the ZooSCAN were calculated by dividing the biovolumes per group by the split and volume filtered through the net for the MOCNESS.

Data products originating from the method: Images of individual zooplankton; estimates of taxonomic composition of imaged zooplankton, abundance and biomass (biovolume) by size and taxon.

\section{Key method references:}

Bachiller, E., J. A. Fernandes, and X. Irigoien. 2012. Improving semiautomated zooplankton classification using an internal control and different imaging devices. Limnology and Oceanography: Methods 10:1-9.

Davis, C. S., and P. H. Wiebe. 1985. Macrozooplankton biomass in a warm-core Gulf Stream ring: Time series changes in size structure, taxonomic composition, and vertical distribution. Journal of Geophysical Research: Oceans 90:8871-8884.

Gorsky, G., M. D. Ohman, M. Picheral, S. Gasparini, L. Stemmann, J.-B. Romagnan, A. Cawood, S. Pesant, C. Garcia-Comas, and F. Prejger. 2010. Digital zooplankton image analysis using the ZooScan integrated system. Journal of Plankton Research 32:285-303.

Lebourges-Dhaussy, A., J. Huggett, S. Ockhuis, G. Roudaut, E. Josse, and H. Verheye. 2014. Zooplankton size and distribution within mesoscale structures in the Mozambique Channel: A comparative approach using the TAPS acoustic profiler, a multiple net sampler and ZooScan image analysis. Deep Sea Research Part II: Topical Studies in Oceanography 100:136-152.

Vandromme, P., L. Stemmann, C. Garcìa-Comas, L. Berline, X. Sun, and G. Gorsky. 2012. Assessing biases in computing size spectra of automatically classified zooplankton from 
imaging systems: A case study with the ZooScan integrated system. Methods in Oceanography 1-2:3-21. 
Method: Particulate inorganic carbon (PIC) by coulometry

Document author and contact info: Antonio Mannino (antonio.mannino@nasa.gov)

\section{Brief description of protocol:}

Large volumes of seawater ( 4 to $10 \mathrm{~L}$ ) are filtered onto plastic (polypropylene or polycarbonate) $47 \mathrm{~mm}$ diameter filters in duplicate (daily triplicates), which do not adsorb appreciable amounts of salts. Residual salts are removed from the filter by rinsing with a borate buffer. Filter sample blanks should also be collected daily by filtering a similar volume of pre-filtered ( $<0.2 \mathrm{um}$ ) seawater as the samples. Filters are packaged individually in foil packets and stored frozen ($20 \mathrm{C}$ should suffice; -80C even better). The coulometer is setup according to manufacturer recommendations. Samples should be permitted to reach room temperature prior to analysis. A standard calibration curve of calcium carbonate should be performed that spans the full mass range of expected PIC on the filters. The filter or carbonate standard is inserted into the bottom of a glass analysis flask and connected to the digestion system on the Coulometer and sealed. Phosphoric acid is introduced into sample flask and allowed to digest the sample until no additional $\mathrm{CO}_{2}$ is measurable inside the Coulometer cell. The inorganic carbon content from each filter analyzed is computed based on the calcium carbonate calibration curve. Finally, the seawater filter blank value is subtracted from total PIC measured on each sample filter. Instrument performance is validated daily with the DIC reference material available from the Dickson lab at Scripps.

\section{Measured Parameter and Units:}

Particulate Inorganic Carbon $-\mathrm{mg} \mathrm{m}^{-3}$ or micromoles $\mathrm{kg}^{-1}$

\section{Uncertainties and quality control concerns:}

Uncertainty in PIC stem from:

1. Seawater filter sample blanks with measurable carbon content; blanks with $<0.5$ ug $C$ are achievable.

2. Uncertainties in the calcium carbonate calibration curve, including the purity of the standard, weighing of the standard, and performance of the Coulometer.

3. DIC reference material correction factor.

4. Accuracy in volume filtered and other filtration handling issues.

5. Low signal due to low concentration of PIC in the absence of high abundances of coccolithophores and other calcium carbonate bearing plankton.

Key method references

1. Johnson, K. M., A. E. King, and J. McN. Sieburth (1985), Coulometric $\mathrm{TCO}_{2}$ analyses for marine studies; an introduction, Marine Chemistry, 16, 61-82.

2. Lamborg, C. H., K. O. Buesseler, et al. (2008), The flux of bio- and lithogenic material associated with sinking particles in the mesopelagic "twilight zone" of the northwest and North Central Pacific Ocean, Deep-Sea Research II, 55, 1540-1563. 
Method: 18S rDNA amplicon analysis of eukaryotic plankton

Document author and contact info: Adrian Marchetti, amarchet@email.unc.edu

Brief description of protocol and relation to export pathways: Duplicate seawater samples $(4 \mathrm{~L})$ are collected in low density polyethylene (LDPE) cubitainers and immediately filtered onto Millipore Supor filters $(0.8 \mu \mathrm{m}$ pore size, $47 \mathrm{~mm})$. Filters are immediately flash frozen in liquid nitrogen and stored at $-80{ }^{\circ} \mathrm{C}$. Onshore, DNA is extracted from individual cut-up filters using the Qiagen DNeasy Plant Mini Kit (Qiagen, Hilden, Germany) according to the manufacturer's protocols with an initial bead beating step. Genomic DNA of Thermus Thermophilus, which is not expected to be present in the water samples, is added as internal standards to quantitatively characterize community composition. The amount of internal standards is determined with qPCR to have internal standards only comprise around $1 \%$ of the total sequenced reads. The V4 hypervariable region is amplified with barcoded custom $18 \mathrm{~S}$ V4 primers $\mathrm{F}$ (5'-CCAGCASCYGCGGTAATTCC-3') and R (5'-ACTTTCGTTCTTGAT-3') (Wang et al., 2018). PCR products are quality checked on a gel and pooled to have similar amounts of DNA from each sample. The pooled library is submitted for sequencing on an Illumina Miseq platform (San Diego, CA, USA). DNA sequences are analyzed in QIIME 2 to profile eukaryotic plankton community composition (Caporaso et al., 2010).

Other contributing protocols: Metagenomics analysis of surface water eukaryotic phytoplankton (Marchetti).

Uncertainties and quality control concerns: $18 \mathrm{~S}$ rRNA gene copy variation, PCR bias and sequencing errors.

\section{Data products originating with this method:}

\begin{tabular}{ll}
\hline Parameter $^{*}$ & Units \\
\hline OTU abundance & Counts \\
DNA sequences & fastq \\
\hline
\end{tabular}

\section{Key method references:}

Caporaso JG, Kuczynski J, Stombaugh J, Bittinger K, Bushman FD, Costello EK, et al. (2010). QIIME allows analysis of high-throughput community sequencing data. Nat Methods 7: 335-336.

Wang S, Lin Y, Gifford S, Eveleth R, Cassar N. (2018). Linking patterns of net community production and marine microbial community structure in the western North Atlantic. ISME $J 1$. 
Method: mRNA sequencing of poly-A selected (eukaryotic) genes

Document author and contact info: Adrian Marchetti, amarchet@email.unc.edu; Weida gong (wdgong@live.unc.edu)

Brief description of protocol and relation to export pathways: Triplicate seawater samples (10L) will be collected in LDPE cubitainers and immediately filtered onto Millipore Supor filters $(0.45 \mu \mathrm{m}$ pore size, $142 \mathrm{~mm})$ by way of a peristaltic pump. Filter times will be limited to a maximum of 30 minutes and conducted under dim light. Filters will be immediately flash frozen in liquid nitrogen and then stored at $-80^{\circ} \mathrm{C}$. In the laboratory, RNA will be extracted from individual thawed filters using TRIzol reagent (Invitrogen, Carlsbad, CA, USA) according to manufacturer protocols with an initial bead beating process. Sequence library preparation and sequencing will be performed at the UNC High Throughput Sequencing Facility in Chapel Hill using standard Illumina library prep protocols (TruSeq Stranded Total RNA kit, San Diego, CA, USA) and the Illumina HiSeq 4000 Platform. Sequences will be assembled using Trinity (v 2.4.0) and annotated with tBLASTx (v 2.6.0) against MarineRefII and Kyoto Encyclopedia of Genes and Genomes (KEGG) for taxonomic and functional information. Sequence abundance will be normalized with R package DESeq2 to assess expression levels of genes. Genes that have significant relationships with rate processes and other physiological parameters will be identified and used to infer the physiological status of both autorophic and heterotrophic protists. See Marchetti et al., (2012) for an overview of the metatranscriptomic approach and Gong et al., (2016) for more details on RNA extraction, library preparation and bioinformatics pipeline.

Other contributing protocols: RNA extraction, cDNA synthesis.

Uncertainties and quality control concerns: RNA extraction efficiency and library preparation quality.

Data products originating with this method:

\begin{tabular}{ll}
\hline Parameter $^{*}$ & Units \\
\hline Transcript abundance & Counts per Million (CPM) \\
Gene expression & Fold change \\
\hline
\end{tabular}

\section{Key method references:}

Gong W, Browne J, Hall N, Schruth D, Paerl HW, Marchetti A. (2016). Molecular insights into a dinoflagellate bloom. ISME J. e-pub ahead of print, doi: 10.1038/ismej.2016.129.

Marchetti A, Schruth DM, Durkin CA, Parker MS, Kodner RB, Berthiaume CT, et al. (2012). Comparative metatranscriptomics identifies molecular bases for the physiological responses of phytoplankton to varying iron availability. Proc Natl Acad Sci U S A 109: E317-25. 
Method: Experimental chlorophyll - 90\% ethanol extraction

AdrianMarchetti (amarchet@email.unc.edu),Weida Gong

University_of_North_Carolina

Triplicate seawater samples $(400 \mathrm{ml})$ were filtered onto polycarbonate filters (via gravity) and GF/F filters (via gentle vacuum) arranged in a series cascade. Filters were then immersed in $6 \mathrm{ml} 96 \%$ ethanol in scintillation vials for 12 hours before the start of extraction (Graff and Rynearson, 2011). The extracted chl a was quantified using a Turner Designs 10-AU fluorometer using the acidification method (Parsons et al., 1984). Water-column integrated chl a was calculated down to the depth of $1 \%$ incident irradiance level. 
Method: New production/Gross primary productivity/Net primary productivity

Document author and contact info: Adrian Marchetti, amarchet@email.unc.edu; Weida Gong wdgong@live.unc.edu

Brief description of protocol and relation to export pathways: Seawater samples (1L) are collected prior to dawn in triplicate using a Trace Metal Clean Rosette (TMC) system at five depths corresponding to $65 \%, 38 \%, 20 \%, 10 \%$ and $1 \%$ of the incident irradiance $\left(\mathrm{I}_{0}\right)$ and inoculated with pre-determined amounts of $\mathrm{NaH}^{13} \mathrm{CO}_{3}$ and $\mathrm{Na}^{15} \mathrm{NO}_{3}$ stable isotopes (i.e., nonradioactive isotopes). From Epoch 2 Day 6 to Epoch 3 Day 2, seawater samples are collected at depths corresponding to $40 \%, 20 \%, 10 \%, 5 \%$ and $1 \%$ of the incident irradiance to capture particulate maximum at depth of $5 \%$ light level. For $\mathrm{C}$, isotope inoculations are performed at concentrations of $180 \mu \mathrm{M}$, assuming an approximate DIC concentration of 1800-2000 $\mu \mathrm{M}$. For $\mathrm{N}$, isotope inoculations are adjusted to achieve $\sim 10 \%$ of the in situ $\mathrm{NO}_{3}$ concentrations, as premeasured via a submersible untraviolet nitrate analyzer (SUNA) located on the Survey ship. Inoculated samples are then incubated within on-deck surface seawater flow-through incubators screened to mimic in situ light levels of the sampled depths. Seawater samples from mixed layer $(65 \%, 38 \%$ and $20 \%$ of irradiance level) are incubated for 6 hours to estimate mixed layer integrated Gross Primary Productivity (GPP) and another set of seawater samples from all five depth are incubated for 24 hours to provide depth profile of Net Primary Productivity (NPP). After incubation, one sample is filtered directly onto a pre-combusted ( $450{ }^{\circ} \mathrm{C}$ for $4 \mathrm{~h}$ ) $\mathrm{GF} / \mathrm{F}$ filter. The other 2 samples are first filtered onto a $5 \mu \mathrm{m}$ polycarbonate (via gentle vacuum pressure) that contains a collection flask for the filtrate. This filtrate is then filtered onto a precombusted $\mathrm{GF} / \mathrm{F}$ filter (via gentle vacuum pressure). Cells collected on the $5 \mu \mathrm{m}$ polycarbonate filter are washed onto a pre-combusted $\mathrm{GF} / \mathrm{F}$ using an $0.2 \mu \mathrm{m}$ filtered seawater. All GF/F filters are placed into acid-cleaned $30 \mathrm{~mm}$ petri dishes, sealed with vinyl tape and frozen at $-20{ }^{\circ} \mathrm{C}$ until onshore analysis. At each Epoch, a time zero is performed on a single sample at a single depth where the seawater sample is filtered immediately following isotope addition onto a precombusted $\mathrm{GF} / \mathrm{F}$ filter. Onshore, filters are dried at $60^{\circ} \mathrm{C}$ overnight and pellitized in tinfoil squares (Elemental Analysis). Mass spectrometry analysis is performed at the UC Davis Stable Isotope Facility. Particulate nitrogen (PN), particulate carbon $(\mathrm{PC})$, atom $\%{ }^{15} \mathrm{~N}$ and atom $\%{ }^{13} \mathrm{C}$ are obtained for each sample along with filter blanks. Estimates of ${ }^{13} \mathrm{C}$ and ${ }^{15} \mathrm{~N}$ incorporation into cells are performed using equations outlined in Slawyk et al., (1977) and Dauchez et al., (1995) and will provide measurements of uptake of DIC, $\mathrm{NO}_{3}{ }^{-}$along with $\mathrm{PC}$ and $\mathrm{PN}$ concentrations. $\mathrm{DIC} / \mathrm{NO}_{3}{ }^{-}$uptake rates are normalized by $\mathrm{POC} / \mathrm{PON}$, or $\mathrm{Chl} a$ concentrations to obtain biomassspecific uptake rates. To calculate rates, measurements of dissolved $\mathrm{NO}_{3}{ }^{-}$and $\mathrm{DIC}$ concentrations are required to be measured on the same samples. DIC uptake rate from 6 hours and 24 hours incubation are depth integrated to estimate depth-integrated GPP and NPP, respectively. New production estimates are calculated from $\mathrm{NO}_{3}$ uptake rates multiplied by the Redfield ratio and normalized to DIC uptake rates as outlined in Aufdenkampe et al. 2002.

Other contributing protocols: mRNA sequencing of poly-A selected (eukaryotic) genes (Marchetti) 
Uncertainties and quality control concerns: Amount of ${ }^{13} \mathrm{C} /{ }^{15} \mathrm{~N}$ incorporated into organic matter that gets respired and/or excreted from phytoplankton during the 6 hour (short-term) and 24 hour (log term) incubations.

Data products originating with this method:

\begin{tabular}{|c|c|}
\hline Parameter* & Units \\
\hline Nitrate uptake rate & $\mathrm{mol} \mathrm{N} \mathrm{m} \mathrm{m}^{-3}$ \\
\hline f-ratio & no units \\
\hline Gross primary production rate & $\operatorname{mol~C~m} \mathrm{m}^{-1}$ \\
\hline Net primary production rate & $\operatorname{mol~C~m} \mathrm{m}^{-3} \mathrm{~d}^{-1}$ \\
\hline
\end{tabular}

\section{SeaBASS submission fields and units:}

/fields=date,depth,rate_13C_uptake_bottle_24hr_5umfilt,rate_13C_uptake_bottle_24hr_0.7umfil t_5umprefilt,rate_13C_uptake_bottle_6hr_5umfilt,rate_13C_uptake _bottle_6hr_0.7umfilt_5ump refilt,rate_15N_uptake_bottle_24hr_5umfilt,rate_15N_uptake_bottle_24hr_0.7umfilt_5umprefilt ,rate_15N_uptake_bottle_6hr_5umfilt,rate_15N_uptake_bottle_6hr_0.7umfilt_5umprefilt

/units=yyyymmdd,m,mol/L/d,mol/L/d,mol/L/d,mol/L/d,mol/L/d,mol/L/d,mol/L/d,mol/L/d

Key method references:

Dauchez S, Legendre L, Fortier L. (1995). Assessment of simultaneous uptake of nitrogenous nutrients $(15 \mathrm{~N})$ and inorganic carbon $(13 \mathrm{C})$ by natural phytoplankton populations. Mar Biol 123: $651-666$.

Slawyk G, Collos Y, Auclair J-C. (1977). The use of the ${ }^{13} \mathrm{C}$ and ${ }^{15} \mathrm{~N}$ isotopes for the simultaneous measurement of carbon and nitrogen turnover rates in marine phytoplankton1. Limnol Oceanogr 22: 925-932.

Aufdenkampe, A. K., McCarthy, J. J., Navarette, C., Rodier, M., Dunne, J. \& Murray, J. W. (2002). Biogeochemical controls on new production in the tropical Pacific. Deep-Sea Res. II 49: 2619-48. 


\title{
Optics Working Group
}

\section{Protocol Brief: Particle Size Distributions from LISST-DEEP}

\author{
Primary Author: Andrew McDonnell, amcdonnell@alaska.edu
}

Brief Description of Protocol: The LISST (Laser In-Situ Scattering Transmissometer) DEEP is an in situ instrument that is equipped with a collimated laser diode and a ring detector that measures intensity of scattering of the laser through the water as a function of scattering angle. The resulting small angle Volume Scattering Function (VSF) is used in a mathematical inversion in order to derive the particle size distribution for particles ranging in size between 1.25 and $250 \mu \mathrm{m}$.

Deployment methodologies: The LISST DEEP is a profiling instrument that will be attached to the CTD rosettes of both the EXPORTS Process and Survey Ships. The instrument measures the scattering that results from particles contained within the water as the rosette descends through the water column.

Measurements are conducted at a $1 \mathrm{~Hz}$ sampling rate and this data is used to construct a vertical profile of the size distribution for every CTD rosette cast conducted. The instrument is powered by the CTD and rated to $3000 \mathrm{~m}$, enabling deep profiles from the surface, through the mesopelagic zone, and into the

Contributing Approaches: (Analysis - approach - potential collaborators)

In situ measurements of the particle size distribution throughout the water column are a core component of EXPORTS and have many potential synergies with other observations. Together, the LISST DEEP and the UVP5 produce information on the in situ particle size distribution across a wide and overlapping range of size classes, enabling the estimation of a unified size distribution estimate. Bottle-collected measurements of the full VSF will also be conducted, and compared to the in situ measurements from the LISST DEEP (which only measures small angle scattering). Size distribution data will be compared to particles collected and analyzed via other methods such as the marine snow catcher (MSC), in situ pumps, bulk sediment traps, polyacrylamide gels. Together, these measurements will be used to derive estimates of particle composition, sinking velocity, and flux as a function of particle size.

\section{Uncertainties and Quality Control concerns:}

Filtered sea water is used to regularly measure scattering blanks in order to determine the background scattering, and this will be used to correct the VSF. Each calibration and computational step does involve unavoidable assumptions and uncertainties especially with regard to particles with differing optical properties. Uncertainties also arise at low particle concentrations.

\section{Data products:}

\begin{tabular}{|l|l|}
\hline Parameter & Units \\
\hline Optical transmission@ $@ 670 \mathrm{~nm}$ & $\mathrm{~m}^{-1}$ \\
\hline
\end{tabular}




\begin{tabular}{|l|l|}
\hline Volume Scattering Function & $\mathrm{m}^{-1} \mathrm{sr}^{-1}$ \\
\hline Particle concentration size distribution & $\mu \mathrm{L} \mathrm{L}^{-1} \mu \mathrm{m}^{-1}$ \\
\hline
\end{tabular}

\section{References:}

Agrawal YC,Whitmire A, Mikkelsen OA, Pottsmith HC (2008): Light scattering byrandom shaped particles and consequences on measuring suspendedsediments by laser diffraction. Journal of Geophysical Research 113,C04023.

Agrawal YC, Pottsmith HC (2000): Instruments for Particle Size and Settling Velocity Observations in Sediment Transport. Marine Geology 168:89-114.

Y.C. Agrawal, I.N. McCave, J.B. Riley, Laser diffraction size analysis, J.M. Syvitski (Ed.), Principles, Methods, and Application of Particle Size Analysis, Cambridge University Press, Cambridge(1991), pp. $119-128$

Slade WH, Boss E (2006): Calibrated near-forward volume scatteringfunction obtained from the LISST particle sizer. Optics Express 14: 3602-3615. 


\title{
Protocol Brief:
}

Particle and zooplankton characterization from the Underwater Vision Profiler (UVP)

\section{Document authors}

Andrew McDonnell, amcdonnell@alaska.edu,

Lee Karp-Boss, lee.karp-boss@maine.edu

\section{Contacts regarding data:}

Revelle: Emmanuel Boss, Emmanuel.boss@maine.edu

Lee Karp-Boss, lee.karp-boss@maine.edu

Sally Ride: Andrew McDonnell, amcdonnell@alaska.edu

\begin{abstract}
A brief description of the method: The Underwater Vision Profiler (UVP5) is an underwater camera system that was designed to record the vertical distributions of large aggregates and zooplankton (> 50 $\mu \mathrm{m}$ ) down to $6,000 \mathrm{~m}$. Two units that consist of red-light emitting diodes (LEDs) illuminate (in $100 \mu \mathrm{m}$ flashes) an area of $4 \times 20 \mathrm{~cm}$ which provides a volume sampling of $\sim 1 \mathrm{~L}$ per frame. The UVP5-HD was mounted on the bottom of each CTD rosette and collected data on each CTD cast (data are collected during down cast).
\end{abstract}

Data processing: The UVP5 software acquires and process images in real time. The gain, shutter and LED pulses are controlled and the background image is removed. Images are acquired and processed to get size and grey level for each image. Size information on all detected particles is stored but only Images of particles and plankton larger than $500 \mu \mathrm{m}$ in equivalent spherical diameter are segmented and saved for later identification. Image post processing and metadata acquisition is accomplished with the Zooprocess software. Tabulated particle data are used to sum the number and volume of particles within predefined size bins, allowing for the computation of the Datasets. Data and images have been uploaded to the Ecotaxa website (http://ecotaxa.obs-vlfr.fr/) which serves as a tool for particle and zooplankton identification with machine learning and human verification, as well as a repository for all globally collected UVP data. Data files for particle and zooplankton abundances

Calibrations: Calibration of the UVP5 are done by the manufacturer and include quantifying the illuminated volume and determining the appropriate conversion between particle area in pixels and $\mathrm{mm}$. The latter is done by measuring the size of particles with a microscope and their corresponding area in the UVP (dropping particles one at a time in the field of view of the camera). The two instruments were sent together to the manufacturer for pre-cruise calibration, where inter-calibration against the same 'standard' UVP was done at the same time. Inter-calibration between UVP 
instruments and a 'standard' is done in situ (Bay of Villefranche, France) and allows for the comparability of all UVP5 data within the global database.

\section{Uncertainties and Quality Control concerns:}

Uncertainties in concentrations increase with increasing particle size as these particles are less abundant. Small image volumes ( $1 \mathrm{~L})$ and low abundances of zooplankton often lead to high uncertainties in concentration due to a low number of identifiable zooplankton. Additionally, some zooplankton have avoidance swimming behavior and avoid being sampled. Thus, quantitative measures of zooplankton may not be possible at high resolutions in space, depth and time. Low image resolution only allows taxonomic identification at the rank of subclass or higher.

\section{Data products:}

\begin{tabular}{|l|l|}
\hline Parameter & Units \\
\hline Total particle concentration (includes zooplankton) & $\# \mathrm{~m}^{-3}$ \\
\hline $\begin{array}{l}\text { Total particle concentration size distribution (includes } \\
\text { zooplankton) }\end{array}$ & $\# \mathrm{~m}^{-4}$ \\
\hline $\begin{array}{l}\text { Total particle volume concentration (includes } \\
\text { zooplankton) }\end{array}$ & unitless \\
\hline $\begin{array}{l}\text { Total particle volume concentration size distribution } \\
\text { (includes zooplankton) }\end{array}$ & $\mathrm{m}^{-1}$ \\
\hline Zooplankton concentration & $\# \mathrm{~m}^{-3}$ \\
\hline Zooplankton concentration size distribution & $\# \mathrm{~m}^{-4}$ \\
\hline Zooplankton particle volume concentration & $\mathrm{unitless}^{-4}$ \\
\hline Zooplankton volume concentration size distribution & $\mathrm{m}^{-1}$ \\
\hline Zooplankton concentration by taxonomic group & $\# \mathrm{~m}^{-3}$ \\
\hline Non-zooplankton particle concentration & $\# \mathrm{~m}^{-3}$ \\
\hline Non-zooplankton particle concentration size distribution \\
\hline Non-zooplankton particle volume concentration & $\# \mathrm{~m}^{-4}$ \\
\hline Non-zooplankton particle volume concentration size & $\mathrm{m}^{-1}$ \\
\hline itless \\
\hline
\end{tabular}


Particle concentration by type $\# \mathrm{~m}^{-3}$

\section{Key References:}

Picheral, M. et al. The Underwater Vision Profiler 5: An advanced instrument for high spatial resolution studies of particle size spectra and zooplankton. Limnol. Ocean. Methods 8, 462-473 (2010).

Guidi et al. 2008. Relationship between particle size distribution and flux in the mesopelagic zone. Deep Sea Research I., 55:1364. 
Document author and contact info: Susanne Menden-Deuer(URI), smenden@uri.edu

Measurement and instrument: Size and abundance measurements of suspended particles with a Beckman Coulter Counter, Multisizer III (version 3.53; Beckman Coulter, Inc, Brea, CA)

A brief description of the method: The measurement of particle sizes and concentrations proceeds through the Coulter principle, which quantifies changes in electrical impedance within a sensing zone surrounding a specified aperture $(20-500 \mu \mathrm{m})$ produced by particles suspended in an electrolyte. The instrument measures only the impedance and does not provide characteristics of particles. As such, particles are not characterized as living or dead. Measurements are made within the 3 to $65 \%$ range of the aperture opening, which is typically $100 \mu \mathrm{m}$ for applications within EXPORTS. Measurements are acquired from discrete samples, from volumes of $1 \mathrm{ml}$ within $<30$ seconds. Thus, high replication is achievable.

Data processing: Size bin and abundance data are stored along with specified standard operating protocol files that help to identify specifics of the run settings. Analysis includes the identification of abundance peaks, their means and standard deviations. The slope of the abundance size spectra is calculated as a means to identify shifts in particle composition.

Calibration: The instrument is regularly calibrated, and calibration is verified with manufacturer supplied microbeads.

Uncertainties and quality control concerns: Abundance of particles naturally decays with increasing size and statistically reliable quantification of particles $>10 \mu \mathrm{m}$ can be difficult. Particle size is reported as 'equivalent spherical diameter'. True particle dimensions (e.g. aspect ratios) are not known, as the electrical impedance within the sensing zone is converted to a volume and then to the ESD. High particle concentrations can lead to coincidence within the sensing zone and result in underestimates of total particle counts and/or volume.

Data products originating from the method: Particle size distributions, abundances and size abundance spectra of discrete samples (from surface flow through and vertical profiles) in the size range of 3 to $60 \mu \mathrm{m}$.

\section{Key method references:}

Evans, J. H., and S. M. McGill. 1970. An investigation of the Coulter Counter in "biomass" determinations of natural freshwater phytoplankton populations. Hydrobiologia 35:401-419 [doi:10.1007/BF00184567]

Kersting, K. 1985. Specific problems using electronic particle counters. Hydrobiol. Bull. 19:5-12 [doi:10.1007/BF02255087]

Kim H., and S. Menden-Deuer. 2013. Reliability of rapid, semi-automated assessment of plankton abundance, biomass, and growth rate estimates: Coulter Counter versus light microscope measurements. Limnology \& Oceanography Methods 11: 382-393

Sheldon, R. W. 1979. Measurement of phytoplankton growth by particle counting. Limnol. Oceanogr., 24(4), $1979,760-767$ 
1. Method: Vertical profiles of protistan grazing capacity, including mesopelagic

2. Contact Info: Susanne Menden-Deuer, smenden@uri.edu; Heather McNair, hmcnair@uri.edu

3. Brief description: To overcome the significant limitation in our ability to quantify grazing rates below the euphotic zone, we will use fluorescent stains and flow cytometry in a series of incubations to measure rate of herbivory, bacterivory and quantify the abundance of active predators from $50-300 \mathrm{~m}$.

To overcome the significant limitations in our ability to quantify feeding below the euphotic zone, we will use incubation assays with live stain LysoTracker Green (LTG), activated by the predators feeding vacuole. In addition, we will enumerate bacteria in all samples and offer phytoplankton prey stained with CellTracker and LysoSensor (nondiatom and diatom respectively) in short term incubation experiments aboard the ship to derive vertical profiles of relative feeding frequency and capacity, in parallel to empirical measurements of grazing rates in surface waters. Seawater samples (5L each) are collected from discrete depths down to $500-1500 \mathrm{~m}$ using a CTD rosette with mounted Niskin bottles. The exact depths will depend on water masses and focus of other EXPORTS investigators. To increase signal to noise ratio, samples are concentrated 10fold and stained with the live stains. Samples are incubated in the dark in the shipboard walk in incubator set to an appropriate temperature $\left(\sim 4^{\circ} \mathrm{C}\right)$. Subsamples of $1-5 \mathrm{ml}$ are removed at discrete intervals for up to 24 hours. Three discrete sample types will be taken for 1) immediate analysis using a flow cytometer, 2) archive samples fixed with paraformaldehyde and glutaraldehyde and 3) an archive sample filtered onto dark, $0.2 \mu \mathrm{m}$ polycarbonate filters, mounted on microscope slides using immersion oil and frozen. The data acquired will deliver estimates to what degree protists consume biomass in the twilight zone and might reduce remineralization rates through bactivory. Together, these rate estimates provide assessments of the transfer rates of organic matter through the twilight zone across ECC states, which are key to building a predictive and global model of carbon export rates.

4. Other Contributing Protocols: Flowcytometry (Guava), vertical profiling, Dilution method, marine snow abundance and characteristics

5. Uncertainty and quality control: The development of these methods is relatively recent, so we will quantify uncertainties through replication at every step (triplicate incubation, replicate sample analysis) to yield coefficients of variation.

6. Data products will be depth (m), predator abundance (cells L-1), ingestion frequency (\%), possibly relative fluorescence (RFU).

6. SeaBASS submission fields and units:

/id_fields_definitions=1id:all_phytoplankton,2id:Synechococcus,3id:heterotrophic_proka ryotes 
/fields=lat,lon,depth,date_start,time_start,date_end,time_end,abun_1id,abun_lid_sd,abun _2id,abun_2id_sd,abun_3id,abun_3id_sd,g_1id,g_1id_se,g_2id,g_2id_se,g_3id,g_3id_se, u $\_$ph_lid,u $\_$ph_lid se,u $\_$ph_2id,u_ph_2id_se,u_3id,u_3id_se,FLH_ex488_em525_1id,FL-H_ex488_em525_1id_sd,FL-H_ex488_em525_2id,FLH_ex488_em525_2id_sd,FL-H_ex488_em525_3id,FL-H_ex488_em525_3id_sd,FLH_ex488_em583_1id,FL-H_ex488_em583_1id_sd,FL-H_ex488_em583_2id,FLH_ex488_em583_2id_sd,FL-H_ex488_em583_3id,FL-H_ex488_em583_3id_sd,FLH_ex488 em695 1id,FL-H ex488 em695 1id sd,FL-H_ex488 em695 2id,FLH_ex488_em695_2id_sd,FL-H_ex488_em695_3id,FL-H_ex488_em695_3id_sd,FSCH_lid,FSC-H_lid_sd,FSC-H_2id,FSC-H_2id_sd,FSC-H_3id,FSC-H_3id_sd

/units=degrees, degrees,m,yyyymmdd,hh:mm:ss,yyyymmdd,hh:mm:ss,cells/1,cells/1,cells/1 ,cells $/ 1$, cells $/ 1$, cells $/ 1, \mathrm{~d}^{\wedge}-1, \mathrm{~d}^{\wedge}-1, \mathrm{~d}^{\wedge}-1, \mathrm{~d}^{\wedge}-1, \mathrm{~d}^{\wedge}-1, \mathrm{~d}^{\wedge}-1, \mathrm{~d}^{\wedge}-1, \mathrm{~d}^{\wedge}-1, \mathrm{~d}^{\wedge}-1, \mathrm{~d}^{\wedge}-1, \mathrm{~d}^{\wedge}-1, \mathrm{~d}^{\wedge}-$

1 ,arbunits,arbunits, arbunits,arbunits,arbunits,arbunits,arbunits, arbunits, arbunits,arbunits,a rbunits,arbunits, arbunits, arbunits,arbunits,arbunits, arbunits, arbunits, arbunits, arbunits,arb units,arbunits,arbunits, arbunits

\section{Key Method references}

Brownlee, E. F., R. J. Olson, and H. M. Sosik. 2016. Microzooplankton community structure investigated with imaging flow cytometry and automated live-cell staining. Marine Ecology Progress Series 550:65-81.

Martínez, R. A., S. Isari, and A. Calbet. 2014. Use of live, fluorescently-labeled algae for measuring microzooplankton grazing in natural communities. Journal of Experimental Marine Biology and Ecology 457:59-70.

Rocke, E., M. G. Pachiadaki, A. Cobban, E. B. Kujawinski, and V. P. Edgcomb. 2015. Protist Community Grazing on Prokaryotic Prey in Deep Ocean Water Masses. Plos One 10:e0124505. 
Method: Plankton population dynamics via deckboard incubations (dilution method)

Contact Info: Susanne Menden-Deuer,smenden@uri.edu; Heather McNair,hmcnair@uri.edu

Brief description: Seawater samples are collected from 1-5 discrete depths corresponding to a range of incident irradiance using a CTD rosette with mounted Niskin bottles. Water is screened through a $200 \mu \mathrm{m}$ mesh to remove large grazers. Water from each light-depth is partitioned into triplicates of three treatments: whole sea water $(<200 \mu \mathrm{m})$, diluted, and nutrient amended treatments. Diluted treatments are prepared with whole seawater diluted with $0.2 \mu \mathrm{m}$ filtered seawater from the corresponding depth. All bottles are incubated for 24 hours in deckboard incubators with screen-manipulated light levels (dark, 10-20\%, 40\%, $65 \%$ and $100 \%$ ). Light-depths above the thermocline were maintained at surface seawater temperature; light-depths below the thermocline were chilled to the corresponding in situ temperature. Grazing, net phytoplankton growth, and gross phytoplankton growth rate estimates are based on differential changes in chlorophyll a between the diluted and whole seawater treatments. Samples for size fractionated chl (GFF and $5 \mu \mathrm{m}$ ), flow cytometry, and microscopy are collected from each bottle following the $24 \mathrm{~h}$ incubation. Chl a is extracted in ethanol and read on a Turner 10AU Fluorometer. Herbivorous protist grazing rate is calculated as the difference in phytoplankton growth rate in the diluted vs undiluted seawater. Gross phytoplankton growth rate is calculated as the sum of the grazing rate and the net phytoplankton growth rate (i.e. the rate of change in chlorophyll a) in the undiluted bottles. The ratio of the grazing vs gross phytoplankton growth rate provides an estimate of primary production consumed and allows predation of a phytoplankton biomass accumulation rate. Flow cytometry and microscopy will facilitate a more detailed view of plankton dynamics with group specific growth and grazing rates and estimates of changes in chlorophyll due to photoacclimation. Experimental design will target euphotic zone integrated rates as well as the effect of light on surface rates. Predation rates are crucial to parameterize carbon flows at the base of the marine food web. These data provide key algorithms to relate plankton community composition, growth and mortality to export through all 5 pathways and across ECC states, which will be essential for building a diagnostic modeling framework to predict export of global PP, now and in future climate scenarios.

Other Contributing Protocols: Chl a extraction (ethanol), Flowcytometry (Guava), Nutrient measurements, vertical profiling, photoacclimation, microscopy to measure species composition and biomass

Uncertainty and quality control: Based on prior analyses, the uncertainty in the $\mathrm{Chl}$ a concentration extraction is between $1-10 \%$. Rate estimates of phytoplankton growth and grazer induced mortality are good within $+/-0.1 \mathrm{~d}^{-1}$ (Morison \& Menden-Deuer 2017).

6. Data products originating with this method:

\begin{tabular}{ll}
\hline Parameter $^{*}$ & Units \\
\hline Phytoplankton growth rate $(\mu)$ & $\mathrm{d}^{-1}$ \\
Heterotrophic protist grazing rate $(g)$ & $\mathrm{d}^{-1}$ \\
Phytoplankton accumulation rate $(\mathbf{r})$ & $\mathrm{d}^{-1}$ \\
Chlorophyll a (GFF and $5 \mu \mathrm{m})$ & $\mu \mathrm{g} \mathrm{L}^{-1}$ \\
\hline
\end{tabular}




\section{SeaBASS submission fields and units}

/fields $=$ r2r_event,lat,lon,depth,lightlevel,date_start,time_start,date_end,time_end,Chl_experimen t_200umprefilt,Chl_experiment_5umfilt_200umprefilt_sd,Chl_experiment_5umfilt_200umprefil t,Chl_experiment_200umprefilt_sd,g,g_se,g_5umfilt,g_5umfilt_se,u_ph,u_ph_se,u_ph_5umfilt,u ph_5umfilt_se

/units=none,degrees, degrees, $\mathrm{m}, \%$,yyyymmdd,hh:mm:ss,yyyymmdd,hh:mm:ss, $\mathrm{mg} / \mathrm{m}^{\wedge} 3, \mathrm{mg} / \mathrm{m}^{\wedge} 3$, $\mathrm{mg} / \mathrm{m}^{\wedge} 3, \mathrm{mg} / \mathrm{m}^{\wedge} 3, \mathrm{~d}^{\wedge}-1, \mathrm{~d}^{\wedge}-1, \mathrm{~d}^{\wedge}-1, \mathrm{~d}^{\wedge}-1, \mathrm{~d}^{\wedge}-1, \mathrm{~d}^{\wedge}-1, \mathrm{~d}^{\wedge}-1, \mathrm{~d}^{\wedge}-1$

\section{Key Method references}

The method was first described in:

Landry, M. R., and R. P. Hassett. 1982. Estimating the grazing impact of marine microzooplankton. Marine Biology 67:283-288.

A recent assessment of uncertainty is here:

Morison F \& Menden-Deuer S. 2017. Doing more with less: balancing sampling resolution with effort in measuring plankton growth and grazing rates. Limnology and Oceanography, Methods DOI: $10.1002 / \operatorname{lom} 3.10200$ 
Document author and contact info: Francoise Morison, fmorison@uri.edu

Measurement and instrument: Characterization of species composition and size distribution of microphytoplankton with a FlowCAM Benchtop B3 Series.

A brief description of the method: The FlowCAM® enumerates and classifies plankton particles through a combination of flow cytometry, microscopy, and image analysis--simultaneously delivering 30 different properties (including various metrics of size) for each particle. These properties can be used in particle identification. The instrument counts and images particles contained in a seawater sample that is drawn through a glass chamber, the flow cell, by means of a syringe pump. The camera images particles passing within the camera's field of view. Particles contained within each image frame are then extracted and separated into individual images. The analysis can be performed in either of two modes: in auto-image mode the instrument images all particles flowing in front of the camera field of view at a fixed, user-specified flow rate and frame rate; in trigger mode, the instrument only images particles that trigger the camera when they exceed either a scatter or a fluorescence set threshold. The size range of the particles that can be analyzed is determined by the size of the flow cell and the recommended corresponding magnification: the depth of the flow cell sets the upper size limit of particles to be analyzed, while the lower size limit depends on the smallest size that the magnification can resolve and can be specified by the operator. Flow cells with depths of 50,100, and/or $300 \mu \mathrm{m}$ are appropriate for plankton analysis, and are used in combination with 20x, 10X and $4 \mathrm{X}$ objectives respectively.

Data processing: Size bin, abundance data, and properties values for each particles are stored along side the operating context files. Size is reported as either 'equivalent spherical diameter' derived from dimensions of a sphere obtained from a series of ferret measurements around the particle, or it is reported as 'Area Based Diameter', i.e. the diameter of a circle of the same number of pixels as the particle. Biovolume calculation assume all particles to be spherical. The software also automatically stores a summary of the run settings and provides summary statistics of each measured property. Classification into taxa is possible after establishing a training set or can be done manually.

Calibration: The instrument can be calibrated using manufacturer supplied microbeads.

Uncertainties and quality control concerns: Abundance of particles naturally decays with increasing size and the analysis of a large number of particles and thus of a large volume of sample is needed to effectively resolve the size spectrum. Standard flow cells are wider than the camera field of view, and thus only a small percentage of the volume aspirated is processed and imaged, and particles flowing outside the field of view are not imaged. In trigger mode however, particles flowing outside the field of view can trigger the camera, which then captures any particle contained in the frame. The software has no way to determine which particle produced the trigger signal. In trigger mode, samples must be dilute enough to allow for only one particle per image.

For quantitative purposes, Field of View flow cells are recommended. Since the size of the flow cell and the magnification used determine the size range of particles to be analyzed, samples may need to be fractionated, which not only requires manipulation of the sample but also switching flow cells and objectives.

Data products originating from the method: Particle images, species composition, particle size distributions, abundances, and size spectra of discrete samples (from surface flow through and vertical profiles) in the size range of 3 to $300 \mu \mathrm{m}$.

\begin{tabular}{|l|l|}
\hline Parameter & Units \\
\hline Particle images & unitless \\
\hline Species composition & taxa (unitless), species diversity indices (unitless) \\
\hline Particle size distribution & frequency per size bin (numbers $/ \mu \mathrm{m})$, slope of \\
\hline
\end{tabular}




\begin{tabular}{|l|l|}
\hline & $\begin{array}{l}\text { numbers vs equivalent spherical diameter line (ESD, } \\
\mu \mathrm{m}),\end{array}$ \\
\hline Abundance & biomass ( $\mu \mathrm{g} \mathrm{C} \mathrm{L-1)} \mathrm{and} \mathrm{cells} \mathrm{L}^{-1}$ \\
\hline Size spectra & $\begin{array}{l}\text { same as particle size distribution but for living } \\
\text { organisms, as opposed to all particles }\end{array}$ \\
\hline
\end{tabular}

\section{Key method references:}

Alvarez, E., Lopez-Urrutia, A., Nogueira, E. and Fraga, S. (2011) How to effectively sample the size spectrum? A case study using FC. J. Plankton Res., 33, 1119-1133.

Alvarez, E., Moyano, M., Lopez-Urrutia, A., Nogueira, E. and Scharek, R. (2014) Routine determination of plankton community composition and size structure: a comparison between FC and light microscopy. J. Plankton Res., 36, 170-184.

Jakobsen, H.H. and Carstensen, J. (2011) FlowCAM: Sizing cells and understanding the impact of size distributions on biovolume of planktonic community structure. Aquat. Microb. Ecol., 65, 75-87.

Sieracki, C.K., Sieracki, M.E. and Yentsch, C. S. (1998) An imaging-in-flow system for automated analysis of marine microplankton. Mar. Ecol. Prog. Ser., 168, 285-296. 
Method: Particle characterization using a Guava flow cytometer

Document author and contact info: Heather McNair, hmcnair@uri.edu

A brief description of the method: Samples to be characterized using the Guava flow cytometer will be pipetted into 96-well plates $(\sim 200 \mu \mathrm{L})$. Particles will be characterized based on the recorded forward scatter, side scatter, red fluorescence $(695 / 50 \mathrm{~nm})$ and yellow fluorescence $(583 / 26 \mathrm{~nm})$ after exciting with a blue laser $(488 \mathrm{~nm})$. To avoid clogging the instrument, samples will be screened through $40 \mu \mathrm{m}$ mesh prior to being run. Gain settings on the photomultipliers will be determined using an initial sample and kept constant for all following samples. A range of different size beads will be used to create an equation to convert forward scatter to size. Data will be processed using InCyte flow cytometry software that allows particles in a sample to be subset into different groups.

Calibration: The instrument may not be calibrated by the user, but the use of microbeads may provide reference to size and an internal standard for calculating concentration (Olson, Vaulot, and Chisholm 1985), and biological controls may aide in establishing settings and interpreting results.

Uncertainties and quality control concerns: The resolution, range, and observation values per particle are highly dependent on collection settings and machine specifications. To minimize complications settings will be kept constant throughout the cruise. Detection limits will be further explored using filtered sea water blanks.

\section{Data products originating from the method:}

\begin{tabular}{|l|l|}
\hline Parameter & Units \\
\hline Scattering per particle & Relative units \\
\hline Fluorescence per particle & Relative units \\
\hline Abundance & Relative units \\
\hline Scatter statistics per group & Relative units \\
\hline Fluorescence statistics per group & Relative units \\
\hline
\end{tabular}

SeaBASS fields and units:

/id_fields_definitions=1id:nanoeukaryote,2id:picoeukaryote,3id:Synechococcus

/fields=r2r_event,lat,lon,depth,lightlevel,date_start,time_start,date_end,time_end,abun_1id,abun_lid_sd,a

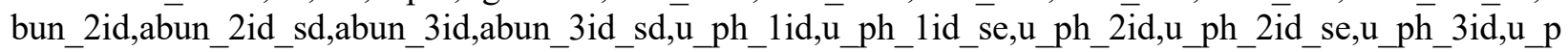
h_3id_se,g_1id,g_1id_se,g_2id,g_2id_se,g_3id,g_3id_se,FSC-H_-1id,FSC-H_1id_sd,FSC-H_2id,FSCH_2id_sd,FSC-H_3id,FSC-H_3id_sd,FL-H_ex488_em695_1id, $\overline{F L}-\mathrm{H} \_$ex488_em695_1id_sd,FLH_ex488_em695_2id,FL-H_ex488_em695_2id_sd,FL-H_ex488_em695_3id,FLH_ex488_em695_3id_sd,FL-H_ex $488 \_$em583_3id,FL-H_ex488_em583_3id_sd

/units=none,degrees, degrees,m,\%,yyyymmdd,hh:mm:ss,yyyymmdd,hh:mm:ss,cells/L,cells/L,cells/L,cells /L, cells/L,cells/L, $\mathrm{d}^{\wedge}-1, \mathrm{~d}^{\wedge}-1, \mathrm{~d}^{\wedge}-1, \mathrm{~d}^{\wedge}-1, \mathrm{~d}^{\wedge}-1, \mathrm{~d}^{\wedge}-1, \mathrm{~d}^{\wedge}-1, \mathrm{~d}^{\wedge}-1, \mathrm{~d}^{\wedge}-1, \mathrm{~d}^{\wedge}-1, \mathrm{~d}^{\wedge}-1, \mathrm{~d}^{\wedge}-$

1 ,arbunits, arbunits, arbunits, arbunits, arbunits, arbunits, arbunits, arbunits, arbunits, arbunits, arbunits, arbunits, arbunits,arbunits

\section{Key method references:}

BD BioSciences. 2009. An Introduction to Compensation for Multicolor Assays on Digital Flow Cytometers. Technical Bulletin. BD Biosciences, San Jose, CA.

Millipore Sigma. 2017. Guava easyCyte HT System. User Guide. EMD Millipore, Darmstadt, Germany. 
Olson, R.J., D. Vaulot, and S.W. Chisholm. 1985. Marine Phytoplankton Distributions Measured Using Shipboard Flow Cytometry. Deep Sea Research Part A. Oceanographic Research Papers 32 (10). Elsevier:1273-80. 


\begin{tabular}{|l|l|}
\hline Variable & Light Absorption Coefficient Spectrum of CDOM \\
\hline SeaBASS Name & $\mathrm{ag}$ \\
\hline Units & $1 / \mathrm{m}$ \\
\hline Sampling & Niskin bottle on rosette \\
\hline
\end{tabular}

Document author and contact info: Norman Nelson, normannelson@ucsb.edu

Updated $7 / 21 / 16$

Light absorption by CDOM will be measured from samples collected and prepared according to the UCSB CDOM Laboratory protocol (Nelson et al., 2007). Samples are analyzed in an UltraPath spectrophotometer according to the same method with recent modifications as specified by the draft NASA CDOM Group UltraPath analysis protocol (reference TBA).

Samples are collected from Niskin bottles using silicone tubes by analysts wearing nitrile gloves. The samples are collected into combusted $60 \mathrm{ml}$ brown borosilicate glass EPA vials with Teflon lid liners.

To remove particles the samples are filtered through 0.2 micron pore $25 \mathrm{~mm}$ Nuclepore polycarbonate filters that have been pre-extracted with $60 \mathrm{ml}$ ultrapure water (Barnstead Nanopure, $18 \mathrm{M} \Omega-\mathrm{cm}$, low carbon filter cartridge).

Samples are stored at $4 \mathrm{C}$ in the dark until analysis, generally within 6 months to 1 year. 2-year stability of samples stored in this manner has been documented by Swan et al. (2009).

On analysis day sample vials are allowed to equilibrate to room temperature and are analyzed for UV and visible absorbance in an UltraPath single-beam long path $(200 \mathrm{~cm}$ cell) spectrophotometer. Samples are referenced against ultrapure water (Barnstead Nanopure, $18 \mathrm{M} \Omega-\mathrm{cm}$, low carbon filter cartridge) and are corrected for refractive index effects using concurrently measured apparent absorption spectra of $30 \mathrm{~g} / \mathrm{l}$ and $40 \mathrm{~g} / \mathrm{l}$ solutions of sodium chloride (SigmaUltra $>99.97 \% \mathrm{NaCl}$ ), interpolated by the salinity of the sample. Corrected spectra are converted to naperian absorption coefficient by the formula $a=2.303 \mathrm{~A} / \mathrm{l}$ where $\mathrm{A}$ is the decadal absorbance of the sample, I is the pathlength $(\mathrm{m})$, and 2.303 converts decadal to natural log scale.

Reference spectra of a water solution of Suwanee River Fulvic Acid Standard 1, IHSS \#1S101F (http://www.humicsubstances.org/elements.html) vs ultrapure water at approximately $0.25 \mathrm{mg} / \mathrm{l}$ is also measured at the time of sample analysis, and is converted to specific absorption $\left(\mathrm{m}^{2} / \mathrm{mg}\right)$.

All spectra are null corrected at long wavelength (690-710 nm avg), in accordance with the current draft protocol.

Reported data include the CDOM absorption spectrum $\left(\mathrm{a}_{\mathrm{g}}\right)$, the estimated error (based on the average of $\sim 6$ scans over $30 \mathrm{~s}$, propagated through the analysis arithmetic), the raw absorbance average and its standard deviation, and the SRFA and $\mathrm{NaCl}$ reference spectra.

Data products originating with this method:

\begin{tabular}{|l|l|}
\hline Parameter & Units \\
\hline CDOM absorption, $a_{\mathrm{g}}$ & $\mathrm{m}^{-1}$ \\
\hline
\end{tabular}


References:

Nelson, N.B., D.A. Siegel, C.A. Carlson, C. Swan, W.M. Smethie, Jr., and S. Khatiwala, (2007). Hydrography of chromophoric dissolved organic matter in the North Atlantic. Deep-Sea Res. 54, 710-731.

Swan, C.M., D.A. Siegel, N.B. Nelson, C.A. Carlson, and E. Nasir (2009) Biogeochemical and hydrographic controls on chromophoric dissolved organic matter distribution in the Pacific Ocean. Deep-Sea Res. I 56: 2175-2192. 


\begin{tabular}{|l|l|}
\hline Variable & In water radiometric profiles \\
\hline SeaBASS Name & Ed, Lu \\
\hline Units & uW/cm²/nm, uW/cm^2/sr//nm \\
\hline Sampling & C-OPS hand held profile \\
\hline
\end{tabular}

Document author and contact info: Norman Nelson, normannelson@ucsb.edu

Updated 5/8/18 nbn

At-sea operations: The Biospherical C-OPS is a light weight, hand deployed package to measure the downwelled irradiance and upwelled radiance sunlight field (Morrow et al 2010). Nineteen discrete wavelengths in the UV, visible, and near IR are measured and there is a surface mounted deck irradiance sensor with matching wavelengths. The package also has pressure, tilt and roll, water temperature. The package weighs about $30 \mathrm{lbs}$ in air and just a few lbs in water. The package is attached by an electrical cable that is held on a cable bucket ( 35 gal poly trash can) on the fantail. The instrument is allowed to free-fall to approximately $100 \mathrm{~m}$, which takes about 6 minutes. The instrument is then hand hauled back to the surface by 1 or 2 persons and the cable is spooled back into the cable. Between casts, the profiler is kept in the lab to prevent overheating of the sensors.

Constraints: The following parameters control the quality of the light profiles (Mueller et al 2003):

1) Ship shadow. Our deployment procedure attempts to keep the profiler away from the ship's underwater shadow.

2) Ship bearing. If the sun direction is anywhere aft of amidships, we should have no problems. Worst bearing is with the sun directly ahead.

3) Ship movement through the water. We have $300 \mathrm{~m}$ of cable that we spool out as the instrument sinks, so if the ship is also moving through the water, much of the cable is laid out horizontally and we don't reach our desired depth before reaching the end of our cable. Ideal forward speed is a one half knot.

Before the cast: Controlling computer is started up, and the Biospherical software is used to collect dark current data on both profiler and surface reference instruments.

Start of cast: We will require radio or squawk-box comms between the person deploying the light profiler, the bridge, and the computer operator in the lab. A minimum of 2 persons on deck, with one primarily for communications since the deployer will have both hands occupied. There is no need for the ship to return to the Station location for the light cast (we're close enough.)

We attempt to get the profiler about $20 \mathrm{~m}$ behind the ship before we start the free-fall. Getting the probe clear of the stern is the most demanding part of the cast. Often a $30 \mathrm{sec}$ mild bump ahead with the main will both move the ship forward and sweep the instrument aft with the prop wash.

Once the light profiler is about $20 \mathrm{~m}$ aft and at the surface, the instrument is allowed to free-fall to the desired depth. During the free-fall, the cable is kept slack by paying out the wire just fast enough to keep the wire smoothly pulling over the stern railing near the port corner. The angle that the cable enters the water is constantly observed to make sure it continues to lead aft and away from the stern.

As the light profiler nears the target depth, the computer operator calls out every $10 \mathrm{~m}$ pressure mark. At the target depth, or when the maximum safe amount of cable to let out is reached, cable deployment is stopped and retrieval begun.

Data processing: We use standard ocean color radiometry protocols (Mueller et al 2003) carried out through a Matlab implementation of the BBOP data processing system (Siegel et al. 2005). Tilt criteria and the depth of extrapolation for determination of surface properties are determined for each cast depending on the conditions. 
References:

Morrow, J.H., S.B. Hooker, C.R. Booth, G. Bernhard, R.N. Lind, and J.W. Brown, (2010), Advances in Measuring the Apparent Optical Properties (AOPs) of Optically Complex Waters, NASA Tech. Memo. 2010-215856, NASA Goddard Space Flight Center, Greenbelt, Maryland, 80 pp.

Mueller, J. L. , C. Pietras, S. B. Hooker, R.W. Austin, M. Miller, K. D. Knobelspiesse, R. Frouin,B. Holben, and K. Voss (2003), Ocean Optics Protocols For Satellite Ocean Color Sensor Validation, Revision 4, Volume II: Instrument Specifications, Characterization and Calibration, edited by J. L. Mueller, G. S. Fargion and Charles R. McClain, NASA Technical Memorandum, NASA/TM-2003-21621/Rev-Vol II, National Aeronautical and Space administration, Goddard Space Flight Space Center, Greenbelt, Maryland, available at http://oceancolor.gsfc.nasa.gov/DOCS/Protocols_Ver4_VollII.pdf.

Siegel, D.A., M.C. O'Brien, J.C. Sorensen, D.A. Konnoff, and E. Fields, (1995), BB̄OP data processing and sampling procedures, Version 1. U.S. JGOFS Planning Report Number 19. U.S. JGOFS Planning and Coordination Office, Woods Hole. 


\section{README.EXPORTS2018.CTD 20191002 EDITION}

Document author and contact info: Norman Nelson, normannelson@ucsb.edu nbn 20190213 revised 20190221

revised 20190306, 20191002

This README file details the CTD processing for the EXPORTS 2018 North Pacific campaign. Four CTDs were deployed on the campaign that we present here, all SeaBird 911+ units. One was on the rosette sampler on the R/V Sally Ride (SR 1812, or "survey" in the SeaBASS files), one on the main rosette on the R/V Roger Revelle (RR 1813 SIO, "process"), one on the UHawaii trace metal rosette (RR 1813 TM, "TM") and one on the MOCNESS system (RR 1813 MOCNESS, "MOCNESS"). Other CTDs present on the IOP packages, the wirewalker, etc. are not covered in this data release. This release should be still considered preliminary, as we refine post-cruise corrections to the data new releases will be made.

\section{Notes on SeaBASS preparation for this release (20191002)}

There are two SeaBASS files for every cast. One is the "unbinned" processed data (see below for processing pipeline) which features minimal filtering, and flagging by loopedit and wildedit for data quality. One is the $1 \mathrm{~m}$ binned downcast only data. The SeaBASS files do not contain the 'secondary' T and S sensor data.

\section{Flags and Bins}

We ran the SeaBird programs WILDEDIT and LOOPEDIT on the unbinned data files to identify outliers and data contaminated by ship heave. LOOPEDIT identifies samples collected on upward heaves during a cast and increments the flag column. WILDEDIT uses a two pass process to identify data points lying 2 or 20 standard deviations outside the mean, respectively. Data scans flagged in this way are not used to compute bins, but the data in the "Unbinned" data files are not altered by flagging.

SeaBird's software allows the recovery of the numbers of samples used in each bin, but no statistics. There is a "bincount" column in each SeaBASS file which gives the number of valid samples used to compute the binned value.

SeaBird's binning algorithm is as follows (as applied using depth)

$X_{i}=\frac{\left(x_{c}-x_{p}\right) *\left(z_{i}-z_{p}\right)}{z_{c}-z_{p}}+X_{p}$

where $X_{i}$ is the value variable $x$ at depth $i, z_{p}$ is the average depth of the previous bin, $z_{c}$ is the average pressure of bin $i, X_{c}$ is the average value of the $X$ data in bin $i, z_{i}$ is the center value for depth in bin $i$, and $X_{p}$ is the average value of variable $X$ in the previous bin (SeaBird Scientific Unviersity, Module 13, Advanced Data Processing). 


\section{Calibration Data}

Configuration and calibration data for each sensor package / cast are included in the .XMLCON files that correspond to each cast. This XML format file contains calibration coefficients and dates for each sensor, as deployed. It is important to examine these files because of configuration problems with the SIO rosette CTD package in the first week of the cruise caused significant changes in the configuration.

\section{Post-Cruise Corrections}

This release (R1) of the SeaBASS files contains corrections to selected variables as computed by the members of the EXPORTS Synthesis Working Group 4 (lead authors A. Thompson (T\&S), D. Nicholson $\left(\mathrm{O}_{2}\right)$, chlorophyll fluorescence (M. Feen) and optical backscatter (X. Zhang). These preliminary reports are attached to this file. What follows here is a brief summary and the reports include more details.

Temperature and salinity corrections were found by using the Sally Ride primary C \& T sensors as the "gold standard." No corrections were deemed necessary to apply between the Ride and the Revelle sensors, so no changes were made. Rough corrections to the process cruise TM and MOCNESS sensors were made by comparison to adjacent Revelle CTD rosette cast data by N. Nelson. These corrections may be revised in the future.

Winkler titration measurements of dissolved oxygen collected on the survey cruise were used to correct the Ride and Revelle CTD oxygen sensors, and corrections were applied to both for the SeaBASS release.

In situ stimulated chlorophyll a fluorescence measurements were calibrated to in situ chlorophyll using total chlorophyll a as determined by the GSFC HPLC lab, from bottle samples on both survey and process ships during night-time (PAR values $<20 \mathrm{umol} / \mathrm{m}^{2} / \mathrm{s}$ ) casts only (to avoid nonphotochemical quenching of fluorescence during the day). M. Feen used the raw voltage signals from the fluorometers compared to the discrete HPLC measurements to arrive at a distinct computation for each of the main rosette sensors. N. Nelson used the Revelle values to prepare a rough correction of the fluorometers on the MOCNESS and TM packages.

At present we are using factory calibrations for the backscatter sensors on the rosette packages. X. Zhang evaluated the sensor on the survey ship CTD and determined the 05/18 calibration (not the most recent) was valid.

Post-cruise correction of beam transmissometer data is planned for Release 2, once POC and transmissometer data from lowered packages are available.

\section{Original processing notes from version 20190306 / 20190916}


The 20190916 version of the data should be identical to the 20190306 version of the data, which was apparently deleted from the Google Drive by a user who was not aware of their actions.

We used identical processing pipelines for each data file from the different instruments. All data were processed from raw (.HEX) format files (and .XMLCON configuration and .BL bottle trip data files) using SeaBird Data Processing version 7.26.7 on a Windows 10 system at UCSB following the cruise. This data release includes all the raw data, Program Setup (.psa) files, batch processing configuration scripts, and batch processing meta-scripts that can be used to reprocess the entire data set quickly. Tau corrections were used for oxygen sensors.

Within each instrument directory there is one subdirectory for each final product, as well as subdirectories for the raw data (including the .xmlcon and .bl files) and for the .psa files. A scratch directory is present but no relevant files are there. The instrument directory includes the SeaBird and Windows batch files used to process the data.

The file formats for each product are SeaBird .cnv or .btl ascii files. I've provided a simple loadcnv.m script to load the .cnv files and selected metadata into memory in MATLAB.

There is also a directory containing WHPO exchange format (ascii .csv) files with the bottle data, and the scripts used to create them from the .btl files. The loadwhpobot.m script will load these files into memory in MATLAB. These files do not have the statistics ( $\mathrm{min} / \mathrm{max} / \mathrm{nscans}$ ) that are included with the .btl files.

Further information on sensor serial numbers and calibrations and so forth is available in the $\mathrm{xml}$ sections of the data files.

Important notes on this release (20190306):

Post-cruise instrument corrections are not applied to the data found in the EXPORTS LO CTD DATA folders on the Google Drive. Post cruise instrument corrections ARE applied to the SeaBASS files.

Fixes in this release (20190306):

MOCNESS and RR SIO CTD data streams had the incorrect raw voltage out channels. Minor changes to the filter settings and wildedit settings to ensure consistency between all instruments.

The WHPO Exchange Format bottle files are not included in this release (broader fixes are necessary and they will be added at a later date)

\section{Processing pipeline schematic:}




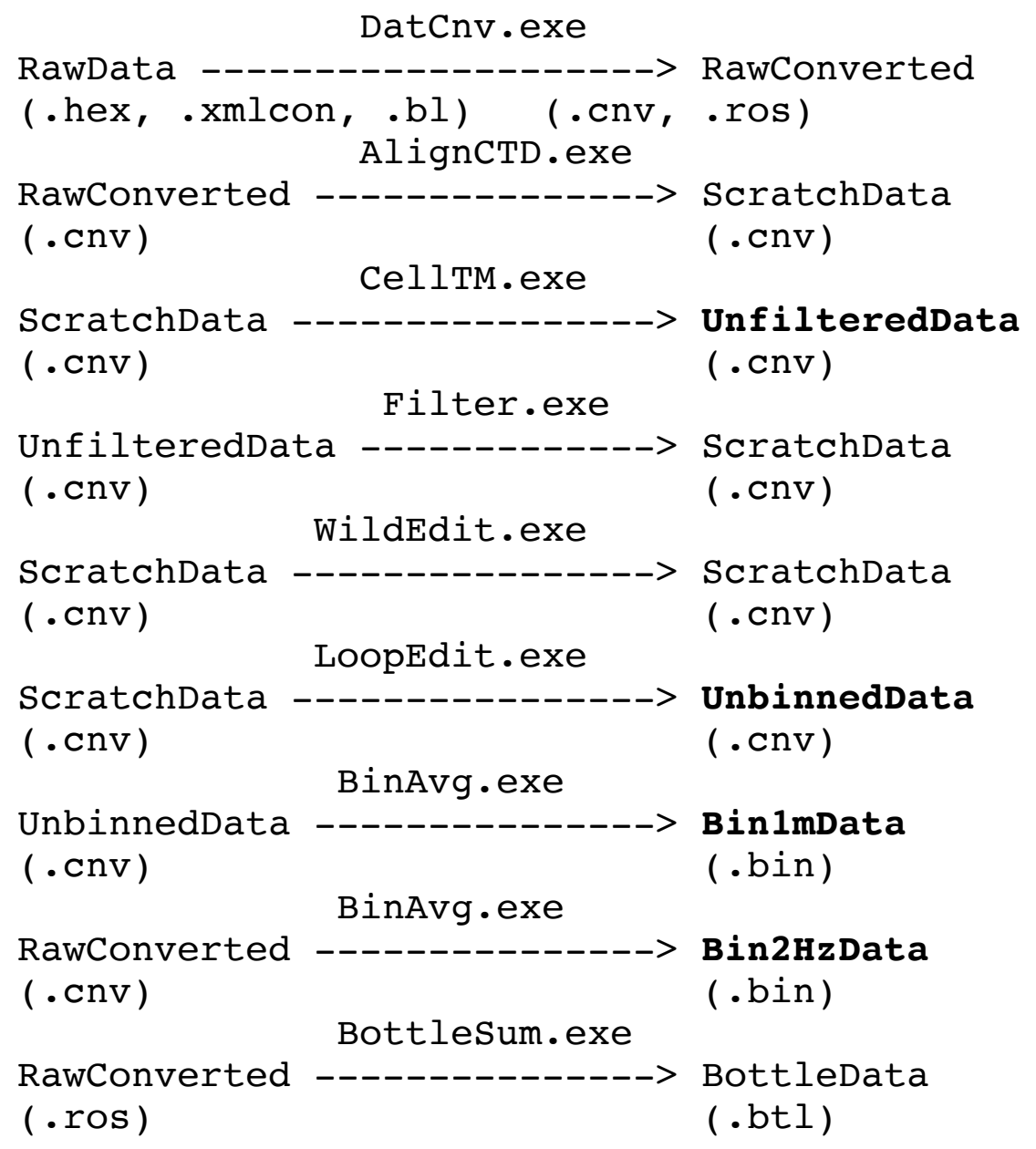

Explanation of the processing pipeline by step:

DatCnv . exe takes raw data from the .hex files, configuration data from the .xmlcon files, and bottle trip data from the .bl files in the RawData and creates an ascii raw data file (.cnv) and rosette summary (.ros) file in the RawConverted directory.

AlignCTD. exe synchronizes the pressure,conductivity, and temperature data in the RawConverted file to account for the different position of the temperature+pressure and conductivity sensors in the package. The aligned file is placed in ScratchData.

CellTM. exe corrects the conductivity data for cell thermal mass effects in the file in ScratchData and places the corrected file in UnfilteredData. This is a product. Standard SeaBird settings for the 911 sensor package were used.

Filter . exe applies low-pass filters to the pressure and conductivity sensors. We used the default SeaBird settings for low-pass filtration. UnfilteredData .cnv files back to ScratchData. 
WildEdit. exe looks for outliers in the data using a $2 \sigma$ criterion (first pass) and a $20 \sigma$ criterion (second pass). Note this does not remove the data from the file but it increments the flag column in the data. ScratchData .cnv files back to ScratchData.

LoopEdit. exe attempts to flag 'loop' features in the profile caused by ship roll and gradients. This also increments the flag column in the data. We used the SeaBird default settings. ScratchData .cnv files were edited and saved to UnbinnedData. This is a product.

BinAvg . exe was used to make $1 \mathrm{~m}$ downcast only files from the unbinned data .cnv files saved as .bin (still ascii files in cnv format) in Bin 1mData. This is a product.

BinAvg . exe was used to make $2 \mathrm{~Hz}$ files from the (complete cast) unbinned data .cnv files saved as .bin (still ascii files in cnv format) in Bin2 $\mathbf{H z} \mathbf{D a t a}$. This is a product.

BottleSum . exe was used to make bottle files (in SeaBird ascii .btl format) from the .ros files in RawConverted and the .xmlcon files in RawData. Bottle files were saved in the BottleFiles subdirectory. This is a product. We included statistics ( $\mathrm{min} / \mathrm{max} / \mathrm{number}$ of scans averaged) as well as the averages.

Directory structure of this release:

https://drive.google.com/open?id=1j02wGDwVYBe0H3dDhXVKqgH0jnLPv-8H

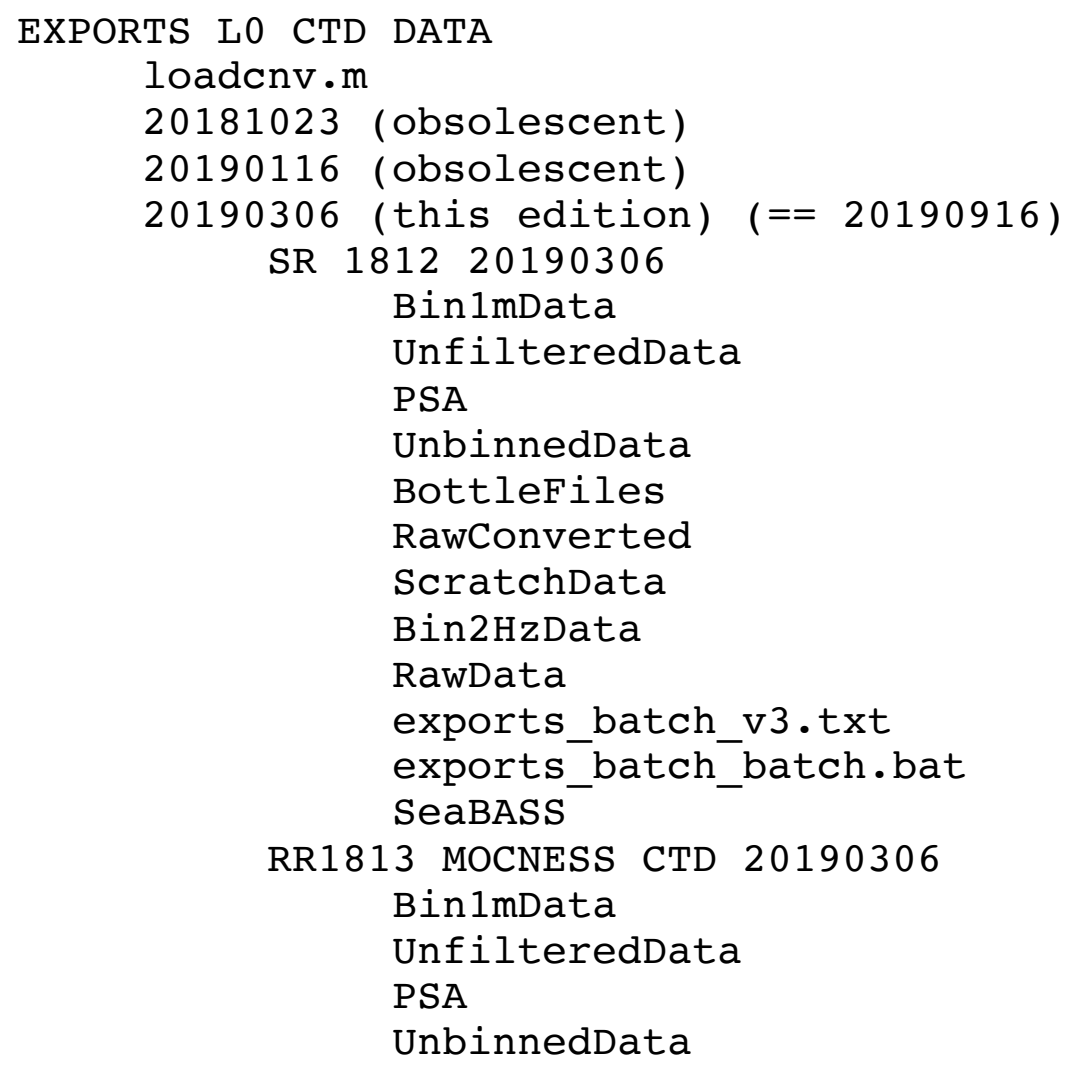




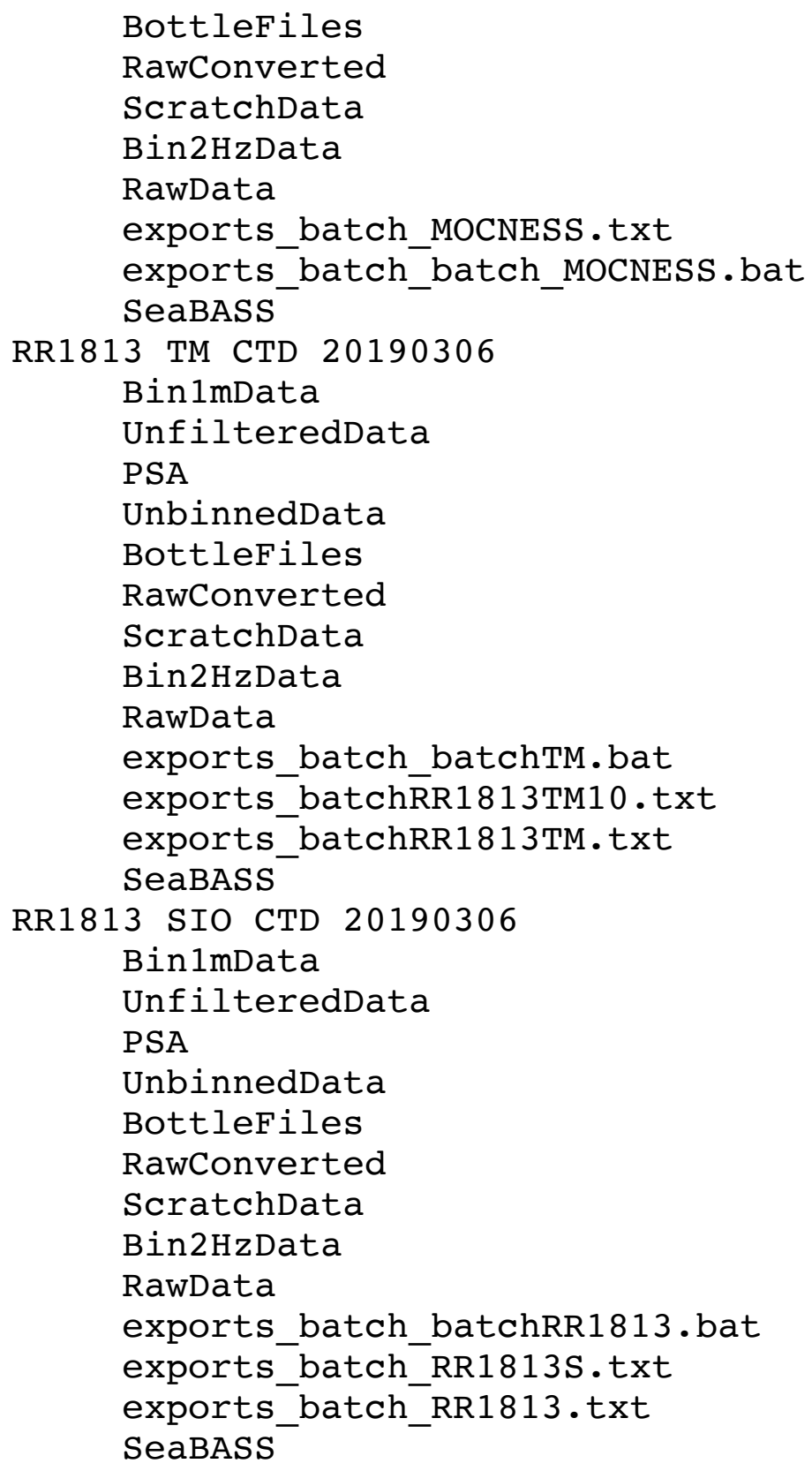

\section{Key to the voltage channels in each data set}

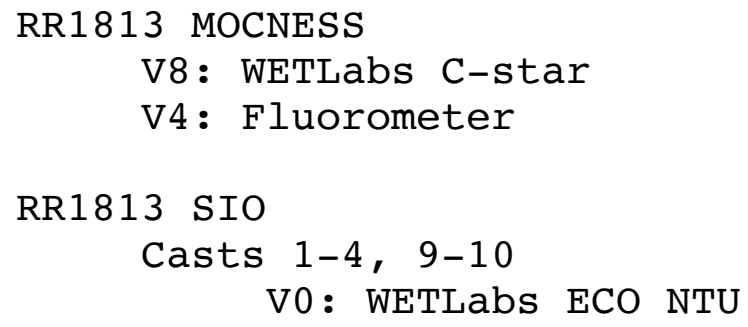


V1: Seatech/WETLabs FLF Fluorometer (Chl)

V4 : LISST

V6: WETLabs C-star transmissometer

Casts 5-8, 11-84

V0: WETLabs ECO Fluorometer (chl)

V1: WETLabs ECO NTU

V4: LISST

V6L WETLabs C-star transmissometer

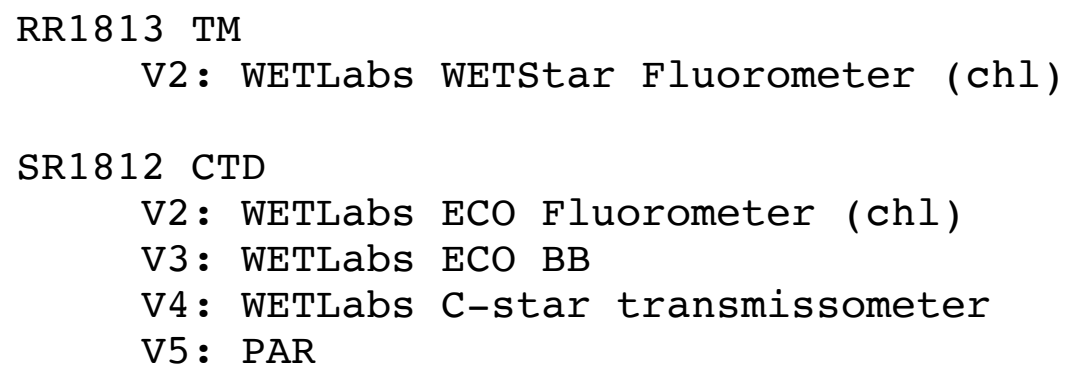

RR1813 TM

V2: WETLabs WETStar Fluorometer (chl)

SR1812 CTD

V2: WETLabs ECO Fluorometer (chl)

V3: WETLabs ECO BB

V4: WETLabs C-star transmissometer

V5: PAR

EXPORTS Synthesis WG 4 Preliminary Instrument Intercomparison Reports

Chlorophyll Fluorescence Calibration_10_7_19_Final_.pdf

EXPORTS2018_O2_Cal_Oct8.pdf

TempSalinityIntercalReport_AFT_Oct8.pdf

inter-calibration of bb sensors_Oct8.pdf 


\section{Method: HPLC Pigment analysis}

Document authors and contact info: Norm Nelson, norm.nelson@ucsb.edu; Collin Roesler, croesler@bowdoin.edu; Ivona Cetinic, ivona.cetinic@nasa.gov; Sasha Kramer, sasha.kramer@lifesci.ucsb.edu

Brief description of protocol and relation to export pathways: Algal pigments will be analyzed with High Pressure Liquid Chromatography on samples obtained from both the survey and process vessels. Water samples will be collected with a CTD-Niskin bottle rosette at approximately 8 depths, 3-4 times a day. In order to ensure compatibility between pigment, carbon and optical samples, Niskin bottles from each depth will be collected into a large volume carboy using a funnel with $1 / 2$ inch tubing. Carboys will be kept cold and dark until subsampling. Subsamples for each analysis will be collected from the carboy after gentle mixing via the Perry method; swirling three times in one direction, three time in the reverse direction, three times in the first direction. Additional samples will be collected from the inline flow-through system once or twice a day, at the intake depth of approximately $3 \mathrm{~m}$. The inline samples on the survey vessel will be size fractionated with $3 \mu \mathrm{m}$ and $20 \mu \mathrm{m}$ cartridge filters (Pall $\AA$ ) in addition to the unfiltered samples. Additional pigment samples will be collected during the "calibration profiles" that will be conducted either during pick up, deployment or encounter with the autonomous assets.

Sample particulates will be collected via low pressure (less than $5 \mathrm{~mm} \mathrm{Hg}$ ) vacuum filtration on a pre-combusted (450C for 4 hours) $25 \mathrm{~mm} 0.7 \mu \mathrm{m}$ Whatman ${ }^{\circledR} \mathrm{GF} / \mathrm{F}$ filter. Exact volume and volume uncertainty are recorded for each sample. Filters will be folded in half, sample side inward, transferred into labeled aluminum foil packages, and stored in liquid nitrogen from the time of collection until the time of delivery to NASA GSFC. Analysis will be conducted at Ocean Ecology Lab at NASA GSFC following the methods described in SIMBIOS intercalibration exercise, and in the SeaWIFS HPLC round-robins.

Other contributing protocols: None

Uncertainties and quality control concerns: Duplicate samples will be collected at a rate of approximately one ever ten samples (i.e., once every other CTD cast or every other day for the inline system). GSFC's sample processing methods include an assessment of the duplicate samples, sample precision by reinjection of samples, and an effective limit of quantitation (lower detection limit) which are all provided with the data.

Data products originating with this method:

\begin{tabular}{|l|l|l|}
\hline \multicolumn{1}{|c|}{ Pigment Name } & \multicolumn{1}{c|}{$\begin{array}{c}\text { Parameter } \\
\text { Symbol }\end{array}$} & \multicolumn{1}{c|}{ Units } \\
\hline Alloxanthin & allo & $\mathrm{mg} \mathrm{m}^{-3}$ \\
\hline Alpha beta carotene & alpha_beta_car & $\mathrm{mg} \mathrm{m}^{-3}$ \\
\hline
\end{tabular}




\begin{tabular}{|l|l|l|}
\hline 19'-Butanoyloxyfucoxanthin & but_fuco & $\mathrm{mg} \mathrm{m}^{-3}$ \\
\hline Chlorophyll c3 & chl_c3 & $\mathrm{mg} \mathrm{m}^{-3}$ \\
\hline Chlorophyllide a & chlide_a & $\mathrm{mg} \mathrm{m}^{-3}$ \\
\hline Diadinoxanthin & diadino & $\mathrm{mg} \mathrm{m}^{-3}$ \\
\hline Diatoxanthin & diato & $\mathrm{mg} \mathrm{m}^{-3}$ \\
\hline Divinyl Chlorophyll a & dv_chl_a & $\mathrm{mg} \mathrm{m}^{-3}$ \\
\hline Divinyl Chlorophyll b & dv_chl_b & $\mathrm{mg} \mathrm{m}^{-3}$ \\
\hline Gyroxanthin diester & gyro & $\mathrm{mg} \mathrm{m}^{-3}$ \\
\hline Fucoxanthin & fuco & $\mathrm{mg} \mathrm{m}^{-3}$ \\
\hline 19'-Hexanoyloxyfucoxanthin & hex_fuco & $\mathrm{mg} \mathrm{m}^{-3}$ \\
\hline Lutein & lut & $\mathrm{mg} \mathrm{m}^{-3}$ \\
\hline Monovinyl chl-a & mv_chl_a & $\mathrm{mg} \mathrm{m}^{-3}$ \\
\hline Monovinyl chl b & mv_chl_b & $\mathrm{mg} \mathrm{m}^{-3}$ \\
\hline Neoxanthin & neo & $\mathrm{mg} \mathrm{m}^{-3}$ \\
\hline Peridinin & perid & $\mathrm{mg} \mathrm{m}^{-3}$ \\
\hline Pheophorbide a & phide_a & $\mathrm{mg} \mathrm{m}^{-3}$ \\
\hline Pheophytin a & phytin_a & $\mathrm{mg} \mathrm{m}^{-3}$ \\
\hline Prasinoxanthin & pras & $\mathrm{mg} \mathrm{m}^{-3}$ \\
\hline Total Chlorophyll a & tot_chl_a & $\mathrm{mg} \mathrm{m}^{-3}$ \\
\hline Total Chlorophyll b & tot_chl_b & $\mathrm{mg} \mathrm{m}^{-3}$ \\
\hline Total Chlorophyll c & tot_chl_c & $\mathrm{mg} \mathrm{m}^{-3}$ \\
\hline Violaxanthin & viola & $\mathrm{mg} \mathrm{m}^{-3}$ \\
\hline Zeaxanthin & zea & $\mathrm{mg} \mathrm{m}^{-3}$ \\
\hline & & \\
\hline
\end{tabular}

\section{Key method references:}

SIMBIOS intercalibration exercise and the SeaWIFS HPLC round-robins. 


\begin{tabular}{|l|l|}
\hline Variable & Inorganic Nutrients \\
\hline SeaBASS Name & $\mathrm{NO}, \mathrm{NO} 2, \mathrm{PO} 4, \mathrm{SiO} 4$ \\
\hline Units & $\mu \mathrm{mol} / 1$ \\
\hline Sampling & Niskin bottle on rosette \\
\hline
\end{tabular}

Document author and contact info: Norman Nelson, normannelson@ucsb.edu compiled $2018 \mathrm{nbn}$ / descriptive text from UCSB MSI Analytical Laboratory (http://msi.ucsb.edu/services/analytical-lab/seawater-nutrients-fia)

Inorganic nutrients are analyzed using flow injection analysis, from rosette samples collected and frozen at sea.

Samples will be collected in clean, pre-rinsed plastic HDPE $20 \mathrm{ml}$ scintillation vials. Samples being analyzed for $\mathrm{Si}(\mathrm{OH})_{4}$ must be collected in plastic HDPE vials. For all other analytes, glass or plastic HDPE containers are acceptable. Some adsorption of $\mathrm{PO}_{4}$ during storage in plastic containers has been noted, so glass may be preferred if $\mathrm{PO}_{4}$ is to be determined.

Caps should have a plastic liner. All foil lined lids should be avoided.

Storage blanks are required if $\mathrm{NH}_{4}$ is to be measured. Storage blanks are recommended for all other analytes to detect possible contamination.

A minimum of $5 \mathrm{~mL}$ of sample is required for the determination of a single nutrient species. $15-17 \mathrm{~mL}$ of sample is necessary for simultaneous determination of all analytes. It is entirely unnecessary to submit more than $20 \mathrm{~mL}$ of sample. If you must submit more than $20 \mathrm{~mL}$ of sample or have other volume concerns, please contact the Analytical Lab.

Mark all samples clearly and directly on the sample container, as well as the lid. If you plan on shipping samples, any masking tape or colored lab-style tape placed on sample vials will fall off during shipment if in the presence of dry ice. Do not use these types of tape to label samples if you plan on shipping samples on dry ice.

Samples should be frozen immediately after collection and stored at $-20^{\circ} \mathrm{C}$ or below. Please allow sufficient headspace when freezing for expansion of the sample without breaking the container.

Do not acidify samples for nutrient analysis.

Please ship samples overnight express using insulated shipping containers and dry ice to keep the samples frozen during transport.

Flow Injection Analysis - Nutrients

- Manufacturer: Lachat Instruments Div., Zellweger Analytics, Inc.

- Model: QuikChem 8500

- Capabilities 
- Simultaneous determination of up to 5 analytes per sample

- Random-access autosampler with racks for up to 120 samples per batch

- Analytical manifolds available:

- Nitrite

- Nitrate plus Nitrite

- ortho-Phosphate

- Silicic Acid

- Ammonium

\section{General Description}

Flow injection analysis (FIA) is a continuous-flow technique for automated wet-chemical analysis. The methodology used by the flow injection analyzer is similar to that used by AutoAnalyzers, with continuously flowing reagent streams, reaction 'manifolds', and flow-through detectors. However, FIA does not use air-bubble segmentation to separate samples and promote mixing. Instead, small diameter tubing is used in the manifolds, resulting in laminar flow conditions in which mixing takes place by axial and radial diffusion, and the manifolds are self-cleaning. Diffusion (dilution and mixing) is controlled by manifold design. A major practical advantage of this technology over that of air-segmentation, is that analytical results are usually available within a minute or so from the time the sample is aspirated, so any problems in the system can be spotted quickly and corrected, with little wasted time. The overall analysis times also tend to be shorter with FIA, so more samples can typically be analyzed in a given period of time. Precision and detection limits are generally comparable between the two technologies.

The software that controls our instrument is Windows 7 based, and displays real-time graphical output of any or all of the active detectors. This is extremely useful for during-run monitoring of the instrument's performance. Data is stored on disk, and is available for post-run processing in a variety of formats. The software also provides a wide range of quality control options to ensure accurate and reliable results. These include check-standards, control samples, same-vial or different-vial replicates, and spikes.

Analyte

Nitrate $\left(\mathrm{NO}_{3}\right)+$ Nitrite $\left(\mathrm{NO}_{2}\right)$

Nitrite $\left(\mathrm{NO}_{2}\right)$

Phosphate $\left(\mathrm{PO}_{4}\right)$

Silicic Acid $\left(\mathrm{Si}(\mathrm{OH})_{4}\right)$

Ammonium $\left(\mathrm{NH}_{4}\right)$

\section{Concentration Range, $\mu \mathrm{M}$ Precision}

$\begin{array}{ll}0.2-300 & +/-5 \% \\ 0.1-100 & +-5 \% \\ 0.1-200 & +/-5 \% \\ 1.0-600 & +/-5 \% \\ 0.1-200 & +/-5 \%\end{array}$


Method: Net community production from mass balance

Document author and contact info: David Nicholson, dnicholson@whoi.edu

Brief description of protocol and relation to export pathways: Mass balance of dissolved oxygen $\left(\mathrm{O}_{2}\right)$, dissolved inorganic nitrogen (DIN) and total organic carbon $\left(\mathrm{C}_{\mathrm{org}}\right)$ in the euphotic will be used to solve for net community production (NCP), which is the whole ecosystem balance between photosynthesis and respiration and provides an important constraint representing the sum of all export pathways.

Within a euphotic zone of thickness, $h$, the column integrated mass balance equations for $\mathrm{C}_{\text {org }}, \mathrm{O}_{2}$ and DIN $\left(\mathrm{mol} \mathrm{m}^{-2} \mathrm{~d}^{-1}\right)$ are:

$$
\begin{aligned}
& h \frac{d\left(C_{\text {org }}\right)}{d t}=\int_{0}^{E Z}\left(P^{C}-R^{C}\right) d z-F_{E Z}^{C}+F_{p h y s}^{C} \\
& h \frac{d\left(O_{2}\right)}{d t}=\int_{0}^{E Z}\left(P^{O}-R^{O}\right) d z-F_{a s}^{O}+F_{p h y s}^{O} \\
& h \frac{d\left(\mathrm{NO}_{3}\right)}{d t}=-P^{N}+R^{N}+F_{p h y s}^{N},
\end{aligned}
$$

where $P$ is photosynthesis, $R$ is respiration, $F_{E Z}$ is sinking flux across the base of the euphotic zone, $F_{p h y s}$ is physical transport by advection and mixing, $F_{a s}$ is air-sea gas exchange and superscripts ' $C$ ', ' $O$ ' and ' $N$ ' refer to whether the term is in carbon, oxygen or nitrogen. Sign conventions for $F_{a s}$ is positive out of the ocean, $F_{E Z}$ is positive for downward flux. For each mass balance equation NCP is equal to the integral $\int_{0}^{E Z}(P-R) d z$ where NCP in units of $\mathrm{C}, \mathrm{N}$ and $\mathrm{O}$ are stoichiometrically related by the photosynthetic quotient and modified Redfield ratios.

Platforms: Proxy for POC, itself to be determined by the hydro group, will be developed from backscatter $\left(b_{b p}\right)$ on the Lagrangian float and Seagliders and beam transmission of the Lagrangian float $\left(c_{p}\right)$. Oxygen will be measured by $\mathrm{O}_{2}$ optodes on the float and gliders. Nitrate will be measured by an ultraviolet nitrate sensor on the float and possibly on a glider as well. NH4 will be determined in water collected from the rosette as part of the nutrient suite by the hydro group. Similarly, dissolved organic carbon (DOC) (the complement to suspended POC, together comprising total organic carbon in the euphotic zone) will be determined on water collected during both survey and process cruises from the rosette samples.

Uncertainties and quality control concerns: The magnitude and uncertainty of each term in 1-3 varies depending on state of the upper ocean system. For example, for $\mathrm{O}_{2}$ the primary balance is often between $(N C P)^{O 2}$ and $F_{a s}^{O 2}$. Seasonally in the subarctic, $\mathrm{NO}_{3}$ drawdown can dominate such that $(N C P)^{N}$ and $h \frac{d(h N)}{d t}$ are the leading order terms. The $\mathrm{C}_{\text {org }}$ budget will be limited by the lack of means to autonomously measure DOC. Quantifying NCP using multiple approaches will add confidence to our estimates, reduce uncertainty and provide a check on assumed values for Redfield ratio and photosynthetic quotient.

Other contributing protocols: Bottle POC, DOC, Winkler $\mathrm{O}_{2}$, Underway $\mathrm{O}_{2} /$ Ar, Bottle nitrate and ammonium

Data products originating with this method:

\begin{tabular}{ll}
\hline Parameter & Units \\
\hline NCP & $\mathrm{mol} \mathrm{C} \mathrm{m}^{-3} \mathrm{~d}^{-1}$ \\
\hline
\end{tabular}

Key method references: 
Alkire, M. B., D’Asaro, E., Lee, C., Jane Perry, M., Gray, A., Cetinić, I., ... González-Posada, A. (2012). Estimates of net community production and export using high-resolution, Lagrangian measurements of $\mathrm{O}_{2}, \mathrm{NO}_{3}{ }^{-}$, and $\mathrm{POC}$ through the evolution of a spring diatom bloom in the North Atlantic. Deep Sea Research Part I: Oceanographic Research Papers, 64, 157-174. https://doi.org/10.1016/j.dsr.2012.01.012

Nicholson, D., Emerson, S., \& Eriksen, C. C. (2008). Net community production in the deep euphotic zone of the subtropical North Pacific gyre from glider surveys. Limnology and Oceanography, 53(5part2), 2226-2236. https://doi.org/10.4319/1o.2008.53.5_part_2.2226

Plant, J. N., Johnson, K. S., Sakamoto, C. M., Jannasch, H. W., Coletti, L. J., Riser, S. C., \& Swift, D. D. (2016). Net community production at Ocean Station Papa observed with nitrate and oxygen sensors on profiling floats. Global Biogeochemical Cycles, 30(6), $2015 \mathrm{~GB} 005349$.

https://doi.org/10.1002/2015GB005349 
Method: Mesopelagic Oxygen Utilization Rate from Autonomous Platform Sensors

Document author and contact info: David Nicholson, dnicholson@whoi.edu

Below the euphotic zone, respiration consumes $\mathrm{O} 2$ (and produces nitrate via remineralization). The rate of oxygen consumption is termed Oxygen Utilization Rate (OUR). OUR can be estimated from the observed time rate of change in dissolved oxygen on an isopycnal in the mesopelagic. A vertical profile of OUR is a means to characterize a 'Martin Curve' or the attenuation of sinking flux with depth. The Lagrangian float will drift directly below the euphotic zone where remineralization and flux attenuation is most rapid, thereby minimizing advection and optimizing the $\mathrm{POC}, \mathrm{O}_{2}$ and $\mathrm{NO}_{3}$ budgets. In this Lagrangian frame, the timerate of change of $\mathrm{O}_{2}$ and $\mathrm{NO}_{3}$ yield independent estimates of OUR and thus the attenuation of export flux. Our Lagrangian approach is ideally suited to quantifying OUR at depth, because effects of lateral advection are removed which, in the Eularian frame, can be of similar magnitude to OUR in the mesopelagic (Pelland, 2015). Profiles from the gliders, and potentially Bio-Argo can potentially extend OUR estimates through the mesopelagic down to $1000 \mathrm{~m}$ and yield full depth profile of OUR.

Platforms: Oxygen optode and UV nitrate sensor on Lagrangian float.

Uncertainties and quality control concerns: A primary source of uncertainty is the quantification of advective fluxes. In the purely Lagrangian frame, advection is zero, but current shear will result in all Pacific mesopelagic has been estimated as approximately $4 \mu \mathrm{mol} \mathrm{kg} \mathrm{y}^{-1}$ on average. Directly below the well calibrated $\mathrm{O}_{2}$ optode can be controlled to $\pm 0.5 \mu \mathrm{mol} \mathrm{kg}^{-1} \mathrm{y}^{-1}$ using air calibration (Bushinsky et al., 2016), indicating that we will be able to resolve expected OUR rates on about weekly to monthly scales for the upper mesopelagic and monthly to seasonal scales for the lower mesopelagic.

Other contributing protocols: NBST traps, ${ }^{234}$ Th flux, Bottle respiration rates, Seaglider $\mathrm{O}_{2}$ and $\mathrm{NO}_{3}$.

\begin{tabular}{ll}
\hline Parameter & Units \\
\hline $\mathrm{O}_{2}$ derived OUR & $\mathrm{mol} \mathrm{O} \mathrm{m}^{-3} \mathrm{~d}^{-1}$ \\
& $\mathrm{~mol} \mathrm{O} \mathrm{m}^{-3} \mathrm{~d}^{-1}$ \\
\hline
\end{tabular}

\section{Key method references:}

Bushinsky, S. M., Emerson, S. R., Riser, S. C., \& Swift, D. D. (2016). Accurate oxygen measurements on modified Argo floats using in situ air calibrations. Limnology and Oceanography: Methods, 14(8), 491-505. https://doi.org/10.1002/lom3.10107

Martz, T. R., Johnson, K. S., \& Riser, S. C. (2008). Ocean metabolism observed with oxygen sensors on profiling floats in the South Pacific. Limnol. Oceanogr, $53(5$ part 2), 2094-2111.

Pelland, N. A. (2015). Eddy Circulation, Heat and Salt Balances, and Ocean Metabolism: Observations from a Seaglider-Mooring Array at Ocean Station Papa. University of Washington, Seattle, WA.

(Bushinsky et al., 2016; Martz et al., 2008; Pelland, 2015) 
Method: $16 \mathrm{~S} / 18 \mathrm{~S}$ amplicon sequencing of surface ocean microbial community

Document author and contact information: Alex Niebergall, alex.niebergall@,duke.edu

Brief description of protocol and relation to export pathways: Duplicate $4 \mathrm{~L}$ water samples were taken from the $5 \mathrm{~m}$ Niskin bottle in the dawn cast and filtered through a $0.2 \mathrm{um}$ Sterivex filter. Samples were filtered within 1 hour of collection. Sterivex were sealed with clay and flash frozen in liquid nitrogen immediately after filtering. Samples were stored in $-80^{\circ} \mathrm{C}$ until DNA extraction. The cells on filter were lysed by bead-beating for 1 min using $0.2 \mathrm{~g}$ of zirconium beads in $400 \mu 1$ of lysis buffer AP1 (Qiagen). DNA was then extracted following protocols from Qiagen DNeasy Plant Mini Kit. V4 and V4-V5 hyper-variable regions of the 16S and 18S rRNA gene will be amplified using primers outlined in Parada et al. 2016 and Walters et al. 2015. Individual 6bp barcodes, designed following Bystrykh 2012, will be added to each sample primer for sample identification after sequencing. Following Fadrosh et al. 2014, a 0 to $7 \mathrm{bp}$ 'heterogeneity spacer' will be added to the primers to allow the samples to be sequenced out of phase. Internal spikes of a known quantity of Thermus thermophilus and Schizosaccharomyces pombe will be used for quantitative sequencing following methods outlined in Lin et al (submitted) and Wang et al. 2018. Amplified PCR products will be sequenced on an Illumina MiSeq with a 300 bp paired end run. DNA sequences will be assigned into amplicon sequence variants following protocol outlined in Callahan et al. 2017.

\section{Other contributing protocols: \\ NCP O2/Ar Protocol}

\section{Uncertainties and quality control concerns:}

To relate these data to sinking aggregates, it is critical that the same PCR primers are used to amplify $16 \mathrm{~S}$ and $18 \mathrm{~S}$ rDNA of sinking aggregates.

\section{Data products originating with this method:}

Data table of amplicon sequence variants (ASVs) - csv file

DNA sequences- Fasta files

\section{Key method references:}

Bystrykh LV. Generalized DNA barcode design based on Hamming codes. PloS one. 2012 May 17;7(5):e36852.

Callahan BJ, McMurdie PJ, Holmes SP. Exact sequence variants should replace operational taxonomic units in marker-gene data analysis. The ISME journal. 2017 Dec;11(12):2639. 
Fadrosh DW, Ma B, Gajer P, Sengamalay N, Ott S, Brotman RM, Ravel J. An improved dual-indexing approach for multiplexed 16S rRNA gene sequencing on the Illumina MiSeq platform. Microbiome. 2014 Dec;2(1):6.

Lin, Y., Gifford, S., Ducklow, H., Schofield, O., Cassar, N. Towards quantitative marine microbiome community profiling using internal standards. Submitted.

Parada AE, Needham DM, Fuhrman JA. Every base matters: assessing small subunit rRNA primers for marine microbiomes with mock communities, time series and global field samples. Environmental microbiology. 2016 May;18(5):1403-14.

Walters W, Hyde ER, Berg-Lyons D, Ackermann G, Humphrey G, Parada A, Gilbert JA, Jansson JK, Caporaso JG, Fuhrman JA, Apprill A. Improved bacterial 16S rRNA gene (V4 and V4-5) and fungal internal transcribed spacer marker gene primers for microbial community surveys. mSystems 1: e00009-15. Google Scholar. 2015.

Wang S, Lin Y, Gifford S, Eveleth R, Cassar N. Linking patterns of net community production and marine microbial community structure in the western North Atlantic. The ISME Journal. 2018 Jun 22:1. 
Flux of large sinking particles from profiles of optical spikes (Pathways 2 and 3)

Melissa Omand; momand@uri.edu, Mary Jane Perry; perrymj@ maine.edu

Last updated: December 27, 2017

This document describes protocols for estimating the flux associated with large sinking particles that appear in bio-optical measurements of backscatter (bbp). Spikes that appear in beam attenuation (cp) profiles may also be associated with large sinking aggregates, and this could easily become a methodological contribution from EXPORTS. Presently however, Briggs et al (2011, hereafter B2011) is the only paper to explicitly quantify the spikes (from bbp) and directly link them to a sinking flux. Therefore, this document focuses upon the methodology described in this manuscript.

\section{Step 1: Create a uniform 'data point density' over a profile and across platforms.}

The analysis presented in B2011 is primarily derived from glider profiles, which generally sample more slowly (intervals of 5 to 90 seconds), and move vertically more gradually $(\sim 10 \mathrm{~cm} / \mathrm{s})$ than CTD casts or Wirewalker profiles. It is recommended that the various platforms be sub-sampled, or adjusted in some appropriate manner to maintain a constant sample rate over depth and time. Since raw bbp typically has a skewed distribution with spikes representing rare, high bbp events, in order to adequately quantify these as a proxy for large particle concentration, we must statistically sample the spikes in a manner that creates some consistency between profiles and across platforms. It may be most useful to convert the raw data into a 'data point density' for a particular sample strategy (the number of data points collected per meter profiled) and make this quantity consistent within a single platform profile and across platforms.

\section{Step 2: Convert raw data to bbp.}

Convert raw voltages (for FLNTU) or digital counts (for ECO Pucks) to volume scattering functions $\beta(\theta, \lambda)$ using scale factors from manufacturer's calibrations, modified to account for the centroid angle $\theta$ of each instrument (see Sullivan et al. 2013). Next, subtract the volume scattering function of seawater, $\beta \operatorname{sw}(\theta, \lambda)$, (Zhang et al. 2009) from $\beta(\theta, \lambda)$ to get the scattering due to particles, $\beta \mathrm{p}(\theta, \lambda)$ and convert this to bbp (integrated particulate backscattering) using the equation: $\operatorname{bbp}(\lambda)=2 \pi \chi$ $\beta \mathrm{p}(\theta, \lambda)$, where $\chi$ is 1.132 for FLNTU and 1.077 for ECO Pucks.

\section{Step 3: Filter for spikes in bbp.}

There are a variety of options for spike filtering. The basic idea is to apply some low-pass filter to the bbp data, and then subtract this from the original signal to get a spike data set bbpsp. B2011 used a 7-point running minimum filter followed by 7-point running maximum filter, and then subtracted a noise threshold based on twice the 90th percentile value prior to a date when large spikes were rare (setting all values below this to zero). Some MatLAB functions for spike filtering created by Nathan Briggs are given at the end of this file.

\section{Step 4: Bin average the remaining spike dataset.}

Now bin-average bbp $_{\mathrm{sp}}$ in time and depth. Bins should be selected such that they contain at least 100 points (including zeros). In B2011, the bins were 2 days and 50 meters, in a data set that combined 4 glider records.

\section{Step 5: Calculate an aggregate POC mass from the binned data.}

The final step is to look for patterns - particularly any descending features in the bin-averaged dataset. These features may be indicative of major sinking flux events. A linear regression would then allow the estimation of a sinking rate. The concentration of POC associated with the spikes can be inferred from the slope of the POC vs bbp relationship derived from bottle and CTD comparisons. Finally, the flux attenuation coefficient (ie. the 
Martin Curve exponent) can be derived from the decrease in bbp $p_{\mathrm{sp}}$ along the sinking feature (if seen) or may be applied from other EXPORTS observations.

\section{Key method references:}

Briggs, N., MJ Perry, I Cetinić, C Lee, E D'Asaro, AM Gray, E Rehm (2011). High-resolution observations of aggregate flux during a sub-polar North Atlantic spring bloom. Deep Sea Research Part I: Oceanographic Research Papers 58 (10), p. 1031-1039.

Sullivan J.M., Twardowski M.S., Ronald J., Zaneveld V., Moore C.C. (2013) Measuring optical backscattering in water. In: Light Scattering Reviews 7. Springer Praxis Books. Springer, Berlin, Heidelberg

$\% \% \% \% \% \% \% \% \% \% \%$ Matlab Scripts for Spike Filtering \%\%\%\%\%\%\%\%\%\%\%\%\%\%\%\%\%

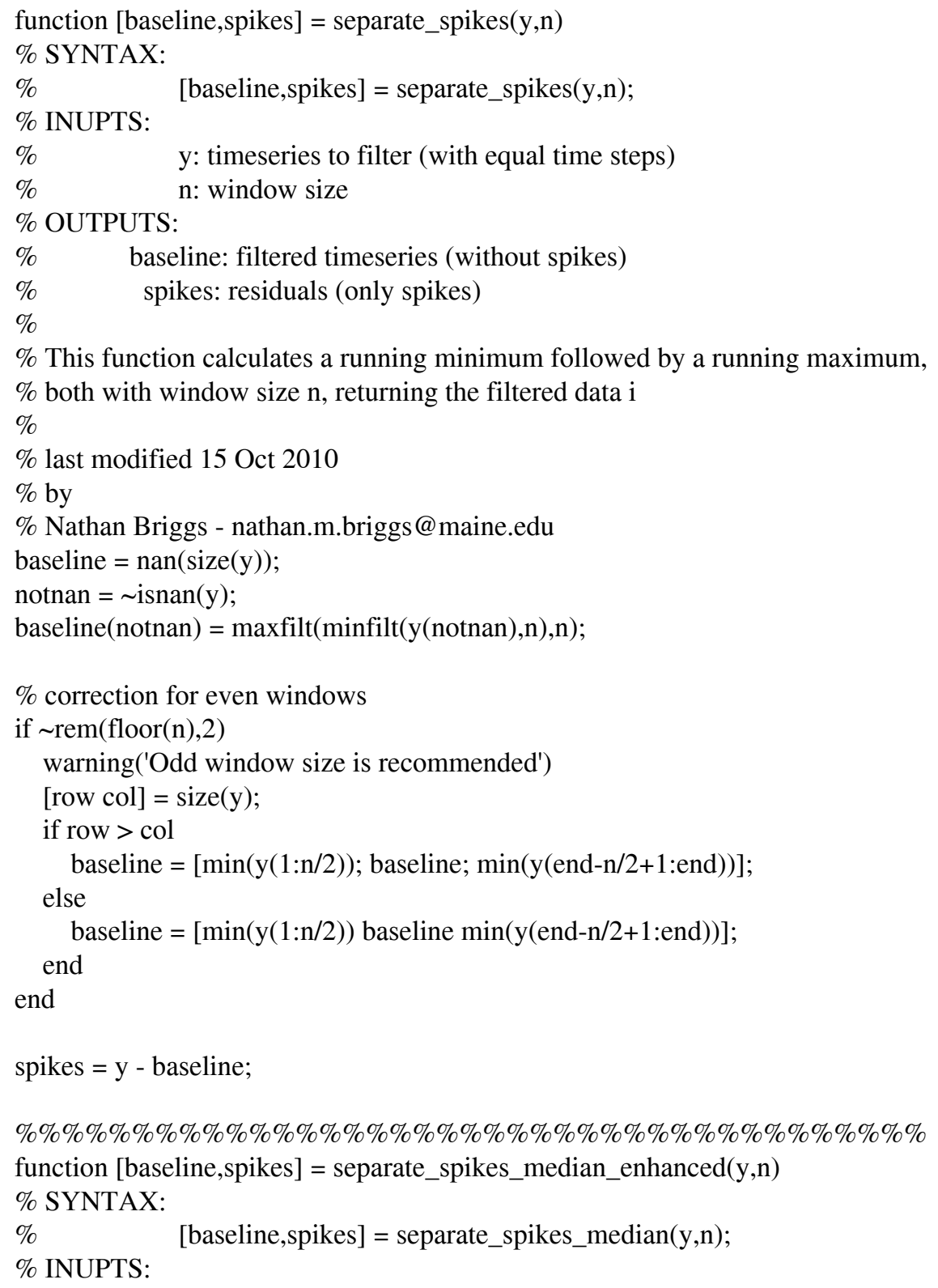




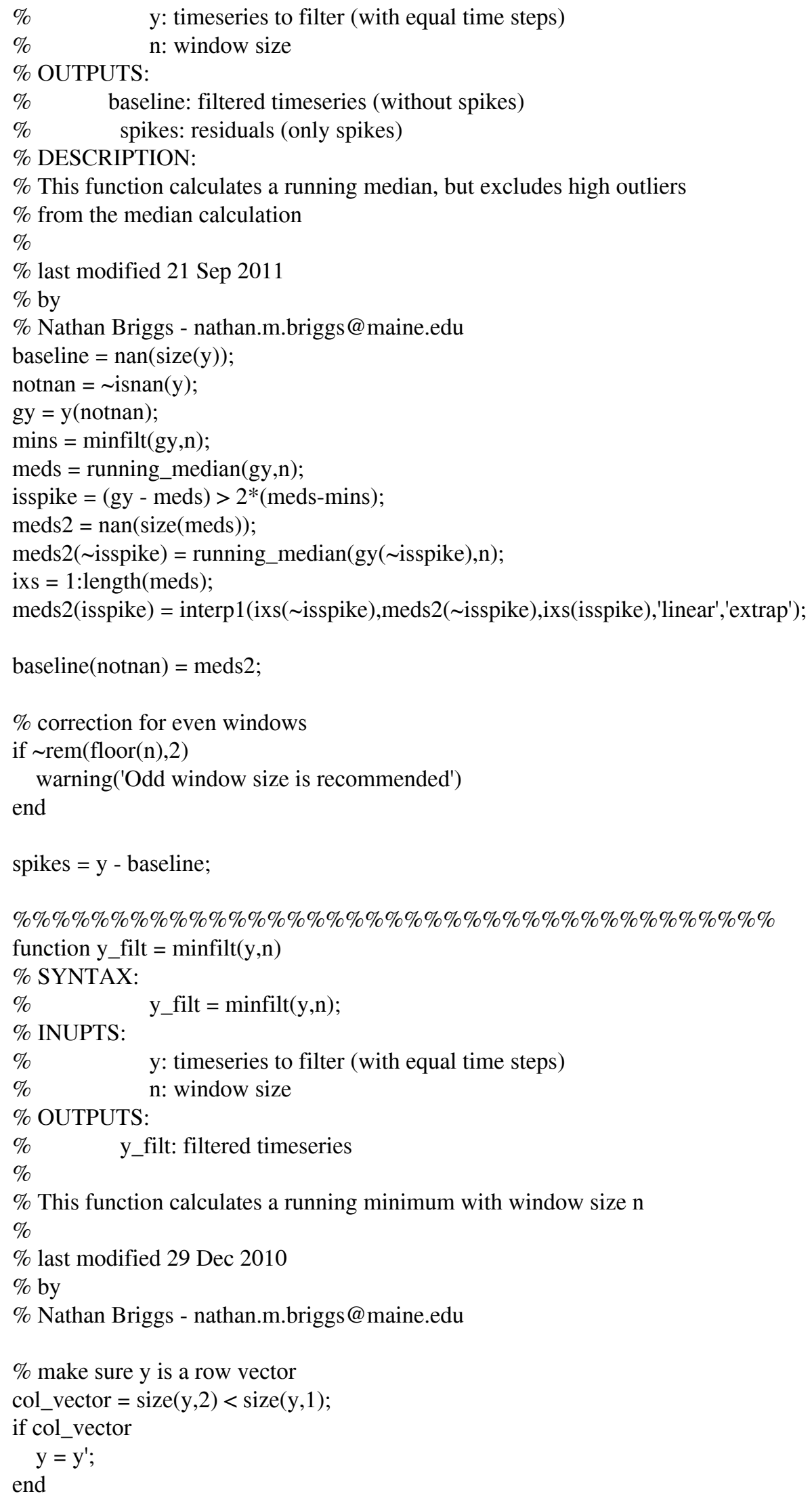




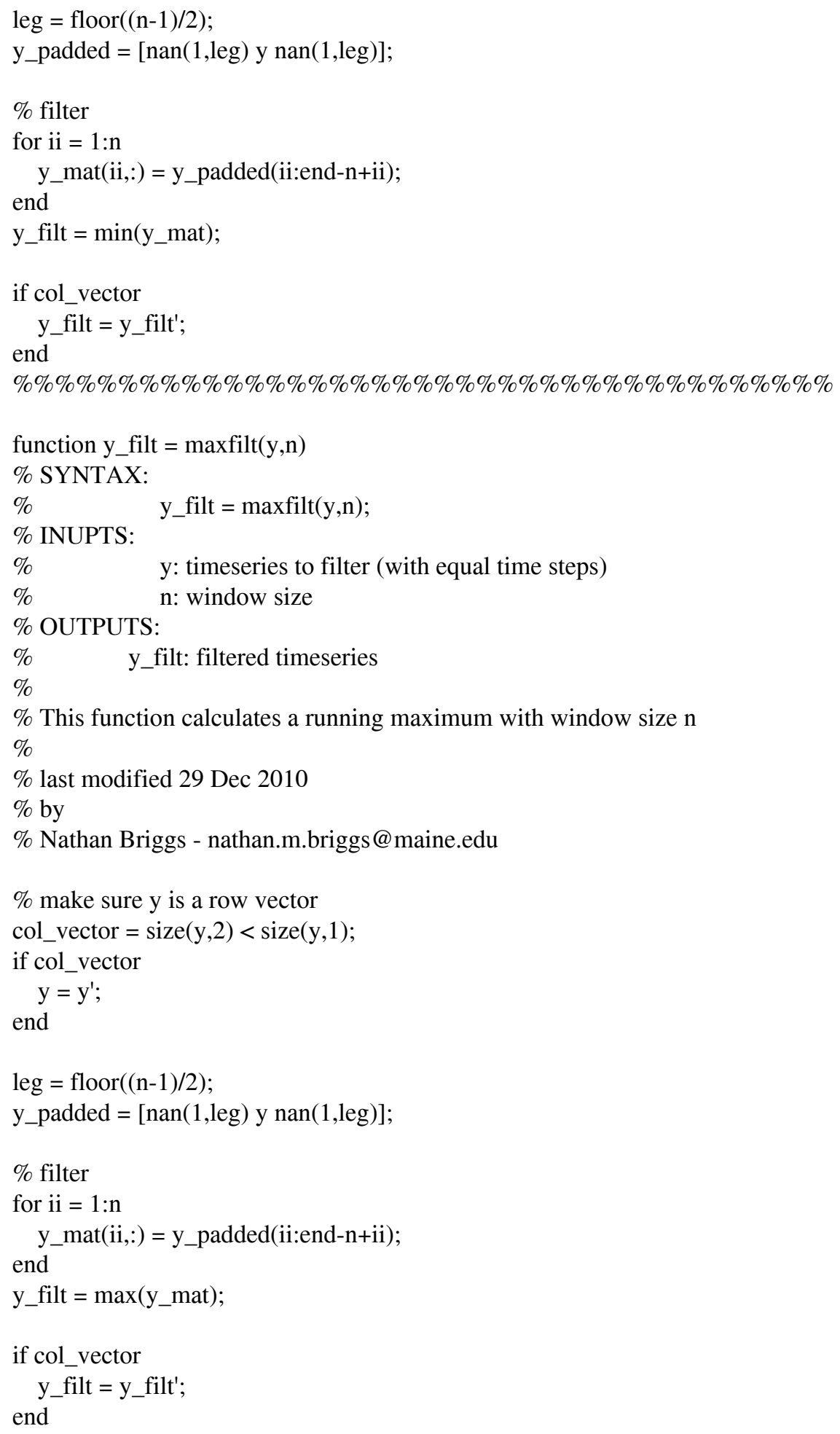


Method: Quantification of Transparent Exopolymer Particles (TEP) in the water (collected via Niskin bottles)

Document author and contact info: Uta Passow, uta.passow@mun.ca

\section{Brief description of protocol and relation to export pathways:}

Transparent exopolymer particles, TEP, are essential for aggregation, as TEP form the matrix of aggregates, holding the individual component particles together. TEP thus allow the formation of rapidly sinking aggregates. However, excess density of TEP is negative, so they impact the sinking velocity of aggregates, and if unassociated with ballasting particles, TEP move upwards into the sea surface microlayer.

Sample collection: water for TEP measurements was sampled about twice per epoch at 10-12 depths between the surface and $500 \mathrm{~m}$, using the SIO-CTD. Between 3 and 5 liters of water were sampled at each depth, and between 1 and 1.5 liters filtered onto 0.4 PC $(25 \mathrm{~mm})$ filters in triplicates, stained with Alcian Blue and frozen until later TEP analysis.

TEP analysis: TEP concentrations were determined on triplicate filters (PC $0.4 \mu \mathrm{m}, 25 \mathrm{~mm}$ diameter) using the colorimetric method (Passow and Alldredge, 1995). Between 100 and 2000 $\mathrm{mL}$ were fitlered and stained and stained filters stored froozen in facon tubes till analysis. Results are expressed in Gum Xanthan equivalents (GXeq.) and the calibration f-factor was 84.

Uncertainties and quality concerns: Only a first quality control was performed, for this reason values need to be used with caution. TEP values at detection limit (DL) have been removed. Values were considered to be at detection limit if measured uncorrected values were $\leq 2$ times the blank. If uncorrected values were $>2$ times the blank, but $\leq 3$ times the blank, they were considered to be near detection and flagged as near DL.

\section{Data products originating with this method:}

\begin{tabular}{|c|c|}
\hline Parameters & Units \\
\hline TEP_bottle & ug_Gxan_equiv/L \\
\hline
\end{tabular}

\section{Key methods references:}

Passow, U. and Alldredge, A.L., 1995. A dye-binding assay for the spectrophotometric measurement of transparent exopolymer particles (TEP). Limnology and Oceanography, 40(7): 1326-1335. 
Method: Quantification of $P O C, P O N$, total $C, B S i, L S i$ and TEP in sinking particle fractions collected from the Marine Snow Catcher

Document author and contact info: Uta Passow, uta.passow@mun.ca

\section{Brief description of protocol and relation to export pathways:}

The marine snow catcher allows the collection of particles fractionated according to their sinking velocity (rather than size). POC, PON, total C, BSi, LSi and TEP content in non-sinking, slow sinking and fast sinking particles were measured.

Sample Collection: Collection of samples from marine snow catchers (MSC) were conducted $\geq 3$ times in each 8-day epoch, each time from 3 depths, ranging from $25 \mathrm{~m}$ (within mixed layer depth) to $500 \mathrm{~m}$. Choice of sampling depths depended in part on Fluorescence and UVP profiles, but one MSC was always deployed at $95 \mathrm{~m}$ (below euphotic zone). Upon retrieval of the MSC, they were secured in the upright position and a five-liter $\mathrm{t}=0$ sample (T0) collected from the center tap. The MSC were kept in the upright position for exactly 2 hours, and then 10-15 liters of the top ( $t$ ) fraction was collected from the central tap, and the upper portion of the MSC drained through the center tap. This took 5 minutes. Then the lower tap was opened about $1 / 3$ of the way and the lower portion of the upper section of the MSC drained slowly taking 25-30 minutes, so as not to disturb particles in the base of the MSC. Thereafter the upper section of the MSC was removed using a crane, allowing sampling of the base. Overlaying water in the base section was siphoned off (approximately 5 liters) and is called the base (b) fraction, whereas the particles that settled in the tray (500-1000 mL) are considered to be the tray (tr) fraction. The trays were placed at the bottom of the MSC prior to deployment and collected particles sinking rapidly enough to reach the bottom of the MSC. Trays were investigated for the presence of marine snow, and particles $>0.5 \mathrm{~mm}$ photographed, but no marine snow sized particles $(>0.5 \mathrm{~mm})$ were observed in any of the samples. Sometimes fibers were observed, but it was assumed that they were contaminants due to handling of the MSC. The total volume of the tray (tr) fraction was determined and all four fractions subsampled for further analysis.

Analysis method: Each analysis was done 1-2 times per epoch, POC was always measured.

- POC/PON/total_C: Replicate filters (combusted GF/F, Whatmann $25 \mathrm{~mm}$ ) were measured in a CEC44OHA elemental analyzer (Control equipment) after fuming with 10\% HCL. Duplicate filters were analyzed the same way, but without prior acidification and generated total carbon (total_C). Data Product: Particulate organic carbon, particulate organic nitrogen and total carbon concentration in the specific fraction of the MSC. Unit: $\mathrm{mg} \mathrm{m}^{-3}$.

- $\mathrm{BSi} / \mathrm{LSi}$ : Filter samples were covered in $4 \mathrm{~mL}$ of $0.2 \mathrm{~N} \mathrm{NaOH}$ and placed in a $95^{\circ} \mathrm{C}$ water bath for 40 minutes. The samples were then cooled, where $1.0 \mathrm{~mL}$ of $1 \mathrm{~N} \mathrm{HCl}$ was added and vortexed. Samples were centrifuged for 10 minutes at $2500 \mathrm{rpms}$ to separate LSi from BSi. Using a different tube, $4 \mathrm{~mL}$ of the sample solution was added to $6 \mathrm{~mL}$ of Nanopure where the reduced molybdosilicic acid spectrophotographic method by Strickland and Parsons 1968 was used. Samples were then run on a spectrophotometer. Filters left over from BSi were used to determine LSi. Filters were rinsed using Nanopure and left to dry. Once filters were completely dried, they were cooled, and $0.2 \mathrm{~mL}$ of $2.5 \mathrm{M} \mathrm{HF}$ was added to the filter and left to soak for 48 hours. Filters were then vortexed proceeding with an addition of $9.8 \mathrm{~mL}$ of boric 
acid. In a different tube, $8 \mathrm{~mL}$ of the sample solution was added to $2 \mathrm{~mL}$ of Nanopure where the reduced molybdosilicic acid spectrophotographic method by Strickland and Parsons 1968 was used. Samples were then measured on a spectrophotometer.

- TEP analysis: TEP concentrations were determined on triplicate filters (PC $0.4 \mu \mathrm{m}, 25 \mathrm{~mm}$ diameter) using the colorimetric method (Passow and Alldredge, 1995). Between 100 and 2000 $\mathrm{mL}$ were fitlered and stained and stained filters stored froozen in falcon tubes till analysis. Results are expressed in Gum Xanthan equivalents (GXeq.) and the calibration f-factor was 84.

Uncertainties and quality concerns: Only a first quality control was performed, for this reason values need to be used with caution. Values at detection limit (DL) have been removed. TEP values were considered to be at detection limit if measured uncorrected values were $\leq 2$ times the blank. If uncorrected values were $>2$ times the blank, but $\leq 3$ times the blank, they were considered to be near detection and flagged as near DL. The coefficient of variation (standard deviation/average) between triplicates was on average $9 \%$, and always $<20 \%$, with one exception. POC and PON detection limits were 2-7 $\mu \mathrm{g}$ and $1-2 \mu \mathrm{g}$, respectively.

Data products originating with this method:

\begin{tabular}{|c|c|}
\hline Parameters & Units \\
\hline POC & $\mathrm{mg} / \mathrm{m}^{3}$ \\
\hline PON & $\mathrm{mg} / \mathrm{m}^{3}$ \\
\hline total_C & $\mathrm{mg} / \mathrm{m}^{3}$ \\
\hline $\mathrm{TEP}$ & $\mu \mathrm{g} \mathrm{Gxan} \mathrm{equiv} / \mathrm{L}$ \\
\hline $\mathrm{BSi}$ & $\mathrm{mmol} / \mathrm{m}^{3}$ \\
\hline $\mathrm{LSi}$ & $\mathrm{mmol} / \mathrm{m}^{3}$ \\
\hline
\end{tabular}

MSC dimensions:

\begin{tabular}{|c|c|c|}
\hline MSC_height & 149.9 & $\mathrm{~cm}$ \\
\hline MSC_diameter & 27.6 & $\mathrm{~cm}$ \\
\hline Base_height & 12.7 & $\mathrm{~cm}$ \\
\hline Tray_height & 4.4 & $\mathrm{~cm}$ \\
\hline Tray_area & 280.0 & $\mathrm{~cm}^{2}$ \\
\hline
\end{tabular}

Legend:

\begin{tabular}{|c|c|}
\hline MSC_fraction & Description \\
\hline T0 & $\begin{array}{l}\text { Total } P O C / P O N / \text { total_C/BSi/LSi/TEP contained in the Marine Snow Catcher } \\
\text { before partitioning particles according to their sinking velocity (equivalent to } \\
\text { T0) }\end{array}$ \\
\hline
\end{tabular}




\begin{tabular}{|c|c|}
\hline $\mathrm{t}$ & $\begin{array}{l}\text { POC/PON/total_C/BSi/LSi/TEP contained in the top of the Marine Snow } \\
\text { Catcher after } 2 \mathrm{~h} \text { of settling }\end{array}$ \\
\hline $\mathrm{b}$ & $\begin{array}{l}\text { POC/PON/total_C/BSi/LSi/TEP contained in the base of the Marine Snow } \\
\text { Catcher after } 2 \mathrm{~h} \text { of settling }\end{array}$ \\
\hline $\operatorname{tr}$ & $\begin{array}{c}\text { POC/PON/total_C/BSi/LSi/TEP contained in the tray placed in the Marine } \\
\text { Snow Catcher after } 2 \mathrm{~h} \text { of settling }\end{array}$ \\
\hline
\end{tabular}

\section{Key methods references:}

1. Passow, U. and Alldredge, A.L., 1995. A dye-binding assay for the spectrophotometric measurement of transparent exopolymer particles (TEP). Limnology and Oceanography, 40(7): 1326-1335.

2. Strickland, J.D.H. and Parsons, T.R. (1968) A Practical Handbook of Seawater Analyses. Bulletin Fisheries Research Board of Canada, n. 167, Fisheries Research Board of Canada, Ottawa, $311 \mathrm{p}$. 
EXPORT Pathways Working group: Protocol Brief

Name of method: Characterization of Particles collected from the Marine Snow Catcher

Primary Author: Passow, Uta; uta.passow@lifesci.ucsb.edu

Sample Collection: Water for TEP measurements was sampled twice per epic at 10-12 depths between the surface and $500 \mathrm{~m}$, using the SIO-CTD. Between 3 and 5 liters of water were sampled at each depth, and between 1 and 1.5 liters filtered onto 0.4 PC $(25 \mathrm{~mm})$ filters in triplicates and stained with Alcian Blue for later TEP analysis.

Collection of samples from marine snow catchers (MSC) were conducted $\geq 3$ times in each 8-day epic from 3 depths, ranging from $25 \mathrm{~m}$ (within mixed layer depth) to $500 \mathrm{~m}$, with a $95 \mathrm{~m}$ (below euphotic zone) depth at all times. Choice of depths depended in part on Fluorescence and UVP profiles. Upon retrieval of MSC, they were secured in the upright position and a five-liter $\mathrm{t}=0$ sample collected from the center tap. The MSC were kept in the upright position for exactly 2 hours, and then 10-15 liters of the NSP fraction was collected from the central tap, and the upper portion of the MSC drained through the center tap. This took 5 minutes. Then the lower tap was opened about $1 / 3$ of the way and the lower portion of the upper section of the MSC drained slowly taking 25-30 minutes, so as not to disturb particles in the base of the MSC. Thereafter the upper section of the MSC was removed using a crane, allowing sampling of the base. Overlaying water in the base section was siphoned off (approximately 5 liters) and is called the SSP fraction, whereas the particles that settled in the tray $(500-1000 \mathrm{~mL})$ are considered to contain the FSP. Trays were investigated for the presence of marine snow, and particles $>0.5 \mathrm{~mm}$ photographed, but no marine snow sized particles $(>0.5 \mathrm{~mm})$ were observed in any of the samples. The volume of the FSP fraction was determined and all four fractions subsampled for further analysis. The collected FSP and the SSP fractions both contain NSP, and the FSP contains SSP. This was accounted for mathematically.

At times a petri-dish with polyacryl gel was positioned into the tray to collect and immobilize sinking particles. However, these gels were never used when activity (bacterial activity, $\mathrm{O} 2$ consumption, DOC remineralization) was measured, so not to contaminate with carbon.

Salp fecal pellets (produced from salps kept in buckets by Steinberg group) were individually incubated in 1.2 liter rolling tanks at 41Fahrenheit in the dark to determine their sinking velocity using the orbit method. Before incubation pellets were photographed to allow accurate sizing. After 3-5 hours of incubation, when solid body rotation was established the orbit of the particle in the rolling tank was filmed. Thereafter each pellet was photographed again and then filtered onto a GFF for POC analysis. Respiration rate of salp fecal pellets was determined using the microoptode from Unisense in a $700 \mathrm{uL}$ chamber with a stir bar and a screen separating pellet from stir bar. The instrument was calibrated daily (with zero and $100 \%$ oxygenated water) and calbtration and sample measuremetns were submerged in a water bath that held temperature very constant (water bath?). A UPS device helped ensure stable current. Pellets were photographed, inserted into the chamber and stirring speed set to $600 \mathrm{rpm}$. Oxygen measurements were conducted for three or four 10-minute periods with 10 minute breaks between each measurement period. Each measurement point was averaged over 10 seconds. 
Particle types \& Analyses of MSC samples:

All particles combined at $\mathrm{t}=0, \mathrm{POC}$ for reference only

l. Sinking and Non-sinking particles (Non-Sinking (NSP); Slow sinking (SSP: $<18 \mathrm{~m} \mathrm{~d}^{-1}$ ); Fast sinking $\left(\right.$ FSP $\left.\left.<0.5-1 \mathrm{~mm} \&>18 \mathrm{~m} \mathrm{~d}^{-1}\right)\right)$

1. Basic Characterization

a. POC/PON content

b. Fixed samples

2. Composition

a. Size-frequency distribution (Flow cam)

b. Biochemical composition (POC, BSI, PIC).

c. Lithogenic - Phoebe Lam

d. Omics - Alyson Santura, Ewelina

3. Aggregate formation

a. TEP

b. Stickiness/ aggregation potential

4. Loss processes (profile \# 3 of each stage)

a. Respiration - Scott Grifford

b. Bacterial production \& abundance - Craig Carlson

c. Remineralization rate - Craig Carlson

II. Marine Snow - no marine snow sized particles were collected in the MSC

Uncertainties and Quality Control concerns: High detail on individual characterization implies low sample numbers and low replication; not all measurements could be done each sampling day, so spatial and temporal heterogeneity make comparisons more difficult.

\section{Data products}

Vertical profiles of suspended, slow sinking and fast sinking small particles:

- Partitioning of biochemical parameters like POC between fast, slow and non-sinking, small particles

- Size frequency distributions in each category

- Biogeochemical Characteristics (POC, BSI, PIC) of each category

- TEP content in mass Gum Xanthan equivalent per volume in each category and in whole water

- Stickiness/ aggregation potential (\%, relative number: fraction of particles that aggregate within a fixed time period)

- Respiration rates of each category

- Bacterial production rates

\begin{tabular}{|l|l|}
\hline Parameter & Units \\
\hline Biochemical content of NS, SS, FS, MS* & $\mu \mathrm{g} \mathrm{L}^{-1}$ of POC, PIC, BSi \\
\hline
\end{tabular}




\begin{tabular}{|c|c|}
\hline Size distribution of NS, SS, FS & $\#$ size bin $^{-1}$ \\
\hline Salp pellets sinking velocity as a function of size & $\mathrm{m} \mathrm{s}^{-1}$ \\
\hline TEP content of NS, SS, FS, and whole water & $\begin{array}{l}\text { mass gum xanthan equivalent } \mathrm{m}^{-3} \text { or mass gum } \\
\text { xanthan equivalent MS particle } \mathrm{e}^{-1}\end{array}$ \\
\hline $\begin{array}{l}\text { Proxy for stickiness (aggregation potential) of } \\
\text { suspended or small sinking particles }\end{array}$ & fraction of particles that aggregate $\mathrm{hr}^{-1}$ \\
\hline Respiration rates of NS, SS, FS & $\mathrm{O} 2$ consumed per $\mathrm{MS} \mathrm{hr}{ }^{-1}$ \\
\hline Bacterial production rates & pmol marine snow ${ }^{-1} \mathrm{hr}^{-1}$ \\
\hline Remineralisation Rate & $\mu \mathrm{gCL^{-1 }} \mathrm{hr}^{-1}$ \\
\hline
\end{tabular}

*non-sinking, slow-sinking, fast-sinking particles (NS, SS, FS) 
Method: Determine whether microbially-degraded biomass is important for midwater zooplankton metabolism

Document author and contact info: Brian N. Popp (popp@,hawaii.edu) and Hilary G. Close (hclose@,rsmas.miami.edu)

Brief description of protocol and relation to export pathways: Size-fractionated zooplankton $(0.2-0.5 \mathrm{~mm}, 0.5-1 \mathrm{~mm}$ and $1-2 \mathrm{~mm})$ will be collected from a paired daytime/nighttime $1 \mathrm{~m}^{2}$ MOCNESS tow deployed by D. Steinberg. Each tow will be as quantitative as possible, with colocated environmental data (CTD, DO, PAR, flourometer). Zooplankton from each net will be sieved and the fractions concentrated on pre-weighed Nitex screens, rinsed with isotonic ammonium formate to remove salts, frozen at $-20^{\circ} \mathrm{C}$, dried, re-weighed for dry biomass, and prepared for bulk and amino acid isotopic analyses. A total of 54 zooplankton samples will be analyzed: 3 sizes, 9 depths, and day versus night. Bulk zooplankton isotope and $\mathrm{C}: \mathrm{N}$ ratios will be determined via an on-line $\mathrm{C}-\mathrm{N}$ analyzer coupled with isotope ratio mass spectrometer and will be used to guide our choice of samples for amino acid compound specific isotope analysis (AACSIA) and to compare to published bulk data. Zooplankton will be prepared for AA-CSIA by acid hydrolysis and derivatization to produce trifluoroacetic amino acid esters and analyzed by isotope ratio mass spectrometry (IRMS) using procedures that are now routine (Hannides et al. 2009, Dale et al. 2011). The nitrogen isotopic composition of individual amino acids will allow us to calculate the trophic position of zooplankton. The amino acid carbon and nitrogen isotopic compositions of zooplankton will be compared with that of particles to assess the changes in zooplankton dietary sources over depth and organism size to determine which particle size fractions are used by zooplankton to meet their metabolic demand. Carbon isotopic compositions of essential amino acids (EAA) will be used to distinguish between marine producers versus bacterial sources of EAA to midwater zooplankton, which is related to microbial metabolism on the particles. Our results will provide basic information on the depth variability of food webparticle interactions that are needed to develop predictive models of the ocean's biological pump. Evaluating how variations in surface ocean productivity affect mesopelagic food webs will significantly further our understanding of the role of zooplankton in the export or attenuation of $\mathrm{C}$ and $\mathrm{N}$ flux. Our refined size-class differentiation of particles (see H. Close protocol) will additionally clarify the extent to which zooplankton food webs rely on discrete particle components/size fractions or along the particle size continuum.

Other contributing protocols: Compound-specific carbon and nitrogen isotope analyses of amino acids in size-fractionated particles (H. Close protocol).

Uncertainties and quality control concerns: All AA-CSIA will be conducted in triplicate; analytical uncertainty will be propagated in the calculation of metavariables, and additional uncertainty in $\delta^{13} \mathrm{C}$ values of amino acids will be propagated from analysis of derivatization standards. Suites of amino acid standards will be prepared and analyzed concurrently with each sample batch as external standards for quantitation and mass-balance correction for derivative carbon. Two synthetic amino acids will be added to samples as internal isotope and recovery standards. In addition, cross-lab standard materials (dried, homogenized fish tissue and homogenized cyanobacterial cells) will be prepared and analyzed concurrently with each sample batch. 
Data products originating with this method

\begin{tabular}{|l|l|}
\hline Parameter & Units \\
\hline Zooplankton bulk carbon isotope analysis & $\%$, vs. VPDB \\
\hline Zooplankton bulk nitrogen isotope analysis & $\%,, v s$. AIR \\
\hline Zooplankton bulk carbon content & $\mu \mathrm{g} \mathrm{g}^{-1}$ \\
\hline Zooplankton bulk nitrogen content & $\mu \mathrm{g} \mathrm{g}^{-1}$ \\
\hline Zooplankton bulk carbon:nitrogen ratio & $\mathrm{mol} / \mathrm{mol}$ \\
\hline Zooplankton carbon isotope analysis of individual amino acids & $\% \mathrm{o}, \mathrm{vs}$. VPDB \\
\hline Zooplankton nitrogen isotope analysis of individual amino acids & $\% \mathrm{o}, \mathrm{vs}$. AIR \\
\hline
\end{tabular}

\section{Key method references}

1. Dale JJ, Wallsgrove NJ, Popp BN, Holland K (2011) Foraging ecology and nursery habitat use of a benthic stringray from stomach content, bulk and amino acid stable isotope analysis Marine Ecology Progress Series, 433, 221-236, doi: 10.3354/meps09171.

2. Hannides CCS, Popp BN, Landry MR, Graham BS (2009) Quantification of zooplankton trophic position in the North Pacific Subtropical Gyre using stable nitrogen isotopes. Limnology and Oceanography, 54, 50-61. 
Method: The $\mathrm{N}$ and $\mathrm{O}$ isotopic composition of nitrate (nitrate $\delta^{15} \mathrm{~N}$ and $\delta^{18} \mathrm{O}$ ) in seawater using the denitrifier method

Document author and contact info: Patrick Rafter, prafter@uci.edu; Alyson Santoro, asantoro@ucsb.edu

Brief description of protocol and relation to export pathways: Nitrate $\delta^{15} \mathrm{~N}$ and $\delta^{18} \mathrm{O}$ will be determined in seawater samples off-ship by the quantitative reduction of nitrate $\left(\mathrm{NO}_{3}{ }^{-}\right)$and nitrite $\left(\mathrm{NO}_{2}^{-}\right)$to $\mathrm{N}_{2} \mathrm{O}$ using the denitrifier method. Values will be used in support of identifying the degree of surface ocean nitrate consumption and the subsurface source of surface waters.

Other contributing protocols: none

Uncertainties and quality control concerns: Nitrate contamination introduced during sample collection (e.g. collection tubes).

Data products originating with this method:

Parameter* $^{*}$

Nitrate $\delta^{15} \mathrm{~N}$

Nitrate $\delta^{18} \mathrm{O}$

Uncertainty in $\delta^{15} \mathrm{~N}$ (standard

deviation of replicate samples)

Uncertainty in $\delta^{18} \mathrm{O}$ (standard

deviation of replicate samples)

\section{Units}

per mil [\%o]

per mil [\%o]

per mil [\%o]

per mil [\%o]

\section{Key method references}

Sigman, D. M., Altabet, M. A., Michener, R., McCorkle, D. C., Fry, B., \& Holmes, R. M. (1997). Natural abundance-level measurement of the nitrogen isotopic composition of oceanic nitrate: an adaptation of the ammonia diffusion method. Marine Chemistry, 57(3-4), 227-242. https://doi.org/10.1016/s0304-4203(97)00009-1

Casciotti, K. L., Sigman, D. M., Hastings, M. G., Bohlke, J. K., \& Hilkert, A. (2002). Measurement of the oxygen isotopic composition of nitrate in seawater and freshwater using the denitrifier method. Analytical Chemistry, 74(19), 4905-4912. https://doi.org/10.1021/ac020113w

v.1.0, 23 may 2018; par

v.1.1, 24 may 2018; aes 


\section{Method: Chlorophyll analysis - $90 \%$ acetone method.}

Document author and contact info: Collin Roesler, croesler@bowdoin.edu;

1. Preparation Steps.

a. Make up sufficient volume of $90 \%$ acetone solution for sample extraction. Each centrifuge tube requires $10 \mathrm{ml}$; we generally analyze triplicates for each sample.

i. To make up $500 \mathrm{ml}$ of $90 \%$ acetone, pour $450 \mathrm{ml}$ of acetone in a graduated cylinder. This is not a volumetric reaction (i.e. adding $50 \mathrm{ml}$ distilled water will not result in $500 \mathrm{ml}$ of $90 \%$ solution). Bring up to $500 \mathrm{ml}$ volume with deionized or distilled water ensuring that the solution is well mixed.

ii. Work quickly and ensure all containers with acetone are capped, as it is very volatile.

iii. Work with acetone in the hood only and use gloves.

b. Make up sufficient volume of $10 \% \mathrm{HCl}$ solution for the fluorometric readings. Each sample reading requires 3 drops. The dropper bottle holds $30 \mathrm{ml}$ but it is important that the acid is freshly made ( $<1$ month old) to ensure complete reaction.

c. Label sample centrifuge tube (3 per sample).

d. Using the bottle-top pipettor, pipette once or twice into Actone squirt bottle to clear line. Dispense $10 \mathrm{ml}$ (sometimes we will use $5 \mathrm{ml}$ ) of $90 \%$ acetone into each tube. Be very accurate in this step, this is the largest source of error in the analysis. Cap tube tightly. Cap the pipettor after usage.

2. Water sample processing.

a. Place a glass fiber filter (size GF/F is nominal pore size of $0.7 \mu \mathrm{m}$ ) in each filter holder. Attach the filter cups ensuring that they are correctly seated. Don't over tighten.

b. Check the level on the filter trap; it should be empty before you begin.

c. Check the pump pressure, the intake should not exceed $5 \mathrm{~mm} \mathrm{Hg}$ when blocked, the outtake should not exceed 20 when blocked.

d. Gently swirl your sample three times in each direction, three times. Allowing sample to settle is one of the other largest sources of random error in the analysis. Shaking or vigorous swirling can break particle aggregates.

e. Filter a pre-determined volume of sample through each filter. The filtered volume should be sufficient to just see faint color on the filter. The fluorometric method is very sensitive so only a small amount of material is necessary. If too much material is captured on the filter, the extraction efficiency will be reduced and large errors can result.

f. Collect triplicates for each sample until you are confident that you can obtain $<5 \%$ coefficient of variation in replicates, then you may do duplicates. 
g. Turn the vacuum dial off for each sample as it finishes, preventing air from being drawn through the filter.

h. Fold filter and place each filter in its respective centrifuge tube; ensuring the filter is well below the acetone level. Take care not to scrape material off filter with forceps.

i. Shake the sample vigorously a few times, then, Vortex the sample for about 15 seconds. Again, ensure filter is below acetone level.

j. Store centrifuge tubes in the freezer for 24 to 48 hours. Keep them covered in foil to prevent light damage.

3. Readings with the Turner Fluorometer.

a. Turn on fluorometer; warm up at least 15 minutes.

b. Remove sample tubes from the freezer, keeping them protected from light. Process in batches of 6 as possible

c. Shake sample vigorously and vortex $5 \mathrm{~s}$.

d. Centrifuge the tubes for five minutes on setting 5. Keep samples vertical to prevent filter material from resuspending. Centrifuge tubes have to arranged in a balance distribution. If all six slots are not filled, place 4 such that the six slots are $Y$ Y N N Y Y. 3 would be arranged as $Y N Y N Y N$; and 2 would be $Y N N Y N N$.

e. Run $90 \%$ acetone blanks on each scale of the fluorometer. Read only the 0-10 dial scale, record the sensitivity.

f. Pour a sample from the centrifuge tube into the glass fluorometer vials, minimizing the amount of filter material in the tube. While sample is stabilizing in fluorometers, dump remaining sample in waste container, remove filter and wipe sample name from tube.

g. Take a reading on the fluorometer, setting the sensitivity so that the reading is between 2 and 8 if possible. Record both the scale (and the $\mathrm{X} 1$ or $\mathrm{X} 100$ setting) and the dial reading to the nearest 0.1 .

h. Add 3 drops of $10 \% \mathrm{HCL}$, invert with parafilm, set aside.

i. Repeat $f$ - $h$ for the remaining 5 samples.

j. Take a reading on the first acidified sample. Record both the scale (and the $X 1$ or $X 100$ setting) and the dial reading to the nearest 0.1, the value will be lower than the original reading and likely on a more sensitive scale. Pour sample into waste container when done.

$k$. Process the remaining samples from $c$ to $j$.

1. Wash tubes and vials with micro cleaner and rinse well with RO water. Dry upside down in rack or on towels. Regarding tubes on the fluorometers, the assumption is that if they are upside down they are clean, right side up are dirty

4. Calculations.

a. Record the calibration coefficients written on the Turner Fluorometer $(M=$ and $A=$ ) and note the date of those coefficients.

b. $C h l\left(m g m^{3}\right)=M *(F o-F a) *$ (1)

Phaeo $\left(m g m^{3}\right)=M *\left(\left(A^{\star} F a\right)-F o\right) *$ 
Where $M$ and $A$ are the calibration coefficients noted in step $4 b . V_{a c O H}$ is the volume of acetone in the centrifuge tube $(10 \mathrm{ml})$ and $V_{\text {filt }}$ is the volume of sample filtered in $\mathrm{ml}$. Fo and Fa are calculated as follows:

$F_{0}=(3)$

$\mathrm{Fa}=(4)$

Where Ro and Ra are the dial reading values for the sample before and after acidification, respectively, scale is the scale that the reading was made at and $R_{\text {blank }}$ is the dial reading for pure $90 \%$ acetone on the scale that Ro or Ra was made at. For example, if Ro was made on the 100 scale, $R_{\text {blank }}$ in equation (3) is the dial reading for acetone on the 100 scale; if Ra was made on the 316 scale, $R_{\text {blank }}$ in equation (4) is the dial reading for acetone on the 316 scale.

\section{References for extractive technique and applications:}

Yentsch, C.S. and D.W. Menzel. 1963. A method for the determination of phytoplankton chlorophyll and pheophytin by fluorescence. Deep-Sea Res. 10: 221-231.

Holm-Hansen, O., C.J. Lorenzen, R.W. Holmes, and J.D. Strickland. 1965.

Fluorometric determination of chlorophyll. J. Cons. Cons. Int. Explor. Mer 30: 3-15.

Steele, J. H., and C. S. Yentsch. 1960. The vertical distribution of chlorophyll. J. Mar. Biol. Assoc. U.K. 39: 217-226.

Reference for field fluorometer technique:

Lorenzen, C.J. 1966. A method for the continuous measurement of the in vivo chlorophyll concentration. Deep-Sea Res. 13: 223-227.

Cullen, J. J. 1982. The deep chlorophyll maximum: comparing vertical profiles of chlorophyll a. Can. J. Fish. Aquat. Sci. 39: 791-803. 


\section{Method: In-line Hyperspectral Size -Fractioned Particulate Absorption}

Document author and contact info: Collin Roesler, croesler@bowdoin.edu;

Brief description of protocol and relation to export pathways: Hyperspectral size-fractioned particulate absorption coefficients were obtained from continuous inline observations collected with a WETLabs acs using a differencing method between unfiltered and filtered observations following Slade et al. (2010). We collected continuous inline observations of temperature and salinity using a SeaBird TSG thermosalinograph. Particulate absorption provides an assessment of the total particulate load and a means to assess phytoplankton from non-phytoplankton particulates. It also provides an assessment of absorption line height for the estimation of chlorophyll concentration in the absence of non-photochemical quenching. The hyperspectral beam attenuation provides an additional proxy for total particulate load and additionally is a proxy for particulate organic carbon. The spectral slope of the beam $\mathrm{c}$ is a size proxy.

Deployment methodologies: The flow through system is configured so that the inline water system is supplied with a diaphragm pump to minimize particle disaggregation. Water entered the inline system through a vortex debubbler followed by at Seabird thermosalinograph, then a Sequoia Flow Meter and finally to the acs. The flow meter automatically switched flow from unfiltered to filtered through a large volume $0.2 \mu \mathrm{m}$ cartridge filter. The automated switch operated continuously through the day such that during each hour 50 minutes is unfiltered and 10 minutes is filtered. Approximately twice per day, an additional filtered configuration was manually triggered such that the hour was parsed into 20 minutes of unfiltered, 15 minutes of $20-\mu \mathrm{m}$ filtration, 15 minutes of $5-\mu \mathrm{m}$ filtration and 10 minutes of $0.2-\mu \mathrm{m}$ filtration. Discrete water samples were collected from each of the size fractions and processed for spectrophotometric particulate absorption, HPLC and POC. An inline CDOM fluorometer, Chl fluorometer and backscattering sensors provide continuous monitoring of dissolved absorption, phytoplankton biomass and particulate biomass, respectively, which are used to interpolate the absorption time series through the fractions.

\section{Data processing}

Raw data were processed to remove noisy data associated with bubbles by computing initial 1minute median bins, then removing raw data that was outside of 1 standard deviation of the median. This was then applied across a range of channels (wavelengths). The raw data were then reprocessed to 1-minute median bins. Standard deviation values were computed for the 1-minute bins.

One-minute binned data was merged with the Ship's navigation data sets that were also processed to 1-minute bins.

Data time series were then parsed into size bins (unfiltered, $<0.2 \mathrm{um},<5 \mathrm{um}$ and $<20 \mathrm{um}$ ). The $<0.2$ um filtered time series was interpolated over the time vector. Particulate absorption was computed by subtracting the interpolated filtered time series from the unfiltered time series for a and c. Uncertainty of the difference was propagated from the 1-minute standard deviation values. 
The spectrally flat scattering correction was applied to the particulate absorption (selecting the $725 \mathrm{~nm}$ to $750 \mathrm{~nm}$ median offset). This is in keeping with the observation that particulate absorption measured in the integrating sphere across the 3 epochs yielded negligible NIR absorption. Scattering spectra were computed by difference. Uncertainty was propagated mathematically for each computation.

Uncertainties and quality control concerns: Uncertainties associated with natural variations in absorption were determined from the standard deviations of the one-minute bin averaged data. Uncertainties for each computation were computed arithmetically.

There was significant fouling of the inline system. Steps were taken to clean the ship's lines with bleach approximately every 3 days. All tubing in the instrumented system was replaced every 35 days as fouling was observed. Raw data exhibited the signal of fouling (exponentially increasing signals in a and c). However, once the particulate IOPs were computed the biofouling trends have disappeared. The values for the inline system have not been validated against ap from center-mounted integrating sphere method yet.

Data products originating with this method:

\begin{tabular}{|c|c|c|}
\hline Parameter & Symbol & Units \\
\hline Particulate absorption coefficient, total & $\mathrm{a}_{\mathrm{p} T}$ & $\mathrm{~m}^{-1}$ \\
\hline Particulate absorption coefficient, $<20 \mu \mathrm{m}$ & $\mathrm{a}_{\mathrm{p}<20}$ & $\mathrm{~m}^{-1}$ \\
\hline Particulate absorption coefficient, $<5 \mu \mathrm{m}$ & $\mathrm{a}_{\mathrm{p}<5}$ & $\mathrm{~m}^{-1}$ \\
\hline Dissolved absorption coefficient, $<0.2 \mu \mathrm{m}$ & $\mathrm{a}_{\mathrm{p}<0.2}$ & $\mathrm{~m}^{-1}$ \\
\hline Particulate absorption coefficient, $0.2-5 \mu \mathrm{m}$ & $\mathrm{a}_{\mathrm{p} 0.2-5}$ & $\mathrm{~m}^{-1}$ \\
\hline Particulate absorption coefficient, $5-20 \mu \mathrm{m}$ & $\mathrm{a}_{\mathrm{p} 5-20}$ & $\mathrm{~m}^{-1}$ \\
\hline Particulate absorption coefficient, $>20 \mu \mathrm{m}$ & $\mathrm{a}_{\mathrm{p}>20}$ & $\mathrm{~m}^{-1}$ \\
\hline
\end{tabular}

\section{Daily files and format}

Daily files for particulate absorption, beam attenuation and scattering (ap, cp and bp, respectively) were constructed for submission to SEABASS. The format is as follows:

ap: Date, time, latitude, longitude, Chl, UChl, ap(1-78 channels), Uap(1-78)

cp: Date, time, latitude, longitude, gamma, RMSEgamma, cp(1-78 channels), Ucp(1-78)

bp: Date, time, latitude, longitude, bp(1-78 channels), Ubp(1-78)

where $\mathrm{Chl}$ is the chlorophll concentration (mg.m3) derived from red peak absorption line height, gamma is the spectral slope of $\mathrm{cp}$, $U$ stands for the propagated uncertainty, and RMSEgamma is a measure of the spectral slope model fit to each spectrum. 


\section{Key method references:}

Roesler, C. S., D. Stramski, E. J. D’Sa, R. Röttgers, and R. A. Reynolds. 2018. Chapter 5: Spectrophotometric Measurements of Particulate Absorption Using Filter Pads. In IOCCG Protocol Series (2018). Inherent Optical Property Measurements and Protocols: Absorption Coefficient, Neeley, A. R. and Mannino, A. (eds.), IOCCG Ocean Optics and Biogeochemistry Protocols for Satellite Ocean Colour Sensor Validation, Volume 1.0, IOCCG, Dartmouth, NS, Canada. http://dx.doi.org/10.25607/OBP-119

Slade, W.H., E. Boss, G. Dall'Olmo, M.R. Langner, J. Loftin, M.J. Behrenfeld, C. Roesler, and T.K. Westberry, 2010: Underway and Moored Methods for Improving Accuracy in Measurement of Spectral Particulate Absorption and Attenuation. J. Atmos. Oceanic Technol., 27, 1733-1746, https://doi.org/10.1175/2010JTECHO755.1

Stramski, D., R. A. Reynolds, S. Kaczmarek, J. Uitz, and G. Zheng, 2015: Correction of path length amplification in the filter-pad technique for measurements of particulate absorption coefficient in the visible spectral region. Appl. Opt., 54: 6763-6782.

Zaneveld, J. R. V., J. C. Kitchen, and C. C. Moore. 1994. Scattering error correction of reflecting-tube absorption meters. Proceedings Volume 2258, Ocean Optics XII, doi: 10.1117/12.190095 


\section{Method: In-line Multi-excitation Chlorophyll Fluorescence, WET Labs ECO 3X1M}

Document author and contact info: Collin Roesler, croesler@bowdoin.edu

Date: 1 August 2019

Brief description of protocol: Multi-excitation chlorophyll fluorescence was obtained from continuous inline observations collected with a WETLabs ECO 3X1M fluorometer using the differencing method between unfiltered and filtered observations following Slade et al. (2010). The fluorometer excites with 3 LEDs (nominally $440 \mathrm{~nm}, 470 \mathrm{~nm}$, and $532 \mathrm{~nm}$ ) and measures chlorophyll fluorescence $(695 \mathrm{~nm})$. The instrument is calibrated against a dilution series of the monospecific culture of the diatom Thalassiosira pseudonana to quantify the relative fluorescence response to each of the 3 excitations. Earlier studies have demonstrated that the fluorescence ratios vary as pigmentation varies (Yentsch and Phinney 1985), primarily due to taxonomically-driven variations in pigment composition with secondary dependence on photoacclimation and growth phase (Proctor and Roesler 2010; Thibodeau et al. 2014). The standard method for estimating chlorophyll $a$ concentration is to calibrate in situ observations of chlorophyll fluorescence derived from a $470 \mathrm{~nm}$ LED to paired in situ HPLC TChl measurements. The fluorescence at the other channels is scaled according to the T. pseudonana response. Thus if the in situ phytoplankton was T. pseudonana then all three channels would yield the same calibrated chlorophyll values. Variations in the derived calibrated chlorophyll between channels is then interpreted as pigment variations relative to those observed in $T$. pseudonana, as published in Proctor and Roesler (2010).

Deployment methodologies: A diaphragm pump installed in the sea chest of the R/V Armstrong delivered continuous seawater to the wet lab, with minimal particle disruption. The inline optical system consists of serial flow in the following order: MSRC VDB-1 vortex debubbler, Seabird thermosalinograph, Sequoia Flow Meter, WET Lab acs, WET Labs ECO 3X1M, WET Labs ECO BBFL2 and WET Labs ECO BB3. The ECO 3X1M was configured in a WET Labs cylindrical ECO flow cell. The flow meter automatically switched flow from unfiltered to filtered through a large volume $0.2 \mu \mathrm{m}$ cartridge filter. The automated switch operated continuously through the day such that during each hour 50 minutes is unfiltered and 10 minutes is filtered. Approximately twice per day, an additional filtered configuration was manually triggered such that the hour was parsed into 20 minutes of unfiltered, 15 minutes of $20-\mu \mathrm{m}$ filtration, 15 minutes of $5-\mu \mathrm{m}$ filtration and 10 minutes of $0.2-\mu \mathrm{m}$ filtration. Discrete water samples were collected from each of the size fractions and processed for spectrophotometric particulate absorption, HPLC and POC.

Data processing: All flow through data were processed into 1 minute bin median and standard deviation values. Observations compromised by bubbles were removed. Data were time-merged with the ship navigation GPS data streams, also processed into 1-minute bin median values. Data stream was parsed into unfiltered and filtered intervals, with transitional data removed. Filtered observations were interpolated to 1-minute intervals and subtracted from unfiltered data, thus yielding blank-subtracted fluorescence values (Slade et al. 2010). Non-negligible nonphotochemical quenching was observed within 2 hours of local midnight. Match-ups between 
discrete HPLC TChl values and unquenched inline chlorophyll fluorescence values were used to generate an in situ calibration for the $470 \mathrm{~nm}$ excitation channel, with $M\left(\frac{m g}{m^{3}} d c^{-1}\right)$, representing the slope of the matchup relationship

$$
\operatorname{Chl}\left(\frac{m g}{m^{3}}\right)=M\left(\frac{m g}{m^{3}} / d c\right) \times\left(F_{\text {unfilt }}-F_{\text {filt }}\right) \text {. }
$$

The calibration was scaled to the $440 \mathrm{~nm}$ and $532 \mathrm{~nm}$ channels using the 440:470 and 532:470 blank-corrected digital count ratios established with the T. pseudonana culture. All values are reported in units $\left(\mathrm{mg} \mathrm{m}^{-3}\right)$; non-photochemically quenched values are provided and should not be interpreted as chlorophyll concentration.

Uncertainties and quality control concerns: Uncertainties associated with natural variations in chlorophyll fluorescence were determined from the standard deviations of the one-minute bin median data for filtered, $\sigma_{\text {filt }}$, and unfiltered, $\sigma_{\text {unfilt }}$, observations. Uncertainty in the chlorophyll calculation, $\sigma_{C h l}$, was propagated (Jcgm 2008) as:

$$
\sigma_{C h l}=C h l \times \sqrt{\sigma_{u n f i l t}^{2}+\sigma_{f i l t}^{2}+\left(\frac{\sigma_{M}}{M}\right)^{2}}
$$

where $\sigma_{M}$ is the uncertainty in the regression slope of the HPLC and fluorescence match-up.

Data products originating with this method:

\begin{tabular}{|c|c|c|}
\hline Parameter & Symbol & Units \\
\hline Calibrated Fchl (ex470 nm) & Fchl (470) & $\mathrm{mg} \mathrm{m}^{-3}$ \\
\hline $\begin{array}{c}\text { Thalassiosira pseudonana-equivalent Fchl } \\
\text { (excitation 440 nm) }\end{array}$ & Fchl(440) & $\mathrm{mg} \mathrm{m}^{-3}$ \\
\hline $\begin{array}{c}\text { Thalassiosira pseudonana-equivalent Fchl } \\
\text { (excitation 532 } \mathrm{nm} \text { ) }\end{array}$ & Fchl(532) & $\mathrm{mg} \mathrm{m}^{-3}$ \\
\hline
\end{tabular}

\section{Key method references:}

Jcgm, W. G. 2008. Evaluation of measurement data - Guide to the expression of uncertainty in measurement, p. 134. In B. I. d. P. e. Mesures [ed.], GUM: Guide to the Expression of Uncertainty in Measurement.

Proctor, C. W., and C. S. Roesler. 2010. New insights on obtaining phytoplankton concentration and composition from in situ multispectral Chlorophyll fluorescence. Limnology and Oceanography: Methods 8: 695-708.

Slade, W. H. and others 2010. Underway and Moored Methods for Improving Accuracy in Measurement of Spectral Particulate Absorption and Attenuation. Journal of Atmospheric \& Oceanic Technology 27. 
Thibodeau, P. S., C. S. Roesler, S. L. Drapeau, S. Prabhu Matondkar, J. I. Goes, and P. J. Werdell. 2014. Locating Noctiluca miliaris in the Arabian Sea: An optical proxy approach. Limnology and Oceanography 59: 2042-2056.

Yentsch, C. S., and D. A. Phinney. 1985. Spectral fluorescence: an ataxonomic tool for studying the structure of phytoplankton populations. Journal of Plankton Research 7: 15. 


\section{Method: In-line Three-Channel Backscattering, WET Labs ECO BB3}

Document author and contact info: Collin Roesler, croesler@bowdoin.edu

Date: 1 August 2019

Brief description of protocol: Three-channel backscattering was obtained from continuous inline observations collected with a WETLabs ECO BB3 sensor using the differencing method between unfiltered and filtered observations following Slade et al. (2010). The backscattering sensor was comprised of 3 LEDs, nominally $412 \mathrm{~nm}, 595 \mathrm{~nm}, 715 \mathrm{~nm}$. Sunstone Scientific calibrated the sensor just prior to the EXPORTS North Pacific expedition.

Deployment methodologies: A diaphragm pump installed in the sea chest of the R/V Armstrong delivered continuous seawater to the wet lab, with minimal particle disruption. The inline optical system consists of serial flow in the following order: MSRC VDB-1 vortex debubbler, Seabird thermosalinograph, Sequoia Flow Meter, WET Lab acs, WET Labs ECO 3X1M, WET Labs ECO BBFL2 and WET Labs ECO BB3. The ECO BB3 was configured in a custom-designed casket (Dall'olmo et al. 2009) that minimizes impacts of scattered light within the flow. The flow meter automatically switched flow from unfiltered to filtered through a large volume $0.2 \mu \mathrm{m}$ cartridge filter. The automated switch operated continuously through the day such that during each hour 50 minutes is unfiltered and 10 minutes is filtered. Approximately twice per day, an additional filtered configuration was manually triggered such that the hour was parsed into 20 minutes of unfiltered, 15 minutes of $20-\mu \mathrm{m}$ filtration, 15 minutes of 5- $\mu \mathrm{m}$ filtration and 10 minutes of $0.2-\mu \mathrm{m}$ filtration. Discrete water samples were collected from each of the size fractions and processed for spectrophotometric particulate absorption, HPLC and POC.

Data processing: All flow through data were processed into 1-minute bin median and standard deviation values. Observations compromised by bubbles were removed. Data were time-merged with the ship navigation GPS data streams, also processed into 1-minute bin median values. Data stream was parsed into unfiltered and filtered intervals, with transitional data removed. Filtered observations were interpolated to 1 -minute intervals and subtracted from unfiltered data, thus yielding blank-subtracted fluorescence values (Slade et al. 2010).

The particle backscattering coefficient at each wavelength was computed from:

$$
b_{b p}\left(m^{-1}\right)=M\left(m^{-1} / d c\right) \times\left(D C_{b b_{\text {unfilt }}}-D C_{b b_{f i l t}}\right) .
$$

Where $M$ is the calibration slope provided by Sunstone Scientific (with a best-case accuracy of $2.1 \%$ ) and $D C$ indicates the 1-minute median digital count values for unfiltered or interpolated filtered observations.

Uncertainties and quality control concerns: Uncertainties associated with natural variations in particle backscattering were determined from the standard deviations of the one-minute bin median data for filtered, $\sigma_{\text {filt }}$, and unfiltered, $\sigma_{\text {unfilt }}$, observations. Following the Guide to Uncertainty Measurements (Jcgm 2008), the uncertainty in the particle backscattering coefficient for each channel is computed as: 


$$
\sigma_{b b p}=b_{b p} \times \sqrt{\sigma_{u n f i l t}^{2}+\sigma_{f i l t}^{2}+\left(\frac{\sigma_{M}}{M}\right)^{2}}
$$

where $\sigma_{M}$ is the calibration uncertainty.

Data products originating with this method:

\begin{tabular}{|c|c|c|}
\hline Parameter & Symbol & Units \\
\hline & $b_{b p}(412)$ & \\
bbp (412 nm, $595 \mathrm{~nm}, 715 \mathrm{~nm})$, & $b_{b p}(595)$ & $\mathrm{mg} \mathrm{m}^{-3}$ \\
& $b_{b p}(715)$ & \\
\hline
\end{tabular}

Key method references:

Dall'olmo, G., T. K. Westberry, M. J. Behrenfeld, E. Boss, and W. H. Slade. 2009. Significant contribution of large particles to optical backscattering in the open ocean. Biogeosciences 6: $947-967$.

Jcgm, W. G. 2008. Evaluation of measurement data - Guide to the expression of uncertainty in measurement, p. 134. In B. I. d. P. e. Mesures [ed.], GUM: Guide to the Expression of Uncertainty in Measurement.

Slade, W. H. and others 2010. Underway and Moored Methods for Improving Accuracy in Measurement of Spectral Particulate Absorption and Attenuation. Journal of Atmospheric \& Oceanic Technology 27. 


\section{Method: In-line Single Channel Backscattering and Chlorophyll and CDOM Fluorescence, WET Labs ECO BBFL2}

Document author and contact info: Collin Roesler, croesler@bowdoin.edu

Date: 1 August 2019

Brief description of protocol: Single-excitation backscattering, and chlorophyll and CDOM fluorescence was obtained from continuous inline observations collected with a WETLabs ECO BBFL2 sensor using the differencing method between unfiltered and filtered observations following Slade et al. (2010). The backscattering sensor was comprised of a $660 \mathrm{~nm}$ LED, the Chl fluorometer excites with a $470 \mathrm{~nm}$ LED (emission $695 \mathrm{~nm}$ ), the CDOM fluorometer excites with a $370 \mathrm{~nm}$ LED (emission $460 \mathrm{~nm}$ ). Calibrations were performed just prior to the EXPORTS North Pacific expedition: the backscattering sensor was calibrated by Sunstone Scientific; the CDOM fluorometer was calibrated by WET Labs; the Chl fluorometer was calibrated by WET Labs and also in-house using a monospecific culture of Thalassiosira pseudonana (Proctor and Roesler 2010; Roesler et al. 2017). The standard method for estimating in situ chlorophyll $a$ concentration is to calibrate in situ observations of chlorophyll fluorescence derived from a 470 nm LED to paired in situ HPLC TChl measurements.

Deployment methodologies: A diaphragm pump installed in the sea chest of the R/V Armstrong delivered continuous seawater to the wet lab, with minimal particle disruption. The inline optical system consists of serial flow in the following order: MSRC VDB-1 vortex debubbler, Seabird thermosalinograph, Sequoia Flow Meter, WET Lab acs, WET Labs ECO 3X1M, WET Labs ECO BBFL2 and WET Labs ECO BB3. The ECO BBFL2 was configured in a custom-designed casket (Dall'olmo et al. 2009) that minimizes impacts of scattered light within the flow. The flow meter automatically switched flow from unfiltered to filtered through a large volume $0.2 \mu \mathrm{m}$ cartridge filter. The automated switch operated continuously through the day such that during each hour 50 minutes is unfiltered and 10 minutes is filtered. Approximately twice per day, an additional filtered configuration was manually triggered such that the hour was parsed into 20 minutes of unfiltered, 15 minutes of $20-\mu \mathrm{m}$ filtration, 15 minutes of $5-\mu \mathrm{m}$ filtration and 10 minutes of $0.2-\mu \mathrm{m}$ filtration. Discrete water samples were collected from each of the size fractions and processed for spectrophotometric particulate absorption, HPLC and POC.

Data processing: All flow through data were processed into 1-minute bin median and standard deviation values. Observations compromised by bubbles were removed. Data were time-merged with the ship navigation GPS data streams, also processed into 1-minute bin median values. Data stream was parsed into unfiltered and filtered intervals, with transitional data removed. Filtered observations were interpolated to 1 -minute intervals and subtracted from unfiltered data, thus yielding blank-subtracted fluorescence values (Slade et al. 2010).

The particle backscattering coefficient was computed from:

$$
b_{b p}\left(m^{-1}\right)=M\left(m^{-1} / d c\right) \times\left(D C_{b b_{u n f i l t}}-D C_{b b_{f i l t}}\right) .
$$


Where $M$ is the calibration slope provided by Sunstone Scientific (with a best-case accuracy of $2.1 \%$ ) and $D C$ indicates the 1-minute median digital count values for unfiltered or interpolated filtered observations.

Non-negligible non-photochemical quenching was observed within 2 hours of local midnight. Match-ups between discrete HPLC TChl values and unquenched inline chlorophyll fluorescence values were used to generate an in situ calibration for the $470 \mathrm{~nm}$ excitation channel, with $M\left(\frac{m g}{m^{3}} d c^{-1}\right)$, representing the slope of the matchup relationship (with a computed uncertainty in the regression slope of $\sigma_{M}$ ):

$$
\operatorname{Chl}\left(\frac{m g}{m^{3}}\right)=M\left(\frac{m g}{m^{3}} / d c\right) \times\left(F_{\text {unfilt }}-F_{\text {filt }}\right) \text {. }
$$

Non-photochemically quenched values are provided and should not be interpreted as chlorophyll concentration.

Uncertainties and quality control concerns: Uncertainties associated with natural variations in particle backscattering and chlorophyll fluorescence were determined from the standard deviations of the one-minute bin median data for filtered, $\sigma_{\text {filt }}$, and unfiltered, $\sigma_{\text {unfilt }}$, observations. Following the Guide to Uncertainty Measurements (Jcgm 2008), the uncertainty in both backscattering coefficient and chlorophyll concentration are computed as:

$$
\sigma_{X}=X \times \sqrt{\sigma_{u n f i l t}^{2}+\sigma_{f i l t}^{2}+\left(\frac{\sigma_{M}}{M}\right)^{2}}
$$

where $X$ is either $b_{b p}$ or $C h l$, and $\sigma_{M}$ is the uncertainty in the calibration.

\section{Data products originating with this method:}

\begin{tabular}{|c|c|c|}
\hline Parameter & Symbol & Units \\
\hline $\operatorname{bbp}(660 \mathrm{~nm})$ & $b_{b p}(470)$ & $\mathrm{mg} \mathrm{m}^{-3}$ \\
\hline Calibrated Fchl (ex470 nm) & $\mathrm{Chl}$ & $\mathrm{mg} \mathrm{m}^{-3}$ \\
\hline
\end{tabular}

\section{Key method references:}

Dall'olmo, G., T. K. Westberry, M. J. Behrenfeld, E. Boss, and W. H. Slade. 2009. Significant contribution of large particles to optical backscattering in the open ocean. Biogeosciences 6: $947-967$.

Jcgm, W. G. 2008. Evaluation of measurement data - Guide to the expression of uncertainty in measurement, p. 134. In B. I. d. P. e. Mesures [ed.], GUM: Guide to the Expression of Uncertainty in Measurement. 
Proctor, C. W., and C. S. Roesler. 2010. New insights on obtaining phytoplankton concentration and composition from in situ multispectral Chlorophyll fluorescence. Limnology and Oceanography: Methods 8: 695-708.

Roesler, C. and others 2017. Recommendations for obtaining unbiased chlorophyll estimates from in situ chlorophyll fluorometers: A global analysis of WET Labs ECO sensors. Limnology and Oceanography: Methods: n/a-n/a.

Slade, W. H. and others 2010. Underway and Moored Methods for Improving Accuracy in Measurement of Spectral Particulate Absorption and Attenuation. Journal of Atmospheric \& Oceanic Technology 27. 


\section{Method: Surface Hyperspectral Radiometry}

Document author and contact info: Collin Roesler, croesler@bowdoin.edu;

Brief description of protocol and relation to export pathways: Hyperspectral remote sensing reflectance will be obtained at each daytime (1000-1400) CTD station using a Satlantic Hyper Tethered Spectral Radiometer Buoy (H-TSRB). Downwelling irradiance is measured with a cosine sensor in air at 123 wavebands from $398 \mathrm{~nm}$ to $800 \mathrm{~nm}$ with approximately $3 \mathrm{~nm}$ resolution. Upwelling radiance is measured $63 \mathrm{~cm}$ below the air-sea interface with a nadir-viewing radiance sensor with $81^{\circ}{ }^{\circ} \mathrm{FOV}$. Upwelling radiance is propagated through the interface following the approach of Morel et al. (2007) modified for hyperspectral radiometry to retrieve water leaving radiance, $L_{w}(\lambda)$. Remote sensing reflectance is computed from the ratio of hyperspectral water leaving radiance to incident downwelling irradiance. Remote sensing reflectance measured at the sea surface provides the ground truth observation for top-of-the atmosphere remote sensing reflectance obtained from ocean color sensors such as the currently in orbit multi-spectral MODIS and the propose hyperspectral PACE sensors. Semi-analytic inversions of ocean color reflectance yield estimates of inherent optical properties such as component absorption and backscattering coefficients and carbon-based optical proxies such as POC and DOC.

Deployment methodologies: The H-TSRB is deployed by hand from the deck of the ship of the sunny side of the vessel. It remains tethered while it is allowed to float away to greater than three optical depths from the ship to avoid shadow and reflection. At least one minute of observations is collected. The radiometer is temporarily retrieved, caps are placed on the radiometers and it is redeployed in order to obtain temperature and stability dark readings that are removed from sample observations.

Uncertainties and quality control concerns: Uncertainties associated with natural variations in the radiometry observations are computed by standard deviation of the 60-second burst samples. Instrument uncertainty is assessed by mean and standard deviation of the 60-second burst sample of dark readings. These are arithmetically propagated from radiance and irradiance to remote sensing reflectance computations.

Data products originating with this method:

\begin{tabular}{|c|c|c|}
\hline Parameter & Symbol & Units \\
\hline Upward radiance at $63 \mathrm{~cm}$ depth & $\mathrm{L}_{\mathrm{u}}(\lambda, 0.63)$ & $\mu \mathrm{W} \mathrm{cm}{ }^{-1} \mathrm{~nm}^{-1} \mathrm{sr}^{-1}$ \\
\hline Upward radiance at $0 \mathrm{~cm}$ depth & $\mathrm{L}_{\mathrm{u}}(\lambda, 0.0)$ & $\mu \mathrm{W} \mathrm{cm}^{-1} \mathrm{~nm}^{-1} \mathrm{sr}^{-1}$ \\
\hline Water leaving radiance & $\mathrm{L}_{\mathrm{w}}(\lambda)$ & $\mu \mathrm{W} \mathrm{cm}{ }^{-1} \mathrm{~nm}^{-1} \mathrm{sr}^{-1}$ \\
\hline
\end{tabular}




\begin{tabular}{|c|l|c|}
\hline Incident downward irradiance & $\mathrm{E}_{\mathrm{d}}(\lambda, 0+)$ & $\mu \mathrm{W} \mathrm{cm} \mathrm{nm}^{-1}$ \\
\hline Remote sensing reflectance & $\mathrm{R}_{\mathrm{RS}}(\lambda)$ & $\mathrm{sr}^{-1}$ \\
\hline
\end{tabular}

\section{Key method references:}

Morel, A., Huot, Y, Gentili, B, Werdell, P.J., Hooker, S.B., and Franz, B.A. 2007. Examining the consistency of products derived from various ocean color sensors in open ocean (Case 1) waters in the perspective of a multi-sensor approach. Remote Sensing of Environment, 111( 1): 69-88. ISSN 0034-4257, https://doi.org/10.1016/j.rse.2007.03.012. 


\section{Protocol: Spectrophotometric Particulate Absorption Analysis - EXPORTS Date: July 2019 \\ Document author and contact info: Collin Roesler, croesler@bowdoin.edu}

Brief Overview: Spectral absorption coefficients of particulate matter is determined from spectrophotometric analysis of particles filtered onto glass fiber filters. The particulate matter is partitioned chemically into in vivo pigments (phytoplankton absorption) and non-extractable particulate matter (non-algal particles). The conversion of absorbance to absorption required quantification of the geometric pathlength $(\mathrm{m})$, accounted for by the ratio of the volume filtered

$\left(\mathrm{m}^{3}\right)$ and the effective filter area $\left(\mathrm{m}^{2}\right)$, and the ratio of the geometric to optical pathlengths, accounted for by experimental comparisons between particulate samples measured in suspension to those on filter pads.

Water sample collection: Discrete water samples were collected from a Niskin bottle rosette sampler from approximately 8 depths, 1-3 times per day. In order to ensure compatibility between pigment, carbon and optical samples, the entirety of each Niskin bottle (from each depth) was collected into a large volume carboy. Carboys were be kept cold and dark until subsampling, within one hour of CTD sampling. Carboys were kept well mixed, by multipledirectional changes in swirling, during subsampling into analysis-specific sampling bottles. Discrete water samples were also collected from an inline water system, pumped from the sea chest with a diaphragm pump, that was coupled to the flow-through optical sensor suite. Samples were collected once or twice a day, in conjunction with a CTD cast. The intake depth was approximately $5 \mathrm{~m}$, coincident with the surface Niskin bottle depth. The inline samples were size fractionated with $5 \mu \mathrm{m}$ and $20 \mu \mathrm{m}$ cartridge filters (Pall ${ }^{\circledR}$ ), in addition to the unfiltered samples. Real time optical data display was used to identify when the outflow water was completely size fractionated (approximately 7 minutes for complete sample flow through and reservoir turn over).

Water sample preparation: Discrete water sub-samples were collected in 2-Liter Nalgene sample bottles and filtered through Whatman ${ }^{\circledR}$ glass fiber filters $(25 \mathrm{~mm}$ diameter, nominal pore size $\mathrm{GF} / \mathrm{F})$ under low pressure $(<5 \mathrm{~mm} \mathrm{Hg})$ vacuum with an aspirator pump. The exact volume and volume uncertainty of each sample was recorded. A set of 3-5 blank filter pads for baseline and blank reference scans were prepared in the similar manner but with comparable volumes of MilliQ ${ }^{\circledR}$ purified water filtered for each run of samples. Filter pads were transferred to taped glass petri dishes and laid, in order, on top of moist Kim Wipes ${ }^{\circledR}$ to maintain uniform moisture. Samples were measured immediately after filtration.

Absorbance measurements: Absorbance scans were measured spectrophotometrically in a Cary 300 dual beam spectrophotometer configured with a Labsphere ${ }^{\circledR}$ integrating sphere with centermounted Plexiglas sample holder. The integrating sphere was aligned before the ship departed and the alignment was checked throughout the cruise. The wavelength range was $350 \mathrm{~nm}$ to 800 $\mathrm{nm}$, the slit band width was $2 \mathrm{~nm}$, the wavelength interval was $1 \mathrm{~nm}$, the integration time was $0.2 \mathrm{~s}$ for a scan rate of $300 \mathrm{~nm} / \mathrm{s}$. One of the set of blank filter pads was selected as the baseline filter. After the baseline scan, the filter, untouched, was run as a sample. This is referred to as the zero absorbance scan. This represents the uncertainty due to instrument noise. The remaining 
blank filters were scanned relative to the baseline scan, these are referred to as blank scans. These represent the variability in absorbance due to filter-to-filter variability. Each sample filter was scanned relative to the baseline. The initial scan is referred to as the particulate absorbance scan. The filter is then place back into the filter cup and extracted with approximately $10 \mathrm{ml}$ of hot methanol for 15 minutes. After the methanol was filtered through, samples were rinsed with approximately $10 \mathrm{ml}$ of MilliQ water and examined for residual color. If necessary, extraction was repeated. The extracted filter was scanned; this is referred to as the non-algal particle (or nap) scan (Kishino et al. 1985). Most filters were extracted twice. By the end of the cruise, there was a shortage of methanol and only a single extraction was performed. Phycobilipigments are not extracted with methanol and those samples were extracted with hot water (Roesler and Perry 1995). In some cases residual pigment absorption was observed and the fully extracted absorbance was estimated by exponential fit (see data processing).

Data Processing: The absorbance scans from the EXPORTS NE Pacific cruise were at the low end of the optimal absorbance range, approximately 0.1 to 0.2 in the blue to green spectral band. However, they were much noisier than is typically found for coastal water samples with similar sample loading on the filter. This was true for samples collected on the Revelle process ship, stored in liquid nitrogen, and processed in the same spectrophotometer in the lab. Thus it is not an instrumental artifact nor a filter loading artifact, but likely a result of the size and composition of the natural particles. The sample absorbance scans were thus smoothed with a $9 \mathrm{~nm}$ moving box average filter. They were smoothed twice.

The sample absorbance, $A_{\text {sample }}$, was corrected for pathlength amplification following the empirical relationship of Stramski et al. (2015):

$$
A=0.323 \times\left(A_{\text {sample }}^{1.0867}\right) \text {. }
$$

Spectral absorption coefficients, $a(\lambda)\left(\mathrm{m}^{-1}\right)$, for both the particulate and non-algal particles were computed from the corrected absorbance scans using the following equation:

$$
a(\lambda)=2.303 \times 100 \frac{A}{\left(V_{\text {filt }} / \pi r^{2}\right)}
$$

where 2.303 converts the $\log _{10}$ absorbance to $\log _{\mathrm{e}}$ absorption, $A$ is the measured absorbance corrected for pathlength amplification, $V_{\text {filt }}$ is the volume filtered $\left(\mathrm{ml} \mathrm{or} \mathrm{cm}^{3}\right)$, and $\pi r^{2}$ is the effective area of the filter $\left(\mathrm{cm}^{2}\right)$ and the factor of 100 converts $\mathrm{cm}$ to $\mathrm{m}$. Absorption by the phytoplankton component was computed by difference between particulate and non-algal particle absorption coefficients. Uncertainty values were computed by mathematical propagation of instrumental and sample uncertainty terms following NASA protocols (2018).

In the case of incomplete extraction, an exponential fit to the non-algal particle absorption spectrum was estimated over the wavelength range $375 \mathrm{~nm}$ to $750 \mathrm{~nm}$, the endpoints representing wavelengths for which extractable algal pigment absorption is minimal. The spectral slope of the exponential was assumed to be $0.01\left(\mathrm{~nm}^{-1}\right)$, based upon the least-square best 
fit to well-extracted samples. The revised phytoplankton absorption, $\hat{a}_{\text {phyt }}$, was computed from the difference between the particulate absorption and the modeled non-algal particle absorption, $\hat{a}_{\text {nap }}$.

SeaBASS data file structure: The file structure for the SeaBASS data submission is:

wavelength, $A_{\text {zero }}$, median $A_{p_{-} \text {blank }}$, median $A_{\text {nap_blank }} A_{p}, A_{n a p}, a_{p}$, $a_{\text {nap }}, a_{\text {phyt }}, \hat{a}_{\text {nap }}, \hat{a}_{\text {phyt }}$

where size fractions are ordered total, $<20 \mu m$ and $<5 \mu m$ within each data type.

\section{References:}

Roesler, C. S., D. Stramski, E. J. D'Sa, R. Röttgers, and R. A. Reynolds. 2018. Chapter 5: Spectrophotometric Measurements of Particulate Absorption Using Filter Pads. In IOCCG Protocol Series (2018). Inherent Optical Property Measurements and Protocols: Absorption Coefficient, Neeley, A. R. and Mannino, A. (eds.), IOCCG Ocean Optics and Biogeochemistry Protocols for Satellite Ocean Colour Sensor Validation, Volume 1.0, IOCCG, Dartmouth, NS, Canada. http://dx.doi.org/10.25607/OBP-119

Kishino, M., M. Takahashi, N. Okami, and S. Ichimura, 1985: Estimation of the spectral absorption coefficients of phytoplankton in the sea. Bull. Mar. Sci., 37(2): 634-642.

Roesler, C. S. and M. J. Perry. 1995. In situ phytoplankton absorption, fluorescence emission, and particulate backscattering spectra determined from reflectance. J. Geophys. Res. 100(C7): $13,279-13,294$.

Stramski, D., R. A. Reynolds, S. Kaczmarek, J. Uitz, and G. Zheng, 2015: Correction of path length amplification in the filter-pad technique for measurements of particulate absorption coefficient in the visible spectral region. Appl. Opt., 54: 6763-6782. 
Method: Metabarcoding of water column eukaryotic plankton

Document author and contact info: Ewelina Rubin, ewelina rubin@uri.edu; Tatiana Rynearson, rynearson@uri.edu

\section{Brief description of protocol and relation to export pathways:}

This work is being done as part of the particle characterization EXPORTS working group

Biomass on filters was collected daily from depth between 5 and $73 \mathrm{~m}$ samples onboard the R/V Sally Ride and preserved in -80C. In addition biomass filters were collected from 50-300 m water onboard the the R/V Roger Revelle and preserved Qiagen lysis buffer and stored at 4C. Further, samples from 5-73 m depth were collected, preserved in RNALater and stored at -20C.

DNA will be extracted with the Power Water DNA extraction kit (Qiagen). If needed, it will be purified with Zymo Spin IV- $\mu$ HRC columns (Zymo Research) which removes many environmental PCR inhibitors. The DNA will be quantified with the Qubit DNA broad range assay (Life Technologies). Amplicon libraries targeting the V4 region of SSU rDNA will be generated with the eukaryotic universal primers, designed by Stoeck et al., (2010) and modified by Bradley et al., (2016). These primers will be customized for MiSeq (Illumina) sequencing by adding, in respective order, an adapter for the amplicon binding to the flow cell, a sequencing primer binding site, and a barcode sequence identifying the sample (Kozich et al., 2013). In addition, the forward primer will include a four random-nucleotide sequence to introduce sequence diversity and thereby increase the ability of the MiSeq instrument to discriminate adjacent fluorescent clusters (Nelson et al., 2014). Three 25- $\mu$ l PCR reactions per sample will be run using Phusion polymerase (Thermo Scientific), with $30 \mathrm{ng}$ of DNA and $0.4 \mu \mathrm{M}$ of primers. The PCR protocol is: $98^{\circ} \mathrm{C}$ for $30 \mathrm{~s}, 30$ cycles of $98^{\circ} \mathrm{C}$ for $10 \mathrm{~s}, 50^{\circ} \mathrm{C}$ for $20 \mathrm{~s}$ and $72^{\circ} \mathrm{C}$ for $40 \mathrm{~s}$, and a final step at $72^{\circ} \mathrm{C}$ for $10 \mathrm{~min}$. Triplicate PCR products will be purified using gel extraction method pooled into one sample and then quantified, and pooled again into a multiplexed library. Paired-end sequencing will be conducted on a MiSeq instrument.

\section{Uncertainties and quality control concerns:}

Given the low abundance of plankton in the water column, there are concerns that $1-2 \mathrm{~L}$ of filtered seawater may yield low DNA concentrations that are difficult to amplify. If this occurs, samples will be subjected to whole genome amplification prior to amplification of the $18 \mathrm{~S} \mathrm{V4}$ region. The $18 \mathrm{~S} \mathrm{~V} 4 \mathrm{rRNA}$ region will provide the best resolution at the genus level with only a subset of sequences identified to species. Additional primer sets may be used to enhance resolution of microzooplankton community members.

\section{Data products originating with this method:}

Raw data as fastq files (separate for each sample) 
Tables and graphs reflecting phylogenetic identification of major eukaryotic groups (mostly likely genera), their relative abundance and the beta diversity for each sampled location.

\section{Key method references:}

Bradley, I.M., Pinto, A.J., and Guest, J.S. (2016). Design and Evaluation of Illumina MiSeq-Compatible, 18S rRNA Gene-Specific Primers for Improved Characterization of Mixed Phototrophic Communities. Appl. Environ. Microbiol. 82, 5878-5891.

Kozich, J.J., Westcott, S.L., Baxter, N.T., Highlander, S.K., and Schloss, P.D. (2013). Development of a Dual-Index Sequencing Strategy and Curation Pipeline for Analyzing Amplicon Sequence Data on the MiSeq Illumina Sequencing Platform. Appl. Environ. Microbiol. 79, 5112-5120.

Nelson, M.C., Morrison, H.G., Benjamino, J., Grim, S.L., and Graf, J. (2014). Analysis, Optimization and Verification of Illumina-Generated 16S rRNA Gene Amplicon Surveys. PLoS ONE 9, e94249.

Stoeck, T., Bass, D., Nebel, M., Christen, R., Jones, M.D.M., Breiner, H.-W., and Richards, T.A. (2010). Multiple marker parallel tag environmental DNA sequencing reveals a highly complex eukaryotic community in marine anoxic water. Mol. Ecol. 19, 21-31. 
Method: Enumeration of phytoplankton and microzooplankton using microscopy

Document author and contact info: Tatiana Rynearson, Rynearson@uri.edu

Brief description of protocol and relation to export pathways: $20-100 \mathrm{ml}$ aliquots of seawater from daily depth profiles will be fixed using $2 \%$ final volume Lugol's solution. Utermoehl settling chambers (1-50ml) and inverted microscopy using 40-400x magnification will be used to identify and enumerate phytoplankton and microzooplankton in the 5-100 micron size range (Lund et al. 1958). Based on the biomass in the fixed samples, settling volumes will be adjusted so that a minimum of 400 cells of each abundant species or genus is counted, to allow for robust downstream statistical analyses (Lund et al. 1958). The settling chambers will initially be enumerated using 40-100x magnification, with the option of examining the sample at higher magnification (200-400x) to identify and count smaller cells and colonies. The length of major axes of the dominant phytoplankton will be measured for 30-50 cells of each species/genus.

Data Processing: Cell abundance will be calculated by dividing the total cells of each species/genus counted by the volume settled in the Utermoehl chamber. Approximate cell volumes will be calculated and converted to carbon concentration using the equations of Menden-Deuer and Lessard (2000).

Calibration: The major axes of dominant phytoplankton are measured on the inverted microscope using an eyepiece with a ruler etched onto it. The ruler is calibrated using a stage micrometer.

Uncertainties and quality control concerns: Phytoplankton can be morphologically identical, especially at the level of light microscopy. The cell counts will be paired with DNA sequencing to resolve species identity of genera known to contain morphologically cryptic species (Pseudonitzschia, Thalassiosira, Skeletonema, Chaetoceros). Not all plankton fix equally well in Lugol's fixative and this will be taken into account when community composition is evaluated using the inverted microscopy counts. The absolute abundance of rare cells will have a large uncertainty. This can be ameliorated up to a point by settling larger volumes.

Data products originating with this method:

Community composition and carbon concentration of depth profiles for phytoplankton and microzooplankton.

\begin{tabular}{|l|l|}
\hline Parameter & Units \\
\hline Community composition & cells species $^{-1}$, cells genus $^{-1}$ \\
\hline Carbon per cell & pg C cell \\
\hline
\end{tabular}




\section{Key method references:}

Lund JWG, Kipling C, Le Cren ED (1958) The Inverted Microscope Method of Estimating Algal Numbers and the Statistical Basis of Estimations by Counting. Hydrobiologia 11:143-170

Menden-Deuer S, Lessard EJ (2000) Carbon to volume relationships for dinoflagellates, diatoms, and other protist plankton. Limnol Oceanogr 45:569-579 


\section{Method: Ecogenomic grazing markers}

2. Contact Info: Tatiana Rynearson,rynearson@uri.edu, Ewelina Rubin ewelina_rubin@uri.edu

3. Brief description: To enhance the resolution of grazing rate measurements, we will be collecting biomass for the identification of genes expressed in actively feeding predators. This work is done in conjunction with laboratory experiments, where biomass from grazing experiments will be harvested and used to validate predator genes whose expression varies depending on feeding status with the long-term goal of using the expression of those genes to determine feeding status in natural communities. Candidate "grazing genes" will be validated using quantitative polymerase chain reaction (qPCR) and/or RNA-seq and compared to traditional methods of determining grazing rate (e.g. dilution experiments).

During EXPORTS, biomass for analysis of grazing genes will be collected from both in situ and dilution experiments to broaden the spatial resolution of available grazing rate data. Once to twice a day, on the process and survey ships, seawater samples will be collected from 3-8 discrete depths in the euphotic zone and two depths below using a CTD rosette with mounted Niskin bottles. Water from 3 depths will coincide with those collected for the dilution method. From each depth, 5-10 L will be screened through a $200 \mu \mathrm{m}$ mesh. Biomass will be collected by filtration, filters will be stored in RNAlater (Life Technologies) and then RNA extracted.

The extracted RNA will be treated in two ways depending on the sample. For a subset of the samples, RNA-seq will be used to obtain metatranscriptomes, which will be analyzed for the expression of candidate grazing genes obtained from laboratory experiments. Expression will be benchmarked using grazing rates obtained from deckboard grazing experiments. For another subset of samples, ten of the most differentially regulated genes identified previously in lab experiments and common to a broad taxonomic range of heterotrophic predators will be chosen and their expression quantified using qPCR. Expression levels of each gene will be determined using standards (linearized plasmids with inserts) and reference housekeeping genes (aka. gene for which the expression does not change with treatment - also determined from RNA-Seq grazing experiments) Relative gene expression will be determined using the $2-\Delta \Delta \mathrm{CT}$ method (e.g. Livak and Schmittgen, 2001).

4. Other Contributing Protocols: Dilution method, Flow cytometry (Guava), Nutrient measurements, vertical profiling, microscopy to measure species composition and biomass,

5. Uncertainty and quality control: Based on previous work, we anticipate the degree of biological uncertainty in the qPCR will reach coefficients of variation on the order of $5 \%$ for biological replicates but only $0.5 \%$ variation due to replicate technical measurements.

6. Data products originating with this method:

\begin{tabular}{ll}
\hline Parameter $^{*}$ & Units \\
\hline Relative transcript abundance & No units \\
Transcript abundance & Transcripts cell ${ }^{-1}$ \\
\hline
\end{tabular}




\section{Key Method references}

Alexander H, Jenkins BD, Rynearson TA, \& Dyhrman ST (2015) Metatranscriptome analyses indicate resource partitioning between diatoms in the field. Proceedings of the National Academy of Sciences 112(17):E2182-E2190.

Livak, K. J. and T. D. Schmittgen. 2001. Analysis of Relative Gene Expression Data Using Real-Time Quantitative PCR and the 2- $\Delta \Delta \mathrm{CT}$ Method. Methods 25:402-408.

Whitney, L. P., J. J. Lins, M. P. Hughes, M. L. Wells, P. D. Chappell, and B. D. Jenkins. 2011. Characterization of putative iron responsive genes as species-specific indicators of iron stress in Thalassiosiroid diatoms. Frontiers in Microbiology 2. 
Method: 16S rRNA gene amplicon analysis of water column bacterioplankton

Document author and contact info: Alyson Santoro, asantoro@ucsb.edu

Brief description of protocol and relation to export pathways: Seawater samples from the depths of the sediment trap deployments are collected from the Niskin rosette in 2-4L bottles and pressure filtered onto sequential $3 \mu \mathrm{m}$ pore size polyester membrane filters and $0.2 \mu \mathrm{m}$ pore size Supor membrane filters. DNA will be extracted from both size fractions and the V4 hyper-variable region of the $16 \mathrm{~S}$ rRNA gene will be amplified using dual-indexed $515 \mathrm{~F}$ and 806RB primer sets modified by Apprill et al. 2015 and Parada et al. 2018. Amplified PCR products will be sequenced on an Illumina MiSeq with a $250 \mathrm{bp}$ paired end run. DNA sequence identities will be assigned by comparing to sequence databases and looking for unique sequence variants.

Other contributing protocols: Genetic characterization of bulk sinking particles in sediment traps (Durkin), Genetic characterization of sinking aggregates in sediment traps (Durkin), Genetic characterization of prokaryotes in bulk sinking particles from sediment traps (Santoro), Genetic characterization of prokaryotes in sinking aggregates collected in gel traps (Santoro)

Uncertainties and quality control concerns: While the presence of a DNA sequence confirms the link between an organism or its remains within sinking particles, the absence of a DNA sequence does not confirm the absence of this link. It is possible for organic matter to be exported without any DNA evidence of its organismal source. To relate these data to surface phytoplankton communities, it is critical that the same PCR primers are used to amplify $16 \mathrm{~S}$ and 18S rRNA of surface plankton communities.

\section{Data products originating with this method:}

Data table of amplicon sequence variants (ASVs) detected in bulk sinking material - csv file DNA sequences - fasta file

\section{Key method references:}

Apprill, A., McNally, S., Parsons, R. and Weber, L., 2015. Minor revision to V4 region SSU rRNA 806R gene primer greatly increases detection of SAR11 bacterioplankton. Aquat Microb Ecol, 75, pp.129-137.

Parada, A.E., Needham, D.M., and Fuhrman, J.A. 2018. Every base matters: assessing small subunit rRNA primers for marine microbiomes with mock communities, time series, and global field samples. Environmental Microbiology. 18: 1403-1414. 
Method: Ammonium concentration in seawater using the orthophthaldialdehyde (OPA) fluorescence method

Document author and contact info: Alyson Santoro; asantoro@ucsb.edu

Brief description of protocol and relation to export pathways: Dissolved ammonium will be determined in seawater samples on-ship by reaction with OPA and quantification by fluorometry. Deep water ( $>1000 \mathrm{~m}$ ) will be used as an analytical blank and to make up standards. Values will be used in support of nitrification rate measurements and to quantify regenerated nutrient supply to the euphotic zone.

Other contributing protocols: none

Uncertainties and quality control concerns: Ammonium contamination of the rosette from deck operations (e.g. cleaning, smoking), ammonium contamination introduced during sample collection (e.g. collection tubes), high blank values from inappropriate analytical blank

\begin{tabular}{|c|c|}
\hline \multicolumn{2}{|c|}{ Data products originating with this method } \\
\hline Parameter ${ }^{*}$ & Units \\
\hline$\left[\mathrm{NH}_{4}^{+}\right]$ & $\mathrm{nM}$ \\
\hline $\begin{array}{l}\text { Uncertainty (standard deviation of } \\
\text { replicate samples) }\end{array}$ & $\mathrm{nM}$ \\
\hline
\end{tabular}

\section{Key method references}

Holmes, R.M., et al. (1999) A simple and precise method for measuring ammonium in marine and freshwater ecosystems. Canadian Journal of Fisheries and Aquatic Sciences 56.10: 1801-1808.

Taylor et al. (2007) Description of improvements to Holmes method Improving the fluorometric ammonium method: matrix effects, background fluorescence, and standard additions. Journal of The North American Benthological Society 26(2):167-177.

\section{v.1.0, 9 apr 2018; aes}


Method: Genetic characterization of prokaryotes in bulk sinking particles from sediment traps

Document author and contact info: Alyson Santoro, asantoro@ucsb.edu; Colleen Durkin, cdurkin@mlml.calstate.edu

Brief description of protocol and relation to export pathways: Each sediment trap will include 1 tube containing RNAlater preservative. Particles in the RNAlater will be collected onto an $0.2 \mu \mathrm{m}$ pore-size Supor filter and frozen. DNA will be extracted and the V4 hyper-variable region of the $16 \mathrm{~S}$ rRNA gene will be amplified using dual-indexed 515F and 806RB primer sets modified by Apprill et al. 2015 and Parada et al. 2018. Amplified PCR products will be sequenced on an Illumina MiSeq with a 250 bp paired end run. DNA sequence identities will be assigned by comparing to sequence databases and looking for unique sequence variants. This analysis contributes to export pathways 1,2, and 3 by specific organisms with particle export. When combined with particle-specific DNA sequencing data, the organisms only exported in small particles can be inferred.

Other contributing protocols: Genetic characterization of bulk sinking particles in sediment traps (Durkin), 16S rRNA gene amplicon analysis of water column bacterioplankton (Santoro), Genetic characterization of sinking particles from the Marine Snow Catcher (Santoro)

Uncertainties and quality control concerns: While the presence of a DNA sequence confirms the link between an organism or its remains within sinking particles, the absence of a DNA sequence does not confirm the absence of this link. It is possible for organic matter to be exported without any DNA evidence of its organismal source. To relate these data to surface phytoplankton communities, it is critical that the same PCR primers are used to amplify $16 \mathrm{~S}$ and 18S rRNA of surface plankton communities.

Data products originating with this method:

Data table of amplicon sequence variants (ASVs) detected in bulk sinking material - csv file DNA sequences - fasta file

Key method references:

Apprill, A., McNally, S., Parsons, R. and Weber, L., 2015. Minor revision to V4 region SSU rRNA 806R gene primer greatly increases detection of SAR11 bacterioplankton. Aquat Microb Ecol, 75, pp.129-137.

Parada, A.E., Needham, D.M., and Fuhrman, J.A. 2018. Every base matters: assessing small subunit rRNA primers for marine microbiomes with mock communities, time series, and global field samples. Environmental Microbiology. 18: 1403-1414. 
Method: Genetic characterization of prokaryotes in sinking aggregates collected in gel traps

Document author and contact info: Alyson Santoro, asantoro@ucsb.edu; Colleen Durkin, cdurkin@mlml.calstate.edu

Brief description of protocol and relation to export pathways: Jars containing polyacrylamide gel layers will be deployed in 1 tube of each deployed sediment trap. Sinking particles and organisms that settle into the gel layer remain distinctly separated, preserving original characteristics of size and quantity and constituents. Individual aggregates will be pipetted out of the gel layer and frozen in cryovials immediately after trap recovery. DNA will be extracted and the V4 hyper-variable region of the 16S rRNA gene will be amplified using dual-indexed 515F and 806RB primer sets modified by Apprill et al. 2015 and Parada et al. 2018. Amplified PCR products will be sequenced on an Illumina MiSeq with a $250 \mathrm{bp}$ paired end run. DNA sequence identities will be assigned by comparing to sequence databases and looking for unique sequence variants.

Other contributing protocols: Genetic characterization of bulk sinking particles in sediment traps (Durkin), Genetic characterization of prokaryotes in bulk sinking particles from sediment traps (Santoro), 16S rRNA gene amplicon analysis of water column bacterioplankton (Santoro), Genetic characterization of sinking particles from the Marine Snow Catcher (Santoro)

Uncertainties and quality control concerns: While the presence of a DNA sequence confirms the link between an organism or its remains within sinking particles, the absence of a DNA sequence does not confirm the absence of this link. It is possible for organic matter to be exported without any DNA evidence of its organismal source. To relate these data to surface phytoplankton communities, it is critical that the same PCR primers are used to amplify 16S and $18 \mathrm{~S}$ rRNA of surface plankton communities.

\section{Data products originating with this method:}

Data table of amplicon sequence variants (ASVs) detected in bulk sinking material - csv file DNA sequences - fasta file

\section{Key method references:}

Apprill, A., McNally, S., Parsons, R. and Weber, L., 2015. Minor revision to V4 region SSU rRNA 806R gene primer greatly increases detection of SAR11 bacterioplankton. Aquat Microb Ecol, 75, pp.129-137.

Parada, A.E., Needham, D.M., and Fuhrman, J.A. 2018. Every base matters: assessing small subunit rRNA primers for marine microbiomes with mock communities, time series, and global field samples. Environmental Microbiology. 18: 1403-1414. 


\section{Method: Water column nitrification rates}

Document author and contact info: Alyson Santoro; asantoro@ucsb.edu

Brief description of protocol and relation to export pathways: Nitrification is the microbial oxidation of reduced nitrogen (ammonia/ammonium) to nitrite and nitrate. The nitrification rate should be related to the water column carbon respiration rate by the $\mathrm{C}: \mathrm{N}$ stoichiometry of the organic matter being respired. Nitrification rates will be measured in shipboard bottle experiments by the addition ${ }^{15} \mathrm{~N}$ tracer $\left(\left[{ }^{15} \mathrm{~N}\right] \mathrm{H}_{4} \mathrm{Cl}\right)$ at approximately $10 \%$ of the ambient $\left[\mathrm{NH}_{4}{ }^{+}\right]$ or $50 \mathrm{nM}$, whichever is greater. Incubations are conducted at as close to in situ light and temperature conditions as possible for $24 \mathrm{~h}$. Timecourse measurements are subsampled approximately every 6 hours, frozen, and analyzed for $\delta^{15} \mathrm{~N}_{\mathrm{NO} 2+\mathrm{NO} 3}$ on return to the laboratory using the 'denitrifier method.' Rates are calculated using a least-squares fitting routine to a model of ${ }^{15} \mathrm{~N} /{ }^{14} \mathrm{~N}$ change in the $\mathrm{NO}_{3}{ }^{-}$pool that includes removal by assimilation. Inputs to the model are the starting atom percent $(A P){ }^{15} \mathrm{~N}$ in the $\mathrm{NH}_{4}{ }^{+}$pool (calculated from the ambient $\left[\mathrm{NH}_{4}{ }^{+}\right]$and the tracer addition), the starting $A P$ in the $\mathrm{NO}_{3}{ }^{-}$pool (measured directly), and the fractionation factor $(\alpha)$ for $\mathrm{NO}_{3}^{-}$uptake (1.005).

Other contributing protocols: $\left[\mathrm{NH}_{4}^{+}\right]$using the OPA-fluorescence method, $16 \mathrm{~S}$ rRNA amplicon analysis of free-living prokaryotic community

Uncertainties and quality control concerns: In addition to the uncertainties associated with any deckboard bottle incubation experiment, key uncertainties in this method are the uncertainty in the $\left[\mathrm{NH}_{4}{ }^{+}\right]$measurement, as the calculated nitrification rate is extremely sensitive to the starting $A P \mathrm{NH}_{4}{ }^{+}$, isotope dilution of the added tracer by newly remineralized, unlabeled $\mathrm{NH}_{4}{ }^{+}$, and potential stimulation of the nitrifying community by the added tracer. Uncertainty is also introduced during model fitting.

Data products originating with this method:
$\begin{aligned} & \text { Parameter* } \\ & \text { Nitrification rate }\end{aligned}$
$\begin{array}{ll}\text { Units } \\ \text { Uncertainty } & \mathrm{nM} \mathrm{N} \mathrm{d} \text { d }^{-1}\end{array}$

\section{Key method references}

Lipschultz, F. (2008) Isotope tracer methods for studies of the marine nitrogen cycle. In: Nitrogen in the Marine Environment, 2nd ed. Capone, Bronk, Mulholland, and Carpenter, eds. Academic Press.

Santoro, A.E., Casciotti, K.L., and C.A. Francis. (2010) Activity, abundance, and diversity of nitrifying archaea and bacteria in the central California Current.

Environmental Microbiology 12: 1989-2006.

v.1, 6 apr 2018; aes 


\section{Method: Particle-associated respiration using an in situ particle capture incubation device (RESPIRE)}

Document author and contact info: Alyson Santoro; asantoro@ucsb.edu

Brief description of protocol and relation to export pathways: Microbial respiration on sinking particles will determined using an in situ particle capture incubation device known as a RESPIRE (REspiration of Sinking Particles In the subsuRface ocean) trap. The interceptor is constructed of a titanium cylinder fitted with a dimpled PVC sphere that acts as a valve to the lower portion of the chamber containing an optical oxygen sensor (Aanderaa 4330 optode). The traps operate with an initial 'collection phase' in which sinking particles are collected and deposited into the incubation portion of the cylinder by the rotation of the PVC sphere, which successfully excludes zooplankton from the inner chamber. Following the collection phase, the PVC sphere ceases its rotation and oxygen drawdown in the chamber is measured by the optode and recorded by a data logger. Respiration rates are then calculated from the timecourse oxygen data. Upon recovery of the RESPIRE traps, the incubated material will be collected for genetic analysis. Three RESPIRE traps will be deployed at the three shallowest depths of the surfacetethered trap (STT) array. This measurement will contribute to EXPORTS SQ2 to explain what controls the transfer efficiency of carbon in the dark ocean.

Other contributing protocols: Water column respiration (Gifford), Bulk trap fluxes (Estapa), Bacterial production (Carlson), Genetic characterization of bulk sinking particles in traps (Durkin)

Uncertainties and quality control concerns: Bias in particle capture during the particle interception phase, temperature fluctuations influencing optode readings, non-linear drawdown of oxygen during particle incubation phase (i.e. curve fitting), uncertainty in carbon conversion factor going from oxygen to carbon units

\section{Data products originating with this method:}

Parameter* Units

Respiration rate $\quad \mathrm{mmol} \mathrm{O}_{2} \mathrm{~m}^{-2} \mathrm{~d}^{-1}$

Respiration rate $\quad \mathrm{mmol} \mathrm{C} \mathrm{m}^{-2} \mathrm{~d}^{-1}$

Uncertainty $\quad \mathrm{mmol} \mathrm{O}_{2} \mathrm{~m}^{-2} \mathrm{~d}^{-1}$

\section{Key method references}

Boyd, P.W., McDonnell, A., Valdez, J., LeFevre, D., and Gall, M.P. (2015) RESPIRE: An in situ particle interceptor to conduct particle remineralization and microbial dynamics studies in the oceans' Twilight Zone. Limnology and Oceanography-Methods 13: 494-508.

McDonnell, A., Boyd, P., and Buesseler, K. (2015) Effects of sinking velocities and microbial respiration rates on the attenuation of particulate carbon fluxes through the mesopelagic zone. Global Biogeochemical Cycles 29: 175-193.

\section{Document History}


Document author and contact info: Heidi Sosik(WHOI), hsosik@whoi.edu

Measurement and instrument: Imaging of phytoplankton and other particles with Imaging FlowCytobot (IFCB; McLane Research Laboratories, Inc, Falmouth, MA):

A brief description of the method: The IFCB is a imaging-in-flow cytometer. As such, it measures not only individual particle fluorescence and light scattering, but also captures a high resolution $(\sim 1 \mu \mathrm{m})$ image of each cell or chain in the size range $\sim 5-150 \mu \mathrm{m}$ width. Controlled flow and illumination conditions ensure a very high rate of images containing in focus, single targets aligned in the flow such that the largest cross-section is imaged. Images can be collected at up to $\sim 10 \mathrm{~Hz}$, depending on particle concentrations encountered. IFCB was operated with chlorophyll fluorescence and scattering triggers enabled and it was configured to sample automatically $5 \mathrm{ml}$ every $\sim 20$ minutes from the uncontaminated seawater flow (diaphragm pump source, pre-debubbler to ensure minimal damage to cells). IFCB was also used to analyze discrete samples from Niskin bottles (some with chlorophyll fluorescence triggering only).

Data processing: Full resolution images are stored, though only the portion of the camera field that contains the target of interest (realtime segmentation is done during acquisition). Post-processing includes a variety of automated image processing steps, feature extraction (geometric and other quantities), and machine learning based classification (taxonomic groups and other groupings, such as detrital particles). Processing code and wiki-based documentation is available at: https://github.com/hsosik/ifcb-analysis

Calibration: Main calibration issues are (1) ensuring sample volume is properly quantified (a function design criteria set during manufacture; user verification is good practice, but experience suggests this does not need to be repeated unless there are hardware changes in the instrument); and (2) determination of image scaling (micrometers per pixel; user determined with particles of interest).

Uncertainties and quality control concerns: Sample volume imaged is sensitive to configuration / operating conditions and requires care to ensure that optical alignment and fluidic control are such that the sample core remains within the field of view of the camera. Optical conditions must also be configured to ensure focus is maintained. See procedures to assess status and troubleshoot problems in "IFCB At Sea Guide" referenced below. Additionally, the combination of trigger threshold and fluorescence sensitivity (high voltage on the detector) must be configured to ensure that the smallest particles of interest are consistently captured. Approaches with a combination of standard beads and selected phytoplankton cultures (e.g,. Isochrysis, Dunaliella) work well.

Data products originating from the method: Images of phytoplankton (cells, chains, and colonies) and other fluorescent particles, including many protozoa (non-fluorescence particles possible if scattering trigger is utilized) in the size range $\sim 5-150 \mu \mathrm{m}$ (minimum dimension; elongated targets up to $\sim 300 \mu \mathrm{m}$ in length); estimates of taxonomic composition of imaged plankton, abundance and biomass (biovolume) by size and taxon.

\begin{tabular}{|l|l|}
\hline Parameter & Units \\
\hline Images of phytoplankton \& other fluorescent particles $(\sim 10-200 \mu \mathrm{m})$ & unitless \\
\hline Biovolume (individual image target) & $\mu \mathrm{m}^{-3}$ \\
\hline Concentration & Cells $\mathrm{mL}^{-1}$ \\
\hline Biovolume concentration & $\mu \mathrm{m}^{-3} \mathrm{~mL}^{-1}$ \\
\hline
\end{tabular}




\begin{tabular}{|l|l|}
\hline Concentration by taxon & Cells $\mathrm{mL}^{-1}$ \\
\hline Biovolume concentration by taxon & $\mu \mathrm{m}^{-3} \mathrm{~mL}^{-1}$ \\
\hline Concentration by size class & Cells $\mathrm{mL}^{-1} \mu \mathrm{m}^{-1}$ \\
\hline Biovolume concentration by size class & $\mu \mathrm{m}^{-2} \mathrm{~mL}^{-1}$ \\
\hline
\end{tabular}

\section{Key method references:}

Olson, R. J., and H. M. Sosik. 2007. A submersible imaging-in-flow instrument to analyze nano- and microplankton: Imaging FlowCytobot. Limnol. Oceanogr. Methods 5: 195-203.

Sosik, H. M., and R. J. Olson. 2007. Automated taxonomic classification of phytoplankton sampled with imaging-in-flow cytometry. Limnol. Oceanogr. Methods 5: 204-216.

Sosik, H. M., J. Futrelle, E. F. Brownlee, E. Peacock, T. Crockford, and R. J. Olson. 2016. hsosik/ifcb-analysis: IFCB-Analysis software system, initial formal release at v2 feature stage [Data set]. Zenodo. http://doi.org/10.5281/zenodo. 153978

Peacock, E.E., E. T. Crockford, and H.M. Sosik. 2018. IFCB at sea user guide. https://docs.google.com/document/d/14IfQBriV2AZs1akefM8JYirSAApnVFbDG2XQ74k1IOI/ 
Method: Reconstruction of Zooplankton Export from Gel and particle ID Traps

Document author and contact info: Deborah Steinberg, debbies@vims.edu

Brief description of protocol and relation to export pathways:

Sinking of zooplankton fecal pellets and other products (e.g., mucous feeding webs, carcasses, molts) is one of the five export pathways. We complement the gel trap analyses by Durkin et al. by analyzing in further detail zooplankton fecal pellets and other products in gel traps and in splits from bulk sediment trap samples to determine the relative contribution of different major zooplankton taxa to export. Identified fecal pellets from gel traps, and/or pellets in bulk sediment trap samples, are further classified into fecal pellet type (e.g., cylindrical crustacean pellets, tabular salp pellets, elliptical larvacean pellets) using archived/binned fecal pellet and other particle images (gel traps) and dissecting microscope (bulk trap splits) for each sediment trap depth. The relative contribution of sinking zooplankton fecal pellets and other products vs. other particle classes for each depth is determined using fecal pellet counts and volume to $\mathrm{C}$ and $\mathrm{N}$ conversions (from the literature, and experimentally-derived from shipboard fecal pellet production experiments with abundant species). The fecal pellet POC/N is subtracted from the total sinking POC/N to determine the relative importance of fecal pellet flux to total flux. Changes with depth in fecal pellet types is analyzed, as an indicator of mesopelagic zone reprocessing.

Other contributing protocols: Visual characterization of zooplankton products in gel traps, Visual characterization of aggregates in gel traps, Zooplankton fecal pellet production, MOCNESS abundance to compare zooplankton community structure to zooplankton products in traps

Uncertainties and quality control concerns: Uncertainty inherent in particle $\mathrm{C}$ to volume conversions. Distinguishing between crustacean molts and carcasses (dead zooplankton that fell into trap), and between carcasses and swimmers (live zooplankton that swam into trap and died), is difficult in trap samples and only possible for some zooplankton species.

Data products originating with this method:

\begin{tabular}{ll}
\hline Parameter & Units \\
\hline Fecal pellet fluxes by pellet type* at each depth & number or $\mathrm{mg}-\mathrm{C} \mathrm{m} \mathrm{m}^{-2} \mathrm{~d}^{-1}$ \\
Larvacean house flux at each depth & number or $\mathrm{mg}-\mathrm{C} \mathrm{m} \mathrm{m}^{-2} \mathrm{~d}^{-1}$ \\
Crustacean molt flux at each depth** & number or mg-C m $\mathrm{d}^{-1}$ \\
Carcass flux at each depth** & number or mg-C m $\mathrm{d}^{-1}$ \\
\hline
\end{tabular}

* To be reported separately for each dominant pellet type

**See Uncertainties (above)

\section{Key method references}

Wilson, S.E., D.K. Steinberg, and K.O. Buesseler (2008) Changes in fecal pellet characteristics with depth as indicators of zooplankton repackaging of particles in the mesopelagic zone of the subtropical and subarctic North Pacific Ocean. Deep-Sea Research II 55(14-15): 1636-1647.

Gleiber, M. R., D. K. Steinberg, and H. W. Ducklow (2012) Time series of vertical flux of zooplankton fecal pellets on the continental shelf of the western Antarctic Peninsula. Marine Ecology Progress Series 471: 23-36. 
Durkin, C.A., Estapa, M.L. and Buesseler, K.O. (2015) Observations of carbon export by small sinking particles in the upper mesopelagic. Marine Chemistry, 175, pp.72-81. 
Method: Zooplankton fecal pellet production

Document author and contact info: Deborah Steinberg, debbies@vims.edu

\section{Brief description of protocol and relation to export pathways:}

Sinking of zooplankton fecal pellets is one of the five export pathways. We will perform live fecal pellet production experiments on dominant species and whole community size fractions to provide measurements of zooplankton contribution to fecal pellet production during each ecosystem state sampled. These will be scaled to community level export using the biomass measures, as well as species identification and size fractionated biomass made with the MOCNESS.

Animals for live experiments are collected within the epipelagic zone from below the chlorophyll max to the surface, using a 1-m diameter ring net with a non-filtering cod end and slow retrieval rate.

Experiments are performed on-board at in situ mixed layer temperature, during night and day, in unfiltered surface seawater using both a mixed size-fractionated zooplankton community (Butler \& Dam 1994, Urban-Rich et al. 1999) and numerically important taxa (Urban-Rich et al. 1999, 2001; WexelsRiser et al. 2001).

Fecal pellet production by each size fraction $(0.2-0.5,0.5-1,1-2,2-5$, and $>5 \mathrm{~mm})$ of the mixed zooplankton community is measured using sets of two large ( $\sim 3.8$ liter) containers with a screen insert in the bottom of the inner container (Butler \& Dam 1994). The screen allows pellets to be collected in the outer container, but keeps animals separated from their pellets to prevent pellet consumption. Mixed animals from the tow are size-fractionated live and placed in ambient water in the nested containers and incubated for 4-6 hours. The screen-bottom container is lifted (removing animals) and animals are saved for enumeration and biomass measurements. Fecal pellets collected in the outer container are rinsed, counted, and concentrated onto combusted GF/F filters for POC/PON analysis. For pellet production by abundant species from representative size fractions, a suspended cylindrical insert containing animals is capped at both ends with 200 (m mesh (or larger mesh for larger size classes) and placed into 1-liter experimental bottles containing surface seawater and incubated for 4-6 hours. At the end of the experiment the insert containing animals is removed, and water in the outer jar poured through a $301 \mathrm{~m}$ sieve to collect fecal pellets. Animals and pellets are processed as above. Fecal pellet POC/PON production rates are combined with zooplankton weight measurements from each experimental incubator/ bottle to calculate weight-specific fecal pellet POC/PON production rates for the community and within size fractions. Occasionally, fecal pellets of abundant single species of interest (e.g., Neocalanus spp., Salpa fusiformis) are collected in separate 'bulk' incubations, to calculate their POC/PON content and better determine their contribution to export.

Other contributing protocols: MOCNESS abundance and biomass sampling to scale individual fecal pellet production experiments to community export.

Uncertainties and quality control concerns: Physiological effect of net capture and incubation. When scaling - the effects of zooplankton patchiness and variation in species physiology.

Data products originating with this method:

\begin{tabular}{ll}
\hline Parameter & Units \\
\hline $\begin{array}{l}\text { Fecal pellet production } \\
\text { zooplankton }^{-1^{*}}\end{array}$ & $\mathrm{mg}-\mathrm{C}(\mathrm{mg} \text { body } \mathrm{C} \text { or dry weight })^{-1} \mathrm{~d}^{-1}$
\end{tabular}




\section{Fecal pellet production zooplankton $^{-1 *}$}

\section{Zooplankton community $\quad \mathrm{mg}-\mathrm{C}$ or $\mathrm{mg}-\mathrm{N} \mathrm{m} \mathrm{m}^{-3} \mathrm{~d}^{-1}$ fecal pellet production \\ ${ }^{*}$ Each to be reported separately for each dominant species}

\section{SeaBASS submission fields and units:}

/fields=Sample,sample_1id,date_start,time_start,date_end,time_end,elapsed_time,bin_diameter_lower,bin _diameter_upper,lightlevel,fecalpellet_production_carbon_dryweight,fecalpellet_production_carbon_carb onweight,namespace_manual,identification_manual,biotic_group

/units=none,none,yyyymmdd,hh:mm:ss,yyyymmdd,hh:mm:ss,seconds,um,um, $\%, \mathrm{mg} / \mathrm{mg} / \mathrm{hr}, \mathrm{mg} / \mathrm{mg} / \mathrm{hr}$,non e,none,none

\section{Key method references}

Butler M, Dam HG (1994) Production rates and characteristics of fecal pellets of the copepod Acartia tonsa under simulated phytoplankton bloom conditions: Implications for vertical fluxes. Marine Ecology Progress Series 114, 81-91

Urban-Rich J, Nordby E, Andreassen IJ, Wassmann P (1999) Contribution by mesozooplankton fecal pellets to the carbon flux on Nordvestbanken, north Norwegian shelf in 1994.

Sarsia 84, 253-264.

Urban-Rich J (2001) Seston effects on faecal pellet carbon concentrations from a mixed community of copepods in Balsfjord, Norway, and the Antarctic Polar Front. ICES Journal of Marine Science 58, 700-710.

Wexels Riser C, Wassmann P, Olli K, Arashkevich E (2001) Production, retention and export of zooplankton faecal pellets on and off the Iberian shelf, north-west Spain. Progress in Oceanography 51, 423-441. 


\section{Physical transport models}

Protocol document

Andy Thompson, andrewt@caltech.edu

Last updated: October 8, 2017

This document describes protocols for archiving any "physical" transport model output for which archiving is required for the EXPORTS project. This output is likely to be a combination of numerical forecast model output in the region corresponding to the EXPORTS field program as well as any idealized model output that is generated as part of the NASA-funded pre-EXPORTS data mining and process-study activities. Most model output will be used primarily to consider the advective (submesoscale) component of the EXPORTS wiring diagram (Pathway 4, Mixing of DOC and particles). However, some of the pre-EXPORTS process studies are also considering the relative importance of sinking and advection. The format of the model output is unlikely to follow a single protocol because of the diversity of the models that may be utilized. However, this document suggests some uniformity in terms of how the output fields should be saved.

Other contributing protocols: Forcing fields (wind stress, air sea fluxes); hydrography; dissolved oxygen, chlorophyll, optical backscatter. In reality, any of the data streams may be useful for future modeling efforts. Observations collected from the autonomous platforms will be of particular interest because they will provide information on states over a longer time period.

Uncertainties and quality control: There are no uncertainties or quality control issues with regard to the model output. However, documentation of the model runs will be essential. This may include information about spatial and temporal model resolutions, the type and location of forcing fields applied, documentation of specific parameterizations used for turbulent mixing and other subgrid-scale processes. In some cases where idealized process models are archived, the input files needed to run the model (for example using a standard model, such as the MITgcm) may be archived rather than all the output fields. It will be critical that meta-data files are submitted along with any archived model output or forcing/input files.

Data products originating from this method: Model output from simulations that were conducted outside of the EXPORTS project is likely to be archived elsewhere; clear documentation of where these files can be found will be sufficient. Archiving input files so that process-based models can be re-run will be critical because it is unlikely that we know a priori all the fields that will be useful for future analysis. Similarly, it is difficult to dictate a standard format for the output in terms of averaging duration (e.g. snapshots, daily/weekly/monthly averages); these differ for various parameters, such as eddy kinetic energy or various tracer fluxes. Standard output will be temperature, salinity, current velocities, tracer/particle concentrations; derived quantities will likely need to be calculated from other model output or re-running the simulation. 


\section{Observation-based vertical advection and mixing of organic carbon to depth by physical oceanographic processes (Pathway 5)}

Andy Thompson \& Melissa Omand; andrewt@caltech.edu, momand@uri.edu Last updated: November 12, 2017

This document describes protocols for deriving the physical transport of particulate and dissolved organic carbon between the surface mixed layer and the seasonal thermocline. We nominally divide this pathway into three: 1) meso- and submesoscale subduction (the eddy-driven pump), 2) vertical mixing and seasonal restratification (the mixed-layer pump), and 3) diapycnal turbulent mixing.

1) The eddy-driven pump of organic carbon: Physical transport of organic carbon may occur either along sloping isopycnals that evolve rapidly in space and time or via a diapycnal flux across density surfaces. A net downward flux occurs when there is a correlation between the vertical velocity anomaly $W^{\prime}$ and the anomaly in organic carbon $C^{\prime}$, such that the mean vertical flux $\left\langle W^{\prime} C^{\prime}\right\rangle$ is negative. We assume that the fluxes will not be resolved directly from observations due to insufficient spatial and temporal coverage. Therefore, initial fluxes will be derived from existing estimates/parameterizations of the vertical velocity in terms of observed properties. These techniques include the omega equation for the mesoscale velocity (Holton 2004, Vallis 2017) and mixed layer baroclinic instability (Fox-Kemper et al. 2008, Omand et al. 2015) and other more recent parameterizations (Bachman et al. 2017) for estimating $w$ at submesoscales. We recognize that our understanding of submesoscale dynamics is changing rapidly, so parameterizations may be superseded over the course of the EXPORTS project. Particulate organic carbon (POC) concentration, anomalies and gradients will be estimated from optical sensors on the autonomous platforms and ships (see POC proxies protocol). Dissolved organic carbon concentrations will be estimated from ship-based bottle measurements. We expect significant differences in the vertical and lateral stratification between the Atlantic and Pacific sites as well as in the temporal correlation between the seasonal cycle of POC and submesoscale velocities. In addition, we will leverage the on-going pre-EXPORTS modeling activity, led by Mahadevan with Thompson, Nicholson and Omand as co-Pls, to run numerical simulations based on the observed conditions, thereby validating or correcting the parameterized flux estimates. Our measurements of physical and ecological data on the same space and time scales, combined with models will address: SQ1d How do physical and ecological processes act together to export organic matter from the surface ocean? SQ2a (submesoscale component): How does transfer efficiency through the mesopelagic vary?

2) The mixed layer pump of organic carbon: Shoaling of the mixed layer caused by large-scale, 1-D surface heat fluxes can also cause organic carbon to be 'left behind' in the seasonal thermocline. This mechanism is different from eddy-driven subduction, which requires 3-D dynamics. It may be difficult to disentangle these two contributions because both may be enhanced at similar times, and lead to a shoaling of the mixed layer. For example during NAB08, eddy-driven subduction of POC was enhanced during spring-time restratification. Shortly after the onset of eddy restratification, the surface heat flux changed sign, continuing to stratify the upper ocean and likely enhancing the retention of subducted carbon below the mixed layer. Protocols to independently quantify the role of the mixed layer 
versus eddy-driven pump are not yet established, and will likely be part of the efforts of the autonomous team and others.

3) Diapycnal mixing of organic carbon: Turbulent mixing across isopycnals can also result in a vertical flux of organic carbon. If possible, the ADCPs on the Lagrangian float and glider will be used to quantify the turbulent vertical diffusivity $\left(\mathrm{K}_{d i}\right)$ as a function of depth and time. If this measurement is made, then the diapycnal turbulent flux can be parameterized from the local gradient in organic carbon (C) measured from the autonomous platforms and the ship according to C Flux di $=-\mathrm{K}_{d i}(\mathrm{~d} C / \mathrm{d} z)$.

Other contributing protocols: Upper ocean hydrography (temperature, salinity, derived quantities including density, mixed layer depth, potential vorticity); Surface forcing (wind stress, buoyancy fluxes); POC concentrations from optical sensors and any direct or derived calculations of turbulent dissipation.

Uncertainties and quality control: Concerns here are more likely to be with regard to spatial/temporal resolution and coverage as opposed to uncertainty in the actual measurements. It is important to note that parameterizations of submesoscale vertical velocities require a scale separation between the larger-scale hydrographic properties (e.g. lateral buoyancy gradients) and the scale of the submesocale eddies. Depending on the scales that are resolved, the eddy-driven portion of the flux can be approached as a diffusive parameterization in a similar manner as the diapycnal mixing flux above

$w^{\prime} C^{\prime}=-\mathrm{k}(\mathrm{d} C / \mathrm{d} z)$

Here the vertical diffusivity $\mathrm{k}$ encompasses the along-isopycnal and diapycnal mixing within some region.

Data products originating from this method: The goal is to generate a time series of the vertical POC flux at the center of the Lagrangian autonomous array for the duration of the deployment of this array. The temporal resolution of this time series can be re-visited, but we expect to be able to estimate the flux at least daily.

\section{Key method references:}

Bachman, S. D., et al., 2017. Parameterization of frontal symmetric instabilities. I: Theory for resolved fronts. Oc. Modell., 109, 72-95.

Fox-Kemper, B., R. Ferrari and R. Hallbert, 2008. Parameterization of mixed layer eddies. Part I: Theory and diagnosis. J. Phys. Oceanogr., 38, 1145-1165.

Omand, M. M., et al., 2015. Eddy-driven subduction exports particulate organic carbon from the spring bloom. Science, 348, 222-225. 
Method: Lipidomics of suspended and sinking particles

Document author and contact information: Ben Van Mooy (bvanmooy@whoi.edu)

Brief description of protocol: This protocol describes the basic steps for collecting particle samples at sea for subsequent lipidomic analysis in the laboratory ashore. For suspended particles, one-liter seawater samples are collected directly from Niskin bottles into round polycarbonate bottles after first rinsing the bottle $3 x$ with $100 \mathrm{~mL}$ of sample seawater. Personnel conducting the sampling wear nitrile gloves since oils and detergents (e.g. fingerprints and hand soap residue) are the primary contamination risks. The samples are then filtered as quickly as possible; lipidomes are highly dynamic and can change drastically within an hour in response to changes in light and/or temperature. A custom vacuum filtration rig with glass filter supports/funnels accommodates up to 12 samples at once. Filters are 47 $\mathrm{mm}$ diameter $0.2 \mu \mathrm{m}$ poresize Durapores. Vacuum in the rig is set to $200 \mathrm{mbar}$, and then the sample bottles are gently inverted into the funnels and held in place by the rig. These samples may then be ignored until the last $100 \mathrm{~mL}$ or so is filtered, which takes about 30 minutes. As soon as the sample is filtered (i.e. just as it "runs dry"), the filter is folded in half, and then placed in a foil envelope. The sample ID is written on the foil with a sharpie, and the sample is immediately immersed in liquid nitrogen, where it should reside for the duration of the cruise. A dry shipper as used as the liquid nitrogen vessel; at the dock prior to shipping the liquid nitrogen is simply dumped, leaving the samples in the shipper ready for transport. The protocol for sinking particles is essentially identical, except that the volume of the samples is dictated by the volume of the splits from the sediment traps.

General sample requests: Lipidomics is a powerful tool with the potentials for revealing both the sources of exported particles and the processes that control the magnitude of particle export flux. Key to realizing these potentials is integrating lipidomic data with other measures of microbes and microbial processes. Thus, we request that process-ship seawater samples for lipidomics of suspended particles be taken from the same depths/times as samples for the following other parameters (in rough order of preference): genomics, HPLC pigments, FCM, POC, nutrients. In addition, MOCNESS and MSC samples are also welcome (zooplankton and particles may simply be preserved on filters, as described above). Samples of sinking particles from sediment traps are also requested; surface moored PITs are OK. Finally, survey-ship samples of suspended particles from only the surface (i.e. mixed layer or satellite optical depth) are also highly sought (but we recognize this may be asking too much).

Other contributing protocols: genomics, HPLC pigments, FCM, POC, nutrients.

Uncertainties and quality control concerns: Usually, we take triplicate samples. Recognizing that this is not a possibility with EXPORTS, absolute concentrations of lipids will carry an assumed uncertainty (standard deviation) of $20 \%$. Relative proportions of lipid (i.e. within sample \%) will carry an assumed uncertainty of $10 \%$. Perhaps triplicate samples could be obtained on a few occasions during the cruise if the opportunities present themselves? There are two major quality concerns: 1) contamination from soaps, detergents, oils, and greases, and 2) sample preservation (if the samples thaw, its over).

Data products originating with this method: Concentrations $\left(\mathrm{mol} \mathrm{L}^{-1}\right)$ of approximately 1,000 lipid molecules, including: triacyglycerols, intact polar diacylglycerols, intact polar monoacylglycerols, chloropigments, carotenoids, diacylglycerols, monoacylglycerols, fatty acids, wax esters, and sterol esters. 
Method: Measurements of $\mathrm{P}_{11}$ (the volume scattering function, VSF), $\mathrm{P}_{12}$ and $\mathrm{P}_{22}$ elements of the scattering Mueller matrix at $517 \mathrm{~nm}$ from $0.1-155^{\circ}$ (nominal) in water.

Document author and contact info: Xiaodong Zhang (Xiaodong.Zhang@usm.edu)

Brief description of protocol: The small angle part of VSFs is measured using ring detectors, identical to the ones used in LISST-200X instrument. The range of angels covered by the rings is 0.088 to $14.8^{\circ}$. For large angles, the VSF and polarized components are measured using a rotating eyeball. The $\mathrm{P}_{11}, \mathrm{P}_{12}$ and $\mathrm{P}_{22}$ are obtained for the particulates defined as the difference between the measurements of bulk and the $0.2 \mu \mathrm{m}$ filtered seawater (serve as the background).

\section{Deployment methodologies:}

Discreet water samples will be used. At each station, the first measurement is to establish the background using $0.2 \mu \mathrm{m}$ filtered water collected from the deepest depth. It takes about $10-15$ min to finish this step. Twenty VSF measurements will be collected at each depth, and mean and standard deviation will be estimated.

\section{Derived parameters:}

Attenuation coefficient $\left(\mathrm{m}^{-1}\right.$, acceptance angle $\left.=0.057^{\circ}\right)$

Volume scattering function at $515 \mathrm{~nm}\left[\mathrm{sr}^{-1} \mathrm{~m}^{-1}\right] . \mathrm{P}_{12} / \mathrm{P}_{11}$ and $\mathrm{P}_{22} / \mathrm{P}_{11}$

Scattering coefficient by integrating VSF from 0.088 to $150^{\circ}\left(\mathrm{m}^{-1}\right)$

Particle size distribution inferred from the VSF $\left(\mathrm{m}^{-3} \mu \mathrm{m}^{-1}\right)$

\section{SeaBASS fields and units:}

/fields=VSF_\#\#\#ang,PSD_DNSD_\#\#\#umsize

/units $=\mathrm{sr}^{-1} \mathrm{~m}^{-1}$,Particles $\mathrm{m}-3 \mu \mathrm{m}-1$

\section{Uncertainties and quality control concerns:}

Instrument: The instrument performance will be validated/calibrated pre- and post- cruise in laboratory using standard beads. If necessary, mid-cruise validation will be conducted on the vessel. Measurement: Uncertainty in VSFs are computed from variability in 20 repeated VSF measurements at each depth.

Key method references

LISST-VSF Multi-angle Polarized Light Scattering Meter User's Manual, Version 3.0. Sequoia

Scientific, Inc. 
Document author and contact info: Xiaodong Zhang, Xiaodong.Zhang@usm.edu

Measurement and instrument: Characterization of size distribution of nanoparticles with a Manta ViewSizer.

A brief description of the method: The ViewSizer tracks Brownian motion of nanoparticles and estimate the size of each particle, which is inversely proportional to the standard deviation of the particle's random

displacement, a theory first developed by Einstein. The methods for measuring PSD of particles generally include two main categories: (1) methods that measure a large number of particles simultaneously (ensemble methods), and (2) methods that measure particles individually (individual-particle methods). The nanoparticle tracking analysis deployed by ViewSizer belongs to the second method, whereas the MVSM method (summarized in another document) belongs to the first method. ViewSizer deploys three laser sources (447 nm, $532 \mathrm{~nm}$ and 655 $\mathrm{nm}$ ) and record video of scattered light from wide-ranging sizes of individual particles simultaneously. Subsequent image analysis tracks the motion of each particle and estimates variation of the particles displacement under Brownian motion.

Data processing: The sample volume is $1.5 \mathrm{~mL}$. A short video typically at a speed of $40 \mathrm{fps}$ (frame per second) is recorded. Through test, we found 200 videos are needed to derive statistically valid estimates for oceanic samples. Between the consecutive video recording, the sample cuvette is automatically shaked. An internal software analyzes each of recorded videos and estimates the sizes of particles found within each video. The size estimated represents the dynamic diameter, of which a sphere would go through the same Brownian motion. The number of size bins and the width of each size bin can be decided by a user. We use 45 size bins, with the smallest bin from $1 \mathrm{~nm}$ to $8 \mathrm{~nm}$ and a center size of $4.5 \mathrm{~nm}$ and the largest bin from $1255 \mathrm{~nm}$ to $1300 \mathrm{~nm}$ and a center size of 1277.5 $\mathrm{nm}$. The statistical analysis of particle size distribution can be repeated later, for instance, with a different bin setting.

Calibration: The instrument is validated using standard microbeads.

Uncertainties and quality control concerns: To eliminate potential interference from larger particles, which tend to settle instead of going Brownian motion, the samples should be filtered, say, using $0.7 \mu \mathrm{m}$ filter. Based on our own lab test using standard beads of various sizes from $25 \mathrm{~nm}$ to $900 \mathrm{~nm}$, we found consistent results for beads of sizes $100 \mathrm{~nm}$ to $700 \mathrm{~nm}$. For smaller beads, the uncertainty is significant because, according to the manufacturer Manta, the sample volume is no longer $1 \mathrm{~mL}$, instead, it should increase with decreasing size of small particles. We're waiting for the company provide the volume correction for particles of sizes $<100 \mathrm{~nm}$. But until then, only the size distributions between 100 and $700 \mathrm{~nm}$ should be used.

Data products originating from the method: videos of particles, particle counts within each video, and particle size distributions from $4.5 \mathrm{~nm}$ to $1277.5 \mathrm{~nm}$ (the size range from $100-700 \mathrm{~nm}$ should be used).

Key method references:

A. Einstein, Investigations on the Theory of the Brownian Movement, Dover Books on Physics (Dover Publications, 1956). 


